
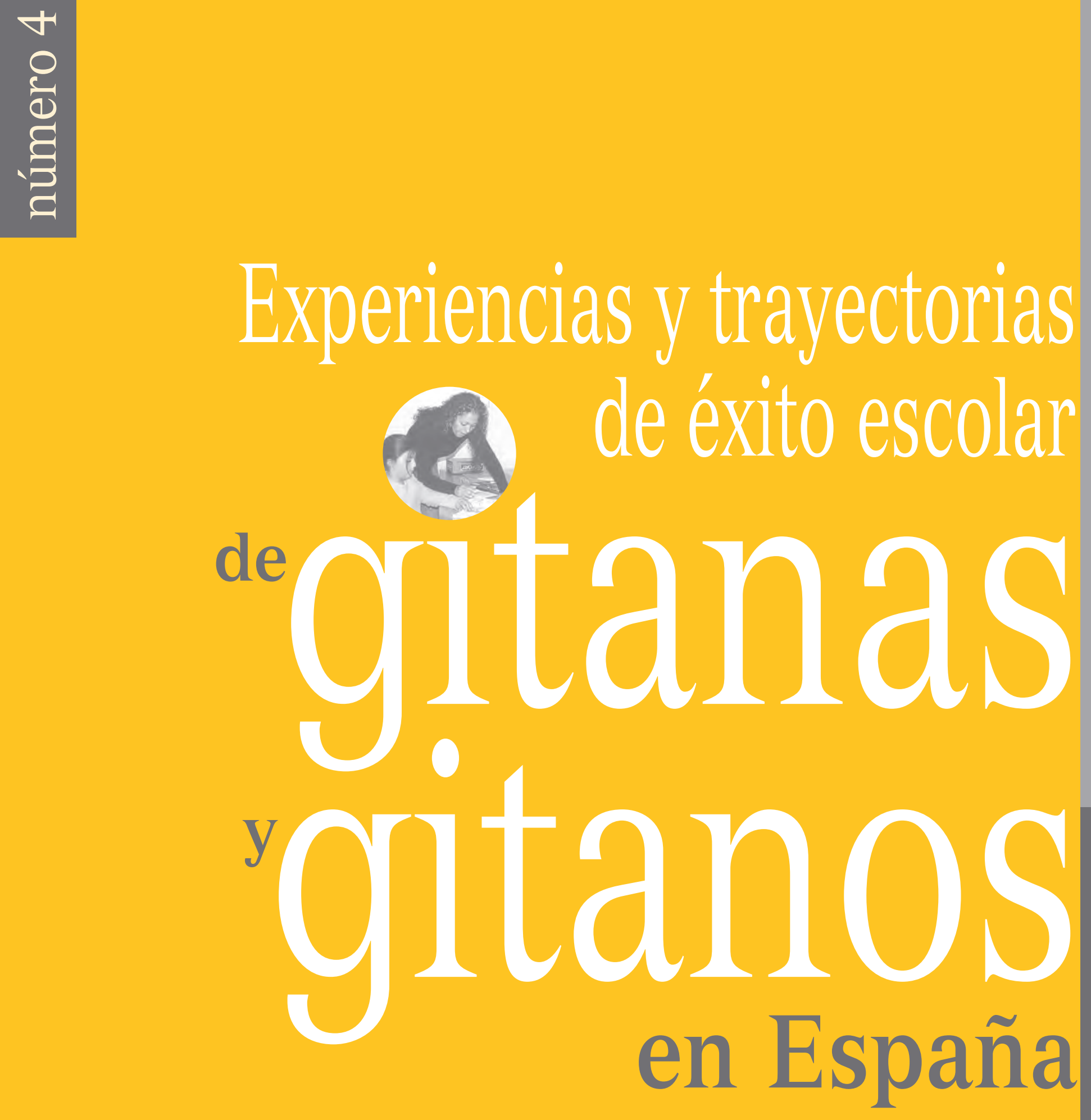

CIDE/INSTITUTO DE LA MUJER

| Mujeres en la Educación | 


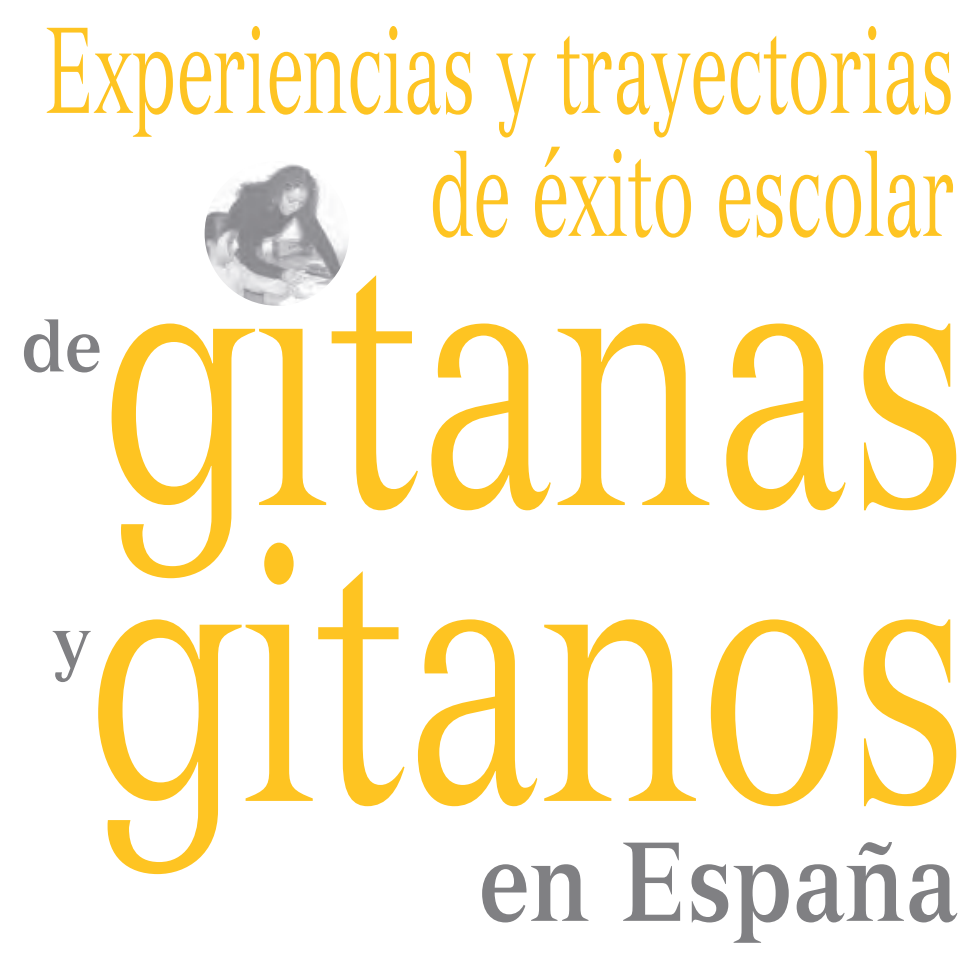

Encrucijadas sobre educación, género y cambio cultural

José Eugenio Abajo y Silvia Carrasco (editor y editora). Equipo de Investigación sobre el Éxito Escolar del Alumnado Gitano. 


\section{Equipo de Investigación sobre el Éxito Escolar del Alumnado Gitano:}

- Coordinador de la investigación y redactor:

José Eugenio Abajo, AEG y Asociación de Enseñantes con Gitanos Amal-Amali de Castilla y León.

- Asesora y redactora:

Silvia Carrasco, responsable del Grup Elima-GIEM (Grup d’Investigació sobre Infància, Educació i Minories), Departament d’Antropologia Social, Universitat Autònoma de Barcelona.

- Coordinadores de la investigación en las cinco CC.AA.:

- Aragón: Betty Moreu, Ma Esther López y Ma Carmen Calvo (Fundación Secretariado General Gitano de Aragón las dos primeras, y Centro Infantil Gusantina la tercera).

- Castilla y León: José Eugenio Abajo (Asociación de Enseñantes con Gitanos Amal-Amali de Castilla y León).

- Cataluña: Silvia Carrasco (Grup Elima-GIEM, Departament d’Antropologia Social, UAB).

- Madrid: Avelina Zorrilla (Asociación de Enseñantes con Gitanos Colectivo de Madrid).

- Navarra: Mamen Zabalza (Secretariado Diocesano de Navarra).

- Equipo de la investigación:

- Aragón: Ma Carmen Calvo, Isabel Jiménez, Ma Esther López, Betty Moreu.

- Castilla y León: José E. Abajo, Alfredo Arribas, Roberto Casado, Valentina de la Torre, Ana Eva Gay, Luis A. González, Ramón Jiménez, Lourdes Martín, José Ma Martínez, Nieves Morales, Ma José Moratinos, Juana Pérez, Avelina Pisa, Victoria Pisa, María Jesús Nieto, Pedro A. Prior, Nieves Santamaría, Carmen Santos, Ángeles Velado, María Velasco.

- Cataluña: Silvia Carrasco, Isabel Juárez, Ábel Bereményi, Laura Hom, Núria Font.

- Madrid: Sara Añino, Juan José Bustamente, Ma Rita Calvo, Remedios Losada, Avelina Zorrilla.

- Navarra: Mamen Zabalza, Rosa García, Ana Pérez.

- Documentalista y Ayudante de Redacción: Isabel Juárez (Elima-GIEM, UAB).

- Coordinación:

Montserrat Grañeras Pastrana.

- Edita:

Instituto de la Mujer (Ministerio de Igualdad) y

Centro de Investigación y Documentación Educativa (Ministerio de Educación, Política Social y Deporte)

Colección Mujeres en la Educación

- Fotos:

Alfredo Arribas, Ábel Bereményi, Roberto Casado, Marta González, Aarón Hernández, Luz Matilla

Lara Orofino, Rosa Otal y David Sanz.

- Producción Gráfica: Grafo, S.A.

- NIPO: 803-08-013-7

- NIPO: 651-04-100-2

- ISBN: 84-688-9970-4

- Dep. Legal: BI-2814-04 
A las mujeres gitanas y a los hombres gitanos que nos han dedicado su tiempo y a quienes no siempre les ha resultado grato ni fácil relatarnos sus vivencias.

A las niñas gitanas y a los niños gitanos, que van al colegio con sus mochilas cargadas de ilusiones. Con el deseo de que les abra un abanico mayor de opciones vitales.

A las niñas y mujeres gitanas, recreadoras de cultura, dentro y fuera de la escuela. 


\section{Índice}

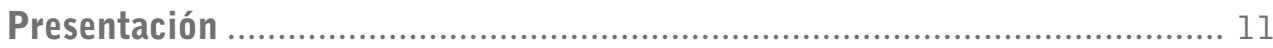

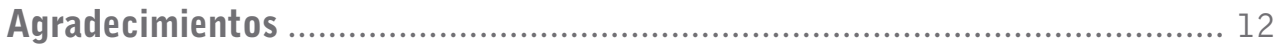

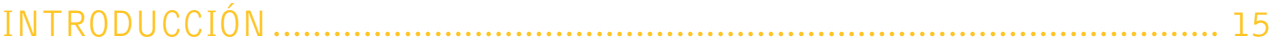

PRIMERA PARTE: Marco teórico y contexto de la investigación..................... 21

Capítulo 1: Sobre género, minorías y educación .................................................. 23

1.1. La población gitana y la educación: supuestos y retóricas ........................... 23

1.2. Minorías, educación y género: consideraciones previas .............................. 30

Capítulo 2: Contexto y diseño de la investigación ................................................ 43

2.1. Síntesis de la situación social de la población gitana en las cinco CC. AA............................................................................... 43

2.2. La investigación: objetivos, hipótesis y metodología ……………………..... 69

SEGUNDA PARTE: Experiencias de éxito y continuidad educativa.....................91

Capítulo 3: Situación educativa del alumnado gitano ............................................93

3.1. Escolarización y continuidad educativa: exploraciones y evaluaciones........ 93

3.2. Invisibilidad étnica y continuidad educativa ............................................. 104

Capítulo 4: Condiciones para el éxito y la continuidad educativa ........................ 107

4.1. La dimensión socioeconómica............................................................... 107

4.2. La dimensión educativa: contexto y clima............................................. 129

4.3. La dimensión afectivo-relacional.......................................................... 146 
Capítulo 5: Cuestiones de género, educación y relaciones interculturales

5.1. Desigualdades por razón de sexo en la valoración y en el apoyo educativos..... 159

5.2. Sobre el impacto del éxito y la continuidad educativa.....

5.3. Relaciones interculturales, parejas mixtas y continuidad educativa 181

Capítulo 6: Repensar el cambio social y cultural desde las experiencias de éxito y continuidad educativa

6.1. Recapitulando: sobre el éxito y la continuidad educativa del alumnado gitano.

6.2. Algunas implicaciones teóricas: continuidad educativa, género y cambio .. 204

Recomendaciones.

Referencias bibliográficas 215 


\section{PRESENTACIÓN}

En el marco del Convenio de colaboración entre el Ministerio de Educación y Ciencia y el Instituto de la Mujer se han ido poniendo en marcha una serie de actuaciones. A partir del año 2001, esta colaboración se ha visto especialmente impulsada mediante el diseño, coordinación y realización de un conjunto de investigaciones sobre las Mujeres en la educación que el CIDE y el Instituto de la Mujer se encargan de auspiciar, en unos casos, y de realizar, en otros, y la financiación de ambos organismos. Fruto de este impulso renovado son los estudios ya realizados que tanto al CIDE como al Instituto de la Mujer les complace presentar en estas páginas.

Con el primero de ellos "Las mujeres en el sistema educativo" (CIDE/Instituto de la Mujer, 2001) veía la luz el numero 0 de la Colección de Estudios, "Mujeres en la educación", que pretende ser portadora de un nuevo empeño: ofrecer a la sociedad española del siglo XXI una mirada en positivo del presente y el futuro de las mujeres, resaltando interpretaciones que muestran libertad femenina y creando un espacio en el que se da voz a mujeres y niñas en su relación con la educación.

En esta obra se presenta una investigación sobre la situación escolar de las ciudadanas y ciudadanos de etnia gitana que cuenta con las siguientes cualidades: haberse llevado a cabo coordinadamente en diversas realidades socioeconómicas y culturales (cinco comunidades autónomas), planteada desde la perspectiva del éxito académico, realizada por un equipo conocedor del tema desde la investigación y desde la práctica educativa, con un diseño empírico y teórico riguroso y que contempla como una dimensión central la diferencia sexual.

El múltiple impacto de las experiencias y trayectorias de mujeres y hombres gitanos revela la situación de encrucijada que se les plantea a las familias y a las chicas y los chicos en la actualidad: encrucijada en lo relativo al papel del hombre y de la mujer ( $y$, por tanto, en lo relativo a las expectativas sobre sus hijas e hijos), encrucijada con respecto a la continuidad educativa y la inserción sociolaboral y, en definitiva, encrucijada frente a la presión de las transformaciones culturales.

Pensamos que este libro ofrece una magnífica oportunidad para analizar, debatir y re-pensar las condiciones educativas y sociales de las gitanas y gitanos de nuestro país, así como el papel que cada uno y cada una de nosotros y nosotras jugamos al respecto. 


\section{AGRADECIMIENTOS}

Hemos contraído una deuda impagable con las gitanas y gitanos con distintas trayectorias de éxito escolar que pacientemente nos han contado su vida y se han entrevistado con los miembros de nuestro equipo. Es obvio que sin sus aportaciones este libro nunca hubiera salido a la luz.

En segundo lugar, queremos agradecer al Instituto de la Mujer del Ministerio de Trabajo y Asuntos Sociales y al Centro de Investigación y Documentación Educativa (CIDE) del Ministerio de Educación y Ciencia el encargo recibido y el apoyo y la comprensión que nos han brindado en todo momento. En especial, queremos destacar el interés de Ana Mañeru y de Montserrat Grañeras por nuestra investigación y su compromiso con la mejora de las oportunidades educativas y vitales de las chicas y los chicos gitanos, personalmente y como responsables de la colección Mujeres en la Educación.

En tercer lugar, aunque este libro representa los primeros resultados de un proyecto de investigación más amplio y en curso, también queremos agradecer el apoyo creciente de diversas instituciones y organismos que nos han facilitado su realización: Consejerías de Educación y Cultura, y de Familia e Igualdad de Oportunidades de la Junta de Castilla y León, Inspecció d’Ensenyament de Barcelona ciutat, Programa d'Educació Compensatòria del Departament d’Ensenyament de la Generalitat de Catalunya, Dirección General de Promoción Educativa de la Consejería de Educación de la Comunidad de Madrid, Departamento de Bienestar Social, Deporte y Juventud del Gobierno de Navarra, y Fundación Caja Navarra.

Nuestra gratitud también a las asociaciones y fundaciones gitanas de las cinco Comunidades Autónomas en las que hemos realizado el estudio y a las Federaciones de Asociaciones Gitanas, que nos han brindado su ayuda y aliento. A la Asociación Nacional Presencia Gitana, la Fundación Secretariado General Gitano, la Federación de Asociaciones Gitanas Cali, Asociación de Promoción Gitana de Burgos, Secretariado Diocesano Gitano de Navarra, Centro Infantil Gusantina de Zaragoza, Asociación Socio-Educativa Barró de Madrid, Equipo de Educación de Calle del Ayuntamiento de León (ISEMA), Asociación de Mujeres Payas y Gitanas Romi de Palencia, Cáritas de Aranda de Duero y de Soria, Secretariado Diocesano Gitano de Valladolid, Centro de Formación del Profesorado e Innovación Educativa (CFIE) II de Valladolid, así como al Institut de Ciències de I'Educació de la UAB. 
Esta obra ha contado con un número importante de personas que han apoyado y/o colaborado desde distintas instancias y niveles y queremos dejar constancia aquí de nuestra gratitud hacia ellas, pues cada tarea realizada, desde las de mayor responsabilidad hasta las más invisibles, han facilitado nuestra labor; cada apoyo forma parte del mismo proyecto y comparte los mismos objetivos: María Aliende, Roberto Alonso, Silvia Alonso, Nieves Álvarez, Maite de Andrés, Carmen Arce, Marta Ayala, César Benito, Amaya Bentué, Rafael Béjar, Javier Tomas Bórnez, Jesús Brojas, Enric Castella, Yolanda Cuenca, Ricardo Eguillor, Lydia Escudero, Sonia Esteve, Yolanda Felipo, Juana Fernández, Mar Fresno, Marga García, María Jesús García, Rosa García, Mari Ángeles Gascón, Cristina González, Elena González, Mariano González, Rosa Mª González, Enrique Gutiérrez, María Hermira, Paloma Jover, Francesa Lacasa, Miguel Laparra, Alberto Lizarraga, Marisa López, Rosa Llopis, Elena Marsá, Manuel Martín, Chema Martínez y alumnado de la Facultad de Educación y Trabajo Social de Valladolid, Ana Méndez, Rafael Miranda, Elena Molina, Rafael Molina, Carolina Moral, Antonio Muñoz, Julia Navarro, Charo Olivares, Justino Pascual y alumnado de la Facultad de Humanidades de Burgos, Jesús Peña, Jesús del Río, Emilio Romero, Carmen Rueda, Elisa Soler, Pepi Soto, Fernando Pablo Urbano, Angi Urrutia, Anna Vicente, Consuelo Villanueva y María Zapico.

Por último, es indudable que en distintas fases de la investigación o a lo largo de todo el proceso -especialmente durante los dos últimos cursos académicosnuestras familias y amigos se han resentido de nuestra dedicación a las tareas requeridas y necesitamos expresarles nuestro infinito agradecimiento por su comprensión y apoyo incondicional. 
Experiencias y trayectorias

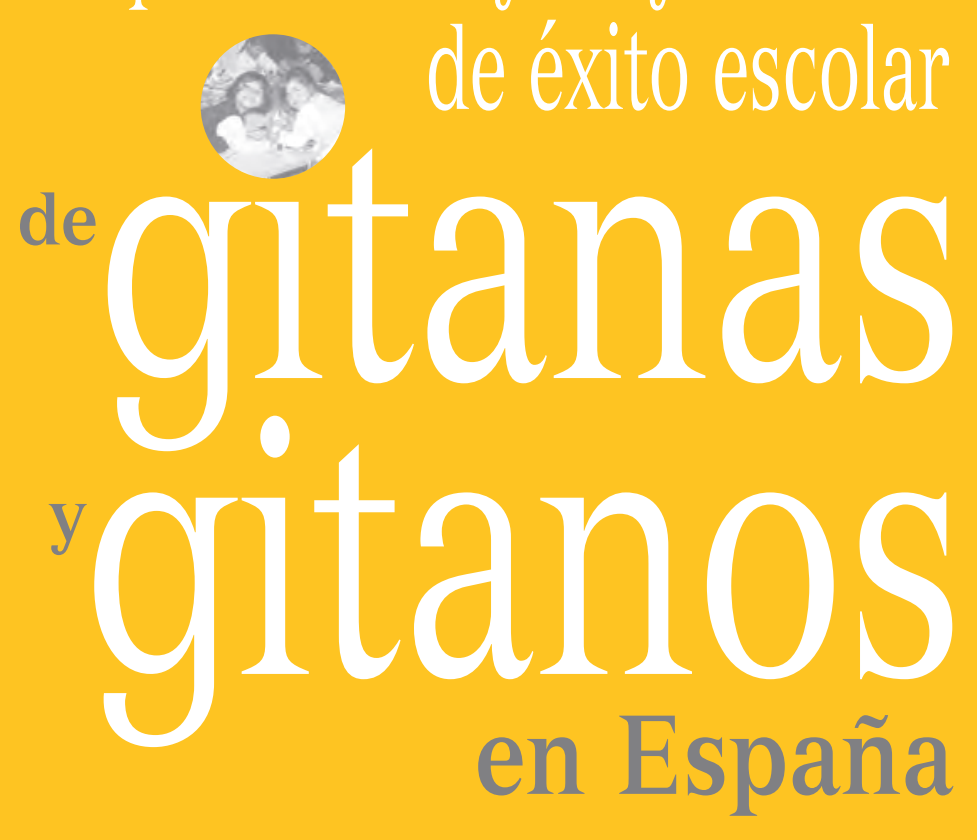

\section{| Introducción |}

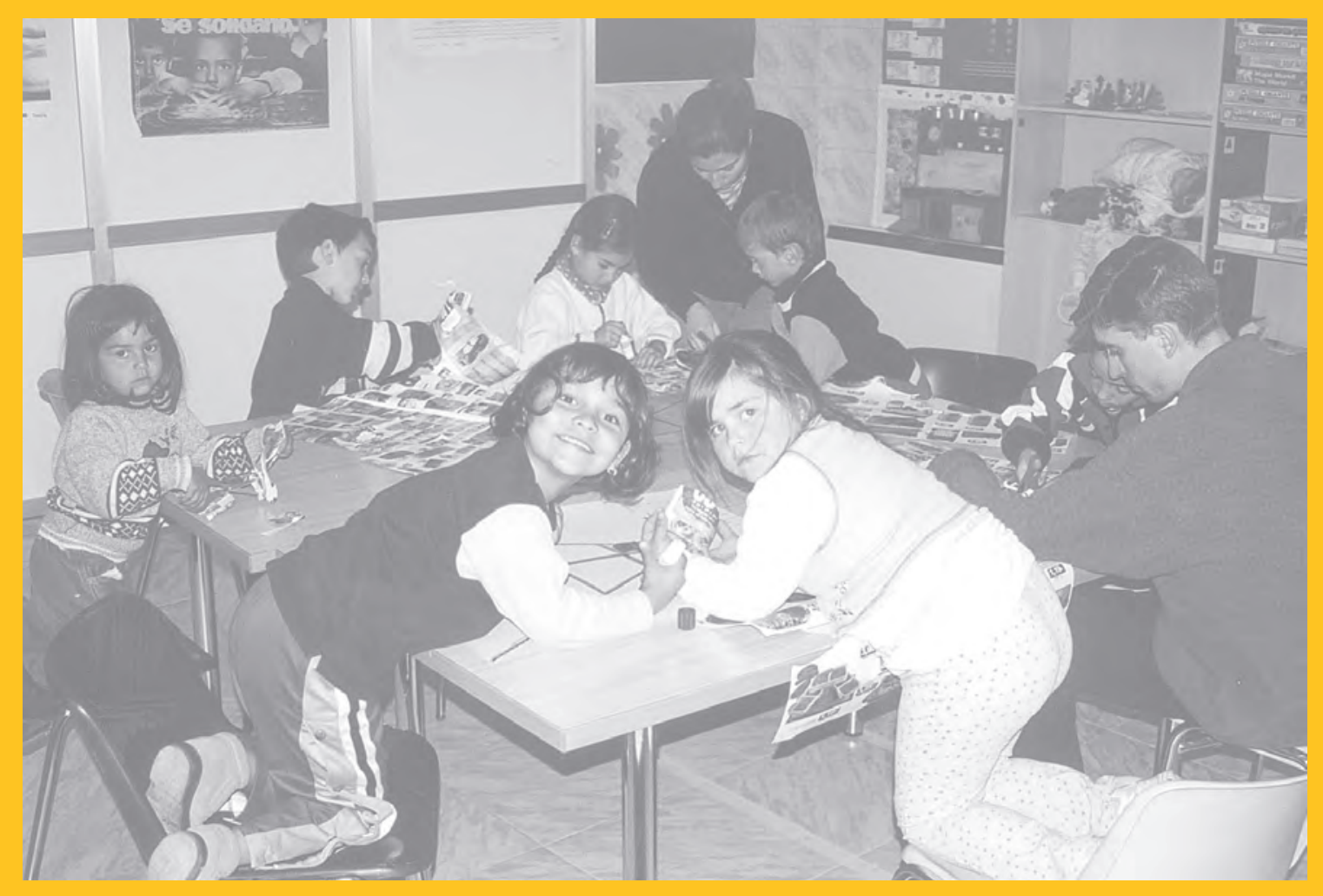




\section{INTRODUCCIÓN}

\section{Origen y motivación de la investigación}

La investigación cuyo proceso y primeros resultados presentamos en este libro obedece a una triple inquietud -humana, profesional e intelectual- de quienes conformamos este equipo investigador, la de profundizar en el conocimiento de las condiciones que favorecen el éxito y la continuidad educativa de la población gitana y su influencia en el proceso de cambio sociocultural.

En septiembre de 2001 y en el marco de una asamblea de la Asociación de Enseñantes con Gitanos (entidad que reúne colectivos de profesionales relacionados con la educación de diversas comunidades autónomas del estado), José Eugenio Abajo planteó la conveniencia de iniciar un cambio de perspectiva, centrando la atención en el éxito escolar, y propuso la realización de una investigación al respecto. A pesar de tener una acogida amplia por parte de distintas personas pertenecientes a colectivos de toda España y del indudable interés que hubiera tenido el trabajo comparativo en todas las situaciones sociales y educativas de la población gitana en el territorio, tal proyecto no se pudo concretar. Finalmente, se constituyeron tres equipos de investigación de la Asociación de Enseñantes con Gitanos - de Castilla-León, Madrid y Aragóny uno del Secretariado Diocesano Gitano - de Navarra-, a los que se sumó un quinto equipo del Grupo Elima-GIEM, dirigido por Silvia Carrasco, de la Universidad Autónoma de Barcelona, quien ya participaba desde el primer momento en la investigación como asesora a distintos niveles. El equipo investigador completo ha estado formado por 37 personas. La coordinadora del equipo de Navarra ha sido Mamen Zabalza; del equipo de Madrid, Avelina Zorrilla; en el equipo de Aragón, tres de sus componentes han compartido al mismo nivel la coordinación, Betty Moreu, Ma Carmen Calvo y $\mathrm{M}^{\mathrm{a}}$ Esther López; del equipo de Castilla y León, el propio José Eugenio Abajo; y del equipo de Cataluña -como ya se ha señalado-, Silvia Carrasco.

El estudio contaba, pues, con dos novedades: la perspectiva del éxito y la diversidad territorial. En un principio, los equipos empezaron a trabajar sin financiación en la fase de discusión, elaboración y concreción del proyecto, y se comprometieron a buscarla para sufragar los gastos derivados del trabajo de campo y del apoyo técnico que un trabajo de tal envergadura requiere, en especial cuando se suma a las obligaciones laborales ordinarias de quienes lo llevan a cabo. Así, varios de nuestros equipos de investigación autonómicos obtuvieron financiación de distintas fuentes ${ }^{1}$ y para diversos aspectos a cubrir, aunque de forma muy desigual. El tamaño y la composición de los equipos y su dedicación era dispar, y así también sus necesidades, y de esta forma se inició la segunda fase, dedicada al trabajo de campo y a la exploración de fuentes

\footnotetext{
1 Comunidad de Madrid (Consejería de Educación: Dirección General de Promoción Educativa), Comunidad Foral de Navarra (Servicio de Planificación del Departamento de Bienestar Social, Deporte y Juventud del Gobierno de Navarra), Fundación Caja Navarra, y Junta de Castilla y León (Consejería de Educación y Cultura, y Consejería de Familia e Igualdad de Oportunidades).
} 
documentales. A finales del 2002, el equipo recibió un gran apoyo ya que, a través del coordinador, se nos transmitió el interés del Instituto de la Mujer (Ministerio de Trabajo y Asuntos Sociales) y del Centro de Investigación y Documentación Educativa (Ministerio de Educación) por nuestro trabajo, con un encargo muy específico que no dudamos en aceptar, porque nuestro trabajo de campo iba apuntando muy seriamente en aquella dirección de una forma central: desarrollar una perspectiva de género en el marco de nuestra investigación sobre éxito y continuidad educativa entre la población gitana española.

El conocimiento de trayectorias de éxito y continuidad educativa del alumnado gitano es muy reciente, más allá de casos de personas de generaciones anteriores que se han percibido como excepcionales y que, por lo tanto, no marcaban ninguna tendencia emergente. Los estudios sobre la situación educativa del alumnado gitano, tanto desde los ámbitos académicos como desde las reflexiones sobre la práctica publicadas en medios más cercanos a los y las profesionales de la educación, coinciden en una valoración negativa y frustrante de la misma. En algunos casos se ha llegado a 'validar' (tanto desde la investigación sociológica, como desde el discurso institucional, y desde la "tradición escolar") la divergencia entre educación escolar y cultura gitana, algo que no sólo constituye una gravísima imprudencia sino también una total inexactitud desde cualquier perspectiva científica especializada, por lo que no vamos a dedicarle mayores comentarios. Ahora bien, nuestra experiencia en escuelas e institutos a lo largo de los años y sin excepción nos ha transmitido la desazón, la renuncia y, en la mayoría de los casos, la incomprensión del profesorado y de muchas autoridades educativas por la persistente falta de continuidad educativa de su alumnado gitano, así como su escaso cuando no nulo conocimiento de experiencias contrarias, aunque fueran excepcionales. Su valoración suele ir acompañada de una aceptación implícita del fracaso y del abandono precoz de los chicos y, sobre todo, de las chicas, la constatación de que incluso los mejores planes de absentismo no logran invertir la tendencia, el convencimiento por parte del profesorado de que las familias gitanas no apoyan la educación escolar de sus hijas e hijos porque no la valoran como es debido, la falta de compromiso de la 'propia comunidad' -concepción también inexacta- con la Educación Secundaria, etc. Ante este panorama general, se ha dedicado prácticamente todo el esfuerzo a analizar la situación desde la perspectiva y -hay que reconocerlo- desde la expectativa, de la limitación del éxito, por medio de prácticas paternalistas y asistencialistas o bien desde algunos planteamientos ingenuos aunque bienintencionados del campo de la educación intercultural. En otro sentido, también es recurrente encontrar en el profesorado una visión de la cultura gitana como equivalente a la cultura de la marginación, tanto si se comparten presupuestos de tipo racista como si se rechazan sinceramente.

Desde nuestro equipo, nos formulamos los primeros interrogantes en sentido contrario: ante tales situaciones adversas de partida -la mayoría, de tipo socioeconómico, pero también de rechazo social y cultural, con una historia de estigmatización y persecución que no hay que olvidar-, ¿qué condiciones, qué factores, han favorecido el éxito y la continuidad académica de un número creciente de gitanas y gitanos?, ¿cómo son estas experiencias?, ¿de qué gitanas y gitanos se trata?, ¿qué implicaciones se derivan de ellas, tanto individualmente como para el pueblo gitano en general? 
Es obvio que la promoción socioeconómica y la generación de expectativas de inserción en los términos mayoritarios de nuevos sectores gitanos viene a plantear situaciones de competencia con la mayoría anteriormente no experimentadas; parece también lógico que los posibles cambios en los nichos ocupacionales y en las formas de trabajar tienen efectos en las relaciones y en las expectativas sociales, alterando las relaciones de producción dentro de la familia y los roles y bases de la autoridad dentro de ella; es así mismo esperable que lo más alejado de la organización social y de los roles y valores tradicionales (por muy adaptativos que hayan resultado para la supervivencia del grupo en otros momentos históricos) es la transformación de las trayectorias y expectativas de las chicas y de las mujeres gitanas dentro de este profundo proceso de cambio. Y, así mismo, resulta evidente que la persistencia de las situaciones de encapsulamiento y guetización les perjudica a ellas en muchísima mayor medida, pero también que las experiencias de continuidad académica inevitablemente conllevan el replanteamiento de las identidades de género y de etnia, y que éste puede parecer un salto en el vacío, acelerado por ellas. Queríamos explorar las cuestiones planteadas y partíamos de todas estas reflexiones.

Nuestro estudio se ha visto posibilitado por varios factores. En primer lugar, nos basamos en un conocimiento previo de la situación social y escolar de la población gitana de nuestras respectivas zonas (por nuestro trabajo y/o pertenencia asociativa, porque algunos de los miembros del equipo de investigación somos gitanos y gitanas, y porque varios de los miembros de nuestro equipo investigador habían realizado ya alguna investigación y/o proyecto sobre temas concomitantes con el objeto de este estudio). En segundo lugar, partimos de la experiencia acumulada y de la red de intercambio que supone la Asociación de Enseñantes con Gitanos, así como del apoyo de diversas personas, grupos y entidades locales y supralocales procedentes del movimiento asociativo gitano, que también se ha reflejado en la composición de los equipos de investigación autonómicos². Por otra parte, hemos contado con el apoyo de las consejerías de Educación y de Bienestar Social de las distintas Comunidades Autónomas.

En tercer lugar, la coordinación entre un equipo investigador tan grande, dispar y disperso ha sido posible gracias a las frecuentes reuniones y llamadas; además de esas herramientas -que podríamos considerar clásicas- nuestra investigación difícilmente se hubiera llevado a cabo sin la existencia de las nuevas tecnologías de la comunicación, que nos han permitido mantener un contacto y un intercambio constante. Y es obvio que la coordinación y el trabajo de reajuste permanente se ha podido llevar a cabo merced a la dedicación exclusiva de José Eugenio Abajo3, quien obtuvo una licencia de estudios durante uno de los cursos académicos ${ }^{4}$ en que venimos trabajando, para tal fin.

\footnotetext{
2 Además del profesorado vinculado a la AEG y de diversos miembros del Grupo de investigación ELIMA-GIEM del Departament d'Antropologia Social de la Universitat Autònoma de Barcelona, ha trabajado o colaborado en esta investigación personal técnico de la Asociación Secretariado Diocesano Gitano de Navarra (entidad responsable y promotora de la investigación en Navarra), la Fundación Secretariado General Gitano, la Asociación de Promoción Gitana de Burgos, el Centro Infantil "Gusantina" de Zaragoza, la Asociación Socio-Educativa Barró de Madrid, el Equipo de Educación de Calle del Ayuntamiento de León (ISEMA) y Cáritas de Aranda de Duero.

3 En su labor de coordinación de la investigación J. E. Abajo ha contado con la ayuda de todas y todos los compañeros del Colectivo de Enseñantes con Gitanos de Castilla y León/Asociación de Enseñantes con Gitanos de Castilla y León Amal-Amali (muchos de ellos/as, a su vez, miembros del equipo de investigación).

4 Licencia por estudios concedida por la Consejería de Educación de la Junta de Castilla y León.
} 
Y, por último, pero sobre todo, esta investigación ha sido posible gracias a la colaboración y paciencia de las personas que se han dejado entrevistar, una y otra vez, gitanas y gitanos con distintas trayectorias de éxito y continuidad educativa que nos han dedicado su tiempo y a quienes no siempre les ha resultado grato ni fácil relatarnos sus experiencias. Aquí rescataremos algunos aspectos muy importantes de todas ellas.

\section{Estructura de la obra}

Este libro se divide en tres partes y está compuesto por seis capítulos, más un apartado último de recomendaciones. La primera parte se dedica a la presentación del punto de partida teórico y al contexto de la investigación. El primer capítulo expone de forma sucinta y crítica algunas ideas sobre la relación entre minorías, educación y género, con especial referencia al caso gitano en España. En el segundo capítulo se presenta el análisis de contexto general y algunas cuestiones específicas de cada Comunidad Autónoma participante y se expone también el diseño de la investigación.

La segunda parte contiene de forma organizada y detallada los resultados del trabajo empírico desde las hipótesis iniciales de la investigación. El tercer capítulo recoge las tendencias y estrategias detectadas sobre éxito y continuidad, y el capítulo cuarto se detiene en las condiciones que la favorecen, a partir de los resultados obtenidos.

En la tercera parte se incluyen algunas interpretaciones, conclusiones y recomendaciones. Así, en el quinto capítulo nos centramos en las desigualdades de género, identidad y relaciones interculturales desde los procesos de continuidad educativa, también a partir de los resultados del trabajo empírico. El capítulo sexto corresponde a la discusión de los resultados, desde la doble perspectiva de la condición de minoría y de género y desde las hipótesis y los objetivos de investigación, a modo de conclusiones. En último lugar se encuentran un conjunto de orientaciones derivadas de ellas, así como las referencias bibliográficas completas del texto. 
Experiencias y trayectorias

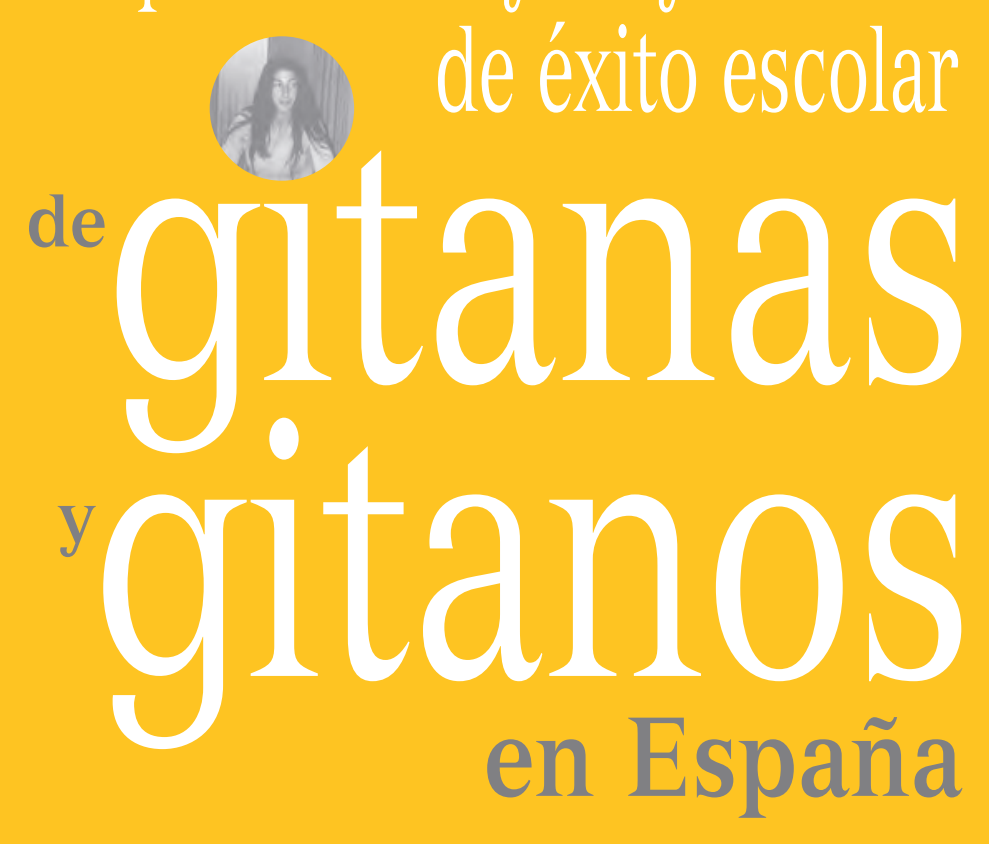

\section{| PRIMERA PARTE |}

Marco teórico y contexto de la investigación

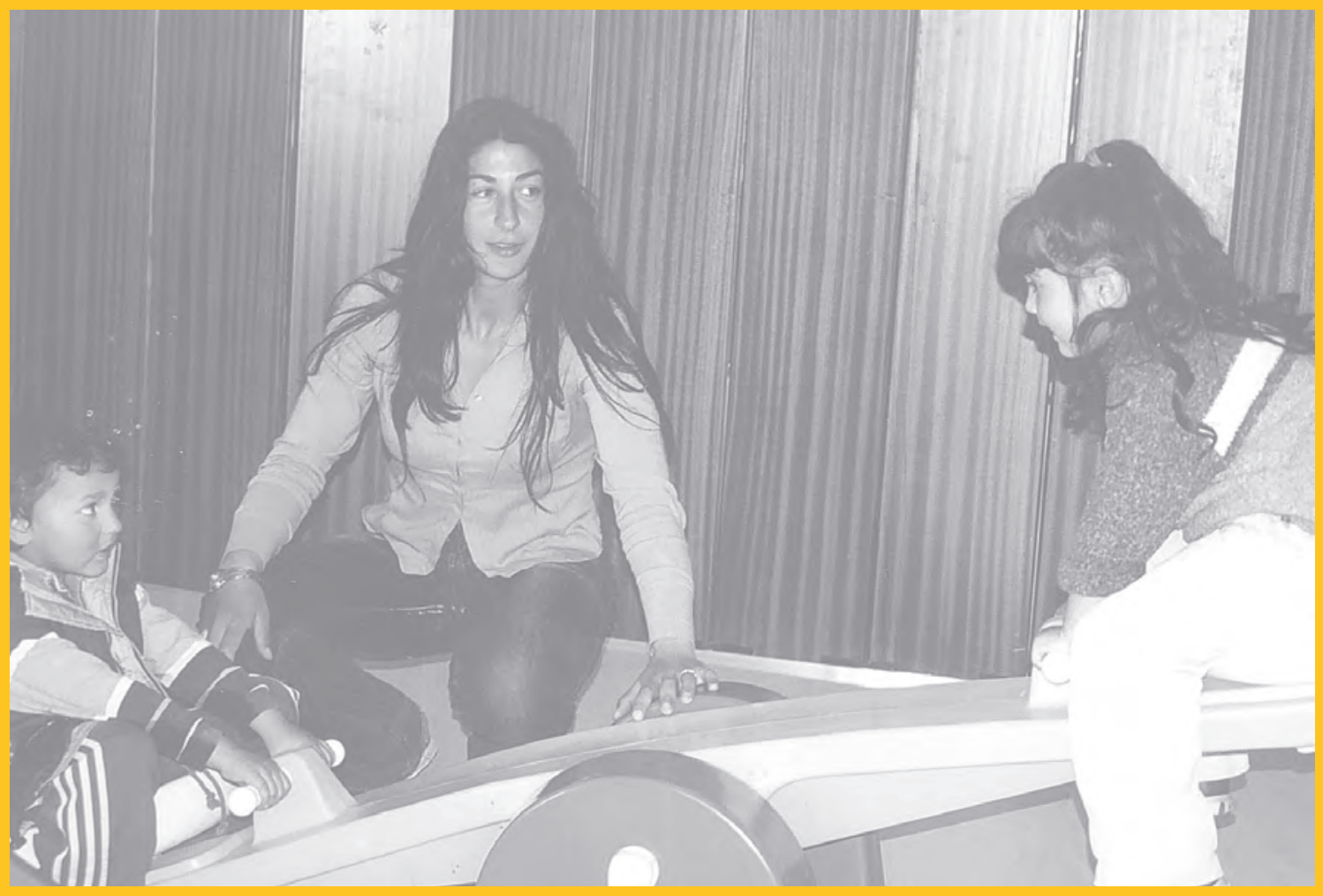




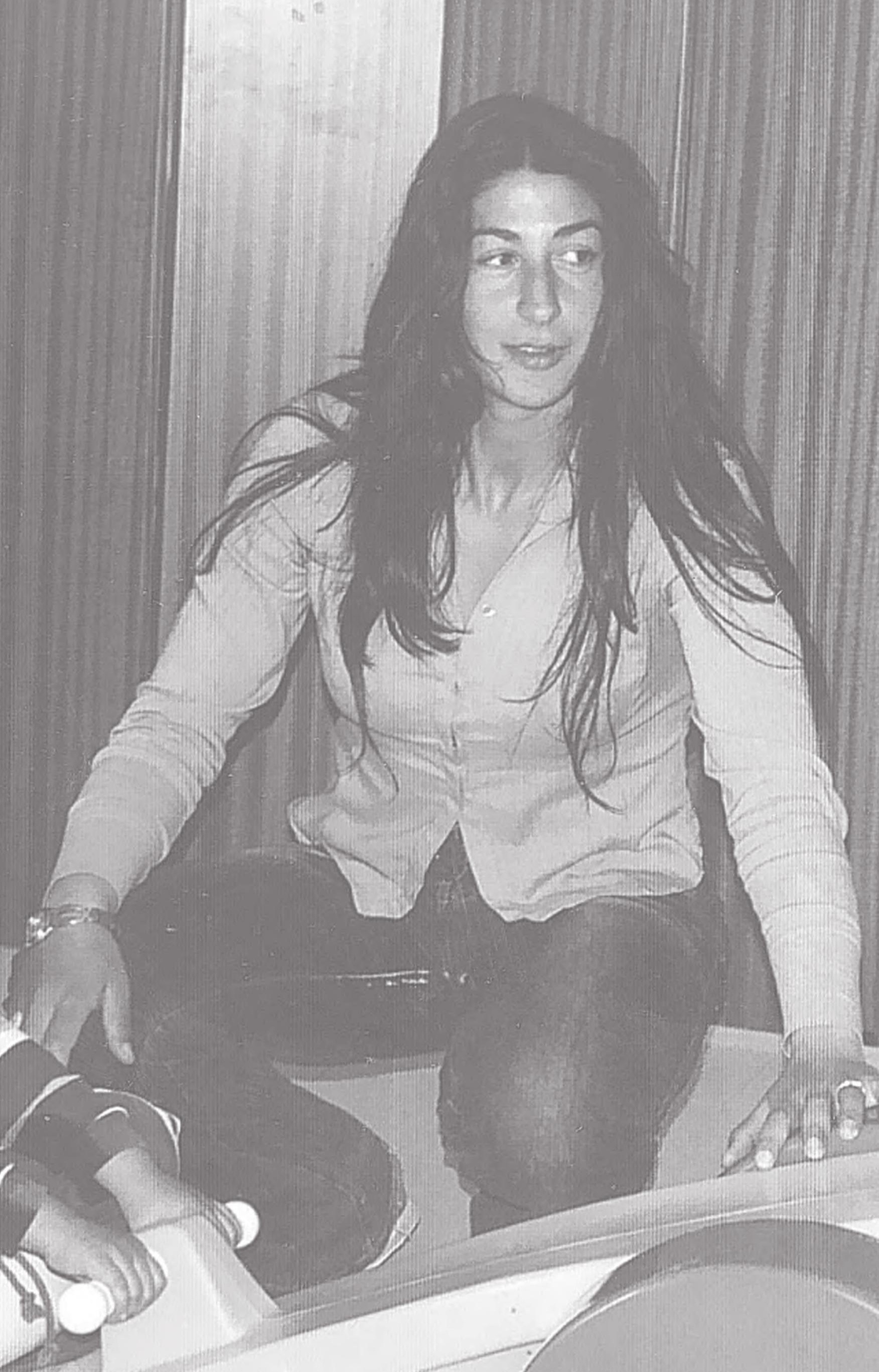




\section{CAPÍTULO 1:SOBRE GÉNERO, MINORÍAS Y EDUCACIÓN}

\subsection{La población gitana y la educación: supuestos y retóricas}

A pesar de la idea que muchos y muchas profesionales de la educación puedan tener, la investigación educativa es increíblemente escasa en nuestro país en general, y la investigación sobre situaciones educativas intolerables todavía lo es más. Por si esto fuera poco, una de las respuestas más frecuentes y frustrantes ante la reivindicación de su legitimidad y urgencia en un contexto científico y social que se supone avanzado y moderno suele ser, por parte de las personas afectadas, implicadas y responsables: '¿para qué?'. La frecuente ausencia de actitud investigadora entre quienes deberían liderar el proceso de enseñanza y aprendizaje revela la inadecuación de su formación universitaria inicial, que inhibe la innovación conceptual, metodológica y actitudinal imprescindibles para enfrentarse con éxito y responsabilidad a su cometido profesional. Por otra parte, entre quienes tienen alguna experiencia, el también frecuente mantenimiento de esta actitud responde a dos ideas igualmente falsas. La primera, que ya sabemos todo lo que hay que saber y la investigación no nos aporta nada o nos aporta cosas inútiles para la escuela. Se aduce, desde esta perspectiva, que 'con el tiempo' se irá 'normalizando' la situación escolar del alumnado gitano, y que lo que hay que hacer es actuar más y 'dejarse de teorías'. La segunda, que algunas 'especificidades culturales' exhibidas por el alumnado gitano (o atribuidas superficial e imprudentemente al mismo) no sólo hacen imposible la comparación con la mayoría de la población no gitana sino también con los procesos y situaciones sociales y educativos de otras minorías en el mundo. En ambas posturas, subyace la idea de que la investigación es 'teoría' y la docencia es 'práctica', como ámbitos naturalmente distintos. Es decir, como si la práctica no estuviera orientada desde alguna posición teórica, explícita o implícita, consciente o inconsciente, y como si la teoría se construyera al margen de la observación y de la contrastación empírica.

Así, se desestima lo que debería ser materia obligatoria de estudio y formación. Conviene recordar que todavía buena parte del profesorado que acude a los cursos de formación permanente -es decir, del profesorado interesado en su mejora profesional- no está convencido de que absolutamente todo el alumnado puede aprender, y de hecho, aprende. Otra cosa muy distinta es qué 'aprende' en su escolarización obligatoria y por qué.

Lamentablemente, a todo ello se añade la falta recurrente de contextualización multidisciplinaria, teórica y comparativa, de las escasas investigaciones existentes, obstaculizando el avance en las formas de entender y explicar las cosas más allá de lo que la experiencia inmediata teñida de aparentes nociones de 'sentido común' nos indica y entorpeciendo la disposición a identificar semejanzas y diferencias a partir de lo que nos proporcionan otras realidades. Por último, se confunden constantemente los objetivos con los interrogantes, el compromiso con y el reconocimiento de los y las desti- 
natarias, con la producción de resultados, su interpretación e implicaciones, la ideología con la ciencia. Porque estimamos que esta situación debe cambiar, aquí nos proponemos hablar de investigación.

A continuación realizamos un breve repaso a lo que hemos denominado supuestos falsos y retóricas habituales sobre población gitana, escolarización y continuidad educativa, con el objetivo de señalar los errores que contienen y las, a veces, inquietantes conceptualizaciones que dejan al descubierto. En la última parte de este capítulo se expondrán algunas aportaciones positivas de la investigación educativa sobre minorías y educación en la literatura internacional, con el fin de rescatar ideas clave para repensar la interrelación entre los procesos educativos y sociales que constituyen el contexto en el que el alumnado gitano se escolariza, con atención especial a la perspectiva de género.

\subsection{1- Pensar que ya se ha trabajado profusamente por la escolarización de la infancia gitana y que todo fracasa}

Un discurso interesado y conservador, localizable en distintos sectores sociales y profesionales y desde distintas opciones políticas, divulga la idea de que existen en la actualidad muchas iniciativas para mejorar la situación educativa de la población gitana, aunque la mayoría fracasan o han fracasado en sus objetivos. Esto, en distintas proporciones, crea una sensación de misterio insondable y frustración permanente que no hace más que llevar a la desesperanza y la acomodación a ella. Sin embargo, una breve ojeada a la realidad nos muestra que precisamente ocurre lo contrario: se han dedicado muy pocos recursos a subvertir de una vez por todas, y desde el conocimiento, la situación existente. En la perspectiva de un sector del profesorado y de las y los responsables educativos, se ha normalizado de forma alarmante el bajo rendimiento y el abandono precoz del sistema educativo, sin más iniciativas y recursos que una mínima compensación educativa de baja expectativa. Desde esta posición y con las páginas de los periódicos ocupadas diariamente en construir otro chivo expiatorio de todos nuestros males sociales y educativos -el alumnado de origen inmigrante extranjero pobre- aún está más reforzada la idea de que son los colectivos específicos los que 'causan' los problemas o los sufren por 'su especificidad', en lugar de observar, críticamente, que es el sistema entero el que necesita una profunda revisión.

El caso más claro que ilustra esta perspectiva es el tratamiento del absentismo escolar. Generalmente, en lugar de plantearse cómo es posible que chicas y chicos gitanos que han pasado nueve años de su vida en un centro de Primaria no estén en condiciones de seguir la ESO, o ni siquiera hayan aprendido a leer y a escribir correctamente (incumpliendo, por lo tanto, algunos derechos educativos básicos), se invierte la cuestión y se dedican todos los esfuerzos a llevar físicamente al alumnado al centro, limitando la exploración de las causas a las razones externas al centro y al sistema. Habría que analizar, además, cuál es el valor que a priori puede ofrecer la escuela para sus expectativas ocupacionales reales y cómo entra en competencia con tareas que sí 
son de subsistencia básica, que implican directa e indirectamente a todo el grupo familiar (lo cual no debe confundirse bajo ningún concepto con especificidad cultural alguna). Y hay que reconocer también el impacto de una educación que es obligatoria y que, en realidad, no es completamente gratuita en determinados sectores de población. Tal vez todo ello puede hacernos entender que las tasas de absentismo (en algunos barrios y sectores superior al 30\% en Infantil y Primaria, y al $40 \%$ en Secundaria), requieren algo más y algo distinto que medidas consistentes en asegurar el traslado físico del domicilio al centro, por muy efectivas que sean en lograrlo.

\subsection{2.- Considerar a la población gitana como homogénea y radicalmente distinta de la población mayoritaria}

Existe cierta tendencia a comparar la población gitana con la población mayoritaria como si se tratara de conjuntos distantes entre sí y homogéneos internamente en relación con la escuela. Nada más lejos de la realidad. De hecho, son muchos los individuos de ambos lados que comparten posiciones muy similares en situaciones de marginalidad (abandono, precariedad, sensación de fracaso, etc.); además, en aquella comparación se habla siempre de la situación mayoritaria desde la perspectiva de clase media alta, la que sí dispone de una tradición de mayor escolarización e instrucción durante generaciones. Sin duda, ésta no es la experiencia de la mayoría de familias españolas, que sólo empezaron a ver un despegue en este sentido hace unos veinte años, cuando algunos hijos e hijas de las clases populares empezaron a acceder a niveles educativos más allá de la educación obligatoria y llegaron a la universidad. Más tarde, el mercado de trabajo disponible para esas mismas clases sociales añadió un nuevo filtro de acceso a los puestos normalizados, el de las acreditaciones, incluso para los de condiciones más precarias. Este nuevo filtro consolidó aquel despegue.

En algunos medios -tanto mayoritarios como gitanos- se sigue declarando impunemente que existe una contraposición de valores culturales entre la cultura gitana y la escuela mayoritaria, aunque nunca se especifica en qué consiste esta contraposición; de hecho, se confunde la tensión interétnica fuera de la escuela -que tiene que ver con las relaciones de poder- con esta supuesta contraposición.

Por ejemplo, cuando se insiste en la importancia de la familia para el alumnado gitano. Sin duda es cierta la presión mayor que puede ejercer todavía la familia en el alumno o la alumna gitanos, pero se deduce de ello que sin la implicación y el apoyo de la familia el alumnado gitano no se interesará por los contenidos escolares. Sin embargo, nuestra investigación sobre el éxito escolar de la población gitana española demuestra que (si bien en algunos gitanos y gitanas el grupo familiar ha sido decisivo para su continuidad escolar) muchos alumnos y alumnas gitanos no han tenido implicación o apoyo alguno de la familia, aunque sí han contado sobre todo con su propia persistencia personal y el apoyo especial de parte del profesorado, lo que les ha permitido tener una continuidad académica más convencional, incluso llegar a estudios superiores (cuando, no lo olvidemos, menos del $20 \%$ de todo el alumnado lo 
hace). Por otra parte, es obvio que existe un espejismo en relación con el mundo no gitano cuando se afirma, implícitamente, que la familia no es importante o no es tan importante para el resto del alumnado, para los mayoritarios. De lo que se trata aquí es de funciones de la familia en unas relaciones interculturales concretas, frente a las instituciones de la mayoría, y no de choque de valores opuestos entre la familia y la escuela, en términos intrínsecos de una cultura.

\subsection{3.- Mantener un concepto erróneo de cultura como supuesto factor de fracaso escolar}

En esta misma línea, otra de las retóricas habituales -a menudo desde fuentes ilustradas- es la que se dedica a abusar cada vez más de una idea popular de cultura esencialista (es decir, lo opuesto al concepto antropológico de cultura) para ocultar los efectos de unas larguísimás y nefastas relaciones interétnicas en las posibilidades o no de establecer una vinculación escolar positiva por parte del alumnado gitano. También en relación con las mayores dificultades en la escuela por parte de alumnado de algunos grupos minoritarios (en especial, lo que nos cuenta la literatura sobre población hispana y afroamericana en EE.UU.), una perversa tendencia suele aducir la existencia de 'valores culturales' de tipo comunitarista a la minoría, contrarios a la orientación individualista del aprendizaje escolar mayoritario. Aparte de una incomprensión total del papel de la cultura y de su significado, este tipo de estudios soslaya con pasmosa naturalidad los efectos de autodefensa del grupo por medio del control social de sus individuos en lo que se interpreta como 'terreno enemigo'. La perversión del argumento estriba en el hecho de que indirectamente atribuye mayor bondad a la supuesta orientación cultural minoritaria, es decir, se proporcionan argumentos a la reproducción de la desvinculación y el abandono y, se quiera o no, se transmite un mensaje 5 bien claro al alumno o la alumna minoritaria, de hecho, el mismo de siempre: como individuo, no puede hacer lo mismo que los demás, porque no es como el resto.

De este modo, se atribuye de manera imprudente y equivocada al alumnado gitano -y ahora, también, al alumnado extranjero, pero curiosamente, sólo si es pobrefrente a la educación la vivencia inevitable de un dilema identitario que, en realidad, sólo se gesta en el seno de los mecanismos políticos de autodefensa étnica de la población adulta. Por si las dificultades fueran pocas para los alumnos y alumnas gitanas, encima deben demostrar algo indemostrable objetivamente, ya que se sitúa al nivel de los sentimientos propios y las percepciones ajenas: la identidad cultural, definida, además, como fidelidad política. Esto es mucho más grave de lo que

\footnotetext{
5 Este extremo también ha sido señalado por Abajo, J. E. (2002): "Se están repitiendo en los últimos años con bastante inercia y, yo diría, con cierta frivolidad (y de las que incluso se hacen eco en ocasiones gitanos con estudios), afirmaciones tales como: 'el niño gitano está tironeado entre dos culturas', 'se trata de dos culturas manifiestamente distintas y opuestas', 'carácter antitético de los valores y las normas de ambas culturas', 'la institución escolar es extraña a la comunidad gitana y forma parte de un universo amenazador', 'la familia gitana y la escuela forman dos fuentes de socialización antitéticas', 'el paso del niño gitano por la escuela puede generar pérdida de identidad'...". (Abajo, J. E. (2002): Cultura gitana y escuela. Arakerando, 86, pp. 8-16).
} 
parece, ya que supone negar validez a la toma de un modelo de referencia no gitano (un profesor o profesora no gitana, un amigo o amiga no gitana, un o una intelectual reconocida no gitana) por parte de un o una estudiante gitana. Lo cual sería plenamente intercultural, por cierto.

\subsection{4.- Confundir el conocimiento sobre una cultura como producto temporal y espacial con el conocimiento de las personas y la relación interpersonal}

Sigue siendo popular la idea de que es imprescindible conocer los entornos culturales del alumnado de minorías cuya situación se asocia al estigma y a la pobreza (nunca si la minoría se asocia a la opulencia y al prestigio cultural) por parte del profesorado, como si socialmente fueran homogéneos dichos entornos y los individuos concretos que los forman. Pero, como no nos cansaremos nunca de repetir quienes nos dedicamos a la formación permanente del profesorado en cuestiones de multiculturalidad y educación, hay que tener cuidado con esto, porque una cosa son las descripciones históricas y antropológicas de las culturas en el tiempo y en el espacio, y otra muy distinta el conocimiento de las personas y las circunstancias concretas. Ningún conocimiento intelectual sustituye las relaciones afectivas, ni éstas mejoran por sí solas la comprensión de las especificidades culturales.

De todas maneras, lo que sí es obvio es que tanto el clima de confianza entre familia y escuela como las propias relaciones educativas entre alumnado y profesorado mejoran cuando éste se acerca con interés legítimo y compromiso profesional al entorno del alumno o de la alumna.

\subsection{5.- Considerar que una buena relación con los padres gitanos conlleva automáticamente una transformación de sus ideas sobre la educación escolar}

Incluso cuando existe una buena comunicación interpersonal entre el profesorado y la familia, debemos ser conscientes de que de ahí no se deriva, forzosamente, una transformación de las ideas educativas de tal entorno respecto a sus hijos e hijas. Éste es uno de los aspectos más frustrantes para el profesorado, cuando ve cómo algunos grupos familiares no modifican sus decisiones ante la posible continuidad educativa de sus hijos e hijas, a pesar de haber creado esa confianza y haber mantenido esa cercanía durante años. Por otra parte, el profesorado debe entender que, tanto en el alumnado minoritario como en el alumnado mayoritario, una mayor inversión o continuidad educativa puede significar para los padres y las madres de sectores sociales populares simplemente terminar la Educación Secundaria Obligatoria, lo cual no va a dar lugar a ninguna mejora de sus oportunidades a corto plazo sin más, 
ya que sólo es el momento en que se abren las puertas para seguir. Mientras que, en situaciones de auto-ocupación o de trabajo no cualificado, la competencia entre la incorporación al trabajo y una continuidad escolar de resultados inciertos, cuando no temidos, puede ser muy alta. En este aspecto, la diversidad interna es tan constatable como en otros grupos. $Y$, repetimos, tan comparable a amplios sectores de la población mayoritaria como en otros.

\subsection{6.- Vaticinar que la 'presencia' de 'la' cultura gitana en las aulas generará un cambio sustancial en la escolarización del alumnado gitano}

Otro aspecto recurrente es la reivindicación de la presencia de la cultura gitana en las aulas como si, en el caso de que tal cosa fuera posible al margen de las personas, resultara decisivo para la motivación, el rendimiento y la continuidad. Este tipo de afirmaciones nunca se han constatado desde la investigación. Es más, si esto fuera así, todavía no existiría ninguna persona gitana con formación académica. Por otra parte, difícilmente se ha incorporado la historia de las mujeres, de los sectores sociales subalternos 0, por poner un ejemplo de la C.A. de Cataluña, de la propia cultura catalana durante el franquismo (teniendo en cuenta que para muchos, el castellano era exclusivamente la lengua de la escuela y de la televisión), sin que por ello se produjera un abandono masivo de las mujeres, las clases populares, o los y las catalanes (hombres y mujeres de todas las clases sociales) en esas mismas fechas. Más bien ocurrió lo contrario. La investigación nos recuerda que, incluso desde posiciones iniciales mucho más adversas, como por ejemplo las que sufren un buen número de alumnos y alumnas extranjeros con una escolarización previa muy precaria, sin referentes familiares o comunitarios con estudios y teniendo lenguas familiares muy alejadas de las lenguas vehiculares del estado, es posible llegar a seguir trayectorias educativas de largo recorrido en destino. Pero esto es factible cuando no se ve a la escuela -y no se transmite a los hijos en edad escolar- como una institución ajena y poco fiable, que puede dañar el valor de las personas a los ojos de la comunidad, sino que se confía en las posibilidades que abre como algo deseable y positivo. Es decir, es posible cuando no existe una historia de contacto amenazadora, ni una experiencia local de relaciones interétnicas claramente negativa, ni una especialización ocupacional etnificada y recurrente, como techo de empleo (legal o alegal).

De hecho, como nos demuestran décadas de investigación y práctica multicultural diversa en otros países, la tan traída y llevada idea de la 'presencia cultural' puede interpretarse desde distintas perspectivas: desde la que tiene por objeto presentar en positivo a la minoría frente a la mayoría -obviando, por supuesto, los elementos de confrontación y toda reflexión alrededor de la experiencia de estigmatización, persecución y exclusión-, o la que pretende realmente un empoderamiento del alumnado minoritario mediante su reconocimiento e inclusión explícitas y visibles, y la de todo su bagaje. Esto último no se obtiene, lógicamente, con actividades sobre romanó-caló, 
flamenco y venta ambulante a partir de cuentos populares, por poner algunos ejemplos, sino con un trabajo mucho más profundo y explícito por parte del centro educativo, cuyos destinatarios deberían ser, indistintamente, el alumnado gitano y no gitanos, como cualquier otro contenido obligatorio.

Entendámonos. Las intenciones con las que se hacen algunas propuestas 0, incluso, las ideas con las que se justifican algunas prácticas, no quedan invalidadas en sí mismas si un análisis sobre las relaciones causa-efecto que postulan revela que no se sostiene tal causalidad desde la investigación. Del mismo modo, los buenos resultados de algunas propuestas y prácticas tampoco validan automáticamente las intenciones y las ideas a las que se asocian. Desde la investigación, parece inaplazable denunciar las situaciones socioeducativas que aún afectan a la inmensa mayoría de los niños y niñas gitanos y contribuir a comprender las causas y los efectos tanto de la continuidad académica como del abandono de la misma, aunque lo que nos digan los resultados de estas investigaciones pueda ser incómodo para todas las personas implicadas, obviamente impredecible, y tal vez sólo válido para un periodo histórico y un contexto concreto.

Como contraposición a estos supuestos y retóricas, hasta el momento, la investigación especializada en los últimos 30 años nos indica que ambos fenómenos -continuidad y abandono-, en las sociedades complejas y desiguales como la nuestra, dependen en mayor o menor medida de tres tipos de factores socioculturales y socio-psicológicos: en primer lugar, el contexto socioeconómico en el que tiene lugar la escolarización (falta de formación y de sensibilización del profesorado, escasez de apoyos profesionales adecuados y no segregadores, espacios e infraestructuras deficientes, falta de material y recursos educativos como los libros de texto, dificultades y retrasos en el acceso a las becas y ayudas económicas indirectas, imposibilidad de uso del espacio escolar como recurso comunitario y de apoyo) para hacerla verdaderamente gratuita y accesible sin condicionantes de ningún tipo; en segundo lugar, el modelo educativo desde el que se lleve a cabo la escolarización (relaciones sociales dentro de la comunidad educativa, participación e inclusividad, metodologías docentes, organización escolar), que es responsable de experiencias igualmente influyentes en el alumnado y sus familias; y, en tercer lugar, el tipo de relaciones interétnicas vigentes entre el grupo minoritario y la sociedad mayoritaria, porque la institución escolar representa el único espacio de contacto obligatorio entre grupos ${ }^{7}$ sociales -diversas minorías, diversas mayorías- y en ella se dirime la experiencia de cooperación o de conflicto, la emancipación o la reproducción de la desigualdad, el rechazo o la inclusión, que implica el reconocimiento y la defensa de todos los miembros de la comunidad educativa, desde la propia comunidad educativa. Pero hay que ser claros: a pesar de todo lo que se puede achacar a la escuela como institución que triunfa en la reproducción de las desigualdades y fracasa sistemáticamente en el objetivo de producir una ciudadanía

\footnotetext{
6 La orientación psicopedagógica nos informa de cómo tienen lugar los procesos de aprendizaje y qué condiciones los favorecen, situándose frente a los fenómenos de continuidad y abandono a partir de un enfoque cognitivo y relacional, desde la perspectiva de los individuos. Siendo totalmente complementarias, en esta investigación se ha primado una perspectiva social. Sería coherente añadir un análisis psicopedagógico de las experiencias de aprendizaje y sus condiciones en desarrollos ulteriores de la investigación.

7 Esta idea ha sido desarrollada por Carrasco, S. con anterioridad. Vid.: Carrasco, S. (2001a, 2001b, 2002).
} 
formada, libre y crítica8, muchas chicas y chicos mayoritarios y también minoritarios -sobre todo chicas, aunque no sólo- reconocen en la escuela una experiencia de mayor igualdad y libertad relativas como individuos, respecto a otros espacios sociales que les ha tocado vivir, empezando por sus familias y comunidades. Además de por otros muchos motivos incuestionables, es por ello inaceptable cualquier coartada que los aleje de la escuela o que, en su nombre, alguien se otorgue de antemano el derecho a decidir sobre las múltiples identificaciones emocionales que puedan desarrollar y negar, a priori, las particulares contribuciones creativas y diversas, o incluso contradictorias, que puedan hacer a la manera de vivir su etnicidad. Ello significaría, sin más, alejarlos de la posibilidad de contribuir a mejorar las condiciones sociales que afectan en mayor medida a su grupo de origen.

\subsection{Minorías, educación y género: consideraciones previas}

\subsubsection{Sobre relaciones de género, minorías culturales y cambio social}

El concepto de género nos remite a la cultura, en un plano local y global. Es una conceptualización cultural porque atribuye pautas de comportamiento específicas socialmente construidas a hombres y mujeres. Es local porque se integra en patrones culturales y normativos específicos, construidos dentro de y por parte de un grupo social determinado en un contexto concreto, que a su vez, y en el caso de la etnia gitana ( $y$ no gitana) en España, incluye una creciente heterogeneidad interna, fruto del proceso de diferenciación social y aculturación ${ }^{9}$ que está teniendo lugar. Y se ha revelado históricamente y todavía en el presente en algunos aspectos de subordinación en el caso

\footnotetext{
8 Éste es ciertamente un objetivo utópico que nos parece irrenunciable, pero indiscutiblemente es también cultural y socialmente específico, ya que pertenece a la definición occidental, moderna y progresista de la educación escolar. Y, desde luego, no es necesariamente compartido por los destinatarios de la educación escolar, sus familias y sus comunidades, sean éstas minoritarias o mayoritarias. Algunas posturas discutidas en este texto parecen olvidarlo.

9 Aculturación es un concepto antropológico que se refiere al proceso de sustitución progresiva y permanente de unos referentes culturales (originarios o secundarios) por otros, en muchos ámbitos adaptativos, tanto a nivel material como a nivel emocional, incluso cognitivo. La escolarización siempre comporta alguna clase de aculturación, más todavía en las circunstancias actuales de rápidos cambios tecnológicos que exigen respuestas adaptativas y aprendizajes constantes a todos los individuos. La aculturación o cambio de referentes culturales es un fenómeno al que estamos expuestas todas las personas (y no sólo las minorías étnicas), en cuanto implica adaptación a las circunstancias cambiantes de la sociedad.

A veces se entiende erróneamente aculturación como algo dramático, asimilación u homogeneización... Sin embargo, conviene dejar bien claro que son fenómenos claramente diferenciados. La asimilación es una aculturación absoluta y permanente a la sociedad y a la cultura mayoritarias y/o de destino y, por tanto, a sus maneras comunes de vivir, pensar y sentir. Las políticas asimilacionistas se basan, explícita o implícitamente, en una consideración jerárquica de los orígenes y de los bagajes culturales, convirtiendo sistemáticamente algunos rasgos culturales o fenotípicos de los grupos y de los individuos en procesos de asimilación o asimilados en estigmas que se acaban confundiendo con las posiciones sociales subordinadas. Es preciso también distinguir el proceso de aculturación del fenómeno de la deculturación, que debe entenderse como una pérdida de referentes culturales originales que no es sustituida, ni siquiera instrumentalmente, con otros referentes culturales organizados de la sociedad de destino o de inserción, lo cual da lugar a la desvinculación de diversos ámbitos de la vida social y, en último término, a diversos tipos de exclusión social. Adaptado de Carrasco, S. (2000-2001): Glossari, Tema del Curs 2000-01: Multiculturalitat i Escola. GUIX. Elements d'Acció Educativa. Para el estudio de los procesos de aculturación entre la población gitana, es de referencia obligada toda la obra de Teresa San Román, especialmente el texto publicado en 1984, Gitanos de Madrid y Barcelona. Ensayos de aculturación y etnicidad. Publicacions d'Antropologia Cultural, n 3 , SP-UAB.
} 
de las mujeres y en un cumplimiento normativo interno/externo diferentes para cada sexo. Pero también debe entenderse como orden global, en tanto que representa dinámicas externas que orientan, condicionan e influyen en el contexto local.

Así, no existe una matriz única entre género y poder, sino diferentes matrices en función de patrones culturales distintos y cambiantes. La situación de las mujeres gitanas de la actualidad no puede compararse a la situación de las mujeres gitanas de hace veinte años o más (como ocurre también con las que no son gitanas), aunque en un principio exista un referente tradicional sexista gitano (y también en la sociedad mayoritaria), con sus respectivas especificidades culturales dentro del espectro del patriarcado. Esta diversidad emerge al analizar las relaciones de género en las trayectorias y experiencias de éxito y continuidad educativa, por ejemplo entre contextos segregados y no-segregados, entre ámbito urbano y ámbito rural, niveles de renta y recursos económicos distintos, o pertenencia a distintos grupos de edad.

El estudio de los modelos de participación y de los diversos intereses y estrategias de las mujeres y hombres, el análisis de la distribución de derechos y deberes entre ambos y sus implicaciones en las relaciones con los distintos actores que los rodean, desde una visión global de la sociedad, se debe a las nuevas reconceptualizaciones que consideran las relaciones entre los sexos como una categoría de análisis integral y no como se percibía anteriormente- como una categoría marginal. Así, el análisis de género contribuye de este modo a una mayor comprensión de la organización social y de los procesos sociales en su totalidad (Potash, 1986). La mayor parte de los escasos estudios sobre las mujeres gitanas hablan de "la mujer gitana" como un tema aislado, marginal y susceptible de ser analizado sin tener en cuenta el conjunto de las relaciones que se establecen entre las y los distintos actores sociales. Nosotras y nosotros consideramos que es necesario hablar de "las mujeres gitanas" en plural, dentro de sus múltiples contextos de relación y desde una visión global que atañe a todos los procesos sociales que los mediatizan.

La escasa literatura existente oscila entre la invisibilidad y la especificidad uniformizadora y marginal, es decir, entre 'el pueblo gitano y la educación' y 'la mujer gitana y la educación', como anexo. Desde este modelo, los cambios socioculturales y educativos que afectan a todos los sectores de la población gitana parecen ser la obra lenta de la lucha entre mantenimiento (como tradición) y transformación (como modernización). Un ejemplo de ello lo constituyen algunos encuentros y jornadas recientes centradas en el análisis de la situación de las mujeres gitanas. Sin querer aludir a ninguno de ellos en particular, hemos constatado algunas tendencias recurrentes en este sentido. En efecto, aunque se reivindica la promoción de las mujeres gitanas e incluso se habla de igualdad, se abunda a la vez en planteamientos que inhiben el desarroIlo del concepto de "mujer y gitana" como ser individual, como persona con opciones al margen de una adscripción étnica de contenido predeterminado y de su pertenencia comunitaria: por ejemplo, se insiste en la familia como forma de organización, en la mediación y el acuerdo como eje de la convivencia, en la colectividad como razón organizativa, en la virginidad entendida como opción cultural, en la maternidad como máximo valor, en el respeto hacia las personas mayores como rasgo cultural diferen- 
cial, en la reivindicación cultural a través de la promoción del pueblo gitano en general. De hecho, se reivindica, finalmente, la "igualdad" de las mujeres como algo "diferente" en el pueblo gitano, como si no se pudiera tratar de la misma "igualdad" reivindicada por las mujeres de la sociedad mayoritaria.

Pero esta perspectiva es en gran medida perversa, pues esconde el proceso de diferenciación social interna y remite a unas supuestas resistencias, surgidas del recelo hacia la mayoría y/o de la inercia de elementos tradicionales sin contexto adaptativo, frente a los nuevos aires que redefinen contenidos culturales y vínculos identitarios desde unas supuestas nuevas generaciones. Las cosas se suelen presentar como si, por una parte, cualquier mujer gitana pudiera 'representar' a las mujeres gitanas, especialmente si su experiencia es de éxito y continuidad educativa y, al tiempo, por otra parte, cada una de estas experiencias concretas se agotara en sí misma, adquiriendo como mucho el estatus de ejemplo de que 'también' las mujeres gitanas 'participan' de aquellos cambios. Este planteamiento no solamente es demasiado simple, sino que es bastante inexacto cuando se profundiza en la reconstrucción comparativa de trayectorias diversas y concretas y en el análisis de su contexto y de su impacto desde y en las relaciones de género. De hecho, los auténticos cambios y su impacto los protagonizan principalmente y no secundariamente las mujeres, pero no sería coherente aproximarse a ellos sin el contexto global de las relaciones en las que éstas los construyen y en las cuales pueden tener una repercusión determinada.

En esta línea, la misma crítica que realizan algunas feministas del mal denominado Tercer Mundo hacia el feminismo occidental por su etnocentrismo y eurocentrismo, por la asunción de implícita superioridad intelectual que caracteriza sus estudios y análisis (Amadiume, 1987 y 1997; Stanley, 1991; Afshar y Maynard, 1994; Arnfred, 1995; Mulinari, 1995), es extrapolable a la crítica del tratamiento académico que suelen recibir en bloque las mujeres de un buen número de grupos minoritarios. La presentación subordinada, dependiente y vulnerable de las chicas gitanas en este sentido es tan distorsionada como la emergencia de explicaciones sobre el éxito académico creciente de las alumnas frente a los alumnos, cuando se hace en términos de la mayor acomodación de las primeras a las exigencias del sistema escolar, por la supuesta interiorización de esas posiciones subalternas dentro de todos los grupos y sectores sociales.

Por último, y además de estas advertencias aplicables a los postulados del mundo académico que se reflejan en las prácticas de investigación y de representación, es necesario tener en cuenta la observación de Dolores Juliano, planteando un paso adelante ante el desarrollo de prácticas feministas y de movimientos feministas específicos dentro de los grupos y sectores sociales identificados con posiciones minoritarias: "La epistemología feminista con su reivindicación del conocimiento posicionado, su conciencia de las micropolíticas implicadas en las investigaciones y su creciente comprensión de la diversidad de problemas (y soluciones) que se esconden detrás de las denominaciones genéricas, ha abierto puertas que permiten salvar las barreras étnicas y de clase. Es importante entonces mantener la apertura epistemológica, para después de haber comprendido la necesidad de hablar de "mujeres" en plural en lugar de una 
mítica "mujer", nos acostumbremos a hablar sin recelos de "feminismos" en lugar de "feminismo", recogiendo en cada caso y analizando las propuestas surgidas de los cuestionamientos prácticos, concediéndoles igual importancia analítica que a las que provienen de las elaboraciones teóricas" (Juliano, 1998:32).

En nuestra investigación hemos querido asumir una perspectiva más compleja y nuestros resultados nos han llevado a considerar la situación actual como de encrucijada, para las mujeres y para los hombres, en plural10, en un momento en el que es necesario y urgente, para muchas chicas y chicos, hombres y mujeres gitanas y no gitanas - de la minoría y de la mayoría- el disponer de elementos para repensar el cambio social y cultural que pueden protagonizar, desde la legítima defensa de su identidad diferencial como pueblo y desde el pleno disfrute de su ciudadanía individual.

\subsection{2. Éxito y continuidad educativa en grupos minoritarios: algunos precedentes}

Como ya mencionábamos en la introducción, pocas investigaciones se han centrado en explorar las condiciones para el éxito y la continuidad educativa de las chicas y chicos de los grupos minoritarios étnico-culturales en la investigación internacional y ninguna de ellas se ha llevado a cabo en España. A continuación revisamos algunas investigaciones en esta línea con el fin de fundamentar mejor nuestras hipótesis iniciales, a través de algunos de los elementos clave que contienen: el influjo de las creencias del alumnado sobre las causas de su éxito o fracaso; los efectos relativos de distintos modelos de escuela sobre la continuidad y el éxito minoritario frente a otros factores; el impacto de la organización escolar y de las relaciones escuela-familia en situaciones específicas; la influencia de las fuerzas comunitarias y de la percepción de la estructura de las oportunidades en el rendimiento académico y en el comportamiento educativo del alumnado de grupos minoritarios estigmatizados; la evolución de la incidencia del género, la clase y la etnia en los resultados académicos.

\section{El impacto de las creencias del alumnado sobre las causas del éxito y el fracaso}

A diferencia de la abundante literatura existente sobre fracaso escolar, sólo algunas investigaciones se han planteado aprender de lo que nos muestra el alumnado pobre y de minorías con éxito escolar. Recuerda Bempechat $(1999,2003)$ que disponemos de un sinfín de comparaciones entre alumnado blanco de clase media y alumnado

\footnotetext{
10 En la publicación del Instituto de la Mujer 50 Mujeres gitanas, se presenta de manera personalizada una multiplicidad de casos que proporcionan una visión heterogénea de las dificultades en las que se encuentra las mujeres gitanas para conciliar su emancipación personal y sus visiones y opiniones sobre el mantenimiento de la cultura gitana (IM, 2002). Este texto profundiza en aquella perspectiva plural.
} 
pobre y minoritario, pero muy pocas que comparen el éxito o el fracaso educativos en un solo grupo dentro de esta última categoría.

La literatura sobre motivación para el éxito ha dado lugar a buenos análisis sobre cómo las perspectivas de unos y otros pueden diferir en relación con el aprendizaje ${ }^{11}$. Las creencias de los chicos y chicas sobre las causas de su éxito (o su fracaso) nos ayudan a comprender por qué algunas personas aceptan los retos y las dificultades mientras otras personas los soslayan y cómo esto tiene un gran impacto sobre sus resultados. Así, Weiner $(1979 ; 1986)$ (UCLA) ha mostrado en sus investigaciones cómo el alumnado que atribuye su éxito o fracaso a factores internos como la habilidad o el esfuerzo personal tiende a obtener mejores resultados que quienes lo atribuyen a factores externos, como la suerte.

¿Qué semejanzas pueden hallarse entre el alumnado de todos los grupos étnicos y sociales con buenos resultados? A pesar de la importancia que se atribuye a la implicación y participación de los padres y madres y las familias en la escuela, ¿existe realmente una correspondencia sistemática entre el alumnado con buenos resultados y una mayor implicación familiar por una parte, y entre el alumnado con malos resultados y una menor implicación de la familia por otra? Los factores que generalmente se aducen para 'explicar' el mayor fracaso escolar entre ciertos grupos son la pobre$\mathrm{za}$, el estatus minoritario, los problemas de lenguaje, el ser familias desestructuradas, o el carecer los padres y madres de instrucción. Se estudió qué tipo de creencias sobre el éxito y qué tipo de participación de los padres y madres (apoyo académico y valoración de la educación) en distintos grupos étnico-culturales se podían asociar a unos u otros resultados. Los datos mostraron cómo, ante la misma situación (por ejemplo, por qué un profesor o profesora te escogería para controlar los gastos del grupo en una excursión) los y las estudiantes con mejores resultados atribuían su posible elección a su habilidad, y los y las estudiantes con peores resultados la atribuían a factores externos, como el hecho de que seguramente fuera su turno para encargarse de ello. Los datos también mostraron que todos los alumnos y alumnas tendían a valorar positivamente la implicación de sus familias en su educación, bien por proporcionar apoyo directo en las tareas escolares, bien por enfatizar el valor del estudio para su posterior inserción laboral o realización personal.

Estas creencias se refuerzan a partir de las diferentes actitudes de los padres y madres: la vinculación entre esfuerzo y éxito puede conllevar una readaptación familiar para crear condiciones que lo favorezcan, mientras que la vinculación entre suerte y éxito no suele dar lugar a ninguna readaptación o atención especial a las condiciones del alumnado. Por otra parte, la vinculación entre habilidad o inteligencia y posibilidad de éxito es mucho más dependiente de las valoraciones explícitas que transmite el profesorado.

Así mismo, sus creencias se ven afectadas por las distintas reacciones emocionales del profesorado ante su rendimiento: de la ayuda inesperada para realizar una actividad 11 Dos autores de referencia en este tema con relación a las diferencias internas que presentan distintos grupos de
alumnos procedentes de sucesivas migraciones hispanas a los EE.UU. son Marcelo y Carola Suárez Orozco, que no discutimos aquí. Para una revisión comparativa de sus aportaciones, ver Carrasco, S. (2002). 
puede inferirse la consideración de poca habilidad, de la sorpresa o la protesta del profesorado ante un mal resultado puede inferirse la consideración de alta habilidad. Para terminar, Bempechat (2003) afirma que "el reto para el profesorado consiste en ayudar a sus alumnos a mantener un sano equilibro entre creer que tienen la habilidad necesaria para aprender y saber que el esfuerzo les ayudará a maximizar esa habilidad". Estos resultados nos llevan a tener en cuenta las dimensiones educativa y afectivo-relacional (dentro y fuera de la escuela) en los casos de éxito y continuidad educativa considerados en la investigación.

\section{Competencia entre modelos de efectividad escolar frente a otros}

\section{factores condicionantes}

Borman y Rachuba (Johns Hopkins University, 2001) se basaron en datos cuantitativos disponibles del gobierno norteamericano para identificar las características individuales que permitían distinguir a los alumnos y alumnas con éxito académico y con un buen nivel de resiliencial2 de grupos minoritarios y de estatus socioeconómico bajo, de sus compañeros y compañeras con niveles de éxito o resiliencia menores. Al mismo tiempo, reformularon y contrastaron cuatro modelos distintos de factores de riesgo y características favorecedoras de la resiliencia en las escuelas, a partir de la investigación disponible hasta el momento: a) el modelo de escuelas efectivas, b) el modelo basado en la composición del grupo de iguales, c) el modelo basado en los recursos disponibles en la escuela, y d) el modelo de comunidad escolar acogedora. Los estudios sobre resiliencia han sido poco divulgados en nuestro país en los medios educativos, y mucho menos aún en el campo de la investigación sobre minorías y educación. Sin embargo, parece una contribución básica para nuestra perspectiva de estudio del éxito académico, en la medida en que toma en consideración la capacidad de las personas para superar y recuperarse de los efectos de condiciones y experiencias adversas a nivel emocional y social, como algunas de las que pueden afectar a buena parte del alumnado gitano dentro y fuera de la escuela.

Sus resultados sugieren que el alumnado minoritario con bajo estatus socioeconómico está expuesto a mayores riesgos y peores condiciones favorecedoras de la resiliencia que los alumnos y alumnas blancos de entornos socioeconómicos similares. En general, sin embargo, los resultados apoyaban la aplicación de modelos de uniformidad individual y escolar de resiliencia académica a todo el alumnado de estatus socioeconómico bajo, independientemente de su adscripción étnico-racial13. De

\footnotetext{
12 Se ha aplicado este concepto con mayor frecuencia a la superación de situaciones extremas y experiencias traumáticas, reconocidas e identificadas como delitos, tales como el maltrato y el abuso, pero sin duda también es aplicable a otras situaciones y experiencias más difusas y generalizadas de desigualdad y exclusión y sus efectos en los individuos concretos. Por esta razón nos ha parecido conveniente tener en cuenta esta perspectiva, que se va abriendo paso en la investigación multidisciplinaria reciente.

13 En la literatura anglosajona sobre el tema se utiliza el término 'race', y siempre entrecomillado, para referirse tanto a las características fenotípicas, como la estigmatización de determinados rasgos dentro de éstas, así como la experiencia de discriminación y reelaboración por parte de las personas identificadas y clasificadas según las categorías culturales vigentes en cada contexto (también referidas como 'ethnicity'), que incluyen aquellas características y rasgos. Su campo semántico coincidiría con parte del que hemos sugerido para el término 'minoría étnica'.
} 
hecho, todos los y las estudiantes de bajo estatus socioeconómico con resultados de resiliencia compartían los rasgos siguientes: una mayor implicación en las actividades académicas, una buena auto-regulación, mayor eficacia en matemáticas, una actitud más favorable ante la escuela y una mayor autoestima. Entre el alumnado de Educación Primaria, las y los autores destacan la poca influencia del contexto social y académico del grupo de pares en las condiciones para desarrollar la resiliencia en el ámbito escolar.

Según las y los autores, la composición social del alumnado y las medidas generales basadas en los recursos escolares constituyen medidas muy imprecisas y ambiguas de cuáles son las relaciones reales del alumno o alumna en la escuela y de los recursos disponibles a los que éste tiene realmente acceso. Es más que probable que la experiencia individual del alumnado difiera considerablemente en ambos aspectos dentro de la misma escuela. Muchos de los esfuerzos realizados por el profesorado se diluyen si se aplican desde una perspectiva global al contexto, sin atender específicamente las relaciones sociales y afectivas desde la perspectiva de alumnas y alumnos concretos.

Así, concluyen que las características escolares más potentes para promover la resiliencia coinciden con las del modelo de comunidad escolar acogedora que, a diferencia de otros modelos escolares (como el de la escuela efectiva), incluye elementos que protegen activamente al alumnado de las situaciones adversas. Sus objetivos y prácticas están claramente orientados a crear un espacio completamente seguro y acogedor, es decir, cuidar ante todo el proceso de adaptación social y personal del alumno a la escuela. En parte, estos objetivos se consiguen estimulando la participación activa del alumnado en el aula y en el centro como el mecanismo más potente para contrarrestar el riesgo de desvinculación y abandono. Esto nos lleva a explorar en las trayectorias de nuestros y nuestras informantes aquellos elementos relativos al clima del centro educativo y a las condiciones de participación que experimentaron en el mismo.

\section{Buenas prácticas escolares y población minoritaria: flexibilidad, apoyo y relación de confianza}

Una reciente investigación, encargada por el Departamento de Educación y Empleo del gobierno británico y llevada a cabo por los prestigiosos investigadores angloindios Bhopal y Gundara entre otros (Institute of Education, Londres, 2001), cuyo objetivo era descubrir y dar a conocer buenas prácticas en la atención educativa al alumnado perteneciente a población gitana itinerante, lleva el significativo título Working towards inclusive education (Trabajando para una educación inclusiva). Se analizaron las estrategias y prácticas ideadas y seguidas por seis escuelas con población básicamente mayoritaria que recibía intermitentemente alumnado de grupos gitanos itinerantes (en su mayoría feriantes). Estas estrategias y prácticas estaban orientadas a elevar los niveles de asistencia y mejorar los resultados académicos, pero las escuelas no se hallaban solas en este proyecto, ya que existe en Gran Bretaña un servicio específico de apoyo al alumnado itinerante, el TES (Traveller Education Service). 
Los hallazgos más importantes de esta investigación, que en parte también evaluaban el funcionamiento y la pertinencia de este servicio, fueron los siguientes: en primer lugar, se destaca el papel crucial del TES en cuanto a información para las familias, gestión en la reserva de plazas, apoyo en los procedimientos de matrícula, organización de transporte si es necesario, provisión de uniformes ${ }^{14}$ y material escolar requerido específicamente en cada escuela, así como asesoramiento a padres y madres y profesorado que permita garantizar una buena continuidad educativa de los niños y niñas. En estas escuelas, además, el TES proporcionaba materiales curriculares y de formación del profesorado para atender adecuadamente los casos de alumnado itinerante. En segundo lugar, se habla del compromiso con un ethos inclusivo en la escuela, asumido explícitamente por todo el profesorado, con planes para evitar el acoso y el racismo entre iguales y el establecimiento de vínculos fuertes con las familias de las comunidades itinerantes. Por último, estas escuelas habían organizado, además, espacios de apoyo al estudio y a la realización de tareas y horarios de cuidado adaptados a las necesidades especiales de los padres y madres.

La conclusión más importante a la que llegan los autores del estudio es que estas escuelas cuidaban con especial esmero las fases iniciales de incorporación del alumnado itinerante al centro, al aula y al grupo de iguales, es decir, las condiciones materiales y afectivas de acceso. En definitiva, los elementos que definen la clave de su éxito son: flexibilidad organizativa, apoyo específico, estrechas relaciones con los padres y madres y compromisos académicos y afectivos explícitos de todo el profesorado con el alumnado, en resumen, el conjunto de prácticas que crean relaciones de confianza.

En España no existe un servicio específico de este tipo para la escasa población que todavía hoy es itinerante, y que empieza a corresponder de forma creciente a grupos gitanos de otros países europeos que llegan a nuestro país como inmigrantes. Pero, aunque ninguno de los casos estudiados pertenece a grupos familiares itinerantes, nos parece extremadamente interesante tener en cuenta aquellos elementos clave en las relaciones de la escuela con las familias, en términos de las acciones emprendidas para crear aquel clima de confianza que los autores resaltan como resultado de su estudio.

\section{Fuerzas comunitarias, estructura de las oportunidades y comportamiento académico15}

Ogbu ha construido y perfeccionado a lo largo de los últimos 30 años un modelo ecológico para comprender la relación entre el comportamiento académico y la condición de minoría, basado en la percepción de la estructura de las oportunidades como techo de empleo, por parte de los grupos minoritarios y en las diferentes relaciones sociales

\footnotetext{
14 En Gran Bretaña, todo el alumnado de niveles obligatorios suele llevar uniforme, aunque esta norma es flexible en distritos con incorporación tardía de alumnado extranjero, a quien se permite vestir su atuendo tradicional, o combinar ambos según su comodidad.

15 Traducimos por 'comportamiento académico' la expresión inglesa 'academic performance', entendiendo que se refiere al conjunto de aspectos asociados al rendimiento y a la adaptación escolar.
} 
desiguales entre minoría y mayoría fuera de la institución escolar. Tipos distintos de historias de contacto y conflicto en la génesis del estatus de minoría darían lugar a dos clases de situaciones: la de las Ilamadas minorías involuntarias -como consecuencia de la esclavitud, la conquista y la colonización- que protagonizarían un bajo rendimiento escolar como adaptación a la institución escolar, percibida como un terreno ajeno cuya función es disolver su resistencia política; y la de las llamadas minorías voluntarias -o inmigrantes- cuyo proyecto de inserción las dotaría de un umbral más alto de tolerancia hacia el racismo y de una mayor disponibilidad para la aculturación y, por ello, para los requisitos y contenidos de la adaptación escolar. Este fue el desarrollo de la investigación de Gibson (1999), que acuñó la expresión acomodación sin asimilación para referirse a las estrategias de adaptación, éxito académico e inserción sociocultural del alumnado sihk del Punjab en California, como minoría inmigrante no incorporada a la sociedad estadounidense por relaciones de dominación directas. Las primeras desarrollarían, además, unas diferencias culturales secundarias derivadas de su oposición, frecuentemente construidas a partir de algunos de sus rasgos estigmatizados.

En un artículo emblemático escrito con su discípula y brillante investigadora afroamericana Signithia Fordham ("Black students' school success: coping with the burden of acting white" , 1987), Ogbu y Fordham plantearon por primera vez la cuestión de la presión del propio grupo de referencia sobre el alumnado, especialmente en el caso de los chicos, calificando su éxito académico individual como indicador de su pérdida de las características positivas que se auto-atribuye el grupo -desde su identificación contracultural- y como prueba de su traición al mismo. Las expresiones de acusación de 'acting white', entre población afro-americana, o de apayarse, entre población gitana, aludirían a idénticos mecanismos de coerción intra-étnica. Posteriormente, Fordham desarrolló la idea del 'parentesco ficticio'16 para entender el tipo de presión del grupo de iguales sobre el estudiantado con buena vinculación escolar y resultados académicos brillantes y su pertenencia identitaria, calificándola de traición. Las dificultades en la negociación dual de una identidad no aceptada o no prevista ni dentro ni fuera de la minoría se pretenden resolver por medio de la invisibilidad étnica ('racelessness') que, más que un proceso de camuflaje, incluye la adopción de pautas y estilos mayoritarios y la renuncia a la asociación pública con estudiantes del mismo colectivo en el seno de las instituciones educativas. Estas estrategias llegan a tener un peso espectacular en los procesos de desarraigo o de abandono escolar en fases críticas de la escolarización, especialmente en la enseñanza secundaria, por lo que la autora califica sarcásticamente sus efectos como una 'victoria pírrica' del grupo minoritario, que no sufre sino los efectos de la reproducción de su posición subalterna.

Estas complejas contribuciones nos sitúan más allá del conjunto de relaciones que se establecen en el centro educativo y nos remiten a la génesis y al desarrollo de las posi-

\footnotetext{
16 De hecho, el referente común para todos las y los afroamericanos es su estigmatización y su experiencia de dominación, cuyas respuestas adaptativas dan lugar a lo que se conoce como 'black culture' en EE.UU., independientemente de los riquísimos y variadísimos orígenes culturales de los y las antiguos/as esclavos/as africanos/as, en un igualmente complejo proceso sincrético hasta el presente, que incluye los distintos movimientos e interpretaciones orientados a su lucha emancipatoria.
} 
ciones de minoría vividas por el grupo gitano y experimentadas y enfrentadas por cada generación. Para esta investigación, parece imprescindible tener en cuenta, como mínimo, las presiones comunitarias ejercidas por medio de las relaciones afectivas $y$, muy especialmente, del grupo de iguales, sobre las mujeres y los hombres que conforman los casos estudiados. Y, por otra parte, deberemos prestar una atención especial a las reacciones y reelaboraciones que éstos han llevado a cabo en sus trayectorias de continuidad educativa como resistencia y proyecto personal frente a las acusaciones de apayamiento y distanciamiento de la comunidad y/o del comportamiento moral esperado, con o sin estrategias de invisibilidad étnica.

\section{Evolución del impacto del género, la clase y la etnia}

\section{en los resultados académicos}

En todas las sociedades avanzadas y complejas, a pesar de las políticas destinadas a combatir la desigualdad educativa que se hayan podido desarrollar, el nivel de éxito para los alumnos/as de algunos grupos sociales y algunas minorías étnicas es significativamente menor que los estándares medios y su experiencia escolar es considerablemente más negativa. En Gran Bretaña, para hacer frente a algunas posiciones que niegan la persistencia de ideas y de prácticas racistas y discriminatorias hacia el alumnado étnicamente minoritario, o identificado dentro de la categoría 'no blanco', destacan algunas de las constataciones de un estudio encargado por el gobierno laborista a los reconocidos investigadores David Gillborn y Heidi Safia Mirza, publicado en el 2.000, que se ha convertido en un texto de referencia obligada en la actualidad.

Los hallazgos más relevantes de su estudio se pueden sintetizar como sigue: aunque todos los grupos étnico-culturales han mejorado sus resultados académicos con el tiempo, la distancia entre el éxito académico del alumnado 'blanco' y el resto (excepto el de origen indio) a los 16 años se ha duplicado desde los años 80. Aunque las chicas de todos los grupos (por etnia y clase social) obtienen mejores resultados que los chicos, las desigualdades asociadas a la etnicidad y a la clase social son mucho más altas que las de género. El alumnado de origen afrocaribeño se incorpora al sistema educativo mejor preparado que el resto de los grupos (sus resultados en el test del Key Stage 1 son claramente superiores), pero se invierte totalmente su situación a medida que avanza en el sistema educativo. Dentro de todos los grupos étnico-culturales, los de clase media obtienen mejores resultados que los de clase trabajadora. Pero el perfil que obtiene con diferencia los mejores resultados son las chicas de origen indio (por encima de todos los demás grupos de origen, género y clase), invirtiendo la tendencia anterior que siempre situaba al alumnado blanco de clase media y alta por encima de todos los demás grupos en los resultados académicos obtenidos.

La conclusión general de los autores es doble: en primer lugar, dentro de todos los grupos hay una proporción de alumnos y alumnas con resultados excelentes, que a menudo se ignoran y no sirven para combatir los estereotipos negativos altamente racializados proyectados sobre el alumnado 'no blanco'; y, en segundo lugar, si no hay nin- 
guna intervención decidida, la tendencia actual anuncia un aumento de estas desigualdades en el futuro porque la inmensa mayoría de los y las responsables educativos locales no se toman seriamente los efectos de la discriminación 'racial'17.

En España no es posible realizar un estudio de este tipo, ni sobre la situación presente ni mucho menos diacrónico, ya que no se registran datos sobre resultados académicos y adscripción étnica. De hecho, ni siquiera podemos hacerlo en relación con el alumnado extranjero, puesto que tampoco se desagregan los datos por nacionalidad en el proceso de registro de resultados académicos o en las pruebas estatales, situándonos entre la más absoluta ignorancia y la mayor de las ambigüedades de la corrección política. Veremos si algunos aspectos de nuestros resultados son coincidentes con alguna de las tendencias descritas por los investigadores británicos, algo que ya parece confirmado en lo que se refiere al conjunto de la población escolar en la literatura internacional y también documentado en España: las alumnas tienen mayores niveles de éxito y menores niveles de disruptividad y, sin duda, su continuidad académica es proporcionalmente muy superior a la de los alumnos, si tenemos en cuenta su incomparablemente peor situación de partida en familias y comunidades (Gómez-Bueno et al., 2002) 18.

En este mismo estudio de Gómez-Bueno et al. (2002) sobre identidades de género y feminización del éxito académico estas situaciones de cambio incipiente y anunciado ya se constatan en las trayectorias interrumpidas de madres y padres (sobre todo, madres) pertenecientes a las clases populares. Aún así, teniendo en cuenta las estrategias familiares de reproducción social y su incidencia en la reproducción de las identidades de género, las autoras sostienen que "en las familias donde la adquisición del capital simbólico y del capital social constituye prácticamente la única forma de acumulación posible, las mujeres son unos valores que hay que mantener a salvo de la ofensa y de la sospecha y que, puestas en juego en los intercambios, pueden producir unas alianzas, es decir, capital social, y unos aliados prestigiosos, es decir, capital simbólico. Así, cuando el beneficio simbólico (de las alianzas) depende del valor simbólico de los objetos de intercambio (reputación y en especial, la castidad de las mujeres disponibles), el honor es una forma de interés en sentido estricto (de aquí que el control de salidas y horarios sea más estricto hacia las chicas que hacia los chicos)" (Gómez-Bueno et al., 2002:297). Si esto fuera cierto, la continuidad educativa de las chicas gitanas quedaría circunscrita a unas condiciones de posibilidad determinadas por el avance del grupo familiar en la ocupación de posiciones integradas a nivel socioeconómico, mientras que las posiciones más desfavorecidas socioeconómicamente y menos integradas en otros aspectos culturales impedirían completamente la consideración de tal continuidad de las chicas.

\footnotetext{
17 Las clasificaciones de las minorías son diversas según los estados y las sociedades y responden a historias de contacto y de incorporación más o menos problemáticas y a su evolución social y jurídica. Como hemos señalado en una nota anterior, recordemos que el término 'race' o 'raza' es utilizado por los autores anglosajones como un sinónimo de 'características fenotípicas'. En cualquier caso, las categorías de agrupación de este estudio son de uso muy común y reflejan aquellas relaciones interculturales específicas y la importancia histórico-social de grupos concretos, así como los términos en los cuales las propias minorías han establecido sus reivindicaciones también específicas en el seno de la sociedad mayoritaria, aunque no todos los individuos procedentes de los grupos minoritarios tienen por qué identificarse con ellas: White, Black African, Black Caribbean, Black Other, Pakistani, Bangladeshi, Indian.

18 Gómez-Bueno, C. et al. (2002), Identidades de género y feminización del éxito académico, Instituto de la MujerCIDE.
} 
Veremos si esta correlación se mantienen cuando entran en juego posiciones minoría-mayoría además de las relaciones y posiciones de clase.

Precisamente para el caso gitano, en su estudio sobre género, etnicidad y escolaridad entre los grupos gitanos de Oporto (Portugal), Casa-Nova (2002) documenta la existencia de conflictos inter e intra-generacionales en lo que concierne a los valores culturales a preservar y a los valores que parecen haber dejado de tener sentido para algunos elementos dentro de esta comunidad, aludiendo a una gran heterogeneidad entre las diversas familias de un mismo barrio, que harían suponer una probabilidad de correlación parcial, pero tal vez creciente. Según Casa-Nova, este debate entre generaciones no se ha asumido, y aún se mantiene en el plano "ideal", y en ocasiones permanece oculto (por parte de los hijos e hijas) por miedo al rechazo o a la no-aceptación. Como consecuencia, se desarrolla una "cultura del compromiso" que posibilita hacer compatibles las posturas de los hijos e hijas y las de los padres y madres, eludiendo el conflicto, y que permite conciliar y vivir, más que entre dos culturas, dentro de dos culturas, como incipiente pertenencia múltiple: por un lado la pertenencia a la comunidad gitana, y por el otro la pertenencia a la sociedad portuguesa. Así, la heterogeneidad y diversidad entre los gitanos y gitanas son indicadoras de la existencia de formas diferenciadas de reflexión interna dentro de la comunidad, de distintas estrategias de educación familiar y de grados diferentes de permeabilidad de las comunidades gitanas frente a la sociedad mayoritaria, además de las presiones locales resultantes de los procesos de globalización a nivel económico y cultural. Las aparentes incoherencias que surgen entre la alta valoración de los aprendizajes escolares por parte de las familias y las prácticas cotidianas que parecen presionar en dirección contraria a la continuidad educativa serían en gran medida el fruto de unas estrategias de control del cambio desde las distintas posiciones dentro de la comunidad gitana estudiada por la autora (aparte de las cuestiones comunes a las clases populares mayoritarias, relacionadas con la apreciación exclusiva de ciertos aspectos instrumentales de la educación formal). Esta perspectiva nos devuelve a una posición que conceptualiza los sujetos de estudio como agentes activos y reflexivos en sus propias trayectorias.

Por último, y siguiendo a Lahire (1993; 1999), en los casos en los que se da una carencia de capital cultural, ésta puede ser compensada por una fuerte inversión de tiempo, esfuerzo y recursos materiales en la escolarización de hijas e hijos. Sin embargo, para que sea efectiva, deberá lograr una implicación afectiva del niño y la niña en la cultura y resultados escolares. En este sentido, el apoyo y la ayuda efectiva pueden ser suministrados por iniciativas y recursos sociales diseñados a tal efecto, ya que las familias desconocen en gran medida los contenidos de las materias que estudian los niños y niñas. Pero no contamos con ningún análisis de la situación educativa de la población gitana desde el punto de vista de su diferenciación social -probablemente no es del todo pertinente hablar de clases-, tal como sí podían plantear Gillborn y Mirza (2000). De momento, podemos adelantar que nuestros y nuestras informantes con éxito académico proceden de posiciones y situaciones socioeconómicas muy distintas y que, como tendencia, nos revelan trayectorias y estrategias de género diferenciadas que vamos a presentar en la siguiente parte del texto. 
De las aportaciones y conclusiones de estos últimos autores (Lahire, 1993; 1999; Gillborn y Mirza, 2000) podemos, así mismo, reforzar dos de nuestras consideraciones explícitas en las hipótesis que se detallarán más adelante: en primer lugar, la reconsideración de la supuesta excepcionalidad del éxito y la continuidad educativas entre las chicas y las mujeres gitanas $y$, en segundo lugar, la disponibilidad y el impacto relativos en las trayectorias de los casos estudiados de un conjunto de recursos sociales dependientes de las actuaciones políticas destinadas a promover la continuidad educativa entre la minoría gitana, como tal, y entre los sectores sociales desfavorecidos, en general.

En el siguiente capítulo se realiza una síntesis de la situación social de la población gitana en las cinco Comunidades Autónomas que han participado en la investigación con el fin de establecer el contexto de la misma y las características en las cuales se han desarrollado las trayectorias y las experiencias de los casos analizados. Este acercamiento a los aspectos comunes y diferenciales de cada contexto concreto nos permitirá situar a las mujeres y hombres que conforman estos mismos casos a través de unos perfiles, así como concretar también esta revisión de precedentes sobre educación, minorías y género en la formulación de las hipótesis de trabajo de la investigación. 


\section{CAPÍTULO 2: CONTEXTO Y DISEÑO DE LA INVESTIGACIÓN}

\subsection{Síntesis de la situación social de la población gitana en las cinco Comunidades Autónomas}

El objetivo de este apartado es mostrar la diversidad interna de los contextos de origen de las mujeres y de los hombres que han desarrollado trayectorias de continuidad educativa y que, atendiendo a tal diversidad, hemos considerado finalmente como casos significativos dentro de ella.

Toda síntesis o evaluación que se quiera efectuar sobre la situación de la población gitana en España debe constatar que nos hallamos ante una situación de claroscuro, de luces y sombras, de notables mejoras y de algunos estancamientos e incluso retrocesos no menos notorios. Sería faltar a la verdad - por mor de reivindicar mejorasoptar por un enfoque meramente crítico y miserabilista, que subrayara en exclusiva las situaciones de marginación; pero sería igualmente falso no dejar bien patente la persistencia y la frecuencia de esas situaciones de exclusión social y desigualdad de oportunidades para un sector importante de las familias gitanas.

Hace sólo 25 ó 30 años los indicadores sobre documentación (grado de existencia de papeles oficiales), nutrición, vivienda, condiciones higiénicas y atención sanitaria, condiciones laborales y de seguros sociales, grado de alfabetización y de escolarización de la población gitana eran netamente peores a los actuales. Muchas familias (no todas, obviamente) en aquella época vivían en unas condiciones pésimas. En el tiempo transcurrido, las familias (como seguramente a lo largo de todos los siglos anteriores) han realizado un esfuerzo adaptativo muy importante; y, por otra parte, y no menos clave, el nivel de vida de la sociedad española ha mejorado en estas últimas décadas cualitativamente, como efecto del desarrollo -aunque irregular e insuficientedel estado de bienestar y del impulso de la Unión Europea.

En cualquier caso, continúa siendo escandalosa la dificultad para realizar una presentación mínimamente completa a partir de datos secundarios sobre la situación de la población gitana porque, sencillamente, o no existen, o son contradictorios o antiguos y por lo tanto inutilizables, o son totalmente fragmentarios y muy dependientes de los objetivos de intervención social o de denuncia que hayan inspirado su recopilación. Aún así, aquí presentamos de forma sintética algunos aspectos clave suficientemente contrastados para entender el contexto de los objetivos de nuestra investigación, a partir del trabajo realizado por los distintos equipos de las cinco CC. AA. y de una multiplicidad de fuentes documentales, orales y fruto de la experiencia acumulada.

De todas maneras, uno de los rasgos que caracterizan la situación de la población española gitana en los últimos quince años es su proceso de diferenciación social interna y sus consiguientes procesos de readaptación cultural. Aunque en 1990, San 
Román"19 describía los extremos de esta readaptación señalando que "salvo algunos casos excepcionales, la población gitana que vive en las grandes ciudades no parece haber encontrado más salidas que la marginación social o la aculturación a la vida paya" (San Román,1990:10-11), es posible que las opciones en desarrollo estén aportando un abanico de complejidades y matices entre uno y otro extremo.

Así, aunque pasemos una breve revista a los escasos datos que nos permiten construir una síntesis del contexto en el que se desarrolla la investigación en las cinco CC.AA., atendiendo a posibles diversidades internas, serían algunas variables transversales de tal diferenciación (renta y actividades laborales, vivienda, instrucción, participación social) las que nos devolverían una situación más compleja y fiel del mismo, que sólo en algunos aspectos se puede presentar. Hemos organizado la información disponible y las consiguientes reflexiones al respecto a partir de algunos aspectos clave, bajo los siguientes epígrafes: población, localización, tipos de viviendas y barrios, situación económica y laboral, situación sociosanitaria, asociacionismo y participación política, presencia y experiencia social, medidas y programas de discriminación positiva. La situación educativa de partida se expone en la segunda parte del texto.

\subsubsection{Población gitana en las cinco Comunidades Autónomas}

A partir de distintas fuentes ${ }^{20}$, se puede estimar que la población española gitana oscila arededor de 650.000 personas, de las cuales se calcula que aproximadamente la mitad son menores de 16 años, no llegando al 10\% la proporción de mayores de 65 años. La publicación más reciente de estimaciones es la que contiene el informe ${ }^{21}$ para la ONU sobre el racismo y la discriminación en España y, por las dificultades señaladas, el mismo documento proporciona dos estimaciones, que reproducimos a continuación y que, como veremos, tampoco coincide con las estimaciones realizadas en las cinco CC. AA.:

\begin{tabular}{|ccc}
$\begin{array}{c}\text { Comunidades Autónomas } \\
\text { (regiones) }\end{array}$ & $\begin{array}{c}\text { Población española } \\
\text { gitana 2001 (1) }\end{array}$ & $\begin{array}{c}\text { Población española } \\
\text { gitana 1999 (2) }\end{array}$ \\
\hline Andalucía & 350.000 & 286.110 \\
Aragón & 9.000 & 18.209 \\
Asturias & 8.000 & 4.780 \\
\hline
\end{tabular}

\footnotetext{
19 San Román, T. (1984), op. cit.
}

20 Presencia Gitana, Fundación Secretariado General Gitano, INE, Informe de la Subcomisión parlamentaria para el estudio de la situación del pueblo gitano en España, Federació d'Associacions Gitanes de Catalunya, Cáritas Diocesana y otras fuentes generales han generado y generan más o menos sistemáticamente algunos datos en este sentido. En la bibliografía general se especifican los documentos consultados.

21 Comité de las Naciones Unidas para la eliminación de la discriminación racial (informes presentados por los estados partes conforme al artículo 9 de la convención). España, 6 de junio de 2003. Datos facilitados al Comité por el MTAS. 


\begin{tabular}{|c|c|c|}
\hline Islas Baleares & 6.423 & 5.423 \\
\hline Canarias & (3) & 854 \\
\hline Cantabria & 2.460 & 4.021 \\
\hline Castilla-La Mancha & 20.664 & 33.552 \\
\hline Castilla y León & 26.010 & 28.339 \\
\hline Cataluña & 65.000 & 52.937 \\
\hline Extremadura & 15.000 & 11.318 \\
\hline Galicia & 8.417 & 13.741 \\
\hline Madrid & 60.000 & 59.082 \\
\hline Murcia & 12.500 & 33.006 \\
\hline La Rioja & 3.850 & 7.361 \\
\hline Comunidad Valenciana & 50.000 & 52.455 \\
\hline Navarra & (3) & 5.954 \\
\hline País Vasco & (3) & 11.675 \\
\hline Ceuta y Melilla & (3) & 2030 \\
\hline Totales & 632.969 & 630.847 \\
\hline
\end{tabular}

(1): Fuente: Datos de población estimada facilitados por las Comunidades Autónomas, referidos al año 2001; (2): Fuente: Elaboración de la Asociación Secretariado General Gitano a partir de una proyección de los datos del estudio Mapa sobre la vivienda gitana en España del Grupo PASS, complementados con los datos que aportan algunos estudios de ámbito autonómico; (3): Sin datos.

Su crecimiento demográfico estimado supera el 5 por 100 y se afirma que "el tamaño medio de la familia gitana es de 5,4 miembros, frente a los 3,7 de la familia media española.22" (B0CG, 1999:10). Aunque en términos generales su tasa de fecundidad sigue siendo alta con relación a la media del estado (se estima una media de alrededor de 3-4 hijos por mujer), esta proporción ha descendido y lo sigue haciendo.

Aproximadamente el $45 \%$ de la población española de etnia gitana vive en Andalucía, seguida de Cataluña (10\%), Madrid (9\%) y Valencia (8\%). La siguiente franja por-

22 Boletín Oficial de las Cortes Generales n 520 del 17 de diciembre de 1999. 
centual, alrededor del 5\%, la ocupan Murcia, Castilla-La Mancha y Castilla-León, seguidas del resto de comunidades que oscilan a la baja entre el 3\% de Aragón y el 0,1 de Ceuta y Melilla o Canarias, franja en la que se encuentra Navarra (0,9\%). Las cinco CC. AA. de nuestro estudio representan, pues, situaciones cuantitativamente distintas en cuanto a la presencia de población gitana, que a su vez es diversa en varios aspectos cualitativos. Madrid y Cataluña son dos ejemplos distintos de comunidades eminentemente urbanas con alta presencia de población gitana. Castilla-León es un ejemplo de comunidad eminentemente rural con islotes poblacionales de ciudades medias, y con presencia relativa media-baja. Y por otra parte, en Aragón y Navarra hay baja presencia de familias gitanas, sin embargo, en Aragón es eminentemente urbana, con algunos enclaves rurales y en ciudades medias, y en Navarra se da una presencia distribuida bastante equitativamente entre pueblos y ciudades.

\subsubsection{Localización de la población gitana}

Las estimaciones sobre el número de gitanos y gitanas residentes en Madrid oscila entre 60.000 y 80.000 personas, pero en la actualidad podrían ser bastantes más, debido al importante crecimiento vegetativo de esta población y, especialmente, a la llegada de inmigrantes gitanos del este de Europa. La mayoría se concentra en la propia ciudad de Madrid, en los barrios del centro (Centro y Latina) y en los del sur (Carabanchel, Villaverde, Usera, Villa de Vallecas y Puente de Vallecas). Respecto a otros municipios de la comunidad, cabe destacar la presencia gitana en ciudades limítrofes como Alcalá de Henares, Alcorcón, Fuenlabrada, Getafe, Leganés, Móstoles, Parla o Torrejón de Ardoz. La mayor parte de esta población es de origen madrileño o extremeño. Los inmigrantes extranjeros gitanos son mayoritariamente de origen portugués, aunque en los últimos años ha aumentado mucho la inmigración de origen rumano.

Los datos anteriores cifraban en 65.000 personas la población gitana en Cataluña, aunque según algunas proyecciones debería situarse alrededor de 70.000 personas. De éstas, aproximadamente 7.000 viven en la ciudad de Barcelona (en los distritos de Nous Barris, Sant Martí, Sants y, en menor medida, en todos los demás distritos, excepto el de Les Corts), que no se distingue por representar una mayor presencia proporcional que en el conjunto de Cataluña. A los lugares de asentamiento histórico -que hoy día no suponen la presencia más importante de población gitana en Cataluña- hay que sumar las poblaciones que crecieron con la inmigración de la segunda mitad del siglo XX, de manera que se localiza población gitana en todas las comarcas y localidades (cinturón industrial, ciudades industriales y/o importantes mercados fuera del cinturón en todas las provincias) además de los barrios que absorbieron población realojada de núcleos chabolistas. La mitad de la población gitana catalana procede de fuera de Cataluña. Una brevísima lista de las localidades donde la población gitana está más representada en Cataluña, además de la capital, incluiría Badalona (municipio con las cifras absolutas y relativas mayores de población gitana de la C.A.), Sant Adrià del Besós, El Prat, Sabadell, Terrassa, Blanes, Mataró, 
Girona, Figueres, Palafrugell, Lleida, Tàrrega, Balaguer, Tarragona, Vilafranca y Reus. En la Cataluña norte (Francia), es de destacar la presencia de población gitana catalanohablante en la ciudad de Perpignan y en la región de La Camargue.

En Aragón, con una estimación de población gitana de 9.000 personas, parece que las capitales absorben la mayor proporción de población gitana de la comunidad autónoma, destacando fuera de ellas las poblaciones de Épila y Alcañiz. El número total de personas gitanas en Zaragoza es aproximadamente de 4.556, distribuidas desigualmente en siete zonas en las que se ha dividido la ciudad por razones de planificación de la intervención social y erradicación del chabolismo. La población gitana se concentra principalmente en los siguientes barrios: Casco Histórico, Barrio Oliver, MIDE y Torrero-La Paz. En Huesca viven unas 1.400 personas de etnia gitana, de las cuales gran parte se encuentra en situación de exclusión social y bastantes en situación de pobreza. (informe ACCEDER 2001, FSGG en Huesca). En la provincia de Teruel, se estima que viven un total de 3.000 personas gitanas, la mayoría de ellas en la comarca del Bajo Aragón (sobre todo, en la cabecera comarcal, Alcañiz - localidad de un total de 15.000 habitantes-; seguida de Calanda) y, en menor proporción, en Teruel capital.

En Castilla-León la población gitana puede ascender a 26.000 personas, eminentemente jóvenes, con una alta tasa de natalidad relativa (alrededor de un 20\%, frente a un $9,5 \%$ de la C.A.) y una escasa población mayor. Agrupando todas las localidades de Castilla y León en tres únicas categorías, en virtud de su número de habitantes, comprobamos que en la actualidad el 74,42 de la población gitana vive en ciudades con una población total de más de 30.000 habitantes (las 9 capitales de provincia, Ponferrada, Miranda de Ebro y Aranda de Duero); el 15,96 \% reside en ciudades que cuentan de 3.000 a 30.000 habitantes; y el 9,61\% restante en pueblos de menos de 3.000 habitantes.

En Navarra, se estimaba que la población gitana era de unas 6.000 personas en 1.999. Según datos facilitados por el propio Ayuntamiento de Pamplona23, se calcula que la población gitana navarra vive en un $40 \%$ en Pamplona y Comarca, con cerca de 2.000 personas, y alrededor de 300 hogares. Y se concentra en los barrios del Casco Viejo (más de 131 familias), Rotxapea (más de 75 familias gitanas y 54 y transmontanas), San Jorge (unas 40 familias y 23 transmontanas) y Etxabakoitz, con más del $20 \%$ de población gitana. En el resto de Navarra, se calcula que vive el 60 $\%$ de la población gitana, al sur de una línea imaginaria a la altura de Pamplona. Por tanto, la presencia y densidad de población gitana en municipios navarros es relativamente baja y desigual (con mayor presencia, por ejemplo, en Estella, y nula presencia en otros núcleos).

23 Ayuntamiento de Pamplona, Área de Servicios Sociales, "La comunidad gitana en la Acción Social en Pamplona. Aproximación a la Comunidad Gitana desde el Trabajo Social”, Pamplona, noviembre de 1998, página 10. 


\subsubsection{Tipo de viviendas y barrios}

Según el Informe de la Subcomisión creada en el seno de la Comisión de Política Social y Empleo, para el estudio de la problemática del pueblo gitano, "ocupan el 95 por 100 de las chabolas o infraviviendas de los grandes núcleos urbanos. El 80 por 100 de estas viviendas tienen menos de 50 metros cuadrados y en ellas se albergan familias cuyo promedio es del 5,4"24 (BOCG, 1999:10). Esta situación está cambiando, se está haciendo más compleja con la llegada de nuevos colectivos gitanos inmigrantes, procedentes de Rumanía y de Portugal. El Plan Nacional para la Inclusión social cifra en 48.000 personas la población chabolista en el año 2.000, afectando entre un 10\% y un 20\% de la población gitana, según Rodríguez (2002).

De hecho, uno de los cambios más palpables como efecto de las políticas sociales parece referirse de forma sistemática a la vivienda: "Si los gitanos se han beneficiado de la universalización de las políticas de bienestar (acceso a los sistemas de protección social, al sistema de salud, al sistema educativo) ha sido el acceso a viviendas y a entornos urbanos más normalizados, que se produjo en los años 70 y 80 , uno de los factores clave en la mejora de las condiciones de vida y en el significativo avance que ha experimentado esta comunidad. El acceso a la vivienda de muchas familias en esos años, ha tenido un especial impacto sobre otros factores económicos, educativos y sociales, y supuso un verdadero impulso para su promoción social. Sin embargo, la situación de aquellas familias que no se han beneficiado de estos planes... siguen padeciendo los efectos de la exclusión" (Rodríguez, 2002: 21).

En la Comunidad de Madrid existen tres tipos de viviendas y barrios donde reside la población gitana: 1) Núcleos chabolistas; 2) Barrios de tipología especial; 3) Viviendas en altura.

Los mayores núcleos chabolistas están en las afueras de la ciudad de Madrid, son: Barranquillas (distrito de Vallecas), Pitis (distrito de Fuencarral) y el Salobral (distrito de Villaverde). Además, hay al menos una docena de pequeños núcleos dispersos por el resto de la comunidad.

Los Ilamados "barrios de tipología especial" fueron construidos por el Consorcio de Población Marginal (organismo dependiente de la Comunidad de Madrid y del Ayuntamiento de Madrid) entre 1990 y 1995, con el fin de realojar en ellos temporalmente a la población chabolista, en su mayoría gitana, como medida previa a su definitivo realojo en pisos de altura, para facilitar su adaptación e integración social. Estos barrios se constuyeron en terrenos municipales a las afueras de la ciudad, aislados espacialmente, y las viviendas eran alquiladas. Pero el inmediato proceso de guetización y marginalización que sufrieron algunos barrios, así como un inadecuado sistema de mantenimiento urbanístico, provocaron la decisión de sustituir el Consorcio de Población Marginal por el actual Instituto de Realojamiento e Integración Social (IRIS) en 1998. Este nuevo ente de derecho público nace con el objetivo de acabar definitivamente con el chabolismo y la infravivienda mediante el realojo de las fami-

\footnotetext{
24 Boletín Oficial de las Cortes Generales n 520 del 17 de diciembre de 1999.
} 
lias afectadas en pisos de altura dispersos por toda la Comunidad de Madrid. En la actualidad aún quedan algunos de estos barrios de tipología especial, son: Las Liebres (distrito de Fuencarral), La Quinta (distrito de Fuencarral), Mimbreras (distrito de Latina), Plata y Castañar (distrito de Villaverde) y Cañaveral (distrito de Vicálvaro).

Tanto los núcleos chabolistas como los barrios de tipología especial son asentamientos segregados espacial y socialmente, cuya población habita en infraviviendas. Algunas familias viven en situación de pobreza, incluso de extrema pobreza, y otras sobreviven únicamente a merced de la economía informal, con todas sus consecuencias. Según el Instituto Nacional de la Vivienda y el IVIMA se estima que el $90 \%$ de las 1.800 familias que habitan en estas condiciones son gitanas, lo que supone en torno al $12 \%$ de las familias gitanas madrileñas.

El resto de la población gitana de esta comunidad vive en pisos de altura en barrios integrados de Madrid y otros municipios. En cuanto a las viviendas de altura se distinguen dos grupos: 1) Viviendas de Protección Oficial y Viviendas de Integración Social; 2) Viviendas normalizadas en régimen de alquiler o propiedad. En el primer caso se incluyen todas aquellas familias que han sido realojadas en los últimos 25 años, primero en viviendas de Protección Oficial y más recientemente, con el IRIS, en viviendas de Integración Social. Los primeros realojos en pisos de altura se realizaron en barrios de Madrid como Carabanchel, Villaverde, Usera, Vallecas, Latina - San Blas, de manera que existen zonas donde la mayor parte del vecindario es población gitana. Posteriormente, el IRIS amplió las zonas de realojo a otros barrios y municipios de Madrid. Este grupo representa entre el $50 \%$ y el $80 \%$ de la población gitana madrileña. Se trata del grupo más numeroso cuyas características socio-económicas son similares a las de la población no gitana de clases media-baja y baja, aunque el mayor impacto de las situaciones coyunturales y del racismo sigue teniendo un peso específico.

Por último, debemos referirnos a las familias gitanas tradicionalmente integradas a la sociedad mayoritaria, que viven en pisos normalizados (es decir, que pertenecen al mercado inmobiliario general) bien en régimen de alquiler 0 de propiedad. Representan entre el $5 \%$ y el $15 \%$ de la población gitana total y habitan principalmente en las zonas de Centro, Embajadores y Vallecas de la ciudad de Madrid.

Por otra parte, en la Comunidad Autónoma de Cataluña es preciso distinguir entre los barrios y enclaves altamente segregados y los demás tipos de entorno. Aunque se puede afirmar que prácticamente ya no existen núcleos chabolistas de población gitana (los últimos núcleos objeto de realojo han sido Can Tunis y la Perona en Barcelona, Riusec en Ripollet, Vallbona y la Riera d'Argentona fuera de Barcelona), como los que habían existido, éste es un fenómeno que aparece cíclicamente y que actualmente afecta a población gitana de origen rumano y portugués y a algunos sectores de población inmigrante. Recientemente se han producido conflictos vecinales relativos al establecimiento de nuevos campamentos en Sant Cugat, Les Franqueses y los barrios de Poblenou y un sector del Besós (Barcelona) que tienen en su haber repetidos fracasos de realojamiento. 
Como contraposición a los núcleos chabolistas, supuestamente erradicados, todavía persisten otros barrios claramente segregados con viviendas verticales generalmente en mal estado o con viviendas de autoconstrucción. La mayoría de estos barrios se formaron como consecuencia de procesos de realojo de núcleos chabolistas y/o de las graves inundaciones catalanas de principios de los años 60. La población chabolista y en situación de precariedad social no era mayoritariamente gitana en aquellos momentos, sino procedente de la inmigración más recientemente asentada del resto de España, pero la mayoría de estos por entonces 'nuevos' barrios fueron perdiendo población no gitana y algunos de ellos se fueron guetizando de forma clara. Actualmente, podemos citar Can Tunis (en proceso de demolición, en la ciudad de Barcelona), San Roque (Badalona), La Mina (Sant Adrià del Besós), Can Roquetas (Sabadell), Vilardell (Terrassa), San Cosme (EI Prat de Llobregat), La Florida (Hospitalet de Llobregat), y Camps Blancs (Sant Boi de Llobregat). También deben mencionarse los barrios de Font de la Pólvora en la ciudad de Girona y Bon Pastor en Figueres, o los Bloques Juan Carlos, del barrio de Mariola, en la ciudad de Lleida, y el barrio de la Esperanza, en Tarragona.

Sin embargo, más allá de estas situaciones, también existe dispersión y mayor integración urbana de la población gitana que vive en barrios obreros con mayor diferenciación social y urbanística. De hecho, se puede afirmar que la población gitana de estos barrios ha seguido los procesos de asentamiento de la corriente migratoria de los años 60, más que estrategias específicas o efectos de segregación relativos a la propia adscripción étnica. Una gran parte de los gitanos y gitanas entrevistadas, que cumplen con los criterios de inclusión en la muestra, bien proceden de Andalucía, o son hijas e hijos de inmigrantes andaluces, aragoneses, gallegos, manchegos y otros, y se localizan en barrios no segregados de las ciudades grandes y medias.

Así mismo, se siguen localizando asentamientos semi-nómadas a lo largo y ancho del litoral de la costa Dorada y el Delta del Ebro, con familias gitanas que viven de forma temporal en campings de la zona, con diversos y reiterados episodios de conflicto y expulsión, como el caso reciente de la Ametlla de Mar25, en la comarca del Baix Ebre.

En Castilla-León, como en el resto de Comunidades Autónomas, las familias que han tenido oportunidad (por poseer suficiente poder adquisitivo o porque en su zona han tenido la ocasión para ello) han ido accediendo a viviendas de protección oficial, y a ser posible en barrios no segregados, o bien han comprado casas antiguas del casco viejo y las han arreglado, o bien viven en casas de alquiler dignas y en zonas no diferenciadas. Pero esta legítima aspiración choca con diversos obstáculos: 1) Enorme carestía de las viviendas (tanto para comprar como en alquiler), agravada en los últimos años; 2) En la última década, en la Comunidad Autónoma se han construido muy pocas viviendas de Protección Oficial y para acceder a las escasas viviendas de Promoción Pública que se construyen las condiciones exigidas en esta Comunidad Autónoma (acreditar ingresos mensuales del 80 \% del salario mínimo) son claramente excluyentes; 3) Persiste la negativa, explícita o solapada, de algunos propieta-

25 Para más información, ver: Oriol Aymí: "Ocho familias gitanas, expulsadas de un camping de l'Ametlla de Mar", El País, 14 de agosto de 2002, edición Tarragona. 
rios a alquilar viviendas a familias gitanas ni siquiera cuando es con la intermediación del ayuntamiento (ejemplo reciente de León capital) o bien rechazo frontal de parte del vecindario (como ejemplo, la manifestación en el barrio Nueva Segovia, en Segovia); 4) Dificultades para acceder a un crédito bancario de aquellas familias que carecen de ingresos estables y oficiales.

Por todo lo anterior, algunas familias jóvenes se han visto obligadas a vivir en la misma casa de las familias de uno de ellos y sus hermanos solteros, con el inevitable hacinamiento. Persisten, por lo tanto, los procesos de guetización, chabolismo y ocupación de infraviviendas:

-Espacios guetizados: En buena parte de las ciudades de Castilla y León hay zonas en las que existe una alta concentración de familias gitanas, debido a que no han podido tener acceso a otras viviendas. Los casos más evidentes son los del poblado de la Tejera en Palencia (a $3 \mathrm{Km}$. del casco urbano) o el poblado El Encuentro (a $2 \mathrm{Km}$. de la ciudad de Burgos). Persisten también situaciones segregadas y guetizadas en un solo edificio, como La Laguna en Peñafiel, o el único edificio de la calle Orfeón Arandino de Aranda de Duero.

-Chabolismo e infraviviendas: Aunque en los últimos 30 años se han ido desmantelando muy paulatinamente diversos poblados de chabolas o infraviviendas, todavía persisten algunas chabolas e infraviviendas en las ciudades castellano-leonesas. Por otra parte, a veces se ha procedido a la demolición de un asentamiento chabolista sin realizar un adecuado plan de realojo, y limitándose a trasladar a esas familias más marginadas a alguna vivienda o zona donde ya viven muchas familias gitanas y donde ha quedado alguna vivienda -a su vez infravivienda- vacía al irse familias no gitanas, contribuyendo de ese modo a guetizar aún más dicha zona. Según el informe monográfico sobre vivienda al que nos hemos referido con anterioridad, "en el año 2001 existían 318 viviendas habitadas en condiciones de extrema marginalidad ... de estas 318 infraviviendas documentadas, encabeza la lista por provincias León con 84 viviendas (destaca Barrio Nuevo en Ponferrada con 27), Burgos con 69 (25 en El Encuentro y 30 en Bakimet), Palencia con 60 (20 en Tarazona y otros 20 en Laguna Salsa) y Valladolid con 42 (30 en el poblado de la Esperanza). En el resto de provincias, la cifra es menor (27 en Segovia, 19 en Zamora, 9 en Salamanca, y 8 en Ávila)" (Rodríguez, 2002:30).

En Aragón, se relaciona el tipo de vivienda con el trabajo desempeñado por las personas gitanas. Así, aquellos gitanos y gitanas que trabajan en el "mercado" generalmente residen en pisos y están en buena relación con su vecindario. Quienes venden pañuelos de papel o mendigan por las calles viven en furgonetas o caravanas u ocupan casas degradadas no suelen ser -como ya apuntábamos anteriormente- gitanos y gitanas españoles, sino portugueses o rumanos. La mayoría viven agrupados en bloques de viviendas en zonas concretas, si se construyen viviendas sociales, suelen convertirse en "el bloque de los gitanos" o "la zona de los gitanos" y esto se debe generalmente a factores ajenos a los propios deseos de las familias gitanas que van a ocupar esas viviendas. 
Los datos disponibles para Zaragoza y Huesca capitales indican que el 77,7\% de la población gitana vive en pisos, seguida de la población que ocupa parcelas (18,3\%), una proporción mínima viven en casas $(2,4 \%)$, y un $1,7 \%$ en lo que se clasifica como vivienda degradada. Respecto al régimen de tenencia, puede observarse que la situación fundamental es la de alquiler ( $42 \%$ ), sin desdeñar el $21,9 \%$ de la población con viviendas de propiedad al que se suma el $28,9 \%$ de la población que está actualmente pagando una vivienda de propiedad. El Ayuntamiento de Zaragoza con el Gobierno de Aragón han presentado un protocolo de Actuación Integral sobre el Chabolismo. Los principales focos chabolistas según el Heraldo de Aragón (artículo del 13 de octubre del 2002) son: Camino del Pilón en el barrio de Miralbueno (25 familias); parte trasera del Pabellón Príncipe Felipe (24 familias); Riberas del Gállego en el barrio de Santa Isabel ( 9 familias), y un campamento en las proximidades de la carretera de Madrid en el barrio de Valdefierro. La FSGG también señala un polo de crecimiento urbano con un núcleo chabolista en el puente de Hierro en la ribera del Río Ebro. Hay que destacar que los núcleos chabolistas de Zaragoza son de reciente creación, ya que hace entre 10 y 15 años el chabolismo estaba erradicado en la capital; lo que evidencia que el acceso a la vivienda está siendo cada vez más dificultoso, en especial para algunas familias gitanas.

En Navarra, según la encuesta que se elaboró para el diseño del Plan de Lucha contra la Exclusión Social en Navarra ${ }^{26}$ : el $53 \%$ de las viviendas familiares de la población gitana son adecuadas y el $43,5 \%$ son inadecuadas. Se da un 3,3\% de esta población que no tiene vivienda, o que cuenta sólo con una infra-vivienda (chabola, furgoneta...). También es reseñable que el Decreto de Vivienda de Integración Social impide seriamente la compra de una vivienda de estas características en Pamplona, por las condiciones laborales y financieras que se exige demostrar. Lo cual obliga a muchas familias a salir de Pamplona, dejar la familia, un posible trabajo e ir a un pueblo, donde no existe ningún lazo afectivo. El Informe señala que la "proporción de propietarios está bastante por debajo de la sociedad mayoritaria: un 60\% de gitanos con viviendas en propiedad frente al $90 \%$ en la sociedad mayoritaria. A su vez, el $30 \%$ de los gitanos navarros vive en régimen de alquiler, frente al 10\% del conjunto de la población" 27(Rodríguez, 2002:36). Y añade que las condiciones de habitabilidad son desequilibradas todavía según las zonas (mejores en la comarca de Pamplona, en la capital misma y en Tafalla).

Se puede decir que en Navarra no hay núcleos chabolistas, como se dan en otras Comunidades Autónomas. Sin embargo, se dan otros problemas que requieren también intervención, como por ejemplo, los realojos que se están llevando a cabo en la actualidad y desde hace años.

Sobre la emergencia de nuevos problemas con la vivienda de la población española gitana, la FSGG apunta los siguientes: el aumento de la concentración en determina-

26 "Plan de lucha contra la Exclusión Social en Navarra. 1.998-2.005", Texto aprobado por el Gobierno de Navarra el 22 de junio de 1.999 y editado por el Departamento de Bienestar Social, Deporte y Juventud del Gobierno de Navarra, febrero de 1.999

27 Opus cit. 
dos barrios por crecimiento de la población gitana en esos mismos barrios, el deterioro de las viviendas en la mayoría de esos barrios, la persistencia de situaciones de hacinamiento en determinados sectores sociales por las dificultades de acceso a nuevas viviendas por parte de la población joven gitana.

\subsubsection{Situación económica y laboral}

Según un estudio de la FSGG la población española gitana se encuentra preferentemente en los siguientes nichos ocupacionales y sectores de actividad:

\begin{tabular}{|c|c|c|c|}
\hline $\begin{array}{l}\text { ACTIVIDADES } \\
\text { REALIZADAS } \\
\text { POR GITANOS }\end{array}$ & DESCRIPCIÓN & $\begin{array}{l}\text { SECTORES DE } \\
\text { ACTIVIDAD }\end{array}$ & $\begin{array}{l}\text { PORCENTAJE } \\
\text { SOBRE TOTAL }\end{array}$ \\
\hline $\begin{array}{l}\text { ACTIVIDADES } \\
\text { TRADICIONALES } \\
\text { (ejercidas por } \\
\text { cuenta propia) }\end{array}$ & $\begin{array}{l}\text { En proceso de } \\
\text { transformación }\end{array}$ & $\begin{array}{l}\text { - Venta ambulante } \\
\text { - Recogida de residuos } \\
\text { sólidos urbanos } \\
\text { - Temporerismo agrario }\end{array}$ & $50-80 \%$ \\
\hline & $\begin{array}{l}\text { Comercio y } \\
\text { espectáculo }\end{array}$ & $\begin{array}{l}\text {-Anticuarios } \\
\text { - Comerciantes } \\
\text { - Profesiones relacionadas } \\
\text { con el mundo } \\
\text { de las artes }\end{array}$ & $5-15 \%$ \\
\hline \multicolumn{2}{|c|}{$\begin{array}{l}\text { NUEVAS ACTIVIDADES } \\
\text { (ejercidas como asalariados) }\end{array}$} & $\begin{array}{l}\text { - Sector construcción } \\
\text { - Obras públicas } \\
\text { - Funcionarios } \\
\text { no cualificados } \\
\text {-Otros }\end{array}$ & $10-15 \%$ \\
\hline
\end{tabular}

FUENTE: Gitanos, pensamiento y cultura (reproducido en varios números, 2002)

La situación económica de la mayoría de la población gitana, según el Informe F0ESSA (1998), correspondía a circunstancias de pobreza grave. Si la extrema pobreza afectaba sólo al 4,4\% de la población no gitana, en el caso de la población gitana llegaba al $21,9 \%$.

La mayor parte de las familias gitanas tiene una ocupación alta, aunque sea informal, relacionada con la subsistencia. Tanto los hombres como las mujeres adultas suelen trabajar fuera del hogar, a menudo en trabajos que requieren la colaboración de varias personas de la familia. Resulta, no obstante, paradójico el hecho de que la mayoría de los gitanos y gitanas se incorporen al trabajo a temprana edad, y que, sin embargo, el paro y el subempleo juvenil estándar sean muy elevados, como consecuencia de varios factores: su escasa cualificación, el colapso de la venta ambulante, la reducción del 
trabajo temporero del campo, la dificultad, desprestigio y poca rentabilidad de la recogida de residuos sólidos, la falta de redes de información e influencia en trabajos alternativos a los tradicionales de sus familias, los recelos racistas para contratarles por parte de muchos empresarios, etc., y también debido a que, como consecuencia, muchos y muchas jóvenes se ven arropados por la venta ambulante de sus padres, aunque a veces no sean imprescindibles como mano de obra.

Existe un sector de gitanos y gitanas con una ocupación laboral fija. Pero en numerosas familias se da alternancia entre diversos trabajos (venta ambulante, temporeros del campo, etc., aunque uno de ellos - la venta, por lo general- sea más predominante), según las posibilidades laborales de cada momento, proporcionando así fuentes de ingresos complementarias, si bien de carácter eventual.

En Madrid, buena parte de las familias gitanas se dedican a actividades tradicionales como la venta ambulante (ropa y calzado, frutas...) y, en menor medida, la recogida de chatarra, cartón y palés de madera. Existen dificultades para conseguir licencias para la venta ambulante en los mercadillos municipales, por lo que hay un número de familias que se ven abocadas a trabajar en situación irregular; son muchos los colectivos gitanos que proponen la regulación de esta actividad también como medida de protección y para distinguirla de forma clara de otras inequívocamente ilegales, como la venta de droga.

Otras personas trabajan como asalariadas de baja cualificación. Se suelen reproducir, en estos casos, modelos de división sexual del trabajo que orientan a los hombres a la construcción o la vigilancia de obras y a las mujeres a la limpieza de edificios o casas particulares. También hay quienes tienen un trabajo mejor cualificado como personal funcionario o como personal empleado en diferentes asociaciones gitanas. Algunas familias que se dedican a la venta han conseguido abrir su propio negocio y hay un número considerable de familias gitanas que tiene su comercio de venta de antigüedades en la zona del Rastro de Madrid. Sólo un porcentaje reducido se dedica como actividad principal al mundo del espectáculo. Son una parte de la élite gitana de Madrid.

EI IRIS reconoce que la mayoría de las familias gitanas con las que trabaja no poseen ingresos declarados. En sus Unidades de Trabajo Social instaladas en núcleos chabolistas y barrios de tipología especial, más del $20 \%$ de las demandas que reciben están relacionadas con la Renta Mínima de Inserción (RMI). Ésta crea una enorme dependencia institucional entre la población que la recibe, lo que genera incertidumbres sobre su objetivo de inserción laboral. El paro, por su parte, sigue afectando a muchas personas gitanas, lo que no significa que no trabajen sino que lo hacen, como hemos dicho, en la economía informal y con trabajos intermitentes (venta ambulante no regularizada, chatarra, y algunas familias en el trabajo temporero en el campo), por eso tan sólo el 7\% demanda empleo normalizado en las Unidades de Trabajo Social. Como ha denunciado repetidamente el asociacionismo gitano, éste es el tipo de población gitana en la que los medios de comunicación se centra a la hora de hablar sobre "gitanos y gitanas", con lo cual muestran sólo una parte de la realidad de la población gitana madrileña y alimentan así una imagen estereotipada de deterioro, precariedad y marginalidad. 
El programa ACCEDER de Formación y Empleo de la FSGG, se lleva a cabo en Madrid desde 1998 para promover el acceso de la población gitana al mercado laboral normalizado. En la Comunidad de Madrid se dispone de tres servicios de empleo, ubicados en Villaverde, Vallecas y Carabanchel.

En Cataluña, el Departament de Benestar Social calcula que el 90\% de la población gitana se dedica a la venta ambulante en todas sus variantes, especialmente en el comercio de productos ligeros y fácilmente transportables (ropa, zapatos, CD, fruta y verdura, etc.); un sector no mayoritario de la misma carece de permisos y, por lo tanto, se halla en situación de ilegalidad, aunque actualmente existe la Asociación de Vendedores Ambulantes, entre cuyas objetivos prioritarios se encuentra la regulación de la venta y la mediación entre comerciantes y administraciones públicas con la intención de conseguir más espacios de venta ambulante legales.

Aún persisten actividades de carácter entre tradicional y marginal como la recogida de residuos en áreas urbanas, especialmente cartón y chatarra, aunque en retroceso. Ocurre lo mismo con los trabajos de temporeros agrícolas. Ha habido a lo largo de veinte años un descenso considerable del porcentaje del total en este tipo de trabajos, aunque se mantiene en determinadas zonas rurales o ciudades limítrofes a zonas rurales, como Figueres en la provincia de Girona, y en toda la zona de Lleida. A la reducción del trabajo propiamente, hay que sumar la competencia de la presencia de población inmigrante en las mismas zonas. En el caso de venta de antigüedades, hay que precisar que la concentración de esta actividad, de por sí muy minoritaria, se da en la zona de el Eixample (anticuarios con mayor reconocimiento) y la zona de Els Encants (rastro), ambas en la ciudad de Barcelona.

Finalmente, en las actividades consideradas tradicionales, encontramos la ocupación de artes escénicas, danza y baile. Hay gitanos y gitanas asentados desde generaciones en zonas costeras que viven de trabajar en tablaos durante todo el año, o bien en temporada alta, en hoteles realizando espectáculos para turistas extranjeros. Persiste una fuerte demanda de este tipo de espectáculos, especialmente en las zonas consideradas destinos turísticos masivos por excelencia, por ejemplo Lloret de Mar (Costa Brava) o Salou (Costa Dorada), pero también en la ciudad de Barcelona. Mención aparte merece el creciente interés en las zonas urbanas, especialmente en Barcelona, por el consumo y la práctica cultural de todo lo referente al mundo del flamenco (demanda de espectáculos, bares musicales específicos, tablaos, centros de música y danza, actividades en centros cívicos) con profesores y profesoras expertos en flamenco y creación de nuevos sellos discográficos, que tienen como objetivo promocionar las y los cantantes flamencos.

A ello le debemos sumar algunos nichos ocupacionales emergentes, como por ejemplo la vigilancia de obras. Hace años que hay gitanos realizando este trabajo, pero no ha sido hasta ahora que se han organizado en compañías de seguridad. Se caracterizan por ser empresas pequeñas, de carácter familiar. Sus tarifas son tan asequibles -hasta un $60 \%$ más baratas que las compañías de seguridad tradicional- que han recibido una gran demanda por parte de las constructoras ${ }^{28}$. Así se abre una posibilidad para

\footnotetext{
28 Aunque incipiente, este sector emerge en distintas CC. AA.
} 
incorporar mano de obra no-cualificada de barrios cercanos a nuevas construcciones de infraestructuras y viviendas. Inicialmente, fueron algunos miembros de la Asociación de Vendedores Ambulantes (ADVA) quienes se ofrecían como intermediarios entre la población activa y las mismas constructoras.

En esta presentación no podemos dejar de lado una tendencia que va en aumento entre gitanos y gitanas con formación académica. Hay una cierta especialización formativa en estudios y/o ocupaciones 'de retorno' a la comunidad, mediante titulaciones medias y superiores de carácter social y asistencial. Algunos empleos específicos se desempeñan en el mundo asociativo, sea por extender sus redes de amistad y/o familiares en la búsqueda activa de empleo, sea por la inserción en el mundo asociativo como usario/usuaria, estudiante en prácticas, o por afinidad étnica. Está por llegar el momento en que esta nueva mano de obra cualificada y creciente deje de ser absorbida mayoritariamente por este tipo de puestos. En este sentido, existen en Cataluña dos equipos del Programa ACCEDER, en Sabadell y en Barcelona, con diversas actuaciones también en otras zonas, como Girona. Por otra parte, en Barcelona está ubicada, así mismo, la sede de la Unión Romaní a nivel estatal.

En cuanto a niveles de renta, no podemos añadir mucho a lo consignado en el apartado anterior sobre el proceso de diferenciación social. Valga como ejemplo que, mientras que en determinados sectores dedicados a la venta ambulante legalizada se han alcanzado niveles de renta y patrimonio medios y altos, en uno de los barrios con mayor presencia de población gitana (el barrio de La Mina), según un informe realizado por la consultoría Idom ${ }^{29}$ en 2003, la renta familiar bruta media es de 3.606 euros anuales, esto es, más del $40 \%$ inferior a la media de Sant Adrià (ciudad a la cual pertenece el barrio) y el $60 \%$ inferior a la media de Cataluña.

Resulta muy ilustrativo detenernos en la situación ocupacional de la Comunidad Autónoma de Castilla y León, por su diversidad y transformaciones. Los gitanos y gitanas castellano-leoneses han llevado tradicionalmente pequeños negocios por cuenta propia (hasta los años 60 como proveedores de ganado y cestería a la zona rural, y posteriormente la venta ambulante los mejor situados y la recogida de chatarra y cartonaje otros), junto a trabajos de temporada (carga y descarga de camiones y trabajos temporeros agrícolas). Este tipo de trabajos ha venido motivado por el margen de oportunidades que han encontrado en el contexto social en el que viven, y también por sus propias potencialidades y carencias: recelos anti-gitanos que han dificultado (y siguen dificultando) la contratación como trabajadores y trabajadoras fijos por parte del sector privado, ausencia de redes de información e influencia para otros trabajos, escasa escolarización y formación reglada, y, por el contrario, conocimiento familiar de estos negocios y red familiar extensa que se expande por varias localidades y que facilita información para las compras, ventas, ferias y mercados. Pero estos pequeños trabajos por cuenta propia y de temporeros generan ingresos económicos muy irregulares. Por ello, en las últimas décadas, los gitanos y gitanas que han tenido oportunidad de lograr un trabajo asalariado fijo lo han hecho (sobre todo, en la construcción, limpieza, jardinería, restauración ... ).

29 Fuente: El País (edición Cataluña) 20/11/2003 pág. 5. 
Sigue predominando sobre cualquier otra ocupación la venta ambulante, principalmente de artículos de confección, en mercadillos que se desplazan por distintas localidades. Dentro de la venta ambulante hay grandes diferencias según el número de licencias que se tenga, que pueden revertir en la mejora del negocio e incluso el paso al comercio fijo, pero se encuentra en proceso de recesión y muchas familias ya tienen que completar sus ingresos con otras ocupaciones, como informa el Programa ACCEDER. Se aducen tres razones, que interesa destacar aquí: 1) aumento de los y las vendedoras, ya que la población joven se incorpora con los mismos recursos que tenían sus padres; 2) competencia de precios en los mismos productos por parte de las grandes superficies que se van instalando en el territorio; 3) competencia con nuevos sectores de población en el mismo nicho ocupacional (tanto de población inmigrante como de población mayoritaria). Lo más frecuente es compaginar la venta ambulante con el trabajo temporero del campo (la vendimia, plantación de la fresa, recogida de patata y remolacha, y otros, según zona y época), que también empeora con la aceptación de peores condiciones por parte de un sector de población inmigrante y con la mecanización creciente de algunos procesos. Algo parecido ha ocurrido con el sector de la construcción, donde un número creciente de jóvenes gitanos se ha empleado, con la emergencia de alguna empresa propia. Algunas mujeres gitanas acceden a puestos precarios que la población mayoritaria rechaza, como la limpieza de domicilios. Sin embargo, la compra-venta de antigüedades se mantiene y se especializa.

Aunque también se trata de una actividad en retroceso, la población en entornos más segregados y marginales suele depender para su difícil subsistencia de la recogida de residuos sólidos (chatarra, cartón) y de algunas prestaciones como la Renta Mínima de Inserción. También queda algún feriante de ganado (muy pocos), especialmente en Castilla y León. Finalmente, los casos de gitanos y gitanas que se dedican a profesiones liberales o con mayor grado de cualificación son excepcionales, los que van constituyendo parte del registro de la investigación, a los que se suman aquellas y aqueIlos que ocupan algún puesto como monitores/as mediadores/as dentro de programas de desarrollo dirigidos al propio colectivo.

En Aragón, parece que persiste una situación económica y laboral entre tradicional y marginal, con poca diferenciación social, especialmente en la ciudad de Zaragoza. Así, según la información obtenida por el equipo de investigación de Cáritas de Zaragoza (a través de una encuesta que ha registrado un 96,7\% de respuesta), la media de ingresos declarada por estas familias se sitúa alrededor de las 90.000 pesetas (en torno a los $541 €$ actuales) al mes, encontrándose un $30 \%$ de familias por debajo de las 30.000 ptas. (es decir, con ingresos inferiores a $180 €$ ).

La mayor parte de los ingresos de las familias gitanas procede del trabajo realizado por algunos de sus miembros. Sin embargo, también es de destacar la importancia que poseen los ingresos procedentes de las prestaciones sociales de la administración. En concreto, el 58\% de las familias gitanas percibe algún tipo de prestación social de la administración, para las cuales, la importancia de las mismas es crucial, ya que del total de ingresos que perciben esas familias, las prestaciones suponen el 55\%. Por otro lado, sorprende el bajo porcentaje de otro tipo de fuentes de ingresos, como los 
procedentes de las entidades sociales, que en el momento de la encuesta, sólo afectaba al $0,6 \%$ de las familias. Además, la mayor parte de estas prestaciones se dan de forma ocasional o por periodos muy breves de tiempo. Dos tercios de las familias perciben ingresos procedentes del trabajo, con o sin suplementos por prestaciones.

La prestación social más extendida entre las familias gitanas aragonesas es la "Prestación por hijo a cargo" (que la perciben el 31\% ), y es a su vez de las que alcanzan una cantidad económica más escasa (18 euros por hijo y 36 euros si tiene alguna minusvalía reconocida). Posteriormente se encuentran las pensiones no contributivas, sean éstas por invalidez o por jubilación y, en siguiente lugar, las asistenciales. Téngase en cuenta a este respecto, que del total de pensiones, el 72\% tienen carácter no contributivo o asistencial, con lo que el grado de protección es bastante bajo. Por último, queda por señalar que de entre el conjunto de familias gitanas que perciben algún tipo de prestación, la gran mayoría, casi el $80 \%$, sólo perciben una ayuda.

Para la mayoría de familias del municipio el trabajo sigue siendo, como en las situaciones más tradicionales, una necesidad para la supervivencia y un reconocimiento del grupo, más que un fin en sí mismo, y participa de los conceptos populares, en el sentido de que compagina la razón económica y la razón moral. Fundamentalmente, nos encontramos ante trabajadores "atípicos" que compaginan diversas ocupaciones, y de acusada polivalencia en cuento a tareas se refiere. Por ejemplo, cualquier chatarrero puede, en una época del año, dedicarse a la vendimia y otras labores de temporada. La venta ambulante y la chatarra permiten el trabajo cooperativo familiar autónomo, sin horarios y turnos fijos que implica las ocupaciones por cuenta ajena, si bien se trata de actividades marginales, infravaloradas por la sociedad mayoritaria, que producen ingresos fluctuantes y casi siempre escasos, si se tiene en cuenta el número de personas que dependen de ellos.

La sedentarización también es clara en Aragón y esto implica necesariamente cambios y readaptaciones. Por ejemplo, el trabajo asalariado al que se dedica un grupo significativo de estos gitanos y gitanas, al entrar en el sistema de contratos municipales, implica un cierto grado de aculturación, pues empieza a romper con la característica cooperación familiar y laboral y con algunos valores en que se basan sus relaciones sociales tradicionales.

En resumen, puede afirmarse la difícil situación económica que atraviesan la gran mayoría de los gitanos y gitanas del municipio de Zaragoza. Y, por último, debemos mencionar que todavía se identifica alguna presencia de trabajo infantil, aunque sea considerado sólo como ayuda familiar.

Finalmente, el caso de Navarra tampoco muestra una situación de diferenciación y cambio en los aspectos ocupacionales y el nivel de renta. También la venta ambulante es una de las principales fuentes de ingresos, seguidos por la compra-venta de antigüedades, la construcción, el transporte y la hostelería. Aunque se está empezando a dar un pequeño grupo de trabajadoras y trabajadores que trabajan en la Administración Pública y en las propias asociaciones gitanas o pro-gitanas. La información de la situación en Navarra, desde una perspectiva descriptiva, tanto en el Plan 
de Lucha contra la Exclusión Social en Navarra" ${ }^{\prime 30}$, como en el trabajo de Laparra31, destaca a la minoría gitana como uno de los grupos que componen el espacio de la exclusión en la Comunidad Autónoma. Como dice el documento del Plan: "Las minorías étnicas padecen situaciones de exclusión con una frecuencia mucho mayor que la mayoría de la población. Las más de 900 familias gitanas identificadas como excluidas suponen una gran parte de las familias gitanas de Navarra, y esto sucede, incluso en mayor proporción con la minoría transmontana". ${ }^{32}$

Además, gracias a la publicación La garantía de ingresos mínimos en Navarra. Un estudio evaluativo de la Renta Básica, 1.990-2.00133, disponemos de datos sobre la evolución de la Renta Básica ${ }^{34}$ y comprobamos que: "el colectivo gitano tiene una presencia constante a lo largo del periodo de análisis, aunque baja ligeramente en el último año"35. Según este informe, entre 1.990 y el 2.001 , el porcentaje de hogares gitanos que perciben la Renta Básica sobre el total de hogares que la perciben va desde un mínimo del $19,3 \%$ en 1.991 , hasta un máximo del $26,3 \%$ en el año 1.996 . Esto nos indica la sobrerrepresentación de la exclusión social dentro de la comunidad gitana navarra ya que, aunque sólo alrededor del $1 \%$ de la población navarra es gitana, suponen de media, entre 1.990 y 2.001 , el $23,96 \%$ de los hogares perceptores de Renta Básica. El mismo estudio afirma: "El nivel de asistencialización aquí es notablemente superior al de ningún otro colectivo, pero, con todo, a pesar del estereotipo establecido, no llega a ser mayoritario: un 38,4\%, aunque podría haber una subrepresentación por ocultamiento (legítimo) en el proceso de tramitación de su origen étnico, bien por su parte o por las mismas profesionales". ${ }^{36}$ Es decir, se considera que algo más de un tercio de las familias gitanas necesitan la Renta Básica para garantizar la cobertura de sus necesidades prioritarias.

\subsubsection{Situación sociosanitaria}

En los últimos 15 años las mejoras en la situación y cobertura sanitaria de buena parte de las familias gitanas han sido enormes, desapareciendo progresivamente los tratamientos sanitarios específicos a través de la antigua beneficencia e incorporándose a las prestaciones generales. La reforma de las prestaciones del estado en la

\footnotetext{
30 "Plan de lucha contra la Exclusión Social en Navarra. 1.998-2.005", Texto aprobado por el Gobierno de Navarra el 22 de junio de 1.999 y editado por el Departamento de Bienestar Social, Deporte y Juventud del Gobierno de Navarra, febrero de 1.999

31 Laparra Navarro, Miguel, Documento de trabajo "Una perspectiva de conjunto sobre el espacio social de la exclusión: el caso de Navarra en el contexto español de precariedad integrada", Pamplona, abril del 2.000.

32 Op. cit., página 35

33 Laparra Navarro, Miguel, Corera Oroz, Conchita, García Ustarroz, Cristina, Macías León, Almudena, Orte de la Peña, Paloma y García Serrano, Carlos, "La Garantía de ingresos mínimos en Navarra. Un estudio evaluativo de la Renta Básica, 1990-2001", Departamento de Bienestar Social, Deporte y Juventud, Gobierno de Navarra, junio 2.003.

34 Por Renta Básica se entiende "la prestación destinada a hogares y unidades familiares, consistente en la prestación de ingresos económicos que garanticen la cobertura de sus necesidades prioritarias", según la publicación "La Garantía de ingresos mínimos en Navarra. Un estudio evaluativo de la Renta Básica, 1990-2001", op. cit., página 37.

35 Idem, página 62.

36 Idem, página 127.
} 
segunda mitad de los ochenta y primeros noventa han sido claves en este sentido. Sin embargo, a pesar del avance en calidad de vida, la esperanza de vida es menor y la mortalidad de personas menores de 65 años es claramente superior que para la mayoría de la población española. Por otra parte, la mejora de las condiciones de vida y el nivel de ingresos tiene efectos sobre el grado de salud en todos los sectores de población en todo tipo de enfermedades (recuérdese que las familias pobres registran tres veces más discapacidades que las ricas: Encuesta sobre Discapacidades, Deficiencias y Estado de Salud, INE, 1999). En este sentido deben entenderse las consideraciones que se incluyen en este apartado, sin olvidar el hecho de la falta de datos generales fiables y de que, lógicamente, los estudios en este campo se concentran inequívocamente en la población que sufre las peores condiciones sociosanitarias.

Así, desde los sectores sanitarios, se sigue mencionando la persistencia de un uso indebido e irregular de los recursos sanitarios por parte de algunos usuarios de la población gitana, desde la perspectiva curativa más que desde la perspectiva preventiva, prevaleciendo algunas concepciones etno-médicas de trastornos que no son considerados como enfermedades si no van acompañados de dolor. Esto se traduce en un mayor uso de los servicios de urgencias y un seguimiento menor de las visitas médicas. Tampoco debe olvidarse que un sector importante de familias gitanas acude preferentemente al sector privado ante la percepción de enfermedades graves, donde se realizan importantes desembolsos, más que utilizar la propia Seguridad Social o bien los servicios contratados mediante seguros médicos privados. En el otro extremo detectamos una mayor desventaja de las familias en situaciones desfavorecidas que son completamente dependientes de la cobertura sanitaria estatal en aquellos aspectos básicos que ésta no cubre (y de los que, en lugar de ampliarse la cobertura, están siendo crecientemente privatizados), como por ejemplo los relativos a la salud dental o la salud visual y sus respectivos aparatos correctores.

En cambio, los aspectos preventivos de la vacunación infantil sí se están generalizando en todos los niveles económicos de la población gitana, aunque persistan olvidos y atrasos en el calendario mayores que en la media de la población. Entre la población gitana marginal, parece que existe una cierta proporción de casos de obesidad pero también de desnutrición infantil, así como la prevalencia mayor de minusvalías físicas, psíquicas y sensoriales, agravadas por la falta de diagnóstico precoz, tratamiento inadecuado y condiciones ambientales negativas. En términos generales, es mayor la prevalencia de diabetes, hipertensión, afecciones de las vías respiratorias y trastornos cardiovasculares entre la población gitana, en gran parte por una mayor proporción de población en peores condiciones de vida ${ }^{37}$. También parece ser más elevada la presencia de trastornos mentales (por ejemplo, depresiones o estados de ansiedad), aunque en este tipo de dolencias puede estar sobre

37 No estamos en condiciones de incluir algunos resultados de estudios epidemiológicos que atribuyen a la mayor endogamia de la población gitana tradicional la prevalencia de algunos trastornos por cuanto no tenemos elementos para valorar su inclusión u omisión de otras variables independientes que podrían resultar claves. Por otra parte, los expertos en cultura, adscripción étnica y salud insisten en los sesgos de este tipo de estudios. Sin embargo, recomendamos consultar la publicación de la Asociación Secretariado General Gitano/Grupo Amat de Sociología (1992): La situación de las personas minusválidas de etnia gitana que residen en la Comunidad Autónoma de Castilla y León. Madrid: Asoc. Secretariado Gral. Gitano; y Martínez Frías, Ma Luisa (1993): Malformaciones congénitas en la población gitana: un estudio epidemiológico en un grupo de la población española. Madrid: Real Patronato de Prevención y de Atención a Personas con Minusvalías. 
representado por formar parte de los motivos de consulta desde la propia población, puesto que se inscribe en su repertorio etno-médico.

Un tema aparte pero igualmente muy importante tiene que ver con los problemas añadidos a la situación socioeconómica precaria y la segregación urbana relacionados con las toxicomanías. En buena parte de los años 70 y 80 la adicción a la heroína entre algunos jóvenes (hombres en su inmensa mayoría) provocó auténticos estragos en sus propias existencias y en las de sus familiares: vidas supeditadas a la adquisición de dicha sustancia psicoactiva, pérdida de otras motivaciones (laborales, obligaciones familiares...), gasto de cantidades muy elevadas de dinero, robos (en primer lugar a la propia familia), reaparición de enfermedades casi erradicadas, aparición del SIDA, aumento de la experiencia carcelaria y de la mortalidad. Los gitanos no fueron los únicos afectados, obviamente, pero muchos jóvenes hombres gitanos de entonces sufrieron sus consecuencias. Por otra parte, algunas familias gitanas vieron en la venta de droga una aparente solución de salida a la crisis económica e industrial que supuso grandes retrocesos en su proceso de inserción social. Es obvio que estas familias no fueron ni son las únicas, ni tampoco los grandes traficantes pero sí, en palabras de San Román (1994), el eslabón más débil y expuesto de la cadena. El culto evangélico supuso una reacción enérgica contra esta situación, al ofrecer tanto un espacio de prevención como de rehabilitación psicológica y moral para los afectados y para sus familias. En estos momentos, además, se ha instalado de forma inequívoca el rechazo hacia las familias relacionadas con la droga por parte de las demás.

Sin embargo, parece que existe una percepción de riesgo muy baja hacia el hachís, la cocaína, el alcohol y las pastillas, tanto por parte de los jóvenes (básicamente, chicos) como de sus familias. Con la heroína se constató que se moría la gente: era "la droga"; sin embargo, las drogas de moda actuales se perciben como inocuas. Obviamente, esta tendencia no es exclusiva de los adolescentes y jóvenes gitanos.

De igual manera, en los adolescentes gitanos se produce actualmente un fenómeno que aumenta su vulnerabilidad: la aparición y consolidación de la juventud sin responsabilidades, una etapa del ciclo vital que no existía previamente en la forma de vida tradicional de los gitanos y las gitanas. La edad del matrimonio se retrasa y de los 12 a los 18 años no existe ubicación en el mundo gitano. No están casados, no estudian (o están abandonando los estudios), y no trabajan o apenas trabajan (no encuentran trabajo y la situación económica de su familia tampoco hace urgente el que precisen trabajar, limitándose a colaborar en algunas actividades, como la venta ambulante). El mantenimiento actual del control de las chicas, especialmente sus enormes restricciones en cuestiones de ocio frente a la libertad de los chicos en esta fase del ciclo vital, las elimina de esta cuestión.

En cambio, sí son las mujeres las que asisten a los centros de Atención Primaria y las que toman mayores medidas en la prevención y tratamiento de las enfermedades, en parte por su contacto con el sistema sanitario debido a cuestiones de salud sexual y reproductiva. En este sentido, algunos estudios indican que aumenta el uso de métodos anticonceptivos, preferentemente los anticonceptivos orales, situándose en el 17\% la proporción de mujeres gitanas que no utilizan ningún método. 


\subsubsection{Asociacionismo y participación política}

El asociacionismo gitano de tipo étnico ha seguido varios caminos, contando con apoyos institucionales muy irregulares y realizando a menudo acciones supeditadas a la duración de las subvenciones. Hace 18 años, Ardèvol38 señalaba: "los ancianos van perdiendo poder debido a la introducción progresiva de otras jerarquías ajenas a los gitanos, como pueden ser las asociaciones gitanas o las cooperativas" (Ardévol, E., 1986: 79-80), en referencia a la progresiva debilitación de las bases tradicionales de organización por medio del parentesco y su transformación, con la consolidación progresiva de la Iglesia de Filadelfia y del movimiento asociativo. Y, más recientemente, hace cinco años, San Román39 reconstruía las fases seguidas por el movimiento asociativo gitano destacando que "se abandonó muy pronto la acción comunitaria, instalándose más bien en lograr la función mediadora entre las instituciones políticas y administrativas, por un lado, y los gitanos marginados por otro" (San Román, T., 1999:14).

En la actualidad, tanto el movimiento asociativo 40 como la Iglesia Evangélica de Filadelfia cumplen funciones de participación comunitaria con menor o mayor proyección social ${ }^{41}$. Como hemos mencionado anteriormente, esta práctica supuso en un momento determinado la reorganización social y familiar en términos endoculturales, aunque en la actualidad se estima que es mayor la proporción de población gitana que siente alguna vinculación comunitaria con el culto que la que realmente mantienen su práctica.

Por otro lado, buena parte de las asociaciones gitanas generalmente se han apoyado en los vínculos sociales preexistentes, es decir, en las relaciones de parentesco y de la familia extensa, para constituirse y desarrollarse, al menos en sus primeras fases. A su alrededor se han ido generando muchas veces trabajos, precarios y discontinuos, relacionados con la mediación y otras funciones de apoyo social. Llevan a cabo fundamentalmente cinco tipos de acciones: a) realizar funciones de asesoría social (en aquellas asociaciones que cuentan con un o una trabajador o trabajadora social de continuo); b) solicitar subvenciones (a la administración local y autonómica, y en ocasiones estatal o del Fondo Social Europeo) para llevar a cabo pequeños programas y actividades dirigidos a sectores específicos (población joven, mujeres), relacionadas con ámbitos de formación profesional para promover la ocupación, con la formación de mediadores y mediadoras interculturales, etc.; c) organizar semanas y jornadas

\footnotetext{
38 Ardèvol, E. (1986): Vivencias y cambio en la cultura de los gitanos. En San Román, T. (comp.) Entre la marginación y el racismo. Reflexiones sobre la vida de los gitanos. Alianza Editorial, Madrid.

39 San Román, T. (1999): "El desarrollo de la conciencia política de los Gitanos" en Gitanos: Pensamiento y cultura, $\mathrm{n}^{\circ} \mathrm{O}$, FSGG, Madrid

40 Recientemente la Unión Romani ha publicado el Directorio de Asociaciones Gitanas 2004, en el que se recoge información sobre las 430 asociaciones gitanas registradas en el conjunto de España.

41 Por ejemplo, el movimiento religioso evangelista mantiene en Madrid 85 congregaciones, donde participan más de 7.000 mujeres y hombres gitanos en espacios de encuentro específicos para niños, mujeres, jóvenes y ancianos, desarrollando actividades de tipo religioso y lúdico, y que no se limita a una práctica religiosa, sino que está estrechamente vinculado a la identidad étnica y al cambio social y cultural. En Cataluña existen contabilizadas 259 Iglesias evangélicas legalizadas, de las cuales 209 se encuentran en la provincia de Barcelona, 20 en la provincia de Girona, 10 en Lleida y 20 en Tarragona.
} 
culturales (charlas, exposiciones, festivales), donde vindicar una imagen digna de la cultura y del pueblo gitano; d) colaborar con el Programa de Educación Compensatoria, seguimiento escolar, clases de apoyo, etc.; e) vehicular reivindicaciones sociales específicas que afectan a la población gitana.

En general, a pesar de sus limitaciones de medios y de gestión, así como de la falta de continuidad de algunos programas y de los no infrecuentes vicios de todo el asociacionismo voluntario - gitano y no gitano-, las asociaciones gitanas suponen una vía de contacto, presión, defensa y representación ante las administraciones y ante los medios de comunicación social, además de su potencial función mediadora en eventuales situaciones de conflictividad. La mayoría de asociaciones emergentes tienen carácter local y en todas las Comunidades Autónomas existen así mismo asociaciones que representan sectores específicos de la población gitana, con diversas composiciones, como asociaciones de mujeres, de jóvenes, o asociaciones mixtas de población gitana y no gitana. Este último tipo de asociaciones representan un indicador de la vitalidad y de la necesidad de repensar y acompañar los evidentes cambios sociales y culturales que tienen lugar en estos momentos en el seno de los grupos gitanos.

Algunas asociaciones gitanas cuentan con publicaciones periódicas, así como páginas de internet, y/o editan libros sobre temas relativos al pueblo gitano (como, por ejemplo, la Unión Romaní, la Asociación Nacional Presencia Gitana, la Fundación Secretariado General Gitano - FSGG-, o la Federación de Asociaciones Gitanas de Cataluña - FAGIC-). La Unión Romaní agrupa a buena parte de las asociaciones gitanas de España, y constituye una fuente de intercambio y asesoramiento para las mismas. Por su parte, la Asociación Nacional Presencia Gitana se ha caracterizado a lo largo de tres décadas por un talante reivindicativo y de denuncia.

La actual Fundación Secretariado General Gitano tiene sus raíces históricas en los primeros 'secretariados gitanos' que en toda España se crearon desde la iglesia católica. Posteriormente se reconvirtieron en una asociación civil, la Asociación Secretariado General Gitano. Desde hace tres años esta asociación ha pasado a ser una fundación. Como tal fundación, más que la participación y representación de sus socios y las reivindicaciones, tiene como objetivo la obtención de recursos financieros (públicos, de entidades bancarias -como el patrocinio de Caja Madrid- y privados) para llevar a cabo programas específicos, contratando profesionales. Su programa estrella es el ACCEDER, dedicado a la orientación y búsqueda de empleo para la población gitana (y también mayoritaria) y la formación para el acceso al mundo laboral. Tiene equipos en todo el territorio del estado. En algunas zonas también lleva a cabo otros programas de apoyo y seguimiento escolar. En esta fundación los equipos son mixtos (formados por payos y gitanos), procurando contratar para sus programas a mujeres y hombres gitanos con formación académica. Realizan acuerdos con los ayuntamientos para concretar actuaciones locales y para establecer formas de colaboración económica y social. Su implantación con esta forma de actuación es reciente y su infraestructura en cuanto a recursos humanos es netamente superior al de las asociaciones gitanas de cada localidad. Su acción requiere la coordinación con las instituciones y (al menos en la fase de toma de con- 
tacto e implantación) con las asociaciones gitanas ya existentes, con el fin de unir esfuerzos en pos de un mismo objetivo y para evitar redes paralelas.

Es interesante observar los cambios en las denominaciones de las asociaciones en el tiempo, apelando explícitamente a la 'promoción', al 'desarrollo' o similares en una primera fase, y recuperando denominaciones mucho más asertivas desde el punto de vista étnico o identitario y siempre en caló, en los tiempos más recientes. Así mismo, se tiende a generar federaciones de asociaciones más pequeñas, tanto a nivel autonómico como estatal e internacional.

En otro sentido, hay que recordar la función que han hecho y, en algunas Comunidades Autónomas continúan haciendo, los Secretariados Diocesanos Gitanos. Éstos, que en un principio estuvieron formados por sacerdotes y monjas y tenían un carácter más asistencial, fueron pasando progresivamente a funcionar por programas y a ser gestionados por técnicos/as y mediodores/as, en muchos casos gitanos y gitanas. Desde la Conferencia Episcopal de la Iglesia Católica se ha establecido que se mantengan los Secretariados Diocesanos Gitanos como un puente de acercamiento a esta comunidad y de que quede constancia nominal de este empeño, con la doble vertiente religiosa y social.

En este punto debemos referirnos (no como asociación de carácter étnico o asistencial, pero sí estrechamente ligada al pueblo gitano, y sobre todo a su infancia y adolescencia) a la Asociación de Enseñantes con Gitanos, impulsora de esta investigación, que en realidad actúa como una federación de asociaciones propias de las distintas Comunidades Autónomas. Esta asociación reúne profesionales de la educación y del campo social de todo el estado y tiene un compromiso explícito con la promoción educativa y social del alumnado gitano y con la formación del profesorado para mejorar las respuestas educativas destinadas a tal fin.

Además de este repertorio comunitario y de asociacionismo de carácter general, existen iniciativas sociales y movimientos explícitamente políticos que no se encuentran en ninguno de los tipos anteriores. Entre ellas mencionamos algunas verdaderamente dispares como, por ejemplo, algunas asociaciones de defensa de los vendedores ambulantes en distintas Comunidades Autónomas o el Partido Nacionalista Caló (que concurrió por primera vez a las últimas elecciones municipales y se presentó también a las elecciones generales de marzo de 2.004) o el recientemente creado partido Alianza Romaní (ARO) (cuyo "primer objetivo" es "obtener el reconocimiento del Estatuto de Autonomía Cultural para el Pueblo Gitano y la elección por sufragio universal de un Consejo Nacional Gitano" ${ }^{42}$.

Sin embargo, a pesar de lo que pueda dar a entender este repaso general al movimiento asociativo y comunitario de la población gitana, no parece existir una gran participación real43 de mujeres y hombres gitanos en el mismo, ni en otras asociaciones o movimientos sociales y políticos de carácter mayoritario. Desde el punto de

\footnotetext{
42 Vid.: Unión Romaní (2004): Alianza Romaní, un partido en marcha. Nevipens Romani, nº 379, 3.

43 Obviamente, ignorando las cifras reales de la población gitana, todavía es más difícil estimar su participación en el movimiento asociativo. Por una parte, intuimos y pensamos que existen grandes diferencias territoriales incluso a nivel local; por otra, Garriga y Carrasco (2000) ofrecen el dato de que el $65 \%$ de las personas de su muestra para la ciudad de Barcelona participaba en alguna medida en el movimiento asociativo, proporción que parece realmente alta.
} 
vista de la participación política, se conocen algunos diputados y concejales en casi todos los partidos mayoritarios estatales (PSOE, IU, PP) y en algunos autonómicos (por ejemplo, $\mathrm{CiU}$ ) en las Comunidades donde se ha llevado a cabo el estudio, pero se estima que la población gitana es, en general, bastante más abstencionista que el conjunto de la población. Según Aguilera Cortés (2000) la representación política y la participación en partidos políticos por parte de gitanos y gitanas es muy escaso; sólo existe un único referente: Juan de Dios Ramírez Heredia, diputado en el Parlamento Español por el PSOE ya en las primeras legislaturas. Del resto de representación política, en las elecciones municipales de 1.999 hubo 15 candidatos gitanos y gitanas, y otros 2 en las elecciones autonómicas, de los cuales sólo 2 fueron elegidos (y, de éstos, sólo 1 salió por una capital de provincia), así como un diputado autonómico en la Comunidad Valenciana y otro en la Asamblea de Extremadura. En conjunto, del total de candidatos, tan sólo 3 fueron mujeres, frente a 14 hombres, y el 95\% de los candidatos tenían relación con el mundo asociativo gitano ${ }^{44}$.

Existen también otras formas de participación política, como la experiencia en el Consell Municipal Gitano del Ayuntamiento de Barcelona, donde están representadas todas las partes relacionadas con el pueblo gitano en la ciudad (desde el ayuntamiento de Barcelona, pasando por la Generalitat de Cataluña, fundaciones y entidades gitanas).

\subsubsection{Presencia y experiencia social}

La población española de minoría gitana sigue apareciendo en todos los estudios de opinión como el grupo más estigmatizado y es innegable que ese rechazo social se expresa por medio de prácticas discriminatorias que se experimentan cotidianamente en multitud de ámbitos de la sociedad.

En este sentido, la Fundación Secretariado General Gitano ha desarrollado en los últimos años proyectos encaminados a promover la igualdad de trato. En el año 2.002 organizó trece seminarios de formación en trece de las diecisiete CC.AA., donde los y las asistentes, de perfil muy variado, recibieron información sobre los procesos y los actores de la discriminación, el marco legislativo de lucha contra la discriminación y las posibles actuaciones antes casos de discriminación. La publicación Discriminación y comunidad gitana. Guía práctica de actuación sirvió de base para el desarrollo de los seminarios. Por lo demás, no existen apenas acciones concretas de lucha contra la discriminación específicas para la población gitana en ningún ámbito, salvo las organizaciones que trabajan contra el racismo desde una perspectiva global en España y a nivel internacional, como S.0.S. Racismo -que anualmente recoge en su informe sobre el racismo un apartado sobre el Pueblo Gitanoo el Movimiento Contra la Intolerancia. Esto significa que ni desde el estado ni desde las CC.AA. se han desarrollado protocolos, medidas, instancias u oficinas, como los existentes en otros países, para denunciar y hacer frente a las representaciones peyorativas y a las experiencias de racismo y discriminación sufridas por las

44 Vid. la página web de la Unión Romani: www.unionromani.org 
personas, que se encuentran, por lo tanto, ante una indefensión legal específica, más allá de las denuncias que se amparen en la legislación de carácter general.

Es obvio que hay una proporción no desdeñable de miembros de la minoría étnica gitana que poseen una experiencia de relaciones interétnicas fluidas y positivas en sus barrios y lugares de residencia, en el trabajo y en los centros educativos. Pero para muchos otros constituye una constatación casi cotidiana el clima de desencuentro y la escasez de interacción entre las personas de una y otra comunidad, así como el riesgo de participar en situaciones de recelo y estereotipos que se aplican recíprocamente. Mujeres y hombres gitanos con frecuencia se lamentan de falta de oportunidades y de rechazos, discriminaciones y aislamientos por motivos racistas. También algunas y algunos adolescentes gitanos se quejan de ser en ocasiones discriminados en el centro escolar o en sus actividades de tiempo libre. Por su parte, en muchas ocasiones un sector importante de la población mayoritaria se queja de los comportamientos inadecuados de algunas vecinas y vecinos gitanos concretos, realizando generalizaciones negativas sobre el conjunto de los miembros del grupo étnico y, de este modo, algunos conflictos entre personas de etnia gitana o bien algún acto delictivo son percibidos por un sector importante de la sociedad mayoritaria como confirmación de sus temores e ideas estereotipadas ${ }^{45}$. En ocasiones se pasa del racismo sociológico implícito y del racismo institucional al racismo más explícito y militante.

Así mismo, se constata una sobrerrepresentación de la población gitana adulta en instituciones penitenciarias tanto de hombres adultos como jóvenes, así como de mujeres adultas ${ }^{46}$, a los cuales les afecta el fenómeno del aumento de estancia carcelaria en los delitos contra la salud y contra la propiedad. Estos datos deben entenderse como indicadores del aumento de las desigualdades y de la radicalización de las situaciones de marginación social; sin embargo, existe una tendencia a utilizarlos para alimentar la representación estereotipada de la población y de la cultura gitana en los medios de comunicación.

En este sentido, hay que reconocer que la presencia en los medios de comunicación social de temas relacionados con la población gitana es más bien escasa y negativa ${ }^{47}$. Veamos dos ejemplos específicos de dos de las Comunidades Autónomas estudiadas.

En primer lugar, un estudio 48 de la situación en Castilla-León revela que cuando esta presencia se produce, existen tres grandes tipos de enfoques al abordar noticias 0

45 Vid sobre este aspecto: LÓPEZ-VARAS, M. L. y FRESNILLO, G. (1995): Margen y periferia. Representaciones ideológicas de los conflictos urbanos entre payos y gitanos. Madrid: Fundación Secretariado General Gitano.

46 También en relación a las mujeres adultas españolas se constata una representación muy elevada de gitanas en el colectivo de presas, tal como pone de relieve: WAGMAN, D. (Director) (2000): Proyecto Barañí. Criminalización y reclusión de mujeres gitanas. Madrid: Asociación La Kalle (policopiado). Este trabajo es un estudio etnográfico sobre la situación de las mujeres españolas gitanas en las cárceles, con análisis de sus causas y propuesta de alternativas.

47 La Unión Romani ha realizado diversos estudios sobre las noticias relativas a la población gitana en más de 100 medios de comunicación desde 1.995, llegando a constatar que el $32 \%$ de las mismas fueron negativas. Unión Romaní: “¿Periodistas contra el Racismo? La prensa española ante el pueblo gitano”, versiones 1995-1996, 1997, 1998-1999, 2000-2001.

48 Para profundizar en este aspecto puede verse la revista "Los gitanos en la prensa", recopilación mensual de noticias y reportajes relativos a los gitanos de toda la prensa nacional, realizada por la FSGG, así como los manuales publicados por la Unión Romaní de "Periodistas contra el racismo". Por lo que respecta al ámbito de Castilla y León, puede consultarse: APARICIO, J. M. (2002): Prensa y educación: Acciones para la desaparición de un gueto. Madrid: Editorial Libre de Enseñanza. Este profesor universitario de la Facultad de Educación y Trabajo Social de Valladolid realiza un estudio pormenorizado de las diferentes noticias (245) de prensa sobre el poblado de la Esperanza de Valladolid (fundamentalmente en los periódicos locales "El Norte de Castilla" y "El Mundo"), analizando los contenidos y el mensaje transmitido por las mismas, así como la adecuación entre las imágenes y el texto, su tamaño, extensión y tipología. 
asuntos relativos a los miembros de esta minoría étnico-cultural: 1) Un tratamiento respetuoso, desde un esfuerzo por la visibilización en positivo, poco frecuente; 2) Un tratamiento sensacionalista y/o miserabilista (recreándose en aspectos colectivos carenciales o problemáticos o en la condición gitana de quien protagoniza algún problema). Es recurrente la práctica de ilustrar noticias positivas relacionadas con la población gitana a base de imágenes de chabolismo y miseria que en absoluto tienen que ver con su contenido; 3) Un tratamiento de denuncia social, cuando alguna persona ha sido objeto de algún tipo de discriminación por su condición gitana.

Por su parte, en segundo lugar, un dictamen del Consell Audiovisual de Catalunya (Dictamen del CAC, 1999: 1-2) constataba que las minorías étnicas -principalmente la minoría gitana- aparecen en la televisión, en tanto que etnias diferenciadas, para hablar exclusivamente de los problemas que se pueden considerar como étnicos. El mismo organismo ${ }^{49}$ encargó un estudio en profundidad (Sorolla, 2000) sobre el tema, en el que se llegó a las siguientes conclusiones: 1) La atención que se presta a los grupos étnicos minoritarios es muy limitada, a excepción que estos grupos se asocien con la violencia, la ilegalidad, la delincuencia o comportamientos culturales que se nos presentan como extraños. Muchas veces los medios informativos describen las minorías valiéndose de estereotipos como "gente problemática" que causa inestabilidad (disturbios, manifestaciones, protestas) o que tiene problemas (trabajo, vivienda, idioma o escuela), y raramente analizan las causas o el contexto en que se producen estos problemas; 2) Las minorías son escasamente utilizadas como fuente informativa principal, incluso en los casos en que son los protagonistas de la información. Esto se debe al hecho de que no suele haber miembros de estas minorías en los medios de producción informativa y que los valores informativos de buena parte de los y las periodistas tienden a excluir a los grupos sociales y culturales minoritarios como fuente de información fidedigna, entre otras razones porque los prejuicios étnicos de éstos/as informadores los llevan a pensar que las minorías tienen menor credibilidad; 3) Los contenidos de las informaciones que afectan a minorías étnicas son generalmente negativos y sesgados; 4) Las actividades "positivas" protagonizadas por las minorías étnicas, como sus contribuciones económicas, a la cultura, las artes o la política son ignoradas o bien infravaloradas; 5) Las actuaciones de las instituciones, la Administración o las autoridades referentes a las minorías se tratan de una manera paternalista: son personas o entidades que llevan a término una tarea "difícil" para ayudar o atender los grupos étnicos minoritarios; 6) La discriminación o el racismo no se presentan como inherentes a una sociedad, sino como consecuencia de la presencia o de las demandas de los mismos grupos minoritarios (Sorolla, 2000: 25-26). 


\subsubsection{Medidas y programas de discriminación positiva}

Es necesario realizar una aclaración fundamental por la nula tradición existente en España en cuestiones de discriminación positiva, ni en temas relacionados con minorías étnicas, ni en temas de género u otros: no se puede confundir bajo ningún concepto la existencia de programas de atención o asistencia específica, inequívocamente dirigidos a paliar las situaciones sociales más extremas sufridas por determinados sectores de la población gitana o mayoritaria, con la voluntad política y la implementación de medidas de acción positiva pensadas para todo el conjunto de la población minoritaria y todos los ámbitos de discriminación que les afectan. Se trataría, por lo tanto, de actuaciones para fomentar el acceso a todos los niveles y ámbitos de la vida social partiendo de una situación de subrepresentación que incluye, lógicamente pero no únicamente, los aspectos socieconómicos.

Algunas de las actuaciones en esta línea son llevadas a cabo por la Fundación del Secretariado General Gitano y otras asociaciones (becas para favorecer la continuidad educativa, promoción de la ocupación normalizada dirigida fundamentalmente a la población gitana, acciones en el marco de la defensa de la representación social de la población y la cultura gitana, etc.), pero podemos afirmar y denunciar, tal como exponíamos también en el apartado anterior, que no existe en este momento ningún plan global y transversal que afecte a todas las políticas públicas y que obligue al sector privado al cumplimiento de objetivos de discriminación positiva, por parte de ningún nivel de administración, local, autonómica o estatal.

Por lo tanto, las acciones de las que se tiene información no se ubican entre lo que constituirían auténticas medidas de discriminación positiva, sino en la categoría de programas asistenciales y paliativos, que no logran transformar las condiciones extremas de la población a la que atienden, minoritaria o mayoritaria. Típicamente, se trata de programas de apoyo y seguimiento escolar, de promoción de la mujer, de atención social básica, de apoyo y seguimiento en procesos de realojo, de salud -la mayoría, dirigidos a población drogodependiente gitana-, de menores y jóvenes, y otras acciones más o menos sostenidas en esta línea. Éste es el planteamiento de muchas acciones Ilevadas a cabo, por ejemplo, en Madrid y en Cataluña, generalmente a través de convenios entre asociaciones gitanas o la FSGG y las administraciones municipales y autonómicas ${ }^{50}$.

Entre los programas de promoción de actitudes interculturales positivas dirigidas a la sociedad en general y a sectores profesionales directamente relacionados con la población minoritaria, S.O.S. Racismo realiza también actuaciones en distintas Comunidades Autónomas. Y a nivel local encontramos programas conjuntos, como el denominado "Kavere Sar Túte (Diferentes como tú). Escuela intercultural y cultura gitana" ${ }^{\prime \prime}$, en Navarra, materiales y publicaciones específicas dirigidas al profesorado

\footnotetext{
50 También existe un "Programa de Desarrollo Gitano", dependiente del Ministerio de Trabajo y Asuntos Sociales, sin apenas dotación presupuestaria, y, por tanto, sin apenas posibilidad de incidencia.

51 Programa promovido por el Ayuntamiento de Pamplona, subvencionado en Navarra por la Obra Social de Caja Madrid y organizado por el Secretariado Diocesano Gitano de Navarra
} 
y al alumnado, como "Pont de Cultures"52, o bien "Ostelinda: jo vinc de tot arreu"53, en Cataluña, o el de "La cultura gitana en el currículo de Infantil y Primaria" (1999) en Castilla y León, y varios otros de este tipo, apoyados desde las administraciones y disponibles en los Centros de Recursos Pedagógicos (C.A. de Cataluña) y en los Centros de Profesores y Recursos (resto de CC. AA.). Mención especial merece el CD realizado por Jesús Salinas con ayuda de otros expertos "Maj khetane (Más juntos). Materiales interactivos para trabajar la cultura gitana" (2003), dirigido especialmente al profesorado y alumnado de los centros de Primaria y Secundaria ${ }^{54}$, financiado y apoyado por administraciones públicas y organizaciones gitanas de todo el Estado. También deben mencionarse los proyectos de investigación e intervención con planteamientos dialógicos como Workaló y Brudila Calli, del grupo de investigación CREA (Universidad de Barcelona). Su objetivo principal es "encontrar vías para superar el absentismo y el fracaso escolar de las niñas y adolescentes gitanas y hacerlo con la implicación de sus familias y de la comunidad gitana en general, como mecanismo fundamental de transformación de la situación de exclusión en que viven muchas mujeres gitanas55" (Puigvert et al., 2003:2).

Pero, junto a estas iniciativas diversas y dispersas de carácter participativo o de la propia sociedad civil, no existen desde ninguna instancia directrices generales de tipo anti-racista y antidiscriminatorio dirigidas permanente y sistemáticamente a la detección de situaciones generales de racismo institucional, de identificación de situaciones de desventaja específica en al ámbito escolar o laboral, ni nada parecido.

Por último, y tal como se detecta en Castilla y León, algunos de los proyectos, acciones y documentos de los programas de Educación Compensatoria han pasado a llamarse "Interculturales", sin aumentar los recursos ni la formación especializada y profunda del profesorado: se pide al mismo profesorado que antes realizaba el apoyo y/o seguimiento escolar del alumnado gitano con necesidades de dicho servicio que ahora centre la atención en los hijos e hijas de inmigrantes.

\section{2. La investigación: objetivos, hipótesis y metodología}

Nuestra investigación se planteó a partir del siguiente doble objetivo general: hacer visible el éxito y la continuidad académica de las mujeres y los hombres gitanos, y desarrollar una perspectiva de género para comprender el cambio social y cultural protagonizado por ellas y ellos, como elemento fundamental (causa y efecto) en el proceso.

\footnotetext{
52 Publicación del Ayuntamiento de Barcelona y el distrito de Sant Martí, bienintencionada pero homogeneizadora e ingenua en sus planteamientos interculturales.

53 Publicación de CCC, realizada por Carme Garriga y Ana Giménez, en forma de cuento infantil (2001).

54 Esta publicación cuenta con el patrocinio de la Comisión de Educación del Programa de Desarrollo del Pueblo Gitano del Ministerio de Trabajo y Asuntos Sociales, Ministerio de Educación, Consejerías de Educación de 15 CC. AA., así como de las principales federaciones de asociaciones y fundaciones gitanas de España.

55 Puigvert, L., Martín, S., Vaqueral, E. "Brudila Callí: Las mujeres gitanas contra la exclusión”, VII Congreso de Sociología, grupo de trabajo de sociología de la educación, sesión $3^{\text {a: }}$ : Educación y desigualdades sociales. Podéis consultarlo en: wttp://ase.es/comunicaciones
} 


\subsubsection{Objetivos específicos}

- Mejorar el conocimiento sobre cuáles son los factores que están contribuyendo de un modo más decisivo al éxito y la continuidad escolar de las alumnas y los alumnos gitanos.

- Conocer las experiencias, percepciones y posiciones de las propias personas interesadas, chicas y chicos, mujeres y hombres gitanos, sobre su proceso de escolarización y continuidad académica.

- Explorar y analizar las diferentes conceptualizaciones del éxito académico, personal y social entre las chicas y los chicos gitanos.

- Identificar las implicaciones del éxito académico para las dinámicas identitarias generales y para el desarrollo de nuevos contenidos y tipos de relaciones entre las mujeres y los hombres jóvenes gitanos.

- Analizar el impacto del éxito académico sobre las relaciones dentro de la comunidad de origen, las relaciones con la mayoría y las posibilidades de inserción sociolaboral en las mujeres y en los hombres gitanos.

- Aportar una mejor comprensión de esta realidad que pueda contribuir positivamente al desarrollo de nuevas formas de intervención sobre la misma, con un efecto transformador.

\subsubsection{Hipótesis iniciales}

A través de nuestras experiencias previas y de la literatura revisada, nos planteamos un conjunto de posibles factores interrelacionados que podían hallarse presentes en aquellas personas de la población gitana con experiencias relativas de éxito y continuidad académica de algún tipo. En primer lugar, profundizamos y delimitamos una definición de éxito coherente con la realidad escolar general de la población gitana en nuestra historia reciente. A continuación, formulamos un conjunto de hipótesis probabilísticas, fruto de la discusión de todos los miembros del equipo. De forma consensuada decidimos incluir las que siguen, con las definiciones operativas que también recogemos. Nuestra investigación pretendía avanzar en el conocimiento de las posibles relaciones e imbricaciones entre las mismas y también poder llegar a desarrollar nuevas hipótesis no contempladas hasta entonces.

De forma consensuada, las hipótesis con las que empezamos a trabajar fueron:

H1. Cuando se dan unas condiciones favorables (socio-económicas, en el plano educativo y afectivo-relacional, en el plano familiar y comunitario) sostenidas en el tiempo existen mayores posibilidades de éxito y continuidad educativa y se hace más improbable el fracaso y el abandono. 
Se entiende por condiciones socio-económicas favorables:

- Vivir en un barrio no segregado, con experiencia de buenas relaciones minoría-mayoría.

A este respecto, definimos como 'entorno segregado' a tres tipos de situaciones: núcleos segregados (chabolas o cuevas, edificios y barrios enteramente segregados, únicamente con población gitana); núcleos degradados en centros históricos de ciudades medianas y grandes; y sectores de alta concentración de población gitana dentro de barrios obreros a su vez segregados (discontinuidades urbanísticas, grandes vías de comunicación o accidentes geográficos) en terrenos industriales y sin equipamientos sociales. $Y$ definimos como 'no segregados': barrios obreros no segregados (población gitana dispersa en distintos sectores dentro del barrio, continuidad urbanística, dotación de equipamientos, diversidad de rentas y ocupaciones), resto de barrios dentro de ciudades medias y grandes, pueblos pequeños con alta sociabilidad general.

- Poseer una posición socio-económica integrada.

Definimos una 'posición económica integrada' como el hecho de tener asegurada una estabilidad económica y de supervivencia familiar fuera de las situaciones de marginalidad. Por el contrario, entendemos que existe un umbral socio-económico por debajo del cual es muy improbable que se puedan activar otros factores.

- Disponer de unos recursos sociales o redes de apoyo no segregados.

Definimos los recursos en dos sentidos: por un lado, como alternativa a la dedicación de recursos humanos, recursos tales como Guarderías (centros de primer ciclo de Educación Infantil); por otro lado, recursos materiales como becas de comedor, becas de libros y material escolar, becas y ayudas de transporte, que permiten compensar las desigualdades de acceso frente a la inversión obligatoria que requiere el sistema educativo español actual (obligatorio pero no totalmente gratuito, como primer factor de desigualdad institucionalizada).

Se entiende por condiciones educativas y afectivo-relacionales favorables:

- Experiencia de valoración, afecto y altas expectativas académicas mantenidas en el tiempo por parte del profesorado.

Entendemos por 'valoración, afecto y altas expectativas' la acción pedagógica explícita que se plantea como meta irrenunciable el éxito de todo el alumnado y así lo transmite al mismo: seguimiento y comunicación individual con el alumnado sobre sus posibilidades y trayectorias, co-responsabilidad, consejo y orientación, detección y acción precoz ante posibles problemas y dificultades, movilización de recursos y materiales extraordinarios para llevar a cabo los objetivos de éxito y continuidad, y realización no segregada de estas acciones.

- Existencia de clima de afectividad y cooperación con el resto del grupo clase. 
Entendemos por 'clima de afectividad y cooperación' el planteamiento metodológico -implícito o explícito- no competitivo sino cooperativo y colaborativo de los objetivos intelectuales y de las actividades de enseñanza-aprendizaje, y el enfoque que parte de las experiencias del todo el alumnado sin establecer estándares de legitimidad en las mismas, también en el ámbito de las relaciones sociales en el aula.

Se entiende por condiciones familiares y comunitarias favorables:

- Existencia de una valoración positiva de la escolarización en la familia y consideración de la vía académica como vehículo de realización personal, promoción socioeconómica y prestigio para las hijas y los hijos.

- Existencia de redes de apoyo desde el asociacionismo gitano y sus prácticas comunitarias y participación activa de la familia en el mismo.

- En el caso del éxito y la continuidad educativa de las mujeres gitanas, existencia de una posición social integrada en las relaciones entre los sexos. En dos sentidos: por una parte, valoración del éxito y/o apoyo explícito a la trayectoria de continuidad de las chicas en igual medida que a la de los chicos; por la otra, reparto de tareas y responsabilidades familiares equilibrado dentro de la familia.

Se entiende por éxito y continuidad educativa:

- Como condición mínima, haber superado en el momento de la entrevista el tercer curso de la Educación Secundaria Obligatoria (LOGSE) dentro del currículo ordinario. De este nivel en adelante, y dadas las condiciones de escolarización general detectadas a través de la experiencia previa, éste ha sido el requisito de búsqueda y el criterio de inclusión en la muestra.

- De forma equivalente, las personas escolarizadas en el sistema educativo de la LGE, anterior a la LOGSE, haber superado $8^{\circ}$ de Enseñanza General Básica y haber realizado $1^{\circ}$ de BUP $01^{\circ}$ de FP (que es lo equiparable al $3^{\circ}$ de la ESO actual). Para estas personas que estudiaron por el plan antiguo (LGE) es necesario satisfacer de estos criterios básicos en adelante, al igual que en el punto anterior.

H2. Aunque se den las condiciones adecuadas en la situación socioeconómica, escolar, familiar y comunitaria, debe existir una valoración compartida por el grupo de iguales de lo positivo de la vía académica para que se dé una mayor probabilidad de éxito y continuidad. 


\subsubsection{Muestras e instrumentos}

\section{a) Población objeto de estudio y muestreo}

Hemos tratado de profundizar en el conocimiento de las condiciones para el éxito escolar entre las chicas y los chicos gitanos de las cinco CC.AA. señaladas anteriormente. Para ello, hemos ido elaborando dos muestras ${ }^{56}$ sobre la población objeto de estudio: a) un censo de población gitana en edad escolar en los niveles pre-obligatorios y obligatorios, y b) un registro de personas a las cuales hemos solicitado su colaboración, aquellas chicas y chicos gitanos o adultos que hayan realizado o estén realizando estudios al menos un curso más allá de $3^{\circ}$ de la ESO, que es igual a haber cursado $1^{\circ}$ de BUP o $1^{\circ}$ de FP en el plan antiguo.

En cada una de las cinco CC. AA., después de múltiples consultas a partir de redes primarias y secundarias, mediante la combinación de la técnica de bola de nieve a partir de casos de éxito accesibles con informaciones iniciales y desde una selección de centros educativos, hemos ido llegando a un número creciente de gitanos y gitanas con algún grado de éxito y continuidad según el criterio de inclusión explicitado. Simultáneamente, hemos ido aplicando los instrumentos para la reconstrucción de trayectorias y entrevistas. La elaboración de esta relación es una tarea laboriosa, porque el cumplimiento de este criterio no consta en ninguna parte y se trata de localizar a personas dispersas en el territorio, explicando detalladamente el objeto de nuestra investigación y el compromiso de confidencialidad estricta.

\section{b) Técnicas de investigación y análisis}

\section{b.1. Recogida y elaboración de la información}

En la medida en que la investigación se plantea como la exploración de factores que han favorecido trayectorias de éxito y continuidad educativa, su posible impacto a distintos niveles (personal, laboral, comunitario, cultural, etc.), así como las percepciones de las personas sobre sus propias experiencias, las técnicas centrales aplicadas han sido de tipo biográfico, mediante diversos instrumentos de entrevista en profundidad. Partimos de unas personas que se van a convertir en nuestros y nuestras "informantes" (y que en este caso constituyen también, de alguna manera, "unidades de observación" en sí mismos) y de unos contextos que les han acompañado y que les rodean. $Y$ analizamos las circunstancias objetivables en las trayectorias y experiencias, así como las reflexiones y opiniones del propio individuo sobre las mismas: el contexto socio-biográfico donde ha crecido y se ha formado, los factores y agentes socio-educativos más decisivos para su trayectoria y que han jugado un papel más importante en su experiencia positiva de escolarización y, por tanto, en su éxito y continuidad académica. Hasta el momento hemos realizado varias entrevistas a cada persona y a un total de 160 personas, de unas 400 personas de nuestro registro.

56 Estas muestras están todavía en proceso de elaboración. Recuérdese que este texto constituye de hecho un primer avance de resultados de una investigación más amplia todavía en curso. 
Obviamente, por la orientación de las hipótesis con las que aquí trabajamos, dejamos para otras fases de la investigación e incluso para otras investigaciones futuras, el trabajo con el profesorado y los centros educativos.

Por otra parte, se ha llevado a cabo un análisis de los distintos contextos socioeconómicos en que han transcurrido las trayectorias y experiencias de éxito y continuidad educativa de nuestros y nuestras informantes.

En concreto, las técnicas que hemos empleado han sido57:

- Relatos biográficos de personas con algún grado de éxito y continuidad educativa pertenecientes a la comunidad gitana. Se ha pedido a cada una de estas 160 personas gitanas que realice un relato personal de su biografía, inicialmente abierto, con la única indicación de detenerse explícitamente en su paso por el sistema escolar.

- Entrevistas en profundidad con las mismas personas. Las entrevistas estructuradas han servido para reconstruir trayectorias, y completar datos objetivos, pero principalmente para recoger cuestiones específicas no tratadas en los relatos y vinculadas a las hipótesis. Se ha trabajado con la trascripción íntegra de todo el material.

- Análisis de documentos y fuentes de datos. Se han analizado también documentos y publicaciones relativos al contexto vivido por estas personas y producidos en ese mismo contexto.

- Análisis bibliográfico. Se ha trabajado con la bibliografía disponible sobre los contextos anteriormente mencionados y sobre el tema de estudio en la literatura internacional.

El equipo investigador de cada una de las cinco Comunidades Autónomas ha trabajado y sigue trabajando para elaborar los siguientes documentos que van a ser la base para este y otros textos que reflejen los resultados de la investigación:

- Censo de población escolar gitana y total por sexo y asistencia escolar.

- Listado abierto de informantes (gitanas y gitanos con alguna trayectoria de éxito escolar) y elaboración de perfiles (en crecimiento continuo).

- Trascripción del total de relatos y entrevistas.

- Análisis individual de los relatos y las entrevistas.

- Análisis cruzado y comparativo de los relatos y las entrevistas.

- Informe de contexto socioeconómico y educativo de la Comunidad Autónoma (a partir de informes, estudios y datos secundarios existentes).

57 El diseño de la investigación ha sido debatido y consensuado por todo el equipo de la investigación. La adaptación para este estudio de las técnicas de recogida y análisis de la información, así como los instrumentos concretos empleados ha corrido a cargo de Silvia Carrasco, con la colaboración de José Eugenio Abajo. 


\section{b.2. Análisis de la información}

El análisis del material procedente de los relatos y las entrevistas ha supuesto transformar y sintetizar la información en categorías más estandarizadas y proceder a la contrastación de las hipótesis propuestas. Se ha prestado especial atención a la emergencia de recurrencias, divergencias e hipótesis nuevas y se ha aplicado una interpretación de todo el material clasificado desde la perspectiva de las diferencias por sexo y por territorio.

Para este trabajo, se han seleccionado 10 casos de cada Comunidad Autónoma y se ha hecho un esfuerzo por mantener los siguientes criterios de inclusión: 5 hombres y 5 mujeres; 5 todavía en periodo de estudios, y 5 en otra fase de ciclo vital y familiar. Para la selección dentro de cada C. A. se ha procurado reflejar el repertorio de perfiles concretos atendiendo a su significatividad, pero también a la calidad de los materiales recogidos. Esto presupone un análisis preliminar y selectivo en cada C. A. y un posterior análisis comparativo de la diversidad de trayectorias, impactos y valoraciones del éxito y la continuidad educativa en distintas situaciones de las CC. AA.

\subsubsection{Perfiles y casos seleccionados en las cinco Comunidades}

\section{Autónomas}

A continuación se muestra el conjunto de características que permiten identificar la diversidad de perfiles y casos de mujeres y hombres seleccionados por cada equipo. Para cada C. A. se consigna, en primer lugar, su distribución geográfica dentro de cada territorio, su distribución por edades, su situación familiar -mediante el estado civil-, los niveles de instrucción alcanzados, y las ocupaciones desempeñadas en el momento de participar en la investigación. En segundo lugar, se agrupan estas características bajo nombres propios ficticios con el fin de agilizar la lectura del texto. 


\begin{tabular}{|c|c|c|c|c|}
\hline \multicolumn{5}{|l|}{ MADRID } \\
\hline & & MUJERES & HOMBRES & TOTAL \\
\hline Distribución geográfica & Barrio segregado & 1 & 1 & 2 \\
\hline \multirow[t]{3}{*}{ (Zonas de Madrid) } & Barrio obrero & 3 & 2 & 5 \\
\hline & Barrio clase media & 1 & 2 & 3 \\
\hline & Pueblo & 0 & 0 & 0 \\
\hline \multirow[t]{5}{*}{ Distribución por edad } & 15 a 19 & 0 & 1 & 1 \\
\hline & 20 a 24 & 1 & 2 & 3 \\
\hline & 25 a 29 & 3 & 2 & 5 \\
\hline & 30 a 34 & 0 & 0 & 0 \\
\hline & 35 a 39 & 1 & 0 & 1 \\
\hline \multirow{4}{*}{$\begin{array}{l}\text { Nivel de instrucción } \\
\text { alcanzado }\end{array}$} & Secundaria & 0 & 1 & 1 \\
\hline & Superior & 0 & 3 & 3 \\
\hline & Profesión Reglada & 2 & 0 & 2 \\
\hline & Profesión no reglada & 3 & 1 & 4 \\
\hline \multirow[t]{6}{*}{ Ocupación actual } & En paro & 1 & 0 & 1 \\
\hline & Ocupación familiar & 1 & 0 & 1 \\
\hline & Rel. Comunidad & 2 & 4 & 6 \\
\hline & No rel. Comunidad & 1 & 0 & 1 \\
\hline & Estudiante & 0 & 1 & 1 \\
\hline & (dedicación exclusiva) & & & \\
\hline \multirow[t]{3}{*}{ Estado civil } & Soltera/o & 3 & 5 & 8 \\
\hline & Casada/o & 0 & 0 & 0 \\
\hline & Otros & 2 & 0 & 2 \\
\hline TOTAL & & 5 & 5 & 10 \\
\hline
\end{tabular}

\section{Casos:}

- Sonsoles, vive en un barrio segregado de Madrid, 26 años, FP Administrativo y Curso de Acceso a la Universidad, en paro, hasta el momento no hay vinculación entre la instrucción realizada y la ocupación, no existe vinculación con el movimiento asociativo, divorciada.

- Elena, vive en un barrio obrero de Madrid, 26 años, Ciclo Formativo de Grado Medio de Jardín de Infancia, venta ambulante, hasta el momento no hay vinculación entre instrucción y ocupación, no existe vinculación con el movimiento asociativo, soltera.

- Marta, vive en un barrio medio de Madrid, 20 años, BUP y curso de azafatas de congresos, azafata de congresos y ferias, vinculación entre instrucción y ocupación, su ocupación está vinculada al movimiento asociativo, vive con su pareja. 
- Mercedes, vive en un barrio obrero de Madrid, 27 años, Graduado Escolar y curso de azafatas de congresos y ferias, directora de una pequeña empresa del sector servicios, vinculación entre instrucción y ocupación, su ocupación está vinculada al movimiento asociativo, soltera.

- Cristina, vive en un barrio obrero de Madrid, 37 años, FPI Administrativo, auxiliar administrativo, vinculación entre instrucción y ocupación, no existe vinculación con el movimiento asociativo, soltera.

- Marcos, vive en un barrio segregado de Madrid, 24 años, Auxiliar Administrativo y curso de mediación sociocultural, técnico socioeducativo, vinculación entre instrucción y ocupación, su ocupación está vinculada al movimiento asociativo, soltero.

- Javier, vive en un barrio de clase media, 23 años, licenciado en Derecho, abogado en área jurídica de una asociación gitana, vinculación entre instrucción y ocupación, su ocupación está vinculada al movimiento asociativo, soltero.

- Carlos, vive en un barrio de clase media de Madrid, 30 años, Doctorado en Ciencias Políticas, periodista, hasta el momento no hay vinculación fuerte entre instrucción y ocupación, su ocupación está vinculada al movimiento asociativo (editor de una revista de una asociación gitana), soltero.

- Adrián, vive en un barrio obrero de Madrid, 25 años, realizando Licenciatura en Derecho, orientador laboral, hay una vinculación entre instrucción y ocupación, su ocupación está vinculada al movimiento asociativo, soltero.

- Pablo, vive en un barrio segregado de Madrid, 17 años, está realizando estudios de Bachillerato con dedicación exclusiva, hasta el momento no hay vinculación entre instrucción y ocupación, no existe vinculación con el movimiento asociativo, soltero. 


\section{CATALUÑA}

MUJERES HOMBRES TOTAL

\begin{tabular}{|c|c|c|c|c|}
\hline \multirow[t]{4}{*}{ Distribución geográfica } & Barrio segregado & 0 & 2 & 2 \\
\hline & Barrio obrero & 4 & 3 & 7 \\
\hline & Barrio clase media & 1 & 0 & 1 \\
\hline & Pueblo, no segregado & 0 & 0 & 0 \\
\hline \multirow[t]{7}{*}{ Distribución por edad } & 15 a 19 & 0 & 1 & 1 \\
\hline & 20 a 24 & 1 & 0 & 1 \\
\hline & 25 a 29 & 1 & 0 & 1 \\
\hline & 30 a 34 & 1 & 0 & 1 \\
\hline & 35 a 39 & 1 & 1 & 2 \\
\hline & 40 a 44 & 1 & 2 & 3 \\
\hline & 45 a 49 & 0 & 1 & 1 \\
\hline \multirow{4}{*}{$\begin{array}{l}\text { Nivel de instrucción } \\
\text { alcanzado }\end{array}$} & Secundaria & 0 & 1 & 1 \\
\hline & Superior & 4 & 2 & 6 \\
\hline & Profesión Reglada & 1 & 2 & 3 \\
\hline & Profesión no reglada & 0 & 0 & 0 \\
\hline \multirow[t]{6}{*}{ Ocupación actual } & En paro & 0 & 0 & 0 \\
\hline & Ocupación familiar & 0 & 0 & 0 \\
\hline & Rel. Comunidad & 4 & 4 & 8 \\
\hline & No rel. Comunidad & 1 & 0 & 1 \\
\hline & Estudiante & 0 & 1 & 1 \\
\hline & (dedicación exclusiva) & & & \\
\hline \multirow[t]{3}{*}{ Estado civil } & Soltera/o & 2 & 1 & 3 \\
\hline & Casada/o & 1 & 4 & 5 \\
\hline & Otros & 2 & 0 & 2 \\
\hline TOTAL & & 5 & 5 & 10 \\
\hline
\end{tabular}

Casos:

- Jordi, vive en un barrio segregado de la provincia de Girona, 15 años, título de la ESO, estudiante, aún no está definida la vinculación entre instrucción y ocupación, no tiene vinculación con el movimiento asociativo, soltero.

- Álvaro, vive en un barrio obrero del Área Metropolitana de Barcelona, 46 años, licenciado en Sociología, investigador, vinculación entre instrucción y ocupación, no vinculación con el movimiento asociativo, casado.

- Ramón, vive en un barrio obrero de Barcelona ciudad, 44 años, Diplomado en Magisterio y Licenciado en Psicología, tiene un cargo en una asociación, sí existe 
vinculación entre instrucción y ocupación, sí existe vinculación con el movimiento asociativo, casado.

- Mariano, vive en un barrio obrero de Área Metropolitana de Barcelona, 36 años, FPI, presidente de asociación, no hay vinculación entre instrucción y ocupación, sí hay vinculación con el movimiento asociativo, casado.

- Pedro, vive en un barrio segregado de la provincia de Girona, 43 años, FPII y Postgrado en Mediación, funcionario de la administración local, sí existe vinculación entre instrucción y ocupación, sí tiene vinculación con el movimiento asociativo, casado.

- Lola, vive en un barrio medio de Barcelona ciudad, 32 años, Licenciada en Historia del Arte, mediadora en asociación, no hay vinculación entre instrucción y ocupación, sí tiene vinculación con el movimiento asociativo, soltera.

- Verónica, vive en un barrio obrero de la provincia de Lleida, 35 años, Licenciada en Derecho, funcionaria de la administración pública, sí hay vinculación entre instrucción y ocupación, no tiene vinculación con el movimiento asociativo, casada.

- Anabel, vive en un barrio obrero de la provincia de Barcelona, 43 años, Diplomada en Educación Social, educadora social, sí existe vinculación entre instrucción y ocupación, no tiene vinculación con el movimiento asociativo, pareja de hecho.

- Teresa, vive en un barrio obrero del Área Metropolitana de Barcelona, 27 años, Diplomada en Trabajo Social, administrativa en una asociación, no hay vinculación entre instrucción y ocupación, sí tiene vinculación con el movimiento asociativo, pareja de hecho.

- Alba, vive en un barrio obrero del Área Metropolitana de Barcelona, 24 años, FP Administrativo, administrativa en asociación, sí existe vinculación entre instrucción y ocupación, sí tiene vinculación con el movimiento asociativo, soltera. 
CASTILLA-LEÓN

MUJERES HOMBRES TOTAL

\begin{tabular}{|c|c|c|c|c|}
\hline \multirow[t]{4}{*}{ Distribución geográfica } & Barrio segregado & 0 & 0 & 0 \\
\hline & Barrio obrero & 4 & 3 & 7 \\
\hline & Barrio medio & 0 & 1 & 1 \\
\hline & Pueblo, (no segregado) & 1 & 1 & 2 \\
\hline \multirow[t]{6}{*}{ Distribución por edad } & 15 a 19 & 1 & 1 & 2 \\
\hline & 20 a 24 & 2 & 3 & 5 \\
\hline & 25 a 29 & 2 & 0 & 2 \\
\hline & 30 a 34 & 0 & 0 & 0 \\
\hline & 35 a 39 & 0 & 0 & 0 \\
\hline & 49 & 0 & 1 & 1 \\
\hline \multirow{4}{*}{$\begin{array}{l}\text { Nivel de instrucción } \\
\text { alcanzado }\end{array}$} & Secundaria & 1 & 1 & 2 \\
\hline & Superior & 2 & 2 & 4 \\
\hline & Profesional Reglado & 2 & 2 & 4 \\
\hline & Profesional no reglado & 0 & 0 & 0 \\
\hline \multirow[t]{6}{*}{ Ocupación actual } & En paro & 0 & 1 & 1 \\
\hline & Ocupación familiar & 0 & 1 & 1 \\
\hline & Rel. Comunidad & 1 & 0 & 1 \\
\hline & No rel. Comunidad & 3 & 1 & 4 \\
\hline & Estudiante & 1 & 2 & 3 \\
\hline & (dedicación exclusiva) & & & \\
\hline \multirow[t]{3}{*}{ Estado civil } & Soltera/o & 2 & 4 & 6 \\
\hline & Casada/o & 1 & 1 & 2 \\
\hline & Otros & 2 & 0 & 2 \\
\hline TOTAL & & 5 & 5 & 10 \\
\hline
\end{tabular}

Casos:

- Laura, vive en un barrio obrero de Palencia, 25 años, estudiante de $3^{\circ}$ de Educación Social, mediadora en asociación de mujeres gitanas, sí hay vinculación entre su instrucción y su ocupación, su ocupación está vinculada al movimiento asociativo, soltera.

- Soledad, vive en un pueblo en la provincia de Segovia, 18 años, estudiante de $2^{\circ}$ de Bachillerato, ama de casa y estudiante, hasta el momento no hay vinculación entre instrucción y ocupación, no tiene vinculación con el movimiento asociativo, soltera.

- Clara, barrio obrero de Burgos, 29 años, FPI Administrativo, ama de casa, hasta el momento no hay vinculación entre instrucción y ocupación, participa en el movi- 
miento asociativo y estuvo unos meses trabajando como administrativa en una asociación gitana, casada.

- Yolanda, vive en un barrio obrero de Valladolid, 28 años, Licenciada en Derecho, administrativa-funcionaria, no existe una clara vinculación entre su nivel de instrucción y su ocupación, no tiene vinculación con el movimiento asociativo, vive con su pareja de hecho.

- Vanesa, vive en Soria, 21 años, estudiante de Ciclo Formativo de Grado Medio en Peluquería, se dedica al cuidado de niños y niñas, no existe hasta el momento vinculación entre instrucción y ocupación, no tiene vinculación con el movimiento asociativo, vive con su pareja de hecho.

- Richi, vive en un barrio obrero de Aranda de Duero, 23 años, Ciclo Formativo de Grado Medio de Carrocería y Ciclo Formativo de Grado Medio de Madera, en paro (si bien ha realizado muy diversos trabajos), no hay vinculación hasta la actualidad entre instrucción y ocupación, no tiene vinculación con el movimiento asociativo, soltero.

- Armando, vive en un barrio obrero de Aranda de Duero, 49 años, FPI Administrativo, administrativo, existe una vinculación entre instrucción y ocupación, exsecretario de una asociación gitana local, casado.

- Luis, vive en un barrio medio de Zamora, 24 años, estudiante de $5^{\circ}$ de Economía, su ocupación es ser estudiante (aunque a veces ayuda a su familia en la venta ambulante), no existe vinculación entre instrucción y ocupación, acude esporádicamente a alguna actividad organizada por la asociación gitana local, soltero.

- César, barrio obrero de Salamanca, 21 años, finalizando diplomatura en Empresariales, su ocupación es ser estudiante, no existe vinculación entre instrucción y ocupación hasta el momento, obtuvo en su día una beca de estudios de una asociación gitana, actualmente colabora en actividades de tiempo libre en una asociación juvenil gitana, soltero.

- Paco, vive en un pueblo de la provincia de León, 18 años, título de la ESO, trabaja en la venta ambulante, no hay vinculación entre instrucción y ocupación, no tiene vinculación con el movimiento asociativo, soltero. 


\begin{tabular}{|c|c|c|c|c|}
\hline \multicolumn{5}{|l|}{ ARAGÓN } \\
\hline & & MUJERES & HOMBRES & TOTAL \\
\hline \multirow[t]{4}{*}{ Distribución geográfica } & Barrio segregado & 2 & 2 & 4 \\
\hline & Barrio obrero & 3 & 2 & 5 \\
\hline & Barrio clase media & 0 & 0 & 0 \\
\hline & Pueblo, no segregado & 0 & 1 & 1 \\
\hline \multirow[t]{5}{*}{ Distribución por edad } & 15 a 19 & 1 & 2 & 3 \\
\hline & 20 a 24 & 1 & 1 & 2 \\
\hline & 25 a 29 & 1 & 2 & 3 \\
\hline & 30 a 34 & 1 & 0 & 1 \\
\hline & 35 a 39 & 1 & 0 & 1 \\
\hline \multirow{4}{*}{$\begin{array}{l}\text { Nivel de instrucción } \\
\text { alcanzado }\end{array}$} & Secundaria & 1 & 2 & 3 \\
\hline & Superior & 3 & 0 & 3 \\
\hline & Profesional Reglado & 1 & 3 & 4 \\
\hline & Profesional no reglado & 0 & 0 & 0 \\
\hline \multirow[t]{6}{*}{ Ocupación actual } & En paro & 1 & 0 & 1 \\
\hline & Ocupación familiar & 1 & 1 & 2 \\
\hline & Rel. Comunidad & 3 & 1 & 4 \\
\hline & No rel. Comunidad & 0 & 2 & 2 \\
\hline & Estudiante & 0 & 1 & 1 \\
\hline & (dedicación exclusiva) & & & \\
\hline \multirow[t]{3}{*}{ Estado civil } & Soltera/o & 2 & 4 & 6 \\
\hline & Casada/o & 2 & 1 & 3 \\
\hline & Otros & 1 & 0 & 1 \\
\hline TOTAL & & 5 & 5 & 10 \\
\hline
\end{tabular}

Casos:

- María, vive en un barrio obrero de Huesca, 26 años, Licenciada en Derecho, coordinación de un proyecto de orientación laboral y despacho propio de abogada, sí existe vinculación entre su nivel de instrucción y su ocupación, una de sus ocupaciones está vinculada al movimiento asociativo, casada.

- Pilar, vive en un barrio obrero de Huesca, 21 años, Bachillerato, mediadora cultural, no hay vinculación clara entre instrucción y ocupación, su ocupación está vinculada al movimiento asociativo y participa en una asociación gitana, soltera.

- Eva, vive en un barrio obrero de Zaragoza, 31 años, realizando Diplomatura en Magisterio, colabora en el negocio familiar, no hay vinculación entre instrucción y 
ocupación, no tiene vinculación con el movimiento asociativo, vive con su pareja de hecho.

- Adriana, vive en un barrio segregado de la provincia de Zaragoza, 18 años, Ciclo Formativo de Grado Medio, en paro, no hay vinculación entre instrucción y ocupación, no tiene vinculación con el movimiento asociativo, soltera.

- Julia, vive en un barrio segregado de Zaragoza, 36 años, Diplomada en Trabajo Social, educadora social en programa municipal, existe una vinculación entre instrucción y ocupación, actualmente no tiene vinculación con el movimiento asociativo (aunque sí la tuvo hace años), casada.

- Jesús, vive en un pueblo de la provincia de Teruel, 29 años, FPI y FPII Informática, informático, existe una vinculación entre instrucción y ocupación, no tiene vinculación con el movimiento asociativo, casado.

- Óscar, vive en un barrio obrero de Zaragoza, 27 años, Formación Ocupacional en fontanería y calefacción, venta ambulante, no existe vinculación entre instrucción y ocupación, no tiene vinculación con el movimiento asociativo, soltero.

- Miguel, vive en un barrio obrero de Huesca, 18 años, Bachillerato, estudiante, aún no está definida la vinculación entre instrucción y ocupación, participa esporádicamente en el movimiento asociativo, receptor de beca para estudios de la asociación gitana, soltero.

- Manuel, vive en un barrio segregado de Zaragoza, 21 años, Ciclo Formativo de Grado Medio Técnico de Mantenimiento de Equipos e Instalaciones Electrotécnicas, electricista, hay vinculación entre su instrucción y su ocupación, no existe vinculación con el movimiento asociativo, soltero.

- Andrés, vive en un barrio segregado de Zaragoza, 18 años, Bachillerato, animador juvenil, no hay una vinculación entre instrucción y ocupación, su ocupación está vinculada al movimiento asociativo, soltero. 


\section{NAVARRA}

MUJERES HOMBRES TOTAL

\begin{tabular}{|c|c|c|c|c|}
\hline \multirow[t]{4}{*}{ Distribución geográfica } & Barrio segregado & 2 & 0 & 2 \\
\hline & Barrio obrero & 2 & 1 & 3 \\
\hline & Barrio clase media & 0 & 1 & 1 \\
\hline & Pueblo, no segregado & 2 & 2 & 4 \\
\hline \multirow[t]{5}{*}{ Distribución por edad } & 15 a 19 & 3 & 3 & 6 \\
\hline & 20 a 24 & 2 & 0 & 2 \\
\hline & 25 a 29 & 0 & 0 & 0 \\
\hline & 30 a 34 & 0 & 1 & 1 \\
\hline & 35 a 39 & 1 & 0 & 1 \\
\hline \multirow{4}{*}{$\begin{array}{l}\text { Nivel de instrucción } \\
\text { alcanzado }\end{array}$} & Secundaria & 2 & 3 & 5 \\
\hline & Superior & 0 & 0 & 0 \\
\hline & Profesional Reglado & 3 & 1 & 4 \\
\hline & Profesional no reglado & 1 & 0 & 1 \\
\hline \multirow[t]{6}{*}{ Ocupación actual } & En paro & 1 & 0 & 1 \\
\hline & Ocupación familiar & 1 & 0 & 1 \\
\hline & Rel. Comunidad & 1 & 0 & 1 \\
\hline & No rel. Comunidad & 2 & 1 & 3 \\
\hline & Estudiante & 1 & 3 & 4 \\
\hline & (dedicación exclusiva) & & & \\
\hline \multirow[t]{3}{*}{ Estado civil } & Soltera/o & 5 & 3 & 8 \\
\hline & Casada/o & 0 & 1 & 1 \\
\hline & Otros & 1 & 0 & 1 \\
\hline TOTAL & & 6 & 4 & 10 \\
\hline
\end{tabular}

Casos:

- Josefa, vive en un barrio segregado de Pamplona, 17 años, Título de la ESO, estudiante, no está definida la vinculación entre instrucción y ocupación, no existe vinculación directa pero sí familiar con el movimiento asociativo, soltera.

- Victoria, vive en un barrio obrero de Pamplona, 17 años, Título de la ESO y Ciclo Formativo de Grado Medio de Auxiliar Sanitario, trabaja como auxiliar sanitaria, sí existe vinculación entre instrucción y ocupación, sí existe relación con el movimiento asociativo, soltera.

- Ana, vive en un barrio obrero de Pamplona, 19 años, Título de la ESO, tareas domésticas en casa, no está definida la vinculación entre instrucción y ocupación, profesora de baile en distintas asociaciones, separada. 
- Juana, vive en un barrio segregado de Pamplona, 22 años, mediadora, en paro, no existe vinculación entre instrucción y ocupación, realiza un curso de mediación, vinculación con el movimiento asociativo gitano, soltera.

- Arantxa, vive en un pueblo cerca de Tudela, 23 años, Título de la ESO, venta ambulante, no existe vinculación entre instrucción y ocupación, tiene vinculación con el movimiento asociativo, soltera.

- Sara, vive en el pueblo de Sangüesa, 36 años, FPI Auxiliar Administrativo, operaria, no existe vinculación entre instrucción y ocupación, no tiene vinculación con el movimiento asociativo, soltera.

- Eugenio, vive en un barrio obrero de Pamplona, 18 años, actualmente cursando $2^{\circ}$ de Bachillerato, estudiante, aún no está definida la vinculación entre instrucción y ocupación, sí existe vinculación con el movimiento asociativo, soltero.

- Ismael, vive en un barrio medio de Pamplona, 15 años, Título de la ESO, estudiante, aún no está definida la vinculación entre instrucción y ocupación, sí existe vinculación con el movimiento asociativo, soltero.

- Antonio, vive en el pueblo de Lumbier, 18 años, Ciclo Formativo de Grado Medio en Mantenimiento y CFGS en Electricidad Industrial, estudiante, no hay vinculación entre instrucción y ocupación, no tiene vinculación con el movimiento asociativo, soltero.

- Juanjo, vive en el pueblo de Sangüesa, 33 años, Bachillerato/COU, funcionario, sí existe vinculación entre instrucción y ocupación, no tiene vinculación con el movimiento asociativo, casado. 


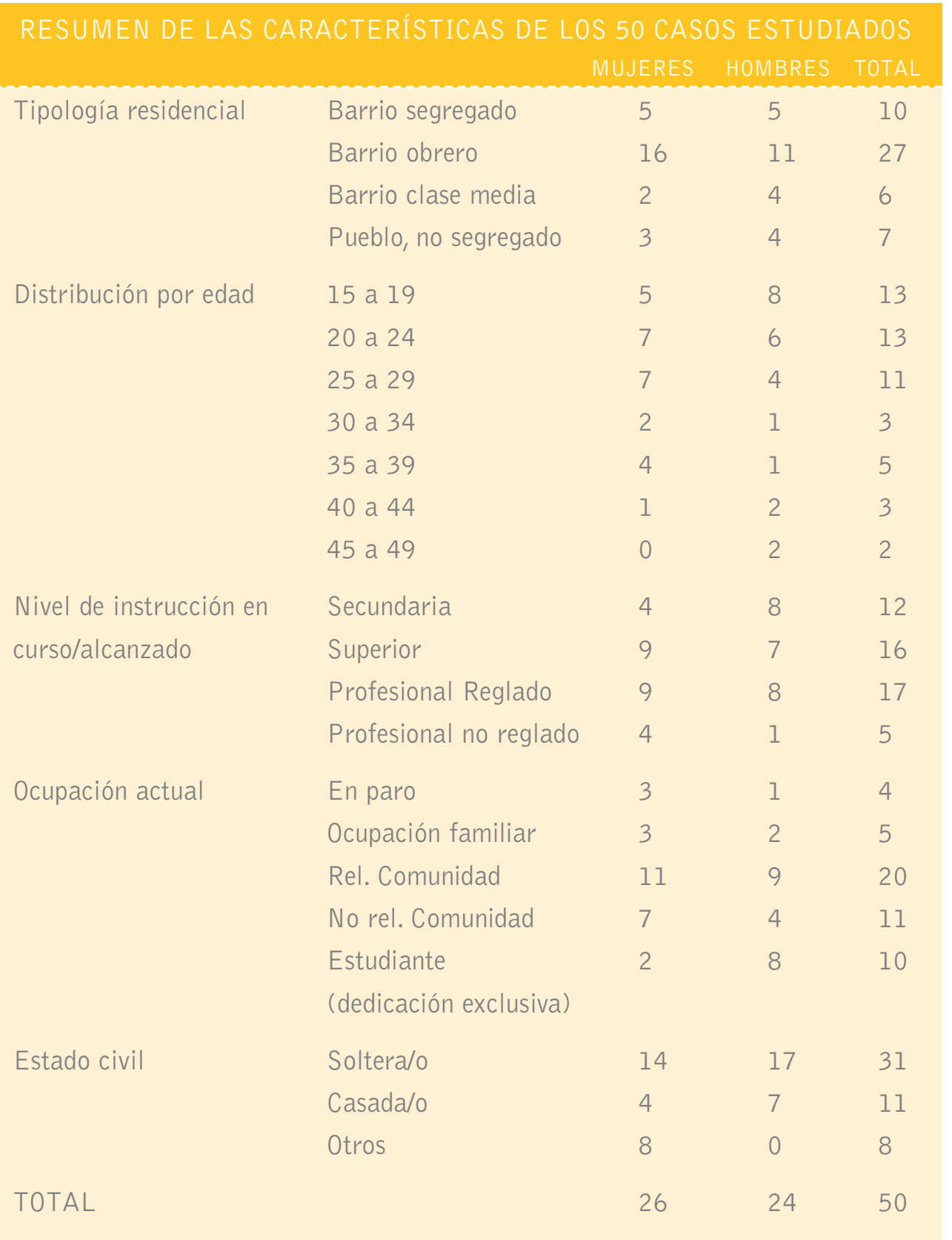

1.En las distintas CC. AA. los perfiles responden al repertorio de situaciones de gitanas y gitanos con éxito académico localizados, aunque se haya hecho un esfuerzo por aplicar los dos criterios de inclusión comunes, en una proporción casi idéntica de mujeres y de hombres y en dos grandes grupos de edad. Por lo tanto, internamente, la muestra es diversa en los términos siguientes:

- En Madrid, la población se concentra en las edades entre 20 y 24, y entre 25 y 29 , con predominio de estudios superiores y no reglados y la residencia se localiza principalmente en barrio obrero seguido de barrio medio, y medio-alto.

- En Cataluña, la población se concentra en las franjas de edad que van de los 35 a los 39 años, y de los 40 a los 44 años, aunque la muestra está muy repartida en los distintos grupos de edad. El tipo de estudios más recurrentes son los supe- 
riores seguidos de estudios de profesionalización reglados. La residencia se concentra básicamente en barrios obreros, seguida de lejos de barrios segregados.

- En Castilla-León, la mitad de la población se encuentra entre los 20 y los 24 años, el resto está disperso en las distintas franjas de edad. Al igual que en Cataluña, los estudios más recurrentes son los estudios superiores y estudios de profesionalización reglados. La residencia se localiza en barrios obreros de ciudades medias principalmente, seguidos de cerca por pueblos.

- En Aragón, la población se concentra en las edades comprendidas entre los 15 y los 19 años y los 25 a 29 años. Los estudios de profesionalización reglados se sitúan en primer lugar, seguidos de Educación Secundaria y Superior respectivamente. En la localización residencial predomina básicamente el barrio obrero, seguido del barrio segregado.

- En Navarra, la población se concentra muy específicamente en la franja de edad que va de los 15 a los 19 años. El tipo de estudios que predomina es la Enseñanza Secundaria y los estudios profesionalizadores no-reglados. La localización residencial más frecuente se da en barrios obreros con zonas de alta presencia de población gitana, seguida de pueblos.

2. Resumen de las características transversales de sexo y edad, que han constituido los criterios de inclusión explícitos y producen en conjunto los siguientes rasgos en la muestra de 24 hombres y 26 mujeres:

- Mujeres mayores de $30^{58}$ años: 7.

- Mujeres menores de 30 años: 19.

- Hombres mayores de 30 años: 6.

- Hombres menores de 30 años: 18.

3.0tros aspectos descriptivos de la muestra resultante global que no han constituido criterios de inclusión preestablecidos, sino que forman parte de las características de los casos con experiencias de éxito y continuidad educativa localizados y seleccionados por las distintas CC. AA. (a partir del registro disponible, teniendo en cuenta también el criterio de mayor calidad y riqueza del material biográfico recopilado y trabajado):

3.1. Tipo de residencia y situación económica familiar

- Mujeres y hombres en barrios segregados y situación económica familiar precaria: 10.

- Mujeres y hombres en barrios no segregados y situación económica familiar no precaria: 40.

58 Se ha considerado el límite de 30 años a partir de las divisiones estándar objeto de políticas específicas de juventud y de la incorporación al mercado de trabajo tras un periodo de estudios prolongado, aún sabiendo que éstas poco tienen que ver con las periodizaciones del ciclo vital tradicional entre la población gitana. 
3.2. Relación entre estado civil y continuidad educativa en la muestra:

- Entre las mujeres menores de 30 años, 10 están solteras y 2 casadas y 5 en otras situaciones, desde divorciadas a parejas de hecho.

- Entre las mujeres mayores de 30 años, 4 están solteras, 2 casadas y 1 vive en pareja de hecho.

- Entre los hombres menores de 30 años, 16 están solteros y 2 casados.

- Entre los hombres mayores de 30 años, 1 está soltero y 5 casados.

3.3. Relación entre movimiento asociativo y continuidad educativa en la muestra:

- Entre las mujeres menores de 30 años, el papel del movimiento asociativo ha tenido influencia en su continuidad educativa en 4 y no la ha tenido en 15.

- Entre las mujeres mayores de 30 años, el papel del movimiento asociativo ha tenido influencia en su continuidad educativa en 1 y no la ha tenido en 6.

- Entre los hombres menores 30 años, el papel del movimiento asociativo ha tenido influencia en su continuidad educativa en 2 y no la ha tenido en 16.

- Entre los hombres mayores 30 años, el papel del movimiento asociativo ha tenido influencia en su continuidad educativa en 1 y no la ha tenido en 5 .

\subsection{Relación entre ocupación actual y contexto comunitario gitano:}

- Entre las mujeres menores de 30 años que han terminado sus estudios, son 6 las que tienen ocupaciones relacionadas con el movimiento asociativo, y 7 han obtenido un trabajo a través de alguna clase de vinculación con el mismo, incluida su formación.

- Entre las mujeres mayores de 30 años que han terminado sus estudios 1 tiene ocupación relacionada con el movimiento asociativo, y ninguna ha obtenido un trabajo a través de alguna clase de vinculación con el mismo, incluida su formación.

- Entre los hombres menores de 30 años que han terminado sus estudios, son 3 los que tienen ocupaciones relacionadas con el movimiento asociativo y 4 los que han obtenido un trabajo a través de alguna clase de vinculación con el mismo, incluida su formación.

- Entre los hombres mayores de 30 años que han terminado sus estudios, son 3 los que tienen ocupaciones relacionadas con el movimiento asociativo, y 1 ha obtenido un trabajo a través de alguna clase de vinculación con el mismo, incluida su formación. 
3.5. Relación entre familia de origen y pareja mixta de los padres en la muestra:

- Entre las mujeres menores de 30 años, las familias de origen mixto son 4 y las familias de origen no mixto son 13.

- Entre las mujeres mayores de 30 años, las familias de origen mixto son 2 y las familias de origen no mixto son 5 .

- Entre los hombres menores 30 años, las familias de origen mixto son 3 y las familias de origen no mixto son 14.

- Entre los hombres mayores 30 años, las familias de origen mixto son 2 y las familias de origen no mixto son 5 .

3.6. Relación entre estado civil y pareja mixta actual en la muestra:

- Entre las mujeres menores de 30 años, las parejas actuales mixtas son 5 y 3 no lo son.

- Entre las mujeres mayores de 30 años, las parejas actuales mixtas son 4 y ninguna de ellas tiene pareja gitana.

- Entre los hombres menores de 30 años, las parejas actuales mixtas son 1 y ninguno de ellos tiene pareja gitana.

- Entre los hombres mayores de 30 años, las parejas actuales mixtas son 3 y otras 3 no lo son. 
Experiencias y trayectorias

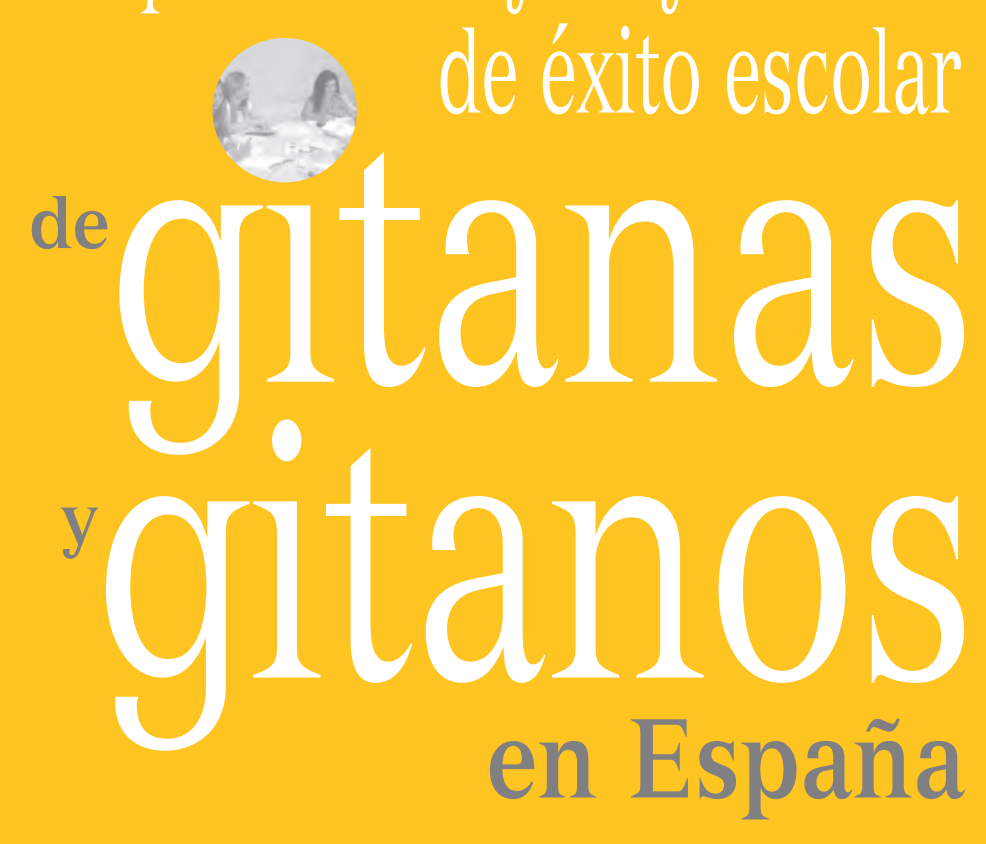

\section{| SEGUNDA PARTE |}

Experiencias de éxito y continuidad educativa

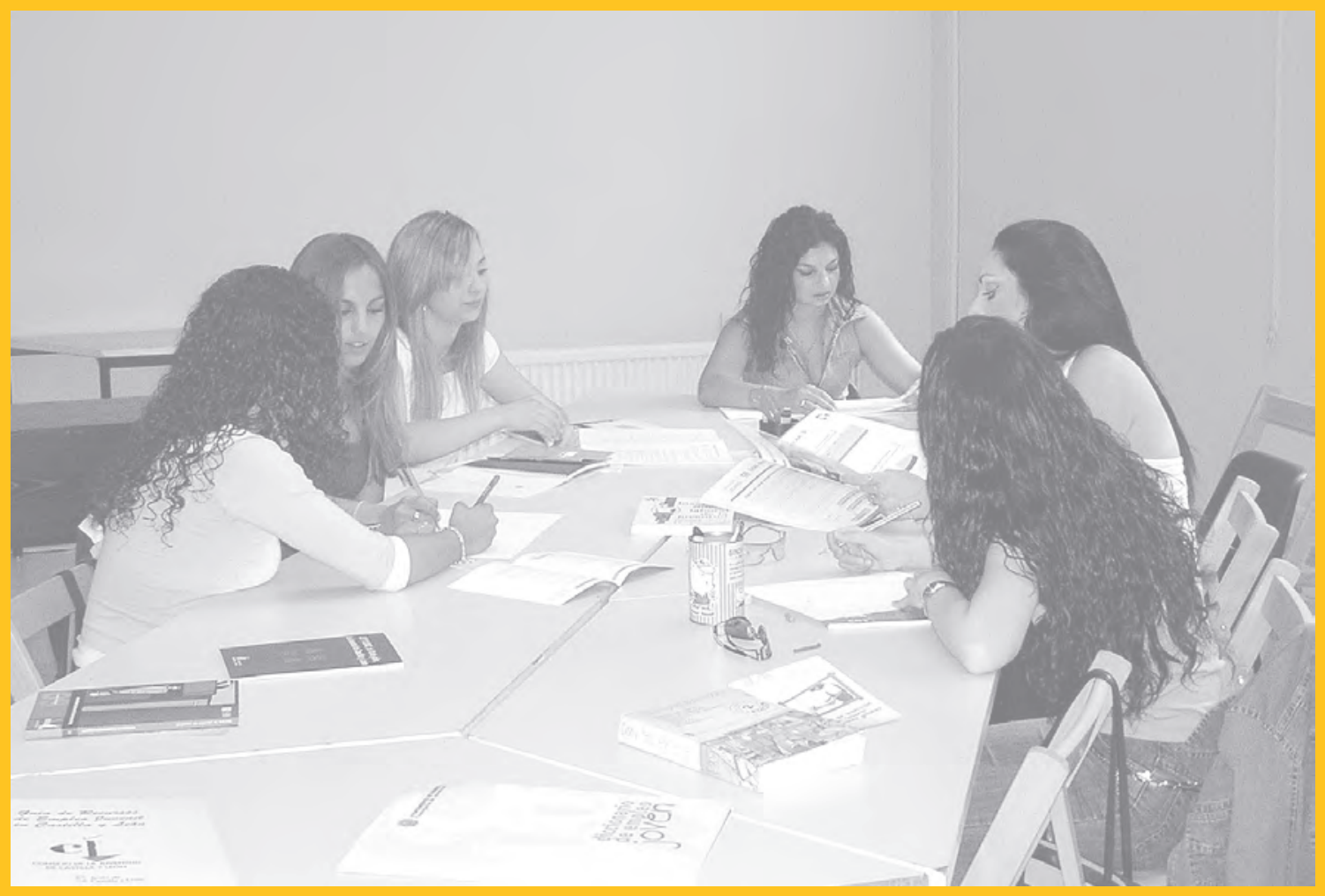




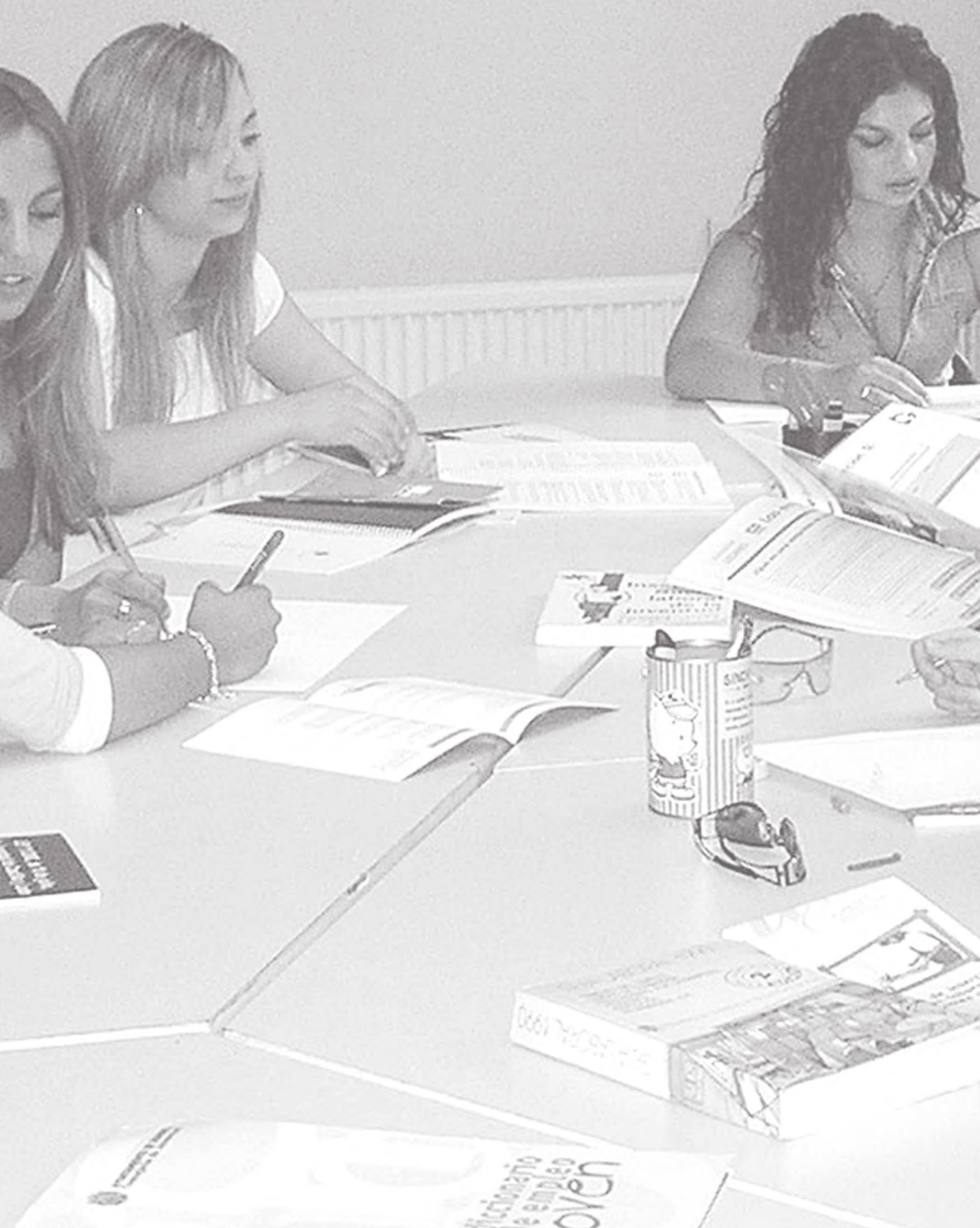




\section{CAPÍTULO 3: SITUACIÓN EDUCATIVA DEL ALUMNADO GITANO}

\subsection{Escolarización y continuidad educativa:}

\section{exploraciones y evaluaciones}

Los datos oficiales más recientes sobre alumnado gitano a nivel estatal corresponden exclusivamente a los centros educativos de las CC. AA. que en el curso 1997-98 todavía estaban gestionados por el Ministerio de Educación, por lo tanto, ya no incluyen a Cataluña y a Navarra. A partir de datos parciales más recientes existen indicios de estancamiento en las cifras de alumnado gitano, o bien disminuyen de forma clara, siguiendo la tendencia general que presenta toda la población escolar en su conjunto, a excepción del alumnado extranjero.

$\begin{array}{lcccc} & \text { C.P. } & \text { I.E.S. } & \text { C.C. } & \text { TOTAL } \\ \text { Aragón } & 2.020 & 402 & 306 & 2.728 \\ \text { Asturias } & 1.476 & 157 & 94 & 1.727 \\ \text { Cantabria } & 659 & 93 & 68 & 820 \\ \text { Castilla la Mancha } & 2.964 & 148 & 280 & 3.392 \\ \text { Castilla y León } & 4.225 & 613 & 487 & 5325 \\ \text { Ceuta } & 102 & 0 & 0 & 102 \\ \text { Extremadura } & 1.553 & 41 & 131 & 1.725 \\ \text { La Rioja } & 613 & 89 & 105 & 807 \\ \text { Madrid } & 6.099 & 251 & 464 & 6.814 \\ \text { Melilla } & 63 & 2 & 0 & 65 \\ \text { Murcia } & 2.892 & 53 & 424 & 3.369 \\ \text { TOTAL } & 22.666 & 1.849 & 2.359 & 2.687 \\ & & & & \end{array}$

Fuente: Ministerio de Educación y Ciencia: Cifras y datos del alumnado en España, curso 1997-98. (Abreviaturas: C.P.: Centros de Primaria; I.E.S.: Institutos de Enseñanza Secundaria; C.C.: Centros Concertados con alumnado de Primaria y de Secundaria). 
La misma fuente proporciona los datos referidos a alumnado gitano atendido desde el Programa de Educación Compensatoria en el mismo curso académico: 7.680 alumnas y alumnos gitanos sobre un total de 18.309 atendidos en Centros de Educación Infantil y Primaria, y 1.044 alumnas y alumnos gitanos sobre un total de 4.024 atendidos en Institutos de Enseñanza Secundaria. Así, la sobrerrepresentación del alumnado gitano en el Programa era más que evidente hace seis años; y se desconocen los datos sobre la situación actual, lo que nos parece un grave error desde el punto de vista del seguimiento de su experiencia escolar y desde la perspectiva de la detección de situaciones de exclusión educativa generadas por el propio sistema escolar.

Es cierto que no se dispone de datos globales ni comparativos sobre población escolar gitana porque los criterios para registrar o no estos datos varían en las distintas CC. AA. Por ejemplo, en Aragón, en Cataluña y en Navarra no se identifica ni se distingue al alumnado gitano como tal de forma oficial ${ }^{59}$, por considerarse que se incurriría en la ilegalidad y porque se mantiene una perspectiva ideológica de trato igualitario, a pesar de que con la llegada de alumnado extranjero estas cuestiones están cambiando y se están repensando. En el otro extremo, en otras CC. AA., se opta sistemáticamente por adscribir a todo el alumnado identificado como de etnia gitana a categorías correspondientes a Necesidades Educativas Especiales o Compensación Educativa. Es decir, se sobreexpone de forma totalmente inadecuada al alumnado gitano asociando peligrosamente la pertenencia étnica a la consideración educativa de déficit. Es obvio que ambas situaciones son insostenibles -la primera, de consecuencias ambivalentes, invisibiliza éxitos y dificultades, mientras que la segunda constituye directamente una estigmatización y una distorsión de la realidad-. Además, ambas situaciones impiden trabajar desde el punto de vista comparativo con datos cuantitativos, situación agravada por el escaso desarrollo de investigaciones locales.

Sin embargo, algunos informes, estudios y datos sobre la situación educativa del alumnado gitano en las CC. AA. estudiadas, aunque no nos permitan hacer una presentación paralela y sistemáticamente comparable entre territorios, sí nos pueden ayudar a llamar la atención sobre distintos aspectos que, en cualquier caso, hay que tener en cuenta de forma global. Además, resulta imprescindible contextualizar las reflexiones sobre la información disponible para las distintas CC. AA. a la luz de los resultados y las perspectivas que nos proporcionan dos recientes estudios sobre la situación educativa del alumnado gitano. Nos referimos, en primer lugar, al estudio de la FSGG, Evaluación de la normalización educativa (2002) y, en segundo lugar, al proyecto europeo coordinado por Ana Giménez, The education of Gipsy Childhood in Europe (2003). En términos comparativos, ambos proyectos de hecho representan, con énfasis distintos, lo que podríamos denominar las luces emergentes y las sombras persistentes de la situación educativa del alumnado gitano. El primero de ellos, sin dejar de señalar algunos puntos críticos referidos especialmente al sector que presenta una mayor exclusión educativa, adopta un tono positivo en la exposición de sus resultados y conclusiones. El segundo, sin embargo, proporciona

59 Es necesario aclarar que existe una diferencia entre el registro obligatorio, el registro voluntario y el registro real de la adscripción étnica del alumnado. De hecho, es posible que existan más datos de los reconocidos, pero éstos no se publican en las estadísticas oficiales. A partir del curso 2.000-2.001, algunas CC. AA. presentan los datos de población escolar gitana dentro de una categoría conjunta denominada "Alumnado inmigrante y otras minorías". 
una imagen ligeramente distinta en su análisis, e incluso en los datos que lo apoyan. A ambos nos referiremos también en este apartado.

Estamos lejos de aquella constatación de San Román en su investigación pionera sobre la escuela y el pueblo gitano de hace 24 años. La autora decía en aquellos momentos: "La irregularidad en la asistencia y los constantes movimientos de la población, dificultan una escolarización continuada y homogénea de los alumnos" (San Román, 1980:185). Diez años después, sus observaciones ya apuntaban en otra dirección: "Los gitanos ven en la escuela sobre todo dos cosas: o bien meramente el aprendizaje de las técnicas de lectura y escritura o bien la puerta para un oficio payo. Y todo ello además de una valoración general de los demás servicios que pueda prestarles a los niños, como el comedor o las colonias. El interés por la escuela no es ajeno a estas expectativas, antes bien, es con ellas con las que directamente se relaciona, de forma que interesa más a quienes ven en ella un camino para la formación profesional que a quienes piensan que su única utilidad real es la alfabetización, y no interesa en absoluto a los que no teniendo aspiraciones de aquel primer tipo, piensan que es, cuando menos, estúpido que un gitano tenga que leer y escribir. El problema está en ese engaño de las expectativas, que hemos visto en choque frontal con la duración del período de escolarización: para aprender a leer es demasiado tiempo; para aprender un oficio es muy justo o incluso poco. (...) El bajo nivel que se alcanza unido a la presión económica y la educación liberal de los gitanos con sus hijos hombres y al desdén por las ocupaciones de sus hijas, cierran en conjunto el paso hacia lo que aparece reiterativamente como un bien deseado y prestigioso: la cualificación laboral". (San Román, 1990:109-110). Las experiencias y trayectorias de las mujeres y de los hombres gitanos con éxito y continuidad educativa que van formando parte del registro general de nuestra investigación, además de los casos analizados aquí, sobre todo las de las personas más jóvenes, ya indican en sí mismas que se empieza a estar en una situación distinta.

Veamos ahora qué aspectos podemos rescatar para construir una imagen más compleja de la situación educativa del alumnado gitano, a partir de un repaso a la situación de las distintas Comunidades Autónomas.

En primer lugar, es de destacar la importancia que tiene para el alumnado en situaciones desfavorecidas y, por lo tanto, para un sector importante del alumnado gitano (que en todo Aragón posiblemente no supera la cifra de 3.000 chicas y chicos en niveles preuniversitarios), el conjunto de medidas tomadas en el año 2.000 por el Gobierno de Aragón a través de su Programa de Interculturalidad. Se trata de algo innovador en el territorio español, ya que se diseña e implementa un programa progresivo de gratuidad de material didáctico y libros de texto -en formato de préstamo- para la totalidad del alumnado. En el curso 2.003-2.004 la gratuidad se extendió a $5^{\circ}$ y $6^{\circ}$ de Primaria. Por otra parte, desde hace tres cursos académicos Aragón ha sido la primera Comunidad Autónoma que se ha planteado llevar a cabo un tratamiento no segregado del refuerzo educativo ante determinadas necesidades educativas especiales: desaparecen las Aulas de Educación Compensatoria y es el profesorado quien se desplaza hasta las aulas ordinarias para hacer una atención personalizada al alumnado que lo necesite. 
También en Aragón, se han iniciado diversas experiencias en la línea de las comunidades de aprendizaje, siendo una de las más conocidas la del I.E.S. Lucas Mallada de Huesca, con una proporción alta de población escolar gitana, y que ha supuesto un trabajo especializado en cuestiones de motivación para favorecer la permanencia del alumnado en Secundaria y su continuidad educativa, así como la contratación de mediadores y mediadoras gitanos. Pero no se dispone de datos sobre niveles de concentración/segregación, absentismo y desescolarización y otros indicadores de exclusión educativa específicos del alumnado gitano.

En Castilla y León, donde sí se cuenta con datos oficiales sobre alumnado gitano -aunque registrados bajo la perífrasis "eufemística" de "minorías étnicas"-, la población escolar gitana es de 5.291 en el curso 2003-2004 sobre un total de 474.450 alumnas y alumnos, lo que representa el $1,11 \%$. Por provincias ${ }^{60}$, la distribución del alumnado gitano por orden decreciente es la siguiente: Valladolid (1.619), Burgos (945), León (767), Palencia (666), Salamanca (497), Zamora (387), Ávila (175), Segovia (168), y Soria (67). Tres cuartas partes del alumnado gitano de la región está escolarizado en centros públicos. En el curso 2.002-2.003 había un total de 1.255 escolares gitanos/as en Educación Infantil, 2.791 en Educación Primaria, 995 en la ESO, y 51 en estudios de Secundaria post-obligatoria.

Existe una notable carencia de plazas públicas o subvencionadas de Primer Ciclo de Educación Infantil, generalmente fuera de los barrios con mayor presencia de población gitana, y en las Escuelas Infantiles de la C. A. ha pasado a ser el criterio preferencial de admisión el que ambos progenitores acrediten un trabajo, por encima del número de hijos e hijas o de la escasez de ingresos económicos, con la consiguiente exclusión de amplios sectores de población gitana. Además, se han constatado algunos casos de discriminación solapada en la admisión de niñas y niños gitanos en los centros.

En Educación Infantil de Segundo Ciclo están escolarizados en torno al 92 \% de los niños y niñas gitanos de 3, 4 y 5 años de Castilla-León; en Primaria, la escolarización de la infancia castellano-leonesa gitana es del $100 \%$; de 12 a los 14 años están escolarizados algo más de dos tercios del total de los de su edad; mientras que a los 15 años no se llega al $10 \%$ de escolarización (lo cual contrasta enormemente con la tasa de escolarización para esa edad del conjunto de la población española, que ya hace 9 años era de 99,7\%)61; a los 16 y 17 años el porcentaje de jóvenes gitanos y gitanas escolarizados es inferior al $5 \%$; y de los 18 a los 22 años es menos del $1 \%$ el porcentaje de la juventud gitana que continúa estudiando. En toda Castilla y León sólo en torno a 50 personas gitanas estudian con 15 años o más en el curso actual, lo que representa el 0,23\% del total de su población.

Por lo tanto, un elevado número de la infancia gitana de 12 a 14 años se halla fuera del sistema escolar. En la actualidad el paso al I.E.S. (con 12 años, o con 13 en el caso de que haya repetido un curso en Educación Primaria) supone el abandono

\footnotetext{
60 Fuente: Consejería de Educación de la Junta de Castilla y León (2004): "Plan de Atención al Alumnado Extranjero y de Minorías. Documento Provisional”. Valladolid (policopiado). (También puede consultarse en la pág. web de educación de la Junta de Castilla y León: www.educa.jcyl.es).

61 M.E.C. (1994): Curso escolar 1994/1995. Datos y cifras. Madrid: Servicio de Publicaciones del M.E.C.
} 
escolar de buena parte del alumnado gitano. Y, en concreto, el paso de las chicas gitanas a los I.E.S. constituye en una gran parte de los lugares de Castilla y León (salvo pequeñas excepciones, como El Burgo de Osma y Soria, y la que pueda resultar de una experiencia en curso en Valladolid) ${ }^{62}$ algo que, sencillamente, no se produce en estos momentos.

En la provincia de Burgos en el curso 1.999-2.000 recibía apoyo el $40 \%$ del alumnado gitano, y el $27 \%$ del inmigrante ${ }^{63}$, cifras completamente alejadas de una situación de normalidad. En los últimos cursos se han creado Comisiones de Absentismo para favorecer la coordinación en los distintos sectores que intervienen en el tema; pero la realidad es que después de 16 años de haberse desmontado las Escuelas Puente, varios colegios de la región se han ido guetizando progresivamente, tanto en zonas del casco viejo como de la periferia (y con frecuencia en una ciudad se cierra uno de los centros más guetizados, y a los pocos años se vuelve a repetir la situación, con centros que concentran el alumnado gitano y de los que ha ido marchándose el alumnado de la población mayoritaria). El estudio que realizó J. E. Abajo (1997) sobre La escolarización de niños y niñas gitanos, basado en su trabajo de campo en Aranda de Duero, describía la responsabilidad de esta situación en la emergencia y en la persistencia de mensajes doble-vinculares (cargados de ambigüedad), que actúan como frenos a la continuidad educativa del alumnado gitano objeto de los mismos.

En la Comunidad Autónoma de Madrid, los datos del curso 2000-01 que constan en el Documento de la U.G.T. Integración y Escuela nos proporcionan las cifras siguientes, según las distintas zonas en las que se divide la Comunidad: Madrid Norte, 38 alumnos y alumnas gitanos en niveles preuniversitarios; Madrid Oeste, 177; Madrid Sur, 587; Madrid Este, 1099 y Madrid Capital, 6.031, con un total de 7.932 alumnas y alumnos gitanos. El 87,59\% del alumnado gitano de Madrid está escolarizado en centros públicos.

Por otra parte, y según un informe del programa de Apoyo y Seguimiento escolar del alumnado gitano desarrollado en la Comunidad de Madrid por la FSGG referido al año 2.001, el Programa había trabajado en 25 colegios, realizando 2.259 intervenciones, con un total de 300 niñas y niños gitanos participantes en diferentes actividades. La mayor dificultad que señalan es la escasa permanencia durante toda la etapa de la Educación Secundaria Obligatoria, por la persistencia del absentismo y la discontinuidad. Aunque obviamente se refiere a una parte y no a la totalidad del alumnado gitano de la Comunidad, la perspectiva de la evaluación realizada por este programa es pesimista, ya que llega a la conclusión de que el salto del colegio al instituto es prácticamente imposible, por varias razones: los institutos suelen estar situados lejos del domicilio familiar, las familias tienen miedos y desconfianza del ambiente que se vive en los institutos (y miedo a la relación de sus hijos e hijas gitanos con los no gitanos), el nivel educativo del alumnado gitanos es más bajo y esta situación puede inhibir la asistencia de los chicos y chicas gitanos y, por último, señalan que la "aten-

62 Vid.: Velasco, M.; Pisa, A.; Pérez, J. (2004): Plan de Zona Pajarillos-Pilarica. Boletín de Enseñantes con Gitanos, $\mathrm{n}^{\circ} 25$ (en prensa).

63 Dato facilitado por el Servicio de Atención a la Diversidad de la Dirección Provincial de Educación. 
ción a la diversidad específica gitana"64 no se da salvo en casos concretos donde se ven implicados profesorado, personal educador y profesionales del trabajo social.

En Navarra se calcula que existían unos 1.300 alumnos y alumnas en niveles preuniversitarios en el curso 2000-2001, aunque se señala que la elevada escolarización en Infantil y Primaria del alumnado gitano lograda en los últimos años no es suficiente. Existen dos documentos clave sobre la persistencia y el aumento de situaciones de exclusión educativa en la Comunidad Foral de Navarra y a ellos nos remitimos. En primer lugar, el Plan de Lucha contra la Exclusión Social constataba un 20\% de desescolarización en edad obligatoria y un 35-40\% de quienes tenían más de doce años. Hay aproximadamente un $30 \%$ de alumnado gitano que abandona prematuramente los estudios. Pero esas cifras parecían demasiado bajas y se investigó si los chicos y las chicas gitanos estaban o no en las listas de matriculación de los centros. Tras la exploración realizada por el equipo de Navarra, incluida en el estudio Procesos de Exclusión Educativa: la escolarización gitana ${ }^{65}$ se estima que falta más del $60 \%$ de alumnado gitano en Secundaria.

Desde el punto de vista de los resultados académicos, el mismo estudio de Zabalza Pérez-Nievas, señala que cerca del $80 \%$ del alumnado de Primaria y de Secundaria de la muestra trabajada 'Necesita mejorar' o suspende en la mayoría de las asignaturas. Todo ello, a pesar de la proporción de Refuerzos Educativos (en un $41 \%$ de los casos en Primaria y en un $67 \%$ en Secundaria) y a pesar de las Adaptaciones Curriculares que asumen (un 23\% en Primaria y un $85 \%$ en Secundaria). Estos resultados son aún más negativos en el caso de las alumnas, y tampoco en los centros concertados el rendimiento académico es mucho mejor. A ello se añade la denuncia realizada desde diversas instancias y asociaciones ante los medios de comunicación, de la segregación que produce la atención específica, en aulas 'paralelas' de refuerzo educativo con la totalidad del alumnado de etnia gitana, supuestamente motivadas por una cuestión de niveles, en el curso 2.001-2.002. No hemos localizado estudios o informes con datos explícitos semejantes en las demás CC. AA., pero esto no quiere decir que tales situaciones no se den.

Por lo tanto, se concluye que la exclusión educativa general, el absentismo, el fracaso y el abandono escolar de los chicos y chicas gitanos en las distintas etapas educativas es alta. Aunque sólo un $18 \%$ de los hogares afectados por algún tipo de exclusión educativa es de etnia gitana, en "un $86 \%$ de las familias gitanas se ha detectado alguna problemática educativa" "66. En un $21 \%$ de los hogares gitanos de Navarra se detectó desescolarización de menores en la etapa obligatoria o analfabetismo en jóvenes, mientras que sólo en $1,1 \%$ de la población mayoritaria se presenta esta exclusión educativa. Por otra parte, en un 10\% de los colegios de Educación Infantil y Primaria de Navarra se concentra el $54 \%$ de las minorías y el $94 \%$ de las becas de comedor para familias desfavorecidas. A pesar de la situación descrita, en los últimos años se

\footnotetext{
64 El entrecomillado es nuestro, puesto que no queda claro el significado que se otorga a esta reivindicación.

65 Zabalza Pérez-Nievas, Mamen, "Procesos de Exclusión Educativa: la escolarización gitana", Trabajo de Investigación, Departamento de Trabajo Social de la Universidad Pública de Navarra, junio del 2001.

66 Idem, página 53.
} 
están dando varios casos de jóvenes gitanos y gitanas con cierta continuidad académica procedentes de barrios segregados y situaciones económicas muy precarias. Para ello ha resultado decisivo el hecho de contar con un centro de apoyo extraescolar promovido por el Secretariado Diocesano Gitano, en torno al cual se va generando un grupo de iguales que continúa estudiando, con especial incidencia en las chicas gitanas.

En Cataluña, a partir de los datos de población, calculamos que debería haber alrededor de 25.000 alumnas y alumnos gitanos entre 0 y 16 años. La cifra para la ciudad de Barcelona que proporcionaban Carme Garriga y Salvador Carrasco (2000) a partir de una encuesta en los centros educativos de Primaria y de Secundaria llegaba a 1.861 alumnos/as en el curso 1.998-1.999 (de los cuales informan que tan sólo 20 estaban cursando estudios post-obligatorios). En conjunto, el 85,22\% de este alumnado estaba escolarizado en centros públicos. La cifra resultante de analizar datos generales facilitados para este estudio por la Inspección de Enseñanza de Barcelona ciudad para el curso 2002-2003, aunque sólo en referencia a la población escolar de las etapas de Educación Infantil y Primaria, llega a los 1.362 alumnos y alumnas (481 en Educación Infantil y 881 en Educación Primaria), $84,36 \%$ de los cuales están escolarizados en centros públicos. A diferencia de los datos del estudio anterior, que no registraba la presencia de alumnado gitano en 4 distritos de los 10 de la ciudad, los datos actuales indican que tan sólo uno de los distritos no tiene población escolar gitana, aunque su peso es diverso en las distintas zonas de la ciudad, sin presentar situaciones de alta concentración en las escue$1 a s^{67}$. En otra ${ }^{68}$ de nuestras investigaciones tampoco se observaba esta concentración en la ciudad de Barcelona.

La situación educativa es diversa en términos cuantitativos y de distribución en el resto de Cataluña. Por ejemplo, en el Área Metropolitana de Barcelona y para el curso 2.002-2.003, Sant Adrià de Besòs cuenta con al menos 664 alumnas y alumnos gitanos de niveles preuniversitarios, de los cuales el $74,25 \%$ pertenecen a un solo barrio. En cambio, en la segunda corona del Área Metropolitana, Sabadell cuenta con al menos 522 alumnos y alumnas gitanas en los mismos niveles, con una dispersión mucho mayor en la ciudad, excepto en dos barrios con mayor presencia. Finalmente, fuera de la zona más poblada de Cataluña, por ejemplo en la zona de Girona, contamos en Girona ciudad con 407 alumnas y alumnos gitanos, en Figueres, con 263 y en Lloret de Mar, con 42. En las dos primeras ciudades existen dos barrios de alta concentración, no así en la tercera. Sin embargo, a pesar de presentar una situación socioeconómica de creciente diversidad interna, todavía no se ha producido una traducción sistemática de las posiciones familiares más desahogadas en trayectorias de continuidad y, por otra parte, persisten claramente las situaciones de absentismo y abandono de más del 30\% en Educación Primaria y de más del 38\% en Secundaria en barrios de fuerte marginalidad, como muestran los recientes diagnósticos ${ }^{69}$ |levados a

\footnotetext{
67 En el curso académico presente se impartirá clase por última vez en el barrio de Can Tunis, objeto de transformación urbanística total que incluye el realojo de últimas familias gitanas que lo habitan.

68 Carrasco, S. y Soto, P. (2003) Immigració i diversitat sociocultural a les escoles de Barcelona. Característiques i concentració a les escoles municipals i de Ciutat Vella. Observatori de la Immigració, Ajuntament de Barcelona.

69 Fernández Moriel, A. (2003): Projecte de millora del procés d'atenció a l'absentisme escolar a la zona IV de Serveis Personals y Annex II. Benchmarking amb altres municipis. Ajuntament de Badalona.
} 
cabo por el conjunto de ayuntamientos de la Región Metropolitana de Barcelona para coordinar sus planes de lucha contra el absentismo.

Entre las iniciativas que se llevan a cabo en Cataluña para promover la continuidad educativa del alumnado gitano desde la diversidad del tejido asociativo general y étnico, 0 desde los servicios educativos públicos, es de destacar por su planteamiento y sus resultados el que desarrolla la Fundación Pere Closa, a través de educadores/as y mediadores/as voluntarios/as, mayoritariamente de etnia gitana, que constituyen por sí mismos referentes inequívocos para la normalización de la continuidad. Su esfuerzo se concentra en el apoyo extraescolar al alumnado con buenas condiciones y probabilidades de continuidad académica y en el trabajo con sus familias en el mismo sentido.

Ciertamente, la escolarización de las niñas y niños gitanos ha experimentado un avance muy importante en los últimos veinticinco años en España y todos los datos así lo confirman. No hay que olvidar que en 1978 la tasa de analfabetismo global de los gitanos y gitanas españolas mayores de 10 años era del 68\% (siendo mucho más acentuado el porcentaje de analfabetismo entre las mujeres), y el volumen de escolarización del periodo escolar obligatorio sólo alcanzaba al 55 \% de los niños y niñas gitanas (Instituto de Sociología Aplicada de Madrid, 1982). Actualmente, se acepta que la escolarización en Educación Primaria es universal70, y que llega al 90 \% de los niños y niñas entre 3 y 6 años, así como el hecho de que entre los gitanos y las gitanas españolas menores de 25 ó 30 años el analfabetismo es casi inexistente. Esto coincide con la mejora general de los mismos indicadores para el conjunto de la sociedad española, por lo que se deduce que en algunos aspectos se reduce la distancia entre la mayoría y la minoría.

Los resultados del estudio de la FSGG (2002) Evaluación de la Normalización Educativa del Alumnado Gitano, que se llevó a cabo en 62 centros de todo el estado, con 998 alumnas y alumnos, proporciona resultados que refuerzan estos aspectos positivos. Según sus datos, el 94\% del alumnado gitano ha iniciado su escolarización a los seis años o antes, y el $96 \%$ ha sido escolarizado en el curso que les corresponde por su edad, situación muy aproximada a la normativa y sin existir apenas diferencias entre niños y niñas. Además, señalan que el $74 \%$ de alumnado gitano ha estado escolarizado en Educación Infantil o ha asistido a Guarderías, así que sólo representa una cuarta parte el alumnado que accede al sistema educativo por primera vez con seis o más años. Señalando otro aspecto positivo, claro indicador de mejora, añaden que "el $85 \%$ de niños y niñas han sido escolarizados por iniciativa de la familia; y el 15\% a partir de la intervención de los servicios de apoyo" (FSGG, 2002: 69)71.

Sin embargo, la escolarización del alumnado gitano en Educación Secundaria es todavía hoy reducida y presenta unos índices de absentismo y abandono escolar muy elevados. A pesar de ser obligatoria la enseñanza hasta los 16 años en nuestro país desde hace ya más de una década, son muchos los alumnos y alumnas gita-

\footnotetext{
70 Vid., por ejemplo, Comisión Consultiva del Ministerio de Trabajo y Asuntos Sociales para el Programa de Desarrollo Gitano (1999) El Pueblo Gitano y la Educación. Documento para debate, Ministerio de Trabajo y Asuntos Sociales, Madrid.

71 Sobre estos mismos aspectos, consultar también: Lasa, B. (2002: 34-37) y Cabanes, P. (1998).
} 
nas que abandonan el sistema escolar antes de iniciar la ESO. Hay que considerar, además, que esto ocurre en un momento en el que la Secundaria es prácticamente universal en la población mayoritaria. No estamos en condiciones de asegurar diferencias cuantitativas importantes en este sentido, pero sí podemos afirmar que las razones que llevan a unos y a otras a alejarse de la escolarización en Secundaria son en muchos casos divergentes.

Así, son todavía mayoría las alumnas y alumnos gitanos que figuran como matriculados en los I.E.S. en algún curso de la ESO, pero o bien no han llegado a acudir jamás, o bien han abandonado totalmente el sistema escolar en los primeros dos cursos y no asisten nunca al I.E.S. Además, entre los alumnos y alumnas gitanas que siguen en la ESO son muy altos los índices de absentismo, bajo rendimiento -no siempre justificado por niveles más bajos de acceso a Secundaria- y fracaso72. Según los datos de la Evaluación de la Normalización Educativa, "el 69\% de los alumnos y alumnas han mantenido una escolaridad continua, mientras que el $31 \%$ ha presentado un absentismo de tres meses o más durante algún curso (...) Estos resultados permiten concluir que "si bien el absentismo prolongado se ha reducido de un modo progresivo (12\%), es un proceso lento y sigue siendo preocupante de cara a la normalización total del alumnado gitano" (FSGG, 2002:70). La misma fuente señala que sólo el $30 \%$ del alumnado de su muestra tiene adquiridas las rutinas escolares, como la realización de deberes en casa.

Nuestra experiencia indica, además, que un porcentaje muy elevado no sigue totalmente el currículo ordinario de su clase, y acuden varias horas al día a clases con el profesorado de Educación Compensatoria o bien, en el Segundo Ciclo, cursan los estudios en el Programa de Diversificación Curricular, en la línea de los primeros datos que presentábamos en este apartado.

El tener que cambiar de centro a los 12 años ha supuesto -en los primeros años de implantación- un frenazo para una parte considerable del alumnado gitano, especialmente para las chicas. Con la ley de Educación de 1.970 a finales de los 80 y primeros 90, se había conseguido que un grupo notable de chicos y chicas gitanos siguiera estudiando en el centro de Primaria hasta el final de la EGB (hasta los 14 años). Con la LOGSE, al pasar a realizar la ESO a los I.E.S. a los 12-13 años, muchas familias no realizan ese cambio, pues siguen contemplando el paso al I.E.S. (ahora adelantado a los 12-13 años) como una barrera, como un lugar que no es para ellas, expresando así una posición de indefensión aprendida. Los grupos de nivel y los itinerarios segregados defendidos y previstos en la LOCE ${ }^{73}$ avalan la creación de una estratificación étnica de aciagos efectos, desgraciadamente muy conocida en otros países que practican este antidemocrático mecanismo conocido en inglés como tracking o streaming. De hecho, en nuestro trabajo de campo hemos podido constatar una vez más cómo todos los dispositivos de adaptación curricular segregados

\footnotetext{
72 Entendido como lo define el propio sistema, es decir, como la no superación de la adquisición de contenidos y competencias de las distintas materias del curriculum, aunque en términos estrictos esta conceptualización da lugar a una visión parcial del fenómeno.

73 En el momento de terminar este texto, el nuevo gobierno socialista acaba de establecer una moratoria de dos años para revisar algunos aspectos de la aplicación de la LOCE, como éste al que nos referimos.
} 
(unidades especiales, externas, etc.) tienen también en Secundaria una sobrerrepresentación de alumnado gitano y de alumnado de origen inmigrante de países pobres. La inquietante situación actual y la que hasta hace poco estaba prevista por la LOCE constituyen un mensaje bien claro y, en este sentido, coincidente, con la sensación de que el centro de Secundaria no está pensado para igualar las oportunidades de un amplio margen de la población, incluido un sector todavía mayor de población gitana, a la luz de los hechos.

Son todavía muy pocos proporcionalmente los gitanos y gitanas que han alcanzado titulaciones académicas. No llega al $1 \%$ del conjunto de los gitanos y gitanas de las cinco CC. AA. que haya logrado acabar $3^{\circ}$ de la ESO (o, lo equivalente en su día: $1^{\circ}$ de BUP, $1^{\circ}$ de FP). En la actualidad son todavía bastantes escasos los miembros de la etnia gitana que llegan a la Universidad. Hasta ahora hemos localizado a un número muy reducido de gitanas y gitanos con titulación universitaria y de gitanas y gitanos que actualmente son estudiantes universitarios.

Al inicio de la ESO el porcentaje de chicas gitanas estudiantes es menor que el de chicos gitanos, aunque parece que paulatinamente la proporción se va invirtiendo. Esta tendencia es el reverso de la moneda de lo que hemos señalado con anterioridad y se analizará más adelante.

Por otra parte, se puede observar una evolución en las expectativas escolares de las familias. Se da una evolución positiva en las familias gitanas con respecto a la escolarización de sus hijas e hijos de una generación a otra, e incluso en ocasiones se produce un cambio en una misma familia gitana con el paso de los años. La experiencia escolar de los padres y madres -desde la mayor hasta la menor duración y éxito relativo de la misma- ha contribuido a generalizar si no las expectativas, sí las prácticas escolares precoces. Sin embargo, la Educación Secundaria no es percibida como un medio para otras posibilidades de inserción sociolaboral, sino, todavía, en la mayoría de las familias de referencia de las y los entrevistados, como una actividad que puede entrar en competencia con otras expectativas de dedicación doméstica y ocupacional dentro de las prácticas familiares.

En el estudio de Carmen Garriga y Salvador Carrasco (2000) ya se introducía una reflexión interesante sobre los cambios en la situación educativa de la población gitana. Por una parte, nos proporcionaban los siguientes datos de la ciudad de Barcelona sobre los niveles de instrucción de la población estudiada en su muestra, donde se registraba que casi el $60 \%$ de la población gitana de Barcelona sabía leer y escribir, indicando la progresiva erradicación del analfabetismo en grupos de edad menores, sobre todo como efecto de la escolarización obligatoria; por la otra, las enseñanzas medias post-obligatorias eran las que presentaban una proporción menor de personas; sin embargo, era ligeramente superior el porcentaje de universitarios y universitarias. Asimismo, existía un desequilibrio entre hombres y mujeres en los tres niveles inferiores, que se igualaba y llegaba a invertirse en los niveles siguientes. Ahora bien, otra parte de la encuesta de Garriga y Carrasco contiene otra información interesante en comparación con estos datos: más de la mitad de las personas encuestadas se mostraban partidarias de la continuidad educativa de sus hijos e hijas hasta niveles supe- 
riores. Es decir, existía y se verbalizaba la aspiración, aunque los datos anteriores y las prácticas registradas en la investigación no lo pudieran corroborar todavía. Es posible que este desajuste, en el que se detecta un cambio de actitudes, coincida progresivamente en el tiempo. También es posible que este indicio de transformación referido a Barcelona sea extrapolable a otras CC. AA. En la misma línea, el estudio de la FSGG sobre la normalización educativa indica que el 77\% de las familias encuestadas estaban muy convencidas de la necesidad de terminar la enseñanza obligatoria.

El proyecto The educational situation of Gypsy chidlhood in Europe ${ }^{74}$ (2003) coordinado, como hemos mencionado más arriba, por Ana Giménez y con la participación de reconocidos especialistas como Leonardo Piasere (Italia) y Jean Pierre Liegeois (Francia), se basa en un análisis comparativo entre los tres países, más una prospección regional en Portugal, a partir de metodologías cuantitativas y cualitativas en dos áreas distintas de las cinco CC. AA. de nuestra investigación (Levante y Sur). Se trata de un diagnóstico de la situación educativa y los procesos de socialización de la infancia gitana en el marco de las políticas educativas de los distintos países de la Unión Europea, abarcando un amplio repertorio de comunidades gitanas que se encuentran en situaciones muy diversas, que tiene como precedente el proyecto transnacional anterior dirigido por Liégeois (1988).

Según este estudio, no se puede afirmar que la mayor parte de la población gitana viva en áreas urbanas marginalizadas, contra la representación generalizada que se realiza de ella. Su estimación es que aproximadamente la mitad de la población española gitana se ubica en áreas rurales y en pequeñas poblaciones de menos de 5.000 habitantes, esto último, especialmente en Andalucía.

En la investigación de Giménez y su equipo se realiza una proyección $n^{75}$ de los datos obtenidos en las zonas estudiadas al territorio estatal, según la cual la proporción de niños y niñas gitanos en centros de enseñanza públicos, es de un 58,2\% (este dato se contrapone al de Francia, donde el $84 \%$ de la infancia gitana se escolariza en centros públicos), un $34,4 \%$ se escolariza en centros concertados y solo un $3,8 \%$ acude a escuelas privadas. En total, se estima alrededor de 70.000 los niños y niñas gitanos en la etapa de Educación Primaria, lo que representa un 2,81\% del total de la población escolarizada en este nivel. La autora confirma la alarmante pérdida de niños y niñas gitanos en el paso de Primaria a Secundaria: se estima que éstos suponen un $1,22 \%$ de la población total escolarizada en Educación Secundaria (unos 22.442 alumnos/as gitanos/as), lo que representa el abandono de más de 45.000 alumnos y alumnas en el paso de un nivel a otro, sólo para el curso 2.001-2.002.

Por otra parte, sus datos indican que en el rendimiento escolar no hay diferencia por sexo entre las y los estudiantes gitanos y, en términos de absentismo, la diferencia entre niñas y niños es prácticamente imperceptible. Nuestra investigación, sin

\footnotetext{
74 Conocido también como OPRE ROMA, nombre del proyecto y del equipo.

75 La diversidad en la proporción de la oferta pública y concertada, así como los datos tomados en algunas ciudades y territorios con elevada presencia de población gitana en situaciones socioeconómicas diferenciadas, nos previene por ahora de utilizar los datos que ofrece esta proyección.
} 
embargo, constata la existencia de experiencias divergentes con relación a las razones que motivan el absentismo de unas y de otros.

Finalmente, dicho estudio detecta y señala que se da con frecuencia un sesgo importante en el análisis de la situación educativa del pueblo gitano desde la perspectiva de género, ya que sólo se realizan análisis comparativos entre niños y niñas gitanos, pero hay un vacío total de análisis comparativo entre la situación educativa de las niñas gitanas y la de las niñas no-gitanas en el marco escolar. Esta es una observación crítica que compartimos plenamente. En esta misma línea, se insiste en la necesidad de distinguir entre opiniones y prácticas en las cuestiones de género, extremo que también compartimos y que ha formado parte central de nuestra metodología. De hecho, lo que en teoría puede parecer una clara delimitación de las responsabilidades según el sexo que -añadimos- puede recordar a la reproducción de un modelo tradicional filtrado por la ideología burguesa (hombres, esfera pública, trabajo extradoméstico; y mujeres, esfera privada, trabajo 'doméstico'), no resulta tan consistente en la prácti$\mathrm{ca}$, puesto que muchas mujeres trabajan 'fuera' de casa y el espacio no aparece como una delimitación real en la práctica.

En definitiva, más allá de los datos disponibles y de los que se puedan ir produciendo con las investigaciones -todas imprescindibles-, la sensación que se tiene en la cuestión de la situación educativa de las chicas y los chicos gitanos nos lleva a formular dos dudas fundamentales. En primer lugar, parece claro que existen dos maneras de interpretar la situación descrita, tomando en menor o en mayor consideración los efectos de la política educativa para sostener una visión más o menos confiada en las condiciones de mejora educativa. En segundo lugar, cabe preguntarse si se trata básicamente de esperar que esa igualación educativa entre minoría y mayoría (con toda su complejidad) se acabe produciendo, aunque 'con retraso', a medida que también aumenten las posiciones económicas integradas entre la minoría. Pensamos que todo ello es más complejo y que la diversidad de trayectorias y experiencias nos lo puede empezar a desvelar.

\subsection{Invisibilidad étnica y continuidad educativa}

Además de la omisión sistemática de información de la población gitana en clave de éxito y continuidad educativa en todos los niveles, es cierto que la identidad étnica de buena parte de los gitanos y gitanas que ha continuado estudiando a partir de $3^{\circ} \mathrm{de}$ la ESO es desconocida por sus compañeros/as y, en niveles universitarios, frecuentemente también la ignora el profesorado. Es obvio que existen varias razones para esta invisibilidad, aparte de la tendencia a la omisión de la información en clave de éxito: algunas personas y sus familias pueden no querer revelar su adscripción étnica 0 puede suceder que algunos centros educativos, especialmente los concertados, se nieguen a reconocer la presencia de alumnado gitano en sus aulas, como hemos podido comprobar en nuestro trabajo de campo y en nuestra experiencia profesional. 
En la mayoría de los casos se trata de gitanos y gitanas que estudian en un I.E.S. (en barrios no segregados), en algún centro concertado o en un centro universitario, sin presencia de otros alumnos y alumnas gitanos. Y, de hecho, algunos/as gitanos/as con estudios superiores que hemos entrevistado nos han insistido en asegurar la máxima confidencialidad de algunos datos que podrían identificarles, pues consideran que esto podría perjudicarles en sus relaciones cotidianas y en su proyección laboral. Otros y otras han declinado participar en la fase de entrevistas, aunque formen parte del censo de base de la investigación.

Así, la persistencia de altísimas dosis de racismo y problematización de la condición étnica gitana, en la experiencia y en la adaptación de un número significativo de nuestros informantes se suma, en una triste paradoja, a la invisibilidad de las trayectorias de éxito y continuidad académica de la minoría, contribuyendo a normalizar su supuesta inexistencia.

Algunas y algunos de nuestros informantes han reflexionado sobre ello:

"Yo, la verdad, muchas veces me pregunto si la gente sabe que soy gitano y si me trataría igual si lo supiera. Lo pienso muchas veces: ¿Este sabrá que soy gitano? ... Y porque yo vaya bien vestido, pues algunos ya piensan que no puedo ser gitano. (...) Y, ya te digo, a veces pienso: con éste me llevo fenomenal, ¿sabrá que soy gitano y a pesar de todo nos llevamos bien?, y si no lo sabe, ¿sería tan amigo mío si supiera que soy gitano? Y lo mismo con alguno que alguna vez he tenido algún problema con él, me pongo a pensar: ¿sabrá que soy gitano, y a lo mejor me mira mal por eso?, ¿o el que sepa o no sepa que soy gitano no tiene nada que ver con habernos enfadado por una cosa en concreto?... Esto de si sabrán que soy gitano o no y si me tratarían igual si lo supieran me da por pensarlo algunas veces." (Richi, Castilla-León, 24 años).

Aunque nunca formó parte de nuestras hipótesis, es de destacar que de forma espontánea varias de las personas entrevistadas aducen que el hecho de tener rasgos físicos gitanos poco marcados ha favorecido su invisibilidad y, en algunos casos, sus condiciones iniciales de mayor integración educativa:

"... y eso ha jugado en mi favor a la hora del colegio, y del instituto, y de la facultad, que no tengo demasiada pinta de gitano. No soy especialmente moreno, ni tengo la nariz ganchuda, ni... es decir, que la gente por lo general no sabe que soy gitano." (Carlos, Madrid, 30 años).

"... pasaba desapercibido como gitano; alguna vez, cuando me daba un poquito más el sol, se me notaba, 'Éste es gitano, éste es gitano', ja, ja, ja, ja [risas]; entonces, cuando se daban cuenta, sí, sí... sí lo notaba, lo notaba, que el profesor, a lo mejor, de... asentir todas mis opiniones vertidas en clase, radicalmente, eh... omitirlas; no hacerles caso o contradecirlas." (Adrián, Madrid, 25 años). 
Además, rasgos fenotípicos y manera de vestir que salen del estándar tradicional asociado al aspecto gitano se unen a otras percepciones:

"Siempre me decían: pues tu padre es payo, o tu madre, o alguien tienes que tener que sea familia paya. Siempre, nunca se lo creían, porque decían que era rubia con ojos azules y blanca y yo qué sé. Y que por qué los gitanos no estudiaban, decían también." (Josefa, Navarra, 17 años).

Está claro que no todos y todas pueden utilizar estas estrategias de invisibilidad. Quienes sí lo hacen reciben, a su vez, todo tipo de atribuciones conductuales y actitudinales supuestamente mayoritarias, e inequívocamente en clave positiva. Algunas y algunos de nuestros informantes han sido definidos por parte de los profesionales que trabajan con ellos de la siguiente manera: "Parece buen chico, inocente, simple, tranquilo y nada problemático", o bien: "Psíquicamente responde perfectamente a la mentalidad de su edad". Por lo tanto, la posibilidad de "ocultación" de la adscripción étnica se plantea como un arma de doble filo que contribuye en sí misma a consolidar el estereotipo negativo de lo gitano, aunque no hemos detectado estrategias de negación de la adscripción étnica como las descritas por Fordham y Ogbu (1987), lo que no quiere decir que no existan.

Pero no es siempre así:

"A mí casi me choca más a veces, cuando mis compañeros o los profesores pues, ¿¿Oye, tú eres gitana?' 0 bien: 'Oye, ¿Te puedo hacer una pregunta?'... Venga, dispara, ya sé lo que me van a preguntar ... : ¿Eres gitana?'; digo: 'Sí', y siempre parece que les choca." (Eva, Aragón, 31 años). 


\section{CAPÍTULO 4: CONDICIONES PARA EL ÉXITO ESCOLAR Y LA CONTINUIDAD EDUCATIVA}

En la investigación existe una proporción importante de casos en los que se detecta un grupo de factores centrales que hacen más probable el éxito y la continuidad educativa del alumnado gitano. Naturalmente, se trata de probabilidades, porque lo que la mayoría de trayectorias y experiencias que las personas participantes nos han brindado es que la ausencia de tales circunstancias no ha impedido superar su influencia negativa.

Por otra parte, no podemos hablar de una suma, yuxtaposición o conglomerado de factores favorecedores del éxito y de la continuidad educativa. Antes al contrario, se trata de condiciones que se entretejen de modo sistémico. En este sentido, agrupamos estos factores en torno a tres grandes dimensiones centrales que hacen más probable la continuidad académica del alumnado gitano, y que son:

1.- La dimensión socio-económica.

2.- La dimensión educativa: contexto y clima.

3.- La dimensión afectivo-relacional.

Como veremos, la presencia de las influencias del contexto familiar debe tratarse de forma transversal a esas tres dimensiones, porque interviene sistemáticamente de distinta manera en todas ellas. La segunda perspectiva transversal de fondo, tanto por su influencia en la creación de condiciones que favorecen el éxito y la continuidad como en las que no lo favorecen, es la del sistema de sexo/género.

Por último, queremos aclarar que aunque se ha explicitado una "dimensión educativa" aislada, debe entenderse que en ella se incluirán aspectos recurrentes en la investigación educativa para el éxito en la literatura sobre minorías étnicas y educación (relativos al contexto y clima escolar y al papel de la familia en la educación formal), a pesar de que todos y cada uno de los subapartados que contiene este texto se dedican al análisis de las experiencias y trayectorias de éxito y continuidad educativa y a los factores que las hacen posibles.

\subsection{La dimensión socioeconómica}

A través del análisis de los casos estudiados de jóvenes gitanos y gitanas con trayectorias de éxito y continuidad educativa constatamos que una dimensión clave es que la familia no se encuentre en situaciones de marginalidad (en lo relativo a vivienda, trabajo, relaciones sociales y expectativas educativas), aunque insistimos en que este extremo por sí solo no conlleva una automática valoración de la vía académica como mantenimiento o mejora de la posición social, ni en la familia ni en la persona que 
estudia. Ahora bien, desde la experiencia de generaciones entre la población gitana, esto comporta un esfuerzo adaptativo importante porque supone realizar una apuesta doble: una apuesta por superar los prejuicios y recelos hacia la sociedad mayoritaria y también una apuesta por los resultados inciertos de una inversión personal, emocional y económica, que sólo se puede asegurar en el presente desde el esfuerzo familiar en nichos ocupacionales conocidos.

Es muy importante aclarar la influencia diferencial entre las situaciones socioeconómicas de mayor integración relativa y las situaciones de aculturación relativa en los aspectos relacionados con la educación. Es evidente que los factores materiales de existencia, la división del trabajo y el contexto de desarrollo de la vida doméstica, así como las expectativas educativas y la vía para la movilidad social sufren procesos de cambio y aculturación hacia formas de mayor marginalidad igual que hacia formas más alejadas de ella, ambas dentro de la sociedad mayoritaria. Así, cuando nos referimos a posiciones sociales más integradas lo hacemos en este último sentido.

Es obvio que muchos de estos factores serían también aplicables al análisis del éxito y la continuidad académica de la población mayoritaria, pero no en el mismo sentido y el mismo nivel, como veremos. Así es como vemos que, en un plano exclusivamente probabilístico, los factores expuestos en las hipótesis crean mejores condiciones iniciales para favorecer el éxito y la continuidad académica del alumnado gitano.

\subsubsection{Contexto urbanístico}

El haber vivido en un contexto urbanístico integrado (bien sea en un pueblo pequeño $o$ en un barrio no segregado) y la experiencia de su familia y del propio niño 0 niña de buenas relaciones minoría-mayoría (en el barrio y/o su padre o madre en el trabajo) constituye un factor positivo, que con frecuencia ejerce su influencia favorable sobre el resto de factores. Aunque el entorno no es determinante en la trayectoria educativa de la persona, puede condicionarla. Lo que observamos es que, generalmente, en contextos fuertemente segregados las personas se enfrentan a un número mayor de obstáculos para proseguir sus estudios. Dependerá luego de su empeño y sus convicciones, o bien del apoyo familiar, de su acceso a becas y otros recursos o de la intervención del tejido asociativo el que esa situación negativa de partida se pueda compensar.

Las historias de nuestros y nuestras informantes son muy diversas, pero hemos detectado características y reacciones recurrentes en momentos cruciales que han ido configurando ciertas tendencias. En este caso, la mayor parte de las mujeres y de los hombres entrevistados (recordemos que 10 de los 50 casos proceden de barrios altamente segregados y de situaciones económicas familiares precarias, frente a los 40 casos restantes) han vivido en un barrio no segregado o en un pueblo, y su familia tenía buenas relaciones con el resto del vecindario. Sin embargo, en los barrios no segregados étnicamente pero en graves situaciones de marginalidad de toda la población, los pocos/as estudiantes que presentan trayectorias de continuidad académica en 
Secundaria obligatoria y post-obligatoria no suelen ser estudiantes gitanos y gitanas, pues en éstos su abandono es aún más precoz. De todas maneras, existen variaciones territoriales importantes que no aportan apoyo empírico a esta generalización, como el caso general descrito por el equipo de la C. A. de Navarra y como también muestran algunos de los casos analizados en otras CC. AA.

\footnotetext{
"No había gitanos ni nada. Éramos sólo nosotros... yo no he estado nunca con gitanos. Sé más o menos cómo viven, pero no he vivido nunca con ellos. En mi barrio no había ninguno... Nadie, en Soria tampoco." (Vanesa, Castilla-León, 22 años).

"Hasta los 10 años u 11 vivía en un barrio que los únicos gitanos éramos nosotros, mis padres, mis dos hermanos y yo, y a los 10 u 11 años nos trasladamos en el mismo barrio, (...), entonces, a partir de esa edad de los 10 a 14 años mi vida fue más con los gitanos. Vivíamos en un barrio donde había población gitana, la relación payo-gitano se acentuaba más porque había más gitanos, sin embargo seguía estudiando en el colegio de mi infancia... Siempre he considerado que mi familia estaba plenamente integrada en la sociedad mayoritaria; es que como únicos vecinos que estamos en el barrio en principio, pues la relación obviamente tenía que ser con los vecinos, pasábamos un poco como camuflados ante la sociedad mayoritaria, un poco escondidos. Camuflados, pues no sé por qué. Cuando bajaba mi madre a la panadería era la única gitana que se encontraba con todos los payos allí... porque cuando iba al colegio era el único gitano... Entonces, de puertas para dentro eras gitano, como cualquiera otro, pero puertas para afuera te lo guardabas donde fueras." (Oscar, Aragón, 27 años).
}

"Allí la mayoría de la población era población no gitana." (María, Aragón, 26 años).

"Yo he vivido siempre en este barrio. En este bloque, mi familia somos los únicos gitanos. Yo siempre me he relacionado con los payos." (Richi, Castilla-León, 24 años).

"Yo he estado en una sociedad que estaba rodeada de payos, y tampoco he tenido ningún problema... Yo no he tenido nunca ningún problema. Tampoco tenía por qué haberlo tenido, porque era normal y corriente... Mis padres eran uno más del barrio. A mi padre le quiere todo el mundo." (Clara, Castilla-León, 29 años).

"En este barrio gitanos sólo estamos nosotros. En este barrio sólo hay payos." (Paco, CastillaLeón, 19 años).

"Yo vivo en el Eixample de Barcelona, que es un barrio donde hay pocos gitanos, la verdad, aunque alguno que otro hay." (Lola, Cataluña, 32 años).

"Es que en la zona que yo vivía no había gitanos. 0 sea, en el bloque donde yo vivía los únicos gitanos que había éramos nosotros. (...) Luego, en el colegio tampoco, éramos mis primas que vivían en otro barrio de Sabadell y nosotros. Éramos cinco o seis, me parece. No había muchos gitanos allí." (Alba, Cataluña, 24 años).

Pero más claro aún resulta en las diferencias entre zona urbana y rural, siendo las relaciones en esta última, por lo general, mucho más estrechas. Se profundiza en dinámicas relacionales afectivas y vecinales y no tanto en función de la adscripción étnica: 
"Allí en Galicia poca gente sabía que éramos gitanos, porque no nos ponemos un cartel en la frente... (...) Es que en ese pueblecito no hay más gitanos, sólo vivimos nosotros." (Soledad, Castilla-León, 18 años).

"En el pueblo sólo estábamos nosotros de gitanos, y entonces, pues claro... el trato no es el mismo, al no vivir en el mismo sitio. (...) Yo creo que también hay un punto de emular a esa gente, de que en los pueblos las familias se dieron cuenta de que la formación también podía ser para ellos... y que el veterinario, el médico, los maestros permanecieran en el pueblo sirvió como modelo para el resto de las familias... el hecho, claro, de que sus hijos estudiaban, fue un modelo... La gente se decía: 'Si la hija del veterinario estudia, ¿por qué mi hija no va a poder estudiar?' Personalmente pienso que esto en los pueblos ha ocurrido hace nada." (Yolanda, Castilla-León, 29 años).

"Yo... estábamos en el pueblo, la única familia [gitana] que estaba en el pueblo era la mía. Nosotros íbamos al colegio y tal, pero ellos [otras familias gitanas] no, ellos estaban fuera, estaban como apartaos." (Sara, Navarra, 36 años).

"Los gitanos podían vivir en todas partes del pueblo. No estaban concentrados en un sitio determinado. Vivían, viven en el centro, a las afueras, hay gitanos por todas partes. No están concentrados en un gueto, ni en un punto determinado. Vivimos en una casa muy grande, una casa preciosa, muy bonita en el centro del pueblo." (Anabel, Cataluña, 42 años).

Las relaciones comunitarias y de vecindad en la experiencia infantil del siguiente informante apuntan de forma clara al impacto positivo de la práctica de la interculturalidad. El entrevistado se refiere a su infancia:

"Los gitanos han enriquecido durante mucho tiempo la Feria de (...) con sus aportaciones, con nuestras aportaciones, culturales y, ¿por qué no?, también comerciales, del trato de ganado (...) Es decir, lo que vengo a destacar es la buena relación que había y hay entre los gitanos y la Feria de (...) y esto es vivencial, y se crea un enriquecimiento entre la población gitana y la que no es gitana. En Extremadura en aquella época uno de los oficios potentes, por decirlo de alguna manera, era uno de los valores más importantes de los gitanos, que les permitía salir a la galería y era muy apreciado por el resto de la sociedad." (Ramón, Cataluña, 44 años).

Algunos/as entrevistados/as han manifestado abiertamente que el hecho de haber cambiado de un barrio segregado a un barrio no segregado, no sólo les ha condicionado positivamente, sino que ha sido sumamente determinante en su continuidad académica.

"Yo nací en el barrio de (...), que es un barrio donde viven muchos gitanos, pero por la mala salud de mi hermano, agravada por las condiciones de la vivienda, mis padres a través de una asistente social consiguieron un piso en un barrio donde no había casi gitanos. Entonces yo bajé allí con dos años. Esto lo cuento porque creo que esto es una de las causas fundamentales de que yo haya estudiado. Porque si yo me hubiese quedado en el otro barrio, donde viven todos mis primos, hubiera sido otra la realidad. Entonces, cuando me vine a vivir a este barrio, 
empecé a relacionarme con niñas payas. En el colegio donde fuimos yo y mis hermanos sólo eran cuatro o cinco gitanos en total. En mi aula siempre he estado como única niña gitana." (Laura, Castilla-León, 25 años).

"Pues cuando nos quitaron de los módulos nos llevaron a un barrio muy tranquilo, casi residencial. Un barrio to Ileno de payos, y muy bien." (Pablo, Madrid, 17 años).

"Entonces cuando yo nací pues había un espacio de barracas [chabolas] y, bueno, pues allí vivían bastantes gitanos. [....] Las condiciones de vida eran durísimas, bueno. Pues por aquí andamos de un barrio a otro y así. (...) hasta que yo tengo 13 años, vivía en Can Tunis. Can Tunis que era una barriada bastante grande (...) venimos a vivir a La Floresta en el 73. El cambio de vivienda fue increíble, pues viniendo de una barraca que nos dieran un piso fue, el cambio cualitativamente gigantesco.(...) Siempre han tenido una buena relación, bien... éramos una familia muy abierta, muy así, muy dialogante, siempre, siempre, desde que yo recuerdo han tenido buena relación con todo el mundo, con payos, con gitanos, con cualquiera." (Alvaro, Cataluña, 46 años).

Un caso paradigmático lo encontramos en la Comunidad Autónoma de Madrid: la mayoría de las personas entrevistadas afirma encontrarse en posesión de una vivienda que se encuentra en buenas condiciones de habitabilidad; el acceso a las viviendas por parte de muchas familias gitanas ha venido determinado por políticas de carácter municipal y autonómico, favoreciendo la compra de viviendas a un precio muy bajo o por realojo. Un tercio de las personas entrevistadas procedían de zonas chabolistas 0 de vivienda prefabricada. En estos casos las ayudas sociales han favorecido la integración en barrios con mejores condiciones o el acceso a un ambiente en el que los y las menores estudiaban normalmente, lo que ha facilitado que los niños, las niñas y adolescentes pudieran desarrollar una vida escolar ordinaria:

"Yo vivía en San Blas. Había unos módulos prefabricados en los que había muchísimos gitanos, y después tiraron. (...) Y el único que iba a la escuela era yo. A lo mejor iba alguno algún día, el día que su madre se acordaba de llevarlos, pero así era yo el único. (...) Nos cambiaron a otras viviendas. Yo tendría unos trece años. $Y$ entonces yo siempre iba a la escuela. $Y$ mis hermanas también, pero iban menos, porque era un barrio... pues para no salir mucho. Pero cuando nos cambiamos ya sí." (Pablo, Madrid, 17 años).

Sin embargo, insistimos en que el barrio de alta concentración no es determinante de la no continuidad educativa:

"Vivo en Pan Bendito. Allí todos son gitanos, la mayoría... nos hemos criado toda la vida juntos y nos Ilevamos muy bien, no tenemos problemas unos con otros. (...) De chica iba al colegio del barrio... ese colegio tiene ya muchos años, iba mi padre cuando era chico, ya están acostumbrados a los gitanos. (...) Yo he estudiado en un Instituto que es de payos... porque era el único sitio donde había instalaciones para estudiar cuando me puse [tenía 18 años]." (Sonsoles, Madrid, 26 años). 
"Los bloques Juan Carlos son un barrio normal y corriente, de viviendas sociales que construyó la Generalitat, ¿sabes? Estas de vivienda social. Entonces allí lo que vivían eran pues, bueno, inmigrantes y empezó pues lo típico, ¿no?, porque allí antes, en ese barrio había unas "barracas", ¿sabes? Y, entonces, toda la gente que vivía en aquellas barracas, allí vivían mis abuelos, y por ello les perteneció un piso. Y bueno empezaron así, y entonces empezaron a vivir unos pocos gitanos, y la cosa fue yendo, fue yendo,... y se hizo un barrio, ya te digo, la gran mayoría; también hay payos, quiero decir, también hay, pero la mayoría de los gitanos viven allí, muchos". (Verónica, Cataluña, 35 años).

Finalmente, incluso en las condiciones menos favorables dentro del barrio, muchas y muchos de nuestros informantes mencionan la disposición abierta de sus familias para establecer relaciones vecinales y de amistad con otras personas de su entorno, gitanas y no-gitanas:

"Quiero decir que mi familia es una familia muy abierta, mucho de coger la gente, como acostumbran a ser todas las familias gitanas, y mi madre se integró por completo." (Verónica, Cataluña, 35 años).

En cambio, algunas de las nuevas situaciones multiculturales derivadas de la inmigración extra-comunitaria pueden generar a su vez nuevos recelos y la percepción de competencia en el espacio público y en el espacio social.

\subsubsection{Contexto socio-económico y laboral familiar}

La situación socio-económica de la familia puede ser importante en un triple sentido: por la influencia de tener el padre o la madre un trabajo integrado (por las expectativas proyectadas), por la incidencia del nivel económico sobre las posibilidades de continuidad académica, y por las condiciones que reúna la vivienda.

El trabajo integrado de la madre o el padre puede comportar que en la red de relaciones laborales del padre o de la madre se encuentren estímulos o modelos para la continuidad escolar de los hijos e hijas, incluso en trabajos precarios y de poca cualificación. De hecho, en nuestra investigación, el factor de probabilidad en este sentido es el trabajo integrado del padre dentro de estructuras domésticas tradicionales/convencionales o bien el trabajo integrado de la madre, cuando es ella quien encabeza la familia, por viudedad o divorcio. Pero a ello cabe añadir que lo relevante de que el padre o la madre se encuentren en un contexto laboral más convencional es la relación que se establece fuera de su entorno gitano y la normalización de la continuidad educativa paralela al desarrollo de expectativas de ocupación de los hijos y también de las hijas en empleos también integrados. Los testimonios siguientes pertenecen a casos que terminaron estudios superiores -o están a punto de hacerlo- y lo relatan con estas palabras: 


\footnotetext{
"Mi padre siempre ha querido que me supere, él decía que si el día de mañana podría encontrar un trabajo en vez de estar en la calle, que mejor." (Elena, Madrid, 26 años).

"Y tenía una referencia y apoyo para continuar estudiando de mis padres, que creo que es lo más importante... (...) Al contrario, mi padre dice que hasta que no termine mi carrera que no me case." (César, Castilla León, 21 años).

"Mis padres me apoyan en todo lo que pueden y... mi hermano ya no estudia, con lo cual es más fácil poderme ayudar a mí... en todos los progresos que yo doy, porque es verdad que siempre dicen: 'Que no es para nosotros, que es por ti, que es por tu bien, que es para tu futuro, que nos gustaría verte... que yo ya soy mayor y nos gustaría verte... porque sabemos lo que vales y lo que puedes hacer en este mundo, siendo que es algo que tienes muy en mente, y sacarlo adelante'." (Pilar, Aragón, 21 años).
}

Por otra parte, está claro que el hecho de disfrutar de una posición económica mínimamente estable y desahogada es necesario para hacer frente a las exigencias vitales y escolares, sin la presión para abandonar los estudios con el fin de contribuir al sustento familiar. Muchas de las personas entrevistadas señalan que su familia no pasaba necesidades, pero tampoco disponía de grandes ingresos económicos y confieren mucha importancia en su continuidad escolar al hecho de haber vivido en una situación socioeconómica no marginal. Ahora bien, es imprescindible no confundir las dinámicas relacionales y estructurales de la marginalidad con las de la precariedad socioeconómica, ya que también hemos observado casos en los que con una precariedad importante (por ejemplo: madre sola, ruptura familiar total con la familia extensa, trabajo de asistenta, tres hijos a su cargo; o bien, grupo de hermanos en situación de acogida en centros del estado), otros factores han tenido más peso y han potenciado la continuidad. Aunque, sin duda, esta es una proporción reducida de la realidad.

Del mismo modo, las posiciones socioeconómicas acomodadas -aunque favorecen en mucha mayor medida una mayor continuidad académica- no garantizan ni éxito, ni apoyo, ni la emergencia de una opción personal por trayectorias de larga duración. Algunas personas entrevistadas aducen que lo más decisivo para ellas fueron las expectativas de la familia y del profesorado, y que la economía fue algo secundario, dadas unas mínimas condiciones de posibilidad.

Así pues, en buena parte de los casos, los ingresos de la familia no son en sí mismos el factor más decisivo para la continuidad escolar, al menos dentro de las etapas obligatorias. La mayor parte de las personas que continúan estudiando estando su familia en situación de pobreza corresponden a mujeres. Mujeres y chicas jóvenes que, como expresan claramente en las entrevistas, son conscientes del cambio de situación que les supone el hecho de estudiar (volveremos sobre este punto varias veces más adelante).

El paso a los estudios postobligatorios y superiores constituye el punto clave en el que sí parece ser más determinante la situación económica familiar: en la inmensa mayoría de los casos, la joven o el joven estudiante sí necesita que su economía familiar 
esté resuelta, y la situación económica familiar puede llevarle al abandono de los estudios, a la elección de estudios de ciclo corto, a decantarse sólo por cursar estudios existentes en su localidad o a realizar estudios a distancia.

Por otra parte, el vivir en una vivienda adecuada (lo que llamaríamos una vivienda digna desde el punto de vista convencional) sin duda constituye un factor facilitador de la implicación en el estudio, unido a otros factores, y así lo habíamos recogido en nuestras hipótesis. Sin embargo, ninguna de las personas entrevistadas ha señalado como determinante el tener habitación de estudio, no disponiendo la mayoría de ellas de la misma, aunque algunas no dejan de reconocer que hubiera estado bien.

Resumiendo y con relación a estos tres factores (trabajo integrado, situación económica estable, vivienda digna) hemos podido construir tres perfiles:

En primer lugar, familias que ocupan o bien ocupaban una posición socio-económica desahogada: Viven en barrios no segregados, con ingresos económicos elevados, piso de propiedad bien acondicionado, posibilidad de acceder a centros privados y concertados, acceso a libros y material escolar. En todos los testimonios consta que trabaja el padre (en este primer grupo de familias, también la madre de forma estable u ocasional, pero subsidiaria) como autónomo con gente a su cargo, con negocio propio o bien dentro del círculo laboral mayoritario o bien a través de nichos ocupacionales "gitanos" que representan ingresos elevados (trato de ganado, venta de antigüedades, etc.), o bien en el funcionariado, manteniendo relaciones con población no-gitana y disponiendo de una economía estable. Los/as hijos/as u otros familiares no precisan trabajar para ayudar a la economía doméstica, aunque en ocasiones algunos hijos o hijas deciden por cuenta propia realizar tareas de carácter temporal sin presión debido a condicionantes económicos. Esta es la menos visible y conocida de las situaciones por parte de la sociedad mayoritaria y de la mayoría del profesorado. Y se da en todas las Comunidades Autónomas.

"También, eh, hombre, aquí hay que tener en cuenta a mis padres, ¿no?, ellos son profesores de Universidad." (Carlos, Madrid, 30 años).

"La economía [de mi familia], pues, francamente bien, y claro me ayudó a seguir estudiando." (Armando, Castilla-León, 49 años).

"... mi padre estuvo trabajando 27 años si mal no recuerdo en [un organismo internacional]... La situación económica era buena, el piso era de propiedad, estaba amueblado a todo lujo, después nos marchamos a un piso mayor, un piso nuevo, que fue cuando nos juntamos con el resto de los gitanos que vivían allí en el barrio totalmente nuevo a estrenar por nosotros, la situación seguía siendo más o menos buena, los sueldos se equipararon los españoles con los americanos y ya no era lo mismo, ya no era esa barbaridad de dinero, pero seguía siendo una economía bastante saneada." (Oscar, Aragón, 27 años).

"Pero es que mis padres tienen tres pisos. Entonces, con el alquiler de los pisos... pues íbamos... Y con las ayudas y eso, pues íbamos bastante bien." (Ana, Navarra, 19 años). 


\begin{abstract}
"A ver, no trabajaba, afortunadamente no tenía necesidad de trabajar... mi padre era el único que trabajaba en casa, yo empecé a trabajar muy tarde, o sea con veintipico años. Había trabajado alguna vez con cositas cortas, de tres meses o aquí, y tal, pero trabajar así en serio pues empecé a trabajar pues con 23 años y mi hermano más o menos igual, por gusto, ¿sabes? No por necesidad, ¿no? Y de hecho, mi madre no ha trabajado nunca, o sea que era mi padre el que trabajaba. No vivíamos como reyes, evidentemente, pero como cualquier familia media." (Lola, Cataluña, 32 años).
\end{abstract}

En segundo lugar, familias que ocupan u ocupaban una posición socio-económica intermedia76: Viven en barrios obreros con ingresos económicos que les permiten la subsistencia básica del grupo familiar aunque con ciertas dificultades. Solicitan en ocasiones recursos no segregados (como becas de comedor, libros, transporte o becas de régimen general en el caso de acceder a la Universidad). Disponen de una red de reciprocidad en la familia extensa, ocupan las mismas áreas de residencia pero se da una diversificación ocupacional que se puede resumir en dos situaciones tipo:

a) En la primera, un perfil en el que el padre trabaja y la madre interviene de forma temporal o combinada en las mismas actividades laborales. Los nichos ocupacionales más habituales son la venta ambulante y otros negocios tradicionalmente llevados por grupos de adscripción étnica gitana. Los y las estudiantes pueden tener una vinculación con trabajos de tipo temporal y vinculados a la familia extensa (trabajan conjuntamente tíos, primos u otros familiares...). Hay fuertes vínculos familiares que ayudan a cualquiera de sus miembros en caso de encontrarse en situación de riesgo, a modo de reciprocidad económica, desplegando sus redes ante la búsqueda de empleo u ofreciendo otro tipo de recursos asistenciales en el interior de la familia.

B) En la segunda, un perfil en el que el padre sufre desocupación temporal y la posición socio-económica se va degradando, aunque son situaciones de carácter ocasional de las que suelen recuperarse. Es habitual que el hijo o la hija "ayuden" a la economía familiar mediante trabajos a tiempo parcial o de temporada (canguros, clases particulares...) de fines de semana, o empleos de verano; esto sirve para subsanar los gastos derivados de la escolarización y no es, en todo caso, una carga que dificulte la asistencia al centro escolar o promueva el abandono de las tareas o deberes. Esta situación es o ha sido la más habitual entre los gitanos y las gitanas que hemos entrevistado.

\footnotetext{
"Nunca hemos tenido un trabajo que se puede decir fijo o continuo, nunca ha habido estabilidad laboral, han sido siempre autónomos, siempre autónomos, dedicándose a la venta, pues si salía y podía hacer antigüedades o algo así, él lo hacía... Normal. La verdad es que lo hemos pasao día a día; mucho pa comer y pa pagar los pagos tampoco, pero como cualquier familia que pueda tener ... que viva de un sueldo, pues más o menos igual. Desahogaos, desahogaos, nunca; hemos ido siempre justos, pa poder vivir, pa pagar los pagos de la casa y todo y comer, siempre hemos
}

\footnotetext{
76 En este contexto "intermedio" significaría integrado y estable pero con características de clase media-baja o de clase obrera.
} 
ido más o menos justos... Como somos muchos en la familia, tenemos muchos gastos, el mundo gitano es algo que no tiene proyectos ni nada."(Manuel, Aragón, 21 años).

"Siempre hemos sido una familia humilde, por lo tanto muchos gastos económicos, de los distintos colegios que he estudiao, han sido privados, pues que había algún problemilla para pagarlos pero siempre se ha subsanao bien." (Miguel, Aragón, 18 años).

"Bueno, sí, una temporada que mi padre no encontraba trabajo, pero ya hace de eso. Sí, y lo normal, no tienes pues vamos y le pedimos a mi tío y después cuando teníamos dinero, se lo pagábamos, sí, sí. Bueno, ay, nosotros no somos de los que... ¡Ay, no sé explicarlo! ¡Sí! Que nunca nos ha faltao na." (Jordi, Cataluña, 15 años).

\footnotetext{
"No, es que yo hasta los veintiún años hice algún trabajo esporádico; trabajé en correos un tiempo, poco eh, trabajé en una plaza cargando y descargando pescado en Mercabarna y todo esto; esto mientras hacía Magisterio, pero antes no, antes mi padre decía para que pudiera dedicarme plenamente a los estudios. Decía que con lo que ganaba había suficiente dinero en casa para que yo me dedicara a los estudios." (Ramón, Cataluña, 44 años).

"Nunca ha faltado, que digas tú, para comer nunca ha faltado, porque mi padre antes era albañil. Mi padre ha trabajado siempre, toda su vida trabajando, hasta que se echó a la venta. Pero siempre. Mi padre y mi madre son muy trabajadores." (Arantxa, 32 años, Navarra).
}

En tercer lugar, familias que ocupaban u ocupan una posición socio-económica precaria: Las personas en esta situación disponen de redes familiares y comunitarias más débiles económicamente. Se distinguen en esta posición dos perfiles:

a) Por una parte, las de aquellos grupos domésticos con una dependencia de prestaciones sociales casi completa y las de aquellos que ocupan trabajos muy precarios con o sin acompañamiento de prestaciones sociales. En este último caso se incluyen algunos trabajos estables con nula cualificación (por ejemplo, limpieza de casas particulares dentro del sector informal) y algunos trabajos tradicionales de tipo temporal (por ejemplo, temporeros agrícolas). Es imprescindible aclarar, sin embargo, que pese a encontrarse ambos sub-perfiles en los límites de la marginación socioeconómica, ninguno de nuestros informantes con éxito académico procede de situaciones familiares todavía más extremas de exclusión vinculadas a una mayor precariedad económica (por ejemplo, mendicidad, tráfico/consumo de drogas, familiares directos encarcelados).

b) Por otra parte, aunque no es mayoritario, existe un número nada desdeñable de personas entre nuestros informantes con éxito escolar que se encontraron en algún momento o se encuentran actualmente en una situación socio-económica bastante o muy precaria. Especialmente, debida a la existencia de enfermedades crónicas de los progenitores que no les permitían trabajar y que precisaban de una atención sanitaria específica. En otro tipo de situaciones, la madre o el padre había muerto y eran otros familiares los que se hicieron cargo de ellos y ellas. Algunas familias vivían o viven sólo con algún tipo de ayudas por incapacidad percibidas por el progenitor enfermo. Algunos carecían o carecen de empleo y recurren a los recursos 
asistenciales de su localidad, que les permite obtener ayudas de los gobiernos locales o participar en programas de inserción municipales, etc. Estas situaciones se pueden combinar con períodos esporádicos dedicados a la chatarra, venta ambulante o trabajo agrícola temporal con o sin itinerancia. Algunos han vivido o viven en barrios segregados y en viviendas muy precarias.

En todas estas situaciones se ha contado y se cuenta con los hijos e hijas para la subsistencia familiar. Esta responsabilización sí constituye un obstáculo para la continuidad académica y para el desempeño de las tareas ordinarias de la escolaridad obligatoria, aunque se distingan presiones distintas en contenido e intensidad según el género (responsabilidades domésticas y cuidado de familiares para la chica, participación directa en tareas de subsistencia extrafamiliares, el chico y también la chica).

\footnotetext{
"Y me acuerdo que teníamos una casa que, ¡buff!, se caía. 0 sea se caía y, ¡buff!, un baño, que bueno, lo tuvimos que hacer, porque, claro, cuando empezamos a ser mayores ya no nos queríamos bañar en bañeras de plástico. La situación económica era mala. (...) Lo saqué con bastante buenas notas [el último curso de Administrativo]. Pero no, no me apetecía... En verano fui a las manzanas a trabajar como todos los años al campo y después me llamaron a la fábrica a seleccionar manzana y allí estuve, pues, autónoma estuve pues dos o tres años." (Sara, Navarra, 36 años).

"... mi padre luchó con su sueldo y trabajaba sábados y domingos. (...) Lo normal era que tengas agua, pues eso faltaba. Faltaba en mi casa eso; mis amigos tenían televisión y yo tenía que ir al bar a verla de pequeño. (...) Éramos muchos hermanos, que sólo entraba el sueldo de mi padre. (...) Yo iba al colegio y no tenía los libros y me tenía que esperar que me los pagase el ayuntamiento y... lo tenía así. Mi padre era pobre..." (Pedro, Cataluña, 42 años).

"Me acuerdo que me ponía a la cadera, la pobre, y siempre he estado de mano en mano, la vecina, la otra... y muy sola... En mi barrio otro chico que iba dos cursos más, su madre me guardaba los libros. Nunca he llevado libros nuevos, siempre borrados. Eso sí, mi madre siempre me borraba los libros y mi hermana A. Y muy mal, porque a veces tardaban... Yo creo que la única dificultad que tengo ahora es la económica. Por cuestión de comprensión y apoyo de los profesores, creo que tengo más que los compañeros de mi clase, mucho más. Están más sensibilizados, pero el económico es más chungo. El simple hecho de no tener ordenador me para. 0, por ejemplo, mis amigas universitarias simplemente tienen que estudiar y ya está, y yo tengo además que trabajar." (Laura, Castilla-León, 25 años).
}

En múltiples ocasiones existe una presión persistente hacia la chica o el chico para que abandone los estudios por la necesidad de su mano de obra y su implicación activa en la supervivencia familiar. Se producen tres tipos de trayectoria. En algunos casos persiste la continuidad escolar aunque coexiste con alguna actividad laboral sistemática y un evidente sobreesfuerzo de la persona por seguir sus estudios. En otros casos, se produce un abandono temporal, durante algún curso académico, y luego se retoman los estudios, aunque con retraso respecto al grupo de iguales en la consecución de los cursos académicos. Finalmente, se dan casos de abandono total de la escolarización en los que la continuidad escolar se reinicia tras la recuperación relativa de la situación 
socio-económica familiar o bien porque la persona se ha emancipado de su familia y quiere proseguir sus estudios, ya en la edad adulta y en otra situación económica.

Los siguientes testimonios ilustran perfectamente este tipo de trayectorias:

"Muchos meses y semanas no nos llegaba para comer. Yo veía allí que a costa mía se gastaban cosiIlas necesarias para la casa, porque es así. Y yo estaba ya cansao; el interés de los estudios se me quitó por eso, porque era un esfuerzo grande. Y la verdad es que me costaba mucho. Era un gran sacrificio. Perdí gusto a todo, perdí gusto a los estudios y estaba solo, no tenía medios... Estaba muy cansado de los estudios, estaba muy cansao, muy cansao, muy cansao. Yo no podía más, de verdad. Estaba muy, muy asqueao, muy harto, y es que otros tres años más, me hubiera sido imposible soportar en aqueIlas condiciones. Es que me era muy difícil estar allí más tiempo, y ya te digo que no era por el trato de... no lo digo por el trato de los compañeros, ni mucho menos por los profesores... No podía más. Me superaba ya, me superaba ya aquello... Y me fui a casa. (...) Si es que donde me ponía con un libro estorbaba, porque era una casa tan pequeña que en la cocina no cabíamos ni tres, y no había más que eso: la cocina y dos habitaciones. No podía ponerme en ningún sitio. (...) Te pusieras donde te pusieras, el estudiar era molestar a los demás. Así que me quedaba en la cocina cuando los demás se habían ido a dormir, y allí acababa por cabecear y quedarme dormido. ¡Cuántas veces mi padre se levantaba y me decía que me fuera a la cama, que estaba dormido!" (Armando, Castilla-León, 49 años).

"Mi padre trabajaba mucho entonces en las obras y luego también se dedicaron a lo típico, a la venta ambulante. El día que venden bastantes pantalones pues bueno, el día que no venden la cosa va más floja. Un círculo de economía sumergida como la mayoría de familias gitanas. (...) La verdad, viviendo, como he dicho, con unas condiciones pésimas. 0 sea, la educación, por supuesto, descartadísima porque el objetivo era poder comer y eso ya era un logro si, si conseguías comer un par de veces al día. La situación económica era tan precaria, a mí ya me preocupaba, ya tenía 13 años, decidí ir a trabajar." (Álvaro, Cataluña, 46 años).

Una entrevistada nos manifiesta que su condición de mujer condicionaba la continuidad de sus estudios básicos, dado que su familia -hermana y cuñado- no le permitía desarrollar una actividad académica, para que apoyara con su trabajo la economía familiar. Ella lo retomó más tarde:

"Hice la E.G.B., pero $8^{\circ}$ no lo pude terminar porque, bueno, porque el marido de mi hermana no me dejó terminar, y mientras sacaba el Graduado estuve trabajando a la vez... Era el marido de mi hermana, el que no quería [que estudiara], pa que trabajara con ellos..." (Eva, Aragón, 31 años).

En las trayectorias de otros y otras informantes más jóvenes se va apreciando la incidencia de un factor que compensa relativamente estas presiones en algunas circunstancias, como es el apoyo económico a través de becas y otros recursos económicos ${ }^{77}$

77 En este mismo sentido, llama la atención el que haya varios gitanos y gitanas ciegos con éxito escolar: estimamos que el factor desencadenante que ha activado los demás factores positivos y la propia implicación del alumno/a ha sido el apoyo extra-escolar propiciado por la ONCE y la coordinación entre sus profesores/as y los/as de los centros escolares, a pesar de la acumulación de factores adversos en los casos estudiados. Así, del mismo modo, diversas iniciativas que organizan este tipo de apoyos en barrios y comunidades pueden favorecer un salto cuantitativo en el número de chicos y chicas gitanos que prosigan por la vía académica en los próximos años. 
y/o asistenciales (FSGG u otras asociaciones pro-gitanas, Cáritas u otras asociaciones de carácter asistencialista; recursos prestados por la propia institución escolar, especialmente aquellas de titularidad concertada religiosa; las becas de la administración local -libros, transporte, comedor-, y finalmente las becas de régimen general del Estado).

"Para los estudios universitarios, sí, solicité beca y siempre se me ha concedido; sí que agradezco que se me haya apoyado económicamente y ello, pues ha facilitado las cosas a mi familia, porque el coste de una carrera universitaria y en un colegio, es muy caro". (María, Aragón, 26 años).

Sin duda, la incidencia sería mayor si las dotaciones fueran realmente substanciales, pero también si los derechos y los circuitos de acceso a los recursos se conocieran mejor.

"... El problema que yo creo que tienen muchos gitanos es que no acceden a los recursos de nada. Una de las cosas que yo siempre digo es que hagan uso de los recursos que hay, porque muchas veces, por ejemplo, con el programa de becas del Secretariado, me dicen: 'Pero hijo, ¿tú te crees que con quince mil pesetas yo puedo... con veinte mil pesetas yo puedo pagar los libros a mi niño? ¡No puedo!', y digo: 'Claro, pero señora, si es que, mire usted, antes de... echar esta beca, usted tiene que ir a la del Ministerio, usted tiene que ir al instituto, y... cuando vaya a apuntar al niño cada año, pídale los papeles de la beca, es que son más, y es más, si vosotros que estáis vendiendo y eso y no tenéis ingresos [digo] pues... eso te dan incluso más todavía, y después le echáis ésta, que ésta, si la pierde, son quince o veinte mil pesetas, pero lo otro son cien o doscientas mil pesetas, ¿no?'Y yo siempre es una de las cosas que siempre hago, ¿no? Es que, es que están para eso, quiero decir, y de los impuestos justamente... que todos pagamos, también tienen derecho a recibir sus ayudas, ¿no?" (Javier, Madrid, 23 años).

De la misma manera, si bien por una parte deben existir plazas suficientes y asequibles de primer ciclo de Educación Infantil (porque la existencia de Guarderías públicas debería hacer más improbable que las chicas a partir de una edad tengan que dejar de estudiar para cuidar a sus hermanos y hermanas menores), constatamos que sólo en algunas posiciones socio-económicas integradas el dejar a las hermanas mayores cuidando de los hermanos menores se considera realmente inapropiado. Es decir, debemos tener en cuenta ambas cosas, la existencia del recurso y el uso del mismo, según el predominio de unas determinadas atribuciones de género. Ya se señalaba hace 14 años (San Román, 1990) que las Guarderías suponían la liberación de las hermanas mayores, aunque se ponía de manifiesto la reserva ante el hecho de tener que dejar a sus hijos en manos de "los payos". El cambio es que actualmente parece que entre algunos sectores gitanos y en algunas realidades locales con oferta de plazas a su alcance, la experiencia de la Escuela Infantil 0-3 forma parte de lo habitual. Lo que realmente es un indicador de cambio es que entre las mujeres y las chicas con continuidad educativa entrevistadas se considera inapropiado supeditarla al cuidado de los hermanos y hermanas pequeñas. 


\subsubsection{Contexto relacional}

Un factor decisivo para el logro del éxito y la continuidad escolar es una valoración compartida por el grupo de iguales de la vía académica; es decir, las y los vecinoscompañeros-amigos continuaban estudiando, sus familias tenían expectativas de que estudiaran Enseñanza Secundaria y/o Universitaria, y estos alumnos y alumnas gitanos/as y sus propias familias consideraban que debían hacer lo mismo.

En los gitanos y gitanas con experiencias de éxito académico ha existido un vínculo positivo con los y las compañeras de su clase, por lo menos, a nivel académico y de expectativas de continuidad. La inmensa mayoría de las gitanas y los gitanos entrevistados recuerdan y relatan buenas relaciones y amistades con sus compañeros y compañeras no gitanas, y subrayan este hecho como determinante en su perfecta adaptación a los centros educativos. A su vez, tener éxito académico, poseer habilidades comunicativas y compartir actividades no académicas (deporte, música, etc.) ha sido destacado espontáneamente por las personas entrevistadas como aspectos clave de su experiencia en el establecimiento de relaciones interétnicas en los centros educativos. Incluso en las situaciones altamente divergentes de la mayoría de chicas gitanas frente a la autonomía y movilidad de sus compañeras no gitanas, que puede reducir considerablemente el disfrute de esas actividades no escolares, esto se ha resaltado repetidamente como algo básico.

En muchas de las personas entrevistadas se observa una doble socialización, siendo relatada en sus términos como una experiencia insustituible: por una parte, sus relaciones familiares y comunitarias y, por otra parte, con su vecindario y amistades del barrio y del colegio, de entorno mayoritariamente no gitano. Las situaciones oscilan entre:

a)Tener poco trato o sólo un trato esporádico con otros/as gitanos/as de su edad (la familia y la persona no tienen su núcleo principal de relación dentro de un entorno social gitano; como ocurre en ocasiones con descendientes de algunos matrimonios mixtos). Es decir, existe una mayor tendencia a la asimilación que al mantenimiento de elementos y vínculos multiculturales.

b)Compaginar un grupo de amigos/as no gitanos/as y otro grupo de amigos/as gitanos/as. Con el primer grupo es aceptado con absoluta normalidad y con el segundo grupo ha logrado un estatus que compagina aprecio como persona y como familiar y admiración como estudiante (no exenta, en ocasiones, de alguna broma sobre su posible "apayamiento"), obtenida tanto por cumplir con las obligaciones esperadas desde el entorno del parentesco y la comunidad como por sus habilidades añadidas. Las personas entrevistadas, hombres y mujeres, que se situarían en este grupo muestran altas habilidades sociales.

Hay aquí múltiples experiencias de relación con el grupo de iguales, por la variedad en las experiencias personales y por la situación en el ciclo vital en el momento de hablar de este tema. Los siguientes testimonios son suficientemente claros y contundentes: 
"Ellas [las gitanas de su pueblo] tienen una mentalidad como de correr, de correr, de correr, y yo no. Y ahora llegas a estar con ellas y pa' mí son unas abuelas. Yo soy, yo soy la rara, la rara, la paya, la... la descarriada. La que ha llevao su vida.... ¿Cómo me veo? A ver, pues yo me veo como... la extraña del grupo. Ni estoy en uno ni estoy en otro. Estoy entre Pinto y Valdemoro. Yo acepto todo lo que diga la comunidad gitana, todo lo que yo pueda meterme, porque tampoco me meto mucho. (...) Se arreglaban, se maquillaban, se pintaban y estaban como mentalizadas pa' casarse y tener niños, y yo no. Yo no me sentía ni madre, ni mujer, ni nada de eso. Yo me sentía como ellas, como mis amigas, o sea pues, yo qué sé, a salir, a beber, a dar una vuelta... pero yo no me sentía madre en aquel momento, ni mujer, ni me arreglaba para que me vieran. Es que no me arreglaba. Es que me negaba... (...) Pues no he tenido mucha relación con los gitanos, la verdad. Pues porque, a ver, yo ya te he dicho que estudiaba. Yo siempre he tenido un grupo de amigas, y con las chicas gitanas con las que iba yo no me encontraba a gusto. Ellas iban en otro ambiente y a mí ese ambiente no me gustaba. Entonces, yo nunca, nunca he tenido amigas gitanas. A mí me llamaban la paya, claro." (Sara, Navarra, 36 años).

"Y siempre estaba con payos... Luego fui al IES... porque me parecía lo más normal ..... Como todos los de mi clase y mis amigos con los que me relacionaba seguían en el instituto, pues yo ni me lo planteé: yo tenía que ir al instituto, porque era lo que hacían todos con los que yo me relacionaba." (Richi, Castilla-León, 24 años).

"... vivíamos en un ámbito fuera del contexto gitano puro, donde nuestra vecindad, nuestros amigos, y donde nuestros compañeros de colegio eran prácticamente todos payos, y eso pues influía en que viéramos de forma normal el ir al colegio, el tener que hacer los deberes, el estudiar y porque el resto de los niños lo hacía, no había comparación con otros niños." (Oscar, Aragón, 27 años).

"Yo mi relación con los gitanos es muy familiar y laboral, aparte de esto, mis amistades no son gitanas. También porque mis amistades suelen ser las de mi compañero. Mis amigas siguen siendo las mismas que las del colegio y no son gitanas y en cambio mi hermano tiene amistades gitanas como no gitanas, se relaciona más con gitanos." (Alba, Cataluña, 24 años).

Los dos contextos - gitano, fuera del ámbito escolar, y no gitano, en el medio escolarenvían a cada joven mensajes muy distintos sobre el valor de la vía académica, produciendo fuertes contradicciones internas en la persona, que pueden desembocar en ocasiones en el intento de abandono o en el abandono temporal de los estudios. Sin embargo, no respondería a la realidad asociar de forma automática la continuidad educativa con el entorno no gitano, en algunos barrios y sectores en especial:

"Bueno, has de tener en cuenta una cosa, que yo también fui a un colegio, ¿eh?... que la mayoría de la gente cuando acabó el cole, entonces empezaban a trabajar, ni gitanos ni no gitanos; me parece de los que acabamos octavo de EGB, podría ser que fuéramos tres o cuatro de la clase que continuamos estudiando. Quiero decir, que, claro, era un cole que lo normal no era continuar tampoco. Y había mucha gente, que esto, se integró en la vida laboral." (Verónica, Cataluña, 35 años). 
Aunque predomina entre los y las informantes la elección basada en una influencia mayor del grupo de iguales del entorno escolar que sí muestra continuidad educativa, lo que les impulsa a proseguir sus estudios y a resistir las presiones del grupo de iguales sin orientación escolar:

"Cuando empecé a estudiar yo decía: es que tengo deberes, y me decían: 'Es que siempre tienes deberes, ¿no.' Y no lo acababan de entender que pudiese estar en casa encerrada cuando todo el mundo iba a dar vueltas y a jugar. Y eso sí que cuesta, al principio cuesta... la influencia de la gente cuesta mucho, porque no es que te machacan para que estudies; al revés. Ahora sí, porque se dan cuenta que es superimportante y que es necesario. Pero antes era como: es que estás estudiando mucho y dejas de lado a los demás. Te estás apayando, ¿vale? Lo que decían era esto... Al principio era como que eres el bicho también porque a mí me gustaba mucho estudiar y eso, siempre estaba en casa y no bajaba nunca, y se quejaban de eso, de que no bajaba, de que siempre me encerraba (...) La mayoría de amigos míos de toda la vida, pues no son gitanos". (Lola, Cataluña, 32 años).

"Eran poco valorados [los estudios], no les daban importancia, tampoco lo veían en su casa, entonces solamente hacían lo que era los estudios obligatorios y ya se veían que tenían mejor futuro, bien vendiendo o dedicándose... pues, eso, para ir vendiendo o metiéndose en el mundo laboral de peones, aprendices, eso era lo mejor, el mejor futuro que tenían ellos, aparte también porque la mayoría de ellos tenían fracaso escolar, unas notas muy malas y no veían que mediante el estudio pudieran llegar a nada... Según quién, lo veían una pérdida de tiempo: porque así no se llega a nada, pierdes años de tu vida estudiando, pero que luego no sirve para nada... Unos decían eso, pero otros vamos, creo yo, lo veían muy bien, porque así un día llegarás a algo, podrían tener una graduación superior y podrás tener un nivel de vida mejor... Mis amigos ninguno han seguido estudios, todos se han salido del colegio en la edad obligatoria; pero tengo familia mía y a mi padre, que sí que han seguido formándose y estudiando." (Manuel, Aragón, 21 años).

"Mis amigas del barrio prácticamente ninguna seguía estudiando, sin embargo sí que valoraban que si valías para estudiar pues que continuases... Sin embargo, mis amigas de clase, sí que valoraban el continuar estudiando y tenían sus planes de futuro, yo sí que me sentía muy identificada con ellas." (Julia, Aragón, 36 años).

"Mis amigos gitanos, ya sabes que se casan muy pronto, muy pronto empiezan su vida laboral y que tal y que cual. Y entonces estar estudiando a mis edades, pues ellos, es una cosa que, aparte de no compartir, siempre me han inculcado el de no hacerlo. Es decir, que si tú tienes un amigo y tú piensas que está mal, pues le intentarás inculcar que no lo haga. Pues ellos siempre me han inculcado eso. Que dejase de estudiar. Que lo dejara y que ganara dinero como ellos ganan. Pero, claro, ello lógicamente es porque tienen una venda y no ven más allá. Solamente ven el corto plazo: el ganar dinero hoy; y no ven la inversión de los estudios, que es una inversión hoy del futuro... Pero, claro, yo siempre me he rodeado pues con gente universitaria, mi pensamiento siempre ha coincidido con mis compañeros de clase." (Luis, Castilla-León, 22 años).

Así, la persona que decide proseguir los estudios ve impotente cómo sus iguales gitanos/as van abandonando la escolaridad, produciéndose en múltiples casos una sensación de soledad palpable y de incomprensión por parte de su grupo de iguales gitano. 
Experimenta un distanciamiento progresivo a medida que la persona va superando los distintos niveles académicos y se va alejando de las prácticas culturales que en un principio y por tradición le son designadas en el cumplimiento de las etapas del ciclo vital, tales como la "pedida", el casamiento o el tener hijos/as a edades tempranas:

"Sí, aunque sigas estudiando bien se sorprenden, porque, quieras o no, mientras progresas de curso también te haces más mayor y [... ] ya no haces lo normal en la comunidad gitana." (Pilar, Aragón, 21 años).

"Claro, tú te veías que estabas estudiando y el resto de las chicas gitanas de tu barrio no lo hacían. (...) Yo por mi parte bien, por ellas muy mal, porque así... en conversaciones o en la calle o en cosas, cosas normales que cualquier persona las sabe, si las preguntabas a ellas y decían: ¿Qué es eso?, ¿Y eso pa qué sirve, y por qué estudias, y es que tú no te piensas casar... ?'; yo les decía: 'Sí, pero que tendré mi trabajo y que el saber no te quita...'; y ellas decían que con la edad que tenían que cómo iban a estar yendo al colegio, que las daba vergüenza y que tal..." (Elena, Madrid, 26 años).

El grupo de iguales puede ver la continuidad académica como ajena a las prácticas de las comunidades gitanas, en términos de competencia y rivalidad. No se trataría tanto de que sus iguales perciban la adquisición de habilidades culturales incompatibles (o de la substitución de unas por otras) por parte de la persona que estudia, pero sí del hecho de que ésta establezca nuevos vínculos y fidelidades como miembro del grupo mayoritario ${ }^{78}$ :

"A mí, también lo que me ha puesto en duda eso de seguir o dejar de estudiar han sido mis amigos, porque yo salgo con unos veinte o veinticinco amigos que todos ya con 14 ó 15 años se iban quitando del colegio. Que si unos hacían unos cursillos de Fontanería, otros de Soldador... Y no han estudiado. No tengo ningún amigo 'estudiaó'. Todos han sido de cursillos de eso. Eso también es otro motivo de los que me ha perjudicado el estudio, pero yo he cogido y he seguido estudiando... Y otro de los motivos también es, yo qué sé, que bastantes veces me rodeo con gente gitana, mis primos, familiares, conocidos, que son gitanos, y muchos de ellos no tienen el nivel académico que tengo yo. $Y$ te vienen y te dicen: '¿Por qué estas estudiando?'. Y le dices 'Porque me gusta'. Y te tratan de payo. Y eso también es muy duro, llevarlo encima contigo. Y vas a otro y: - ¿Qué haces?. -Estudiar. - Pues déjalo ya, que te estás pareciendo a un payo, que te estás apayando. Todo eso lo tienes que llevar encima. Pero pasa el tiempo, y pasa el tiempo, y lo tienes que asumir, y que eso no puede ser así, que tú no vas a ser otro como ellos. ¿A qué? A dedicarte al cartón, a la chatarra, a los palees... Todo eso se va a perder. Va a haber un tiempo, que no vas a obtener nada de eso. También eso es muy duro para Ilevarlo contigo mismo: que tu propia familia, de tu misma etnia, o lo que sea, que te desapoyen de ahí. Y todo eso lo tienes que asumir... Pues yo en mi caso, que yo salgo con veinticinco, treinta payos en una cuadrilla, sólo hay tres o cuatro gitanos. $Y$ en el caso de mis primos, nunca los verás con un payo, siempre están entre ellos juntos. $Y$ te hacen a eso pensar, que tienes ya diferentes costumbres que ellos, que estás pensando ya pues igual que ellos. Y eso es muy difícil ... que te digan... Ilevarlo encima es muy difícil, que vayas un día, y que te digan: 'Vaya payo que estás hecho'. (Eugenio, Navarra, 18 años).

\footnotetext{
78 En términos de Spindler, se trataría de elementos de reclutamiento más que de elementos de mantenimiento percibidos en colisión. Este tema se retomará en el punto 3.
} 
Algunas de las personas entrevistadas señalan que su condición única en un centro educativo les ha podido perjudicar por la soledad en la que han vivido su experiencia, como hemos visto, pero les ha beneficiado por evitar un posible etiquetaje colectivo79, adoptando -en ocasiones- a priori, una estrategia de invisibilidad étnica.

No hemos podido identificar experiencias en que todo el grupo de iguales gitano comparta una valoración positiva de la vía académica y prosigan sus estudios, salvo pequeños grupos embrionarios en torno a centros cívicos o centros juveniles de estudio y de actividades de tiempo libre 0 en alguna Asociación de Mujeres Gitanas ${ }^{80}$. En ningún caso, hay que resaltarlo, como grupos de formación espontánea. La mayoría de experiencias remite a la excepcionalidad en su entorno, aunque se trate de experiencias diversas. Así, la mayor parte de los gitanos y gitanas entrevistadas no han tenido referentes de otros gitanos o gitanas con estudios, pero sienten que ellos y ellas sí pueden ser referentes para otros y otras más jóvenes, como motivación para éstos/as y sus familias pero también cómo presión para ellos y ellas. En otro sentido, sí se mencionan personas como referentes que en momentos clave de toma de decisión les han orientado, sea por su posición como profesor/a, o bien porque han pasado por una experiencia académica de escolarización post-obligatoria, sean éstos gitanos o no; y por último, personas, habitualmente dentro de la familia y/o su entorno inmediato que han pasado por una experiencia escolar obligatoria viendo cómo por causas de diversa índole (económica, decisión familiar, obligaciones dentro de la comunidad -especialmente entre las chicas gitanas-) vieron truncadas sus expectativas de proseguir sus estudios. Éstas últimas representan un contra-modelo, o contra-referente, y mediante sus consejos 0 relato de sus experiencias animan a la estudiante 0 al estudiante a seguir estudios post-obligatorios. Finalmente, encontramos referentes dentro del grupo de iguales, compañeras/os de clase, sean éstos gitanos o no-gitanos, en definitiva el grupo de referencia que conforma la vida relacional de la persona: hay una explicitación de las expectativas futuras, especialmente en los momentos de toma de decisiones (elección de un itinerario curricular determinado, decisión de seguir estudios post-obligatorios dentro o fuera de la escuela, profesionalización y aprendizaje de un oficio, etc...) y una influencia directa de las compañeras y de los compañeros.

Así pues, una parte muy importante de nuestros/as informantes son personas que se han sentido vinculadas con un grupo de iguales no-gitano que valoraba la vía académica; es decir, sus vecinos/as -compañeros/as- amigos/as continuaban estudiando y sus familias tenían expectativas de que estudiaran Enseñanza Secundaria y/o Universitaria, y estas alumnas y alumnos gitanos y sus propias familias han considerado que ellos/as debían hacer lo mismo. En algunos de estos casos, incluso ha existido un vínculo de unión, afecto y cooperación con los compañeros y compañeras de su clase, aunque tal experiencia no es extensible a la mayoría de entrevistados/as.

\footnotetext{
79 Nos referimos al proceso conocido como labelling, especialmente destructivo en la experiencia escolar del pueblo gitano.

80 Otra cosa muy distinta son iniciativas como la de la Fundación Pere Closa en Cataluña, en la que se han reunido gitanos y gitanas titulados/as con el objetivo de servir de referente y estímulo para la continuidad escolar del actual alumnado gitano con claras condiciones y posibilidades para la continuidad, por medio de acciones de apoyo y seguimiento.
} 


\begin{abstract}
"Estábamos muy picados desde $3^{\circ}$ de EGB... si éste saca 7 sobresalientes, pues yo tengo que sacar 8... Los profesores de aquella época eran de los de antes, o sea, de los de la regla, y entonces nosotros éramos de los de no a mí no me pegues y si tengo que estudiar, pues estudio... Tampoco sé realmente por qué en mi generación fuimos tantos... Antes estudiaban aquellos que se esperaba que lo hiciesen. (...) Éramos 32; 28 somos universitarios, y los otros tienen FP." (Yolanda, Castilla-León, 29 años).
\end{abstract}

A través de los testimonios recogidos se puede constatar que existe un debate abierto en el entorno inmediato de las y los niños gitanos. Por un lado hay un rechazo explícito e implícito de la continuidad académica en cuanto supone que la persona a medida que va adquiriendo mayor formación se aleja de los modelos tradicionalistas, y se ve sometido a múltiples presiones de su entorno. Aunque también, de forma paradójica, existe el discurso contrario, el apoyo de su grupo de iguales gitano que ven en los estudios o, mejor dicho, en la obtención de acreditaciones y títulos, una forma de promoción socio-económica. Sin embargo, las trayectorias y experiencias nos muestran de manera inequívoca que esta valoración se manifiesta después de que las personas entrevistadas hayan obtenido una titulación, y no mientras cursaban sus estudios. Por lo tanto, no debería producirse un espejismo en este sentido cuando se observa la valoración de lo obtenido y de la persona que ha conseguido acreditaciones y títulos por parte del entorno familiar y comunitario como un indicador demasiado optimista del cambio de actitudes.

\title{
4.1.4. Asociacionismo
}

En algunas zonas, un factor que está jugando un papel emergente en los últimos años son las asociaciones de mujeres gitanas, constituyendo un ámbito de reivindicación feminista, re-creando la cultura gitana, que puede suponer un acicate para el estudio de las madres y de las niñas y jóvenes gitanas.

Muchas de las chicas gitanas que deciden seguir estudiando se han encontrado con un camino apenas transitado hasta hace unos años por mujeres gitanas, y ese ser pioneras les ha supuesto seguir un estilo de vida extraño para su entorno más próximo, con diversidad de críticas y presiones en su medio, lo cual constituye a menudo una fuente de sufrimiento y desazón interna, e incluso a veces de auténticas crisis personales. La "generación de solitarios", a la que se refiere el maestro gitano Ricardo Borrul en el reciente número monográfico del Boletín de la AEG de 2004, ha supuesto una experiencia más dura aún en el caso de las chicas que en el de los chicos. En este proceso de transformación de pautas tradicionales, las asociaciones de mujeres gitanas pueden desempeñar un papel central, como apoyo para las propias estudiantes y como referentes y grupos de presión para sus familias y entornos comunitarios. Sin embargo, hasta la fecha, ninguna de nuestras entrevistadas ha podido gozar de tal tipo de plataforma en Educación Secundaria, y no ha sido, por lo tanto, determinante en ninguna de las trayectorias contempladas en esta investigación. 
Por otra parte, la participación en el tejido asociativo también tiene un peso importante en momentos ulteriores de la continuidad educativa, en la medida en que permite a las mujeres con más estudios reencontrarse y redefinir sus identidades en un contexto grupal:

\footnotetext{
"Yo en octavo no creía que hubiese nadie que se interesase o que le gustase que una chica gitana estudiase... Al meterme en Romi me ubiqué un poco. Antes estaba pensando que simplemente podía estudiar y que iba a pertenecer mucho al mundo payo... lo que me ha afianzado más Romi es la identidad propia de gitana. Y conocer desde Romi a otros gitanos y gitanas que estudian y que siguen siendo gitanos. Nunca he querido dejar de ser gitana, pero lo veía como... soy gitana, pero aquí tengo que ser paya o... y eso sí... soy gitana y además puedo ir a los sitios y mostrar lo que eres. Para eso me ha servido, para afianzar más lo que soy. Romi es un punto de referencia y de apoyo." (Laura, Castilla-León, 25 años).
}

Así, en contra de lo que planteábamos en una de las hipótesis iniciales, son mayoría los casos de éxito y continuidad académica que apenas han hecho uso de las redes de apoyo desde el asociacionismo gitano, tampoco a través de la participación de sus familias en las mismas. También es cierto que la existencia de una red más generalizada de ayudas es relativamente reciente todavía. Ahora bien, sí que estamos detectando una influencia favorable del asociacionismo en algunas de las personas entrevistadas en ciertas circunstancias:

- En la mayoría de zonas ${ }^{81}$ estudiadas, algunas de las personas entrevistadas con trayectorias de éxito y continuidad se vinculan familiarmente con líderes o cargos directivos de asociaciones gitanas. También puede tratarse de procesos que se retroalimentan, de mutua implicación entre valoración de la continuidad académica y participación asociativa activa como dirigentes por parte de las familias. A este respecto, debemos señalar que las redes asociativas difieren considerablemente en tipo y número en los distintos territorios.

- Las becas y los grupos de encuentro para estudiantes gitanos promovidos por la Fundación Secretariado General Gitano y otras asociaciones se valoran muy positivamente por la población gitana que ha participado en ellos (aunque son una minoría en estos 50 casos). Hay que señalar, no obstante, que estos alumnos y alumnas ya estaban estudiando de $3^{\circ}$ de la ESO en adelante cuando se les han ofertado estas becas y estos encuentros, por lo que no constituyen un factor inicial desencadenante de la continuidad escolar; pero sí pueden suponer un estímulo más para su continuidad. Aunque es de destacar, sobre todo, el contexto de debate que se ofrece para la conciliación del cambio cultural derivado de la continuidad educativa con la recreación de los elementos de la identidad étnica.

Así, aunque debemos ser prudentes en esta valoración ya que su incidencia hasta la fecha no puede haber sido muy alta -por ejemplo, sólo en 8 casos se ha constatado y reconocido el papel del asociacionismo en la continuidad educativa entre la muestra

81 Por razones obvias, no detallamos en qué CC. AA. sí ocurre con mayor frecuencia este fenómeno. 
de 50 casos que estamos trabajando-, sí observamos que este papel parece estar creciendo entre las chicas y los chicos más jóvenes, por su apoyo a la consolidación de las trayectorias postobligatorias.

Pero, independientemente de su impacto real, nuestros y nuestras informantes pueden tener opiniones muy diversas sobre la función de las asociaciones:

"Ya llevan varios años intentando hacer algo, y yo que sepa no ha servido de nada, porque la asociación gitana es algo muy familiar, entran venga millones de subvenciones, todo pa ellos, todo pa la familia, y no hacen nada." (Andrés, Aragón, 18 años).

Habitualmente la participación de las personas entrevistadas en las asociaciones está vinculada al acceso a una dotación monetaria, una ayuda o una beca de colaboración ante una situación permanente 0 temporal de precariedad económica. 0 bien han accedido a recursos tales como: apoyo escolar, orientación psicopedagógica, mediación con las familias, en los centros escolares y su entorno, etc. Sí hay algunos casos que manifiestan el beneficio que reportan o pueden llegar a reportar las asociaciones gitanas ante la continuidad académica de los chicos y chicas gitanas, pero también es cierto que las personas entrevistadas que tienen esta opinión suelen ser parte de la plantilla de este tipo de entidades, en una correspondencia entre su ideario personal y el ideario propio de estas entidades ${ }^{82}$. En cualquier caso, la disponibilidad de estos recursos humanos y materiales en todo el territorio es relativamente reciente y es de suponer que su impacto se podrá medir satisfactoriamente en las siguientes promociones de chicas y chicos gitanos que ahora mismo se encuentran todavía en los niveles obligatorios medios.

"Dentro de la Asociación pues tú empiezas a comentar un poco las inquietudes que tienes respecto a los estudios y toda la gente que hay ahí muy amablemente pues te impulsa, te ayuda, pues vete a este centro, pues vete aquí, pues matricúlate en un centro para adultos... que fue donde terminé de hacer lo que es el bachiller, ¿no? En la Asociación decido continuar estudiando gracias a la motivación de todo el personal de la Asociación y me recomienda I., bueno es que I. J. fue la que me recomendó un centro de adultos, fui allí, me inscribí y terminé de hacer el Bachiller... El hecho de que yo estudiara un poquito más fue gracias a la motivación de la Asociación." (Oscar, Aragón, 27 años).

"Sí, siempre me han ayudado a nivel de casa siempre he tenido alguna ayuda, y luego la Asociación Gitana me ha ayudado siempre más que económica, anímicamente a salir adelante en los estudios... De pequeño participaba en Colonias Urbanas, y ahora quiero entrenar un equipo de fútbol... Yo creo que el asociacionismo gitano puede jugar un papel importante en el apoyo a estudiantes gitanos, siempre y cuando se lleve a cabo un tipo de ayudas económicas para libros, para alguna matriculación, para material escolar ... He tenido alguna pequeña conversación con distintos gitanos que han estudiao y me han intentao orientar para que siga su camino." (Miguel, Aragón, 18 años).

82 Entre nuestros y nuestras informantes constatamos una alta proporción de titulares reabsorbidos por las entidades y asociaciones. Esta opción se ve como una salida profesional para la que, además, la pertenencia étnica constituye un valor añadido, aunque no imprescindible. 
Algunas personas entrevistadas se han referido también a la conveniencia de que existan mediadores y mediadoras interculturales gitanos/as (del mundo asociativo y vinculados a las instituciones educativas), pero no forma parte de sus experiencias y trayectorias sino de sus opiniones. En este sentido observamos que estos apoyos pueden resultar tanto más necesarios cuanto más segregadas sean las situaciones minoritarias, es decir, cuanto menos se dé la dimensión primera: si existe una adecuada integración social la dimensión de contar con respaldos asociativos no parece tan necesaria para la continuidad escolar.

Por otra parte, la Iglesia Evangélica de Filadelfia hasta el momento no está jugando ningún papel crucial en la continuidad escolar del alumnado gitano, ni de las chicas ni de los chicos. No hay casi ninguna constancia de la participación de los entrevistados y entrevistadas en el culto, ni de sus progenitores y hermanos/as. La mayoría tienen una opinión muy crítica en torno al culto, visto como un obstáculo ante la continuidad académica, aunque algunos y algunas afirman que no siempre es así, y depende en gran medida de la incidencia del pastor y el mensaje que éste lanza respecto a la institución escolar, que en ocasiones ejerce una función de lucha contra el absentismo escolar. Pero, por lo general, algunas de las personas entrevistadas señalan que actualmente entre las prioridades del culto no está la de alentar la continuidad escolar.

Sin embargo, ésta puede ser una percepción demasiado superficial, al menos en lo que se refiere a la incidencia indirecta que el culto puede haber tenido sobre aspectos emblemáticos de las relaciones entre los sexos en un pasado reciente, en el cual la escolarización obligatoria mixta en las escuelas Primarias todavía suponía un escollo muy problemático. En 1990, San Román escribía: "La base de la resistencia a la coeducación [escuela mixta] está en las propias raíces de la moral conservadora gitana y de su estructura patrilineal. Cuando a las mocitas les niegan el ir a un cine sin el cancerbero de su hermano o su padre al lado, la justificación es siempre la misma: "Nosotros queremos saber lo que criamos". Por esta razón las sesiones de culto de los Pentecostales Gitanos o "Aleluyas" como se llaman a sí mismos con toda la gracia, se señalaron como revolucionarias para la moral puritana que se impone a la mujer gitana, al situarla junto a los hombres en el rezo, mezclados en el mismo banco." (San Román, 1990: 72).

Ahora bien, entendemos que ambas situaciones - la actualidad de la experiencia y la posición de las mujeres y los hombres entrevistados, por una parte, y el papel histórico señalado por San Román, por la otra- deben ser consideradas como distintos momentos de un mismo proceso en estos últimos 14 años. Probablemente el culto pueda constituir un factor de cambio y ser favorecedor del compromiso con la vía académica, en determinadas circunstancias y en alguna medida. Pero apreciamos, por otra parte, que puede entrañar cierta competencia con los estudios a partir de la adolescencia, ya que el culto pide una militancia y una adhesión fuerte, y recrea la cultura gitana, pero desde unos presupuestos religiosos, étnico-nacionalistas y profilácticos, mientras que los estudios reclaman una mayor inserción a la sociedad común y una primacía del individuo y su libertad. No obstante, esto no es sino una tendencia, es decir, no constituye una presión férrea, y cada pastor y también cada familia y cada persona puede hacer más o menos compatible las dos vías, religiosa y académica. 


\subsection{La dimensión educativa: contexto y clima}

\subsubsection{Contexto escolar (integración en el aula y en el centro)}

El factor que se repite más en las trayectorias y experiencias de nuestros y nuestras entrevistados es el haber estudiado en un colegio integrado, no guetizado. Asistir desde una edad temprana a una escuela en la que hay población gitana y no-gitana parece altamente favorecedor de la continuidad y aparece en la mayoría de los casos. Puede apreciarse cómo este factor está directamente relacionado con la variable relativa a vivir en un barrio integrado, pero tiene aún un peso más decisivo.

Es especialmente relevante que en la totalidad de nuestros casos de éxito y continuidad, los alumnos y alumnas gitanas procedían, no sólo de centros no segregados, o sin alta concentración, sino de aulas no segregadas. Es decir, a lo largo de su trayectoria académica ningún alumno o alumna ${ }^{83}$ pasó por recursos especiales educativos tales como educación compensatoria, unidades de escolarización externa o de adaptación curricular. El estudiar en una clase ordinaria con el currículo ordinario promueve las expectativas de continuidad académica, algo del todo improbable cuando se trata de una clase etiquetada como especial o de ritmo lento, o de nivel bajo. Así pues, evitar la segregación étnica en la escuela y el tratamiento segregado de las necesidades educativas son factores básicos de normalización educativa y, por lo tanto, mayores probabilidades de éxito y continuidad. No debe confundirse una presencia alta 0 exclusiva de compañeras y compañeros gitanos de forma automática con una situación social o educativa guetizada o educativamente problemática. De hecho, algunos de nuestros casos tanto de hombres como de mujeres proceden de este tipo de entornos y experiencias y han proseguido sus estudios sin cambiar de centro educativo. Aquí nos referimos a la ausencia de experiencias de minorización, sin etiquetaje colectivo e individual negativo en el centro y en el aula.

"En Primaria, todos mis compañeros eran gitanos, en el IES ya no, casi no había." (Jordi,

Cataluña, 17 años).

Ningun de nuestros entrevistados o entrevistadas pasó personalmente por estas experiencias de minorización educativa, aunque algunos recuerdan cómo otras y otros compañeros y familiares en sus mismos centros y aulas sí pasaron por ellas. Lo que parece determinante, en definitiva, es no haber sufrido ninguna segregación educativa y haberse mantenido siempre en el aula ordinaria. Esto nos permite concluir que los mecanismos de atención a la diversidad y de compensación que siguen estas prácticas

$83 \mathrm{Tal}$ como hemos señalado, ninguno de nuestros informantes estudió en aulas o centros escolares segregados. Sin embargo, un sector del alumnado gitano que ha accedido a $4^{\circ}$ de la ESO y que ha logrado dicha titulación lo ha hecho por el Programa de Diversificación Curricular (éste es un programa caracterizado no por la segregación, sino por las adaptaciones curriculares y una enseñanza más tutorizada, personalizada y significativa). 
(en cuyas concreciones está sin duda sobre representado84 el alumnado gitano) no sólo no cumplen en absoluto sus objetivos, sino que contribuyen a la reproducción ampliada de la desigualdad educativa y social.

\footnotetext{
"En el colegio, los gitanos muchas veces, yo pienso que no se les tenía igual que a los payos... generalmente a la comunidad mayoritaria si, por ejemplo, uno de la comunidad mayoritaria se portaba mal en clase, no aprovechaba el curso... pues se le aguantaba en clase, aunque se le pusiera falta, se le pusiera lo que sea, pero se le aguantaba en clase. Sin embargo, para la gente gitana y comunidades minoritarias había unos programas especiales, que les Ilaman compensatorios, los tenían como un poco apartaos." (Manuel, Aragón, 21 años).
}

\subsubsection{Clima escolar (experiencias de relación)}

La creación de un clima escolar integrador depende de dos aspectos fundamentales: por una parte, la posición del profesorado en el aula y en el trato al alumnado, y por la otra, la función de acompañamiento que puede realizar el centro en situaciones clave, como la transición de Primaria a Secundaria. Sin duda, el alumno o alumna puede percibir un clima escolar integrador a través del profesorado que es capaz de propiciar un buen rendimiento y altas calificaciones y que transmite una valoración positiva de sus capacidades. El hecho de que algún profesor o profesora muestre afecto, confianza y expectativas altas hacia el alumnado favorece su proceso de aprendizaje, un aprendizaje que en parte es relacional 85 y que afecta a todos los niveles de la persona: intelectual, afectivo y social. En este sentido, la mayoría de las personas entrevistadas repiten que sentían el respaldo y la confianza de sus profesores/as, a través del afecto y de la exigencia. Algunos y algunas quieren recordar y explicitar los nombres de profesores y profesoras que tuvieron papeles cruciales en sus trayectorias.

En algunos momentos (crisis y momentos de duda, periodos familiares difíciles, transición del colegio al IES) la figura de un profesor o profesora que alienta y anima a seguir estudiando puede ser decisiva para resolver las dudas y compensar los desánimos. En algún caso se señalan las visitas domiciliarias y la insistencia personal de algún profesor o profesora con las familias para impedir el abandono escolar y apoyar la continuidad.

Un sector notable de los y las entrevistadas pone de relieve la interdependencia entre su progreso escolar y las altas expectativas por parte del profesorado, aunque ésta no es una tendencia generalizada.

Para algunos y algunas estudiantes gitanas ha sido favorable el hecho de que el profesorado supiera que buena parte del alumnado gitano tiene mayores dificultades en cuanto al acceso y continuidad en los estudios. Este conocimiento ha favorecido la comprensión de sus circunstancias y, por tanto, un empeño en que estas personas con- 
tinúen estudiando. Ahora bien, en nuestra investigación se pone de manifiesto que cuando el alumno o alumna tiene una sociabilidad no segregada, el apoyo específico del profesorado es menos determinante, aunque lo sigue siendo el apoyo inespecífico hacia el grupoclase como un todo. La implicación y la relación afectiva del profesorado con el alumnado gitano es más necesaria cuanto menos integrada socialmente se encuentre la situación familiar y cuanto más segregado sea el barrio del que procede el alumnado gitano.

Debemos recordar que los hombres y mujeres, chicos y chicas gitanos con continuidad académica que representan nuestros casos, han salido de centros donde han fracasado la mayoría de sus compañeros y compañeras gitanos, tanto si éstos eran mayoría como si no. Así, la importancia del tipo de centro y la implicación del profesorado no son factores con influencias determinantes que se confirmen plenamente en nuestra investigación, pero tampoco carecen de importancia. Esto nos hace pensar en un aspecto que, por las características de nuestra aproximación, no estamos en condiciones de contrastar: el tipo de planteamiento educativo y las metodologías docentes. Esto requiere la aplicación de una metodología etnográficas6 escolar en fases ulteriores de la investigación. En cualquier caso, ninguna de las personas entrevistadas se ha referido de forma espontánea o al ser interrogada a un tipo concreto de planteamiento educativo, ni quienes han tenido estas experiencias hace tiempo ni quienes han vivido más recientemente sus experiencias educativas o todavía siguen estudiando. Hacen mención a otro tipo de aspectos como el trato, la implicación o la exigencia:

\footnotetext{
"[La profesora de $8^{\circ}$ ] era una profesora tan cercana, tan cariñosa, tan madre y a la vez tan buena profesora que para mí era un referente buenísimo... Yo en la escuela me sentía como en mi casa, era mi segunda casa. Tenía toda la confianza para tener las llaves de clase, porque en $7^{\circ}$ y $8^{\circ}$ era la única que se quedaba a comer." (Julia, Aragón, 36 años).

"Los profesores en ningún momento se pararon a pensar que fuese o no fuese gitana. Me trataban igual que a todos. Sólo una profesora... me acuerdo que sabía que yo era gitana, y me tenía... no enchufe, pero me decía: '¡Ay, que maja es...!'y qué esto y qué lo otro ... pero más no. Cuando los profesores sabían que era gitana no lo han tomado en contra. Pues igual gente que estaba más sensibilizada y sabían la realidad que había, pues decían: 'Mira que maja Laura...' Pero nunca me han dicho que si necesitaba algo. Y me acuerdo que una profesora, en cuarto, se llamaba doña Pilar, me dio trescientas pesetas para hacerme fotos y sacarme el carné de la biblioteca. [En $1^{\circ}$ de BUP lo pasé mal] la protección que tenía en el colegio de los profesores pues no la tenía allí... (Laura, Castilla-León, 25 años).
}

La valoración y el afecto por parte del profesorado se refleja como elemento fundamental entre algunas personas entrevistadas que retomaron sus estudios dentro de la Formación de Personas Adultas. Veamos un ejemplo:

"Tenía mucho interés y el mismo R. F. me decía: 'Oye, tienes que hacer lo de mayores de 25 años', yo qué sé, no se cuánto, 'Prepárate porque tu tienes buenas aptitudes'. (...) esa interac-

\footnotetext{
86 Algunos miembros del equipo de investigación en Cataluña están desarrollando sus tesis doctorales en centros educativos de Primaria y Secundaria con alumnado gitano realizando observaciones de aula y otros espacios de transmisión e interacción escolar.
} 
ción con estas personas pues fue por llegar, por empezar ahí, para reforzar mis inquietudes y de ello hacia el saber, quiero saber más. Fue determinante, he tenido mucha suerte, me he movido siempre en... tuve la suerte de poder relacionarme en estos ambientes." (Álvaro, Cataluña, 46 años).

Por otra parte, el informe dirigido por J. P. Liégeois (1988) en el que se analizó comparativamente la escolarización del alumnado gitano en varios países de Europa, concluye que la acogida y la afectividad de los profesores/a constituye una dimensión clave. Dicho estudio constató que muchas familias gitanas itinerantes de centro Europa preferían recorrer cada día varias decenas de kilómetros para llevar a sus hijos e hijas a una escuela en la que se sentían más acogidos ${ }^{87}$. Sin embargo, observamos en este sentido tres tipos de experiencias vividas entre nuestros y nuestras informantes de forma diferenciada:

- En primer lugar, los entrevistados y entrevistadas se refieren al profesorado que les ha transmitido distancia, rechazo e incomprensión. Aunque se mencionan estos casos de forma anecdótica, y aparecen con poca frecuencia, se recuerdan de forma muy dolorosa. Algunos casos relatan la percepción de una tendencia general de los centros escolares (públicos o concertados religiosos) a tratar de forma diferencial al alumnado en situación económica precaria y adscripción étnica gitana, que a veces se traduce en una actitud paternalista y de sobreprotección. De todas maneras, encontramos opiniones diversas entre nuestros entrevistados y entrevistadas sobre el impacto de tales actitudes en su continuidad educativa: desde aquellos y aquellas que las recuerdan como una inhibición de sus capacidades hasta aquellas y aquellos que las vivieron como estímulos individuales decisivos.

"En T. [centro escolar del Casco Viejo] es que no les queda otro remedio que acogernos, éramos la mayoría gitanos y no les quedaban otros cojones como aquel que dice que machacarse ahí, estaban amargaos totalmente, no sabían ya qué hacer... Es algo vergonzoso, los profesores de allí no hacen, absolutamente nada de caso, esos sí que van a cobrar el sueldo, nada más (...) [otro, en cambio] ha vivido muchos años aquí, también sabe lo que hay, y está integrao también y se informa de lo nuestro. Pero es que hay gente que absolutamente, la palabra gitana le suena a rechazo. (...) si por mí hubiera sido, lo hubiera dejado". (Andrés, Aragón, 18 años).

"... era súper-racista; pero me motivaba, porque mi visión sobre él, sobre lo que él me informaba, es decir, no es que yo estuviera por encima de él, ni por debajo, pero sus juicios me daban igual; simplemente me gustaba lo que él me informaba, y optimizaba la información, ¿no?, o sea, hacía una criba. A mí no me afectaba; no me afectaba, ¿no?, lo que él... los juicios que él podía vertir. Yo creo que en ese sentido, me abrió puertas, ¿me entiendes? (... ) Para mí todos me abrieron puertas." (Adrián, Madrid, 25 años).

"Pues en algún momento sí que el trato de alguna profesora me hizo sentir diferente, porque a veces les chocaba que siendo gitana no faltara al colegio, como otras niñas gitanas, que siempre llevara el material los primeros días, incluso que los libros cada año fueran nuevos, y te decían que tú eras diferente, que no eras gitana, esas cosas te ofenden porque ves como tienen

87 LIÉGEOIS, J. P. (1998): Minoría y Escolaridad: El Paradigma Gitano, Madrid: Editorial Presencia Gitana/Interface. 
la visión de que los gitanos tenemos que ir en negativo, pero a esa edad no te das cuenta." (Mercedes, Madrid, 27 años).

"En el instituto hay un profesor que siempre decía que... a los alumnos... que nunca se casaran con una gitana, que iban a destrozar su vida, que eran salvajes, que eran no sé qué. (...) a mí no me ha hecho falta el apoyo de los profesores ni sentirme identificada por los profesores. Porque lo único que he hecho ha sido reforzar... a lo largo de mis estudios, lo único que ha hecho ha sido reforzar mi identidad (...) Entonces yo siempre he tenido muy claro que la gente cuando decía eso [comentarios racistas], estaba equivocada, era ignorancia. (...) el colegio creo que es importante pero no influyente. Porque yo he estado en colegios en los que no se ha tenido una buena visión de los gitanos, no se me ha apoyado como alumna, entonces, no me he sentido apoyada, ni identificada nunca con el colegio, pero yo soy universitaria y he acabado una carrera, la que yo he querido. 0 sea, que a mí no me ha hecho falta el apoyo de los profesores ni sentirme identificada por los profesores." (Teresa, Cataluña, 27 años).

- En segundo lugar, se sitúan los testimonios que expresan la falta de influencia del profesorado en su elección de seguir estudiando. Muchas de estas opiniones se relacionan con la mención de "un clima de normalidad" en el centro, en parte debido a la escasa presencia de población escolar gitana, también en parte debido a la existencia de prácticas educativas igualitarias, pero también al desconocimiento de la adscripción étnica o a la negación explícita de su reconocimiento88.

"Nunca me sentí tratado de un modo diferente, ni me acuerdo de ninguno que me diera un trato especial... No me acuerdo del nombre de ninguno, así, especial para mí... Yo era uno más y pasaba desapercibido... Bueno, un par de veces al principio creo que el orientador [del instituto] me dijo que si estaba a gusto y tal... que no me preocupara y estuviera tranquilo y tal.... Pero, vamos, que no hacía falta que me dijera aquello. Yo era uno más. Tenía mis juergas con los compañeros, me llevaba bien con todo el mundo... En las clases bien, y en los recreos, y si había que ir por ahí luego, íbamos todos... Yo era uno más. Y siempre he tenido muy buena relación con todos los profesores y ellos me apreciaban." (Richi, Castilla-León, 24 años).

"J. basaba sus clases en el respeto, en la igualdad. Ella sabía que yo era gitano, pero nunca ha mencionado la palabra gitano, sino es para distinguirme, para exaltarte, pero tampoco de manera exagerada, siempre en la igualdad. Te trataba así, sabiendo que las condiciones económicas no eran las mismas y en consecuencia no te exigía cosas que a otros podía exigir, en cuestión de material... Echo en falta profesores implicados. Tienen que entender que se parten de condiciones diferentes y que a veces lo que se le presenta a los alumnos son unas condiciones a las que se tiene que adaptar, si no quedas excluido." (César, Castilla-León, 22 años).

"Bueno, algunos sí porque no me conocían como gitano, mis profesores igual no me conocían como gitano. Y los que me han conocido, pues, era uno más de ellos, que no ha habido nunca ninguna distinción, entre 'Tú eres gitano, no juegues conmigo, vete de aquí, que hueles mal, no vie-

88 Es necesario recordar que algunos centros educativos confunden la política de igualdad que debe orientar el tratamiento educativo de las minorías con una práctica "asimilacionista" bienintencionada, que en cambio tiene un efecto de ocultación de la diversidad y de su legitimidad en el espacio educativo. 
nes limpio o lo que sea...'. Pues no, siempre he estado con ellos y no ha habido ningún problema por vivir con esa sociedad." (Eugenio, Navarra, 18 años).

"Había profesores que sí que lo sabían. Y habían que ni lo sabían ni eso... pero no, nunca salió nada ni positivo ni negativo a nivel de eso... y con los míos personalmente tampoco." (Alba, Cataluña, 24 años).

- En tercer lugar, el mayor número de casos expresa haber percibido valoración y afecto por parte de profesionales docentes; muchos y muchas recuerdan con emoción el apoyo recibido de un profesor o profesora concretos, mencionan su nombre y recuerdan literalmente algunas de sus palabras. Fueron decisivos/as en la continuidad académica porque:

- La relación alumno/a- profesor/a era cordial en la relación cotidiana.

- En los momentos decisivos y en la toma de decisiones, el profesorado, tutor/a, director/a, etc. influyó positivamente en el cambio de opinión del alumno/a, intercedió a favor de él o ella delante de sus progenitores o responsables, les proporcionó información sobre los posibles itinerarios académicos a seguir; le reforzó aspectos de su propia personalidad aumentando su autoestima personal y reiterando su capacidad individual para proseguir sus estudios; le informó sobre recursos no segregados, como becas o refuerzo escolar.

- Les facilitó el contacto con asociaciones pro-gitanas que tenían proyectos o iniciativas en marcha para fomentar la continuidad académica de los alumnos/as gitanos y gitanas.

- Les informó sobre el acceso a recursos de la propia escuela: comedor gratuito, refuerzo escolar gratuito e individual fuera del aula, $u$ otro tipo de recursos materiales como ropa y material escolar para su uso particular o para otros miembros de la familia.

- Potenció la cohesión grupal y el trabajo cooperativo y/o le facilitó el acercamiento con el resto del alumnado del aula, ante una situación de marginalidad y exclusión entre sus compañeros/as de curso.

- Comprendía y trabajaba con flexibilidad situaciones de absentismo escolar esporádico, el llegar tarde a clase o el no haber hecho las tareas encomendadas.

- Tenía una situación de empatía y/o conocimiento y comprensión de la situación de la comunidad gitana.

- Enfatizaba el trato basado en la igualdad, quería hacer sentir a cada persona dentro del aula y del centro como "a uno/a más".

- Manifestaba altas expectativas sobre su capacidad y continuidad escolar y propiciaba un buen rendimiento académico. 
Ahora bien, parece claro que la relación afectiva del profesorado y el tener una voluntad de implicación con el alumnado gitano es más necesaria cuando la familia ocupa posiciones menos integradas y cuanto más segregado sea el barrio, es decir, cuanto menores sean las expectativas vertidas en el potencial de la continuidad educativa para dotar de oportunidades reales a los hijos e hijas. Los siguientes testimonios ilustran de forma contundente la mayoría de estos aspectos que hemos enumerado:

\footnotetext{
"Los profesores de este Instituto, no son normales porque, por lo menos a mí, a mi hermana y a mi prima nos han ayudao un montón. Nos han pillao más de 400 veces, escapadas, y siempre nos decían: 'Venga, ¿eh?, ya no lo hacéis más', y nosotras: 'Vale'. Y a la otra vez, y otra vez, hasta que al final ya nos dejaban: 'Bah, déjalas, mientras no salgan del Instituto...' Los profesores del Instituto... nos hemos llevao muy bien con ellos... los profesores de aquí la mayoría conocen mucho el mundo de los gitanos, los que son de aquí... Yo creo que sí, que sirvo para estudiar. Que tienen buena opinión, de mí, sí. Pues siempre se han preocupao más por mí que por las demás. Porque, pillaban a tres, ¿no?, y entonces: 'Adriana, tú vente conmigo y vosotras dos veros con aquel'; entonces yo me llevaba, me... gritaban más, me echaban el discurso: 'Porque mira lo que están haciendo tus padres por ti, que... tú puedes, que las demás a lo mejor no, pero tú ya... que ya te falta poco, no sé qué..." Siempre se han preocupao por mí mucho, los de este Instituto mucho, yo creo que en otros institutos no... no hay relaciones como las que tenemos nosotros." (Adriana, Aragón, 18 años).
}

"Empecé en segundo de ESO el primer año de reforma, en el instituto desde allí no he tenido ningún problema, ha sido mi segunda casa y lo sigue siendo tanto los profesores como el alumnado ha estado ayudándome en todo momento, en todo momento... la relación con lo profesores ha sido excelente, no sólo por el trato como alumna." (Pilar, Aragón, 21 años).

"En A. [el IES] no pude, pero me hubiese agradado el agradecer a los profesores, porque allí vi el apoyo, el esfuerzo. Porque que lo hagan... que lo hagan los profesores del colegio, que te conocen desde niña, vale. Pero que lo hagan los profesores del instituto, que a lo mejor te conocen de un año o de dos años, pues es mucho. El director ... me dieron muchísimo apoyo. Me dieron muchísimas facilidades para seguir estudiando. Me dijeron que no viniera todos los días, si no podía, y que luego en los exámenes me iban a ayudar, y tal. Pero yo no quería que me regalaran las notas..." (Soledad, Castilla-León, 18 años).

"Y quinto y sexto lo hice en un instituto privado más alejado de mi calle, de mi zona por dónde yo vivía, y allí conocí a una serie de profesores que me valoraron muy positivamente. Eran muy progres, en aquella época, tenían muy buena relación conmigo y con mis padres y yo les gusté mucho y uno de ellos trabajaba en un instituto en Hospitalet. Y me dijo que por qué no iba a su instituto, que él me hacía la matrícula y yo te acerco. Fueron los años más felices de mi vida porque yo estaba muy bien, allí nos pudimos relacionar con gente con una sensibilidad especial; y ya con quince años nos gustaban los grupos de debate, de discusión, de encuentro para debatir lo que leíamos, y ésas eran mis relaciones." (Ramón, Cataluña, 44 años).

Como hemos señalado al principio de este subapartado, el segundo factor que indica la existencia de un clima escolar integrador es el acompañamiento del centro y del profesorado en la transición de Primaria a Secundaria, especialmente en la genera- 
ción que se halla en este proceso en la actualidad y que, por razones obvias, no está representado en nuestros casos. Una percepción bastante extendida entre nuestros informantes se refiere al trato y a la relación claramente diferenciado que notaron al pasar del centro escolar de Primaria -donde las relaciones son más cercanas y próximas, donde la familia está mucho más implicada-, y el Instituto o centro de enseñanza Secundaria -donde el trato es más esporádico, no tan personal y sí más académico-. Aunque no siempre es así, dependiendo de la implicación del centro y/o del tipo de personal docente:

\footnotetext{
"Ves a los profesores como a unos segundos padres, porque siempre están ahí apoyándote y no te exigen tanto, siempre te están dando las cosas con más tranquilidad. En cambio llegas al instituto es como que te doy la clase y ya está. En cambio antes en el colegio si te ven con algún problema ya están: ¿Qué te pasa?', y yo qué sé... En cambio en el instituto no, ¿sabes?, te dan la clase y ya, se acabó, y eso se nota... [Algunos profesores] notas mucha diferencia, y que muchos de ellos son racistas. Igual están en clase y comentan algo de los gitanos, pero siempre a mal, nunca a bien, ¿sabes? Yo muchas veces me callo, pero otras no aguanto, no aguantas porque sí." (Victoria, Navarra, 17 años).
}

El profesorado puede llegar a convencer a los progenitores del chico o de la chica para que sigua estudiando, frente a las presiones en dirección contraria que muchos padres reciben del entorno y/o de otros miembros de la familia. Realizan tareas de intermediación, animando a la familia y reforzando su confianza en las capacidades de sus hijos e hijas, enfatizando la importancia de los estudios como medio de obtención de mayores oportunidades de cara al futuro:

\footnotetext{
"Era un colegio de monjas y estuvimos allí pues desde que teníamos cuatro años hasta los catorce, luego dejamos los estudios por esto de los gitanos, ya lo sabes, mi padre no quería que siguiéramos estudiando, hicimos corte y confección, cursos diferentes y nada. Pues en el colegio la propia superiora vino a mi casa a rogarle a mis padres que volviéramos porque no tenía alumnas que aprovecharan tanto, allí si vamos al colegio todo el mundo nos conoce; y nada, fuimos otra vez a los estudios porque vino la superiora a casa." (Cristina, Madrid, 37 años).
}

\subsubsection{Posición e implicación familiar en la educación formal}

Algunas de las personas entrevistadas representan una segunda generación de personas gitanas con estudios. La literatura de investigación es unánime en este sentido, el factor de mejor pronóstico en la promoción del éxito y la continuidad académica de los hijos e hijas es la continuidad académica de los padres, especialmente en aquellos que han llegado a los estudios superiores. También constituye un factor favorable el que haya estudiado algún familiar cercano. Contar con referentes familiares, con personas dentro de la familia que ya han estudiado, facilita el terreno y normaliza la continuidad hasta el punto que parece fuera de lugar lo contrario, 
como lo señala la experiencia de algunos/as de nuestros/as informantes/as. Lo mismo ocurre con determinadas prácticas culturales altamente valoradas por la escuela y que han sido mencionadas por algunas de las personas entrevistadas, como la afición a la lectura de alguno de los padres.

En este punto hay que señalar que el factor lingüístico89 no ha sido relevante en ninguno de los entrevistados de Cataluña, donde es la lengua vehicular en la enseñanza90. Sólo dos mujeres entre los gitanos y gitanas con trayectorias de continuidad del registro sobre personas gitanas con éxito y continuidad educativa de nuestra investigación proceden hasta la fecha de entornos familiares y comunitarios gitanos con presencia del catalán. A este respecto, podemos afirmar que el aprendizaje de la lengua catalana entre los gitanos castellano-hablantes se da en las mismas condiciones que entre aquellos sectores de población procedente de otras zonas del estado que no utilizan el catalán como lengua familiar o lo utilizan menos. Por consiguiente, el conocimiento del catalán no es determinante para favorecer el éxito y la continuidad en el sistema educativo de la población escolar gitana. Además, algunas de las personas gitanas entrevistadas insisten en el hecho de que se desarrolla un dominio mayor de registros en catalán que en castellano entre la población gitana actualmente escolarizada, dentro de los sectores que podríamos denominar "de clase media".

Igualmente revelador resulta que los padres u otros familiares próximos guarden un buen recuerdo de su paso por el colegio. Algunos padres y madres jamás se hubieran planteado una vía de continuidad educativa en su momento, pero se lo plantean -con 0 sin reservas- respecto a sus hijos e hijas. A veces esto se hace evidente sólo en el momento de pensar en su escolaridad, pero también existen situaciones en las que el padre o la madre 'confiesa' al hijo o a la hija que tuvo que renunciar a su deseo de continuidad por falta de oportunidades reales y por verse incapaz de superar las presiones de su propia familia y comunidad.

Estas circunstancias hacen más probable el que a la hija o al hijo le llegue un mensaje de confianza en su persona, en la posibilidad que tiene de hacer algo poco previsto y poco frecuente en su medio si cuenta con apoyos y con una valoración de los estudios, lo cual va a repercutir favorablemente en su continuidad académica. Este tipo de mensajes también ha sido minoritario en la experiencia de nuestros/as informantes, pero puede constituir un factor de importancia creciente ya que tiene mayor presencia en las trayectorias y experiencias educativas de los y las más jóvenes.

También es cierto que algunas de las trayectorias recogidas en las que hubo continuidad académica en alguno de los progenitores (generalmente, el padre) no muestran esta fluidez en la normalización de la continuidad, bien porque aquella experiencia paterna no consiguió ser considerada como más que una excepcionalidad personal,

\footnotetext{
89 Actualmente se calcula que alrededor de un $30 \%$ de la población gitana en Cataluña tiene el catalán como una de las lenguas familiares.

90 No parecen comparables la realidad sociolingüística de Cataluña y la de Navarra, ni en términos sociales ni en términos educativos. Lo que sí es constatable es que en las ciudades de Navarra, en la línea en castellano, se concentra alumnado inmigrante, gitano y de familias desfavorecidas, por lo que, de manera indirecta, la existencia de dos líneas divide a la población escolar en este caso. En los últimos años ha habido también alguna alumna y alumno gitano que han sido escolarizados en euskera, la mayoría de los cuales han tenido o están teniendo una escolaridad con mayor continuidad.
} 
bien porque la fluidez es altamente selectiva y sólo normaliza la continuidad de los hijos hombres. De todas maneras, en la mayoría de los casos recogidos no se ha contado con referentes de otros gitanos o gitanas con estudios medios o superiores en su familia, ni siquiera en su contexto más próximo, sino que ellos y ellas han sido o están siendo los primeros y las primeras estudiantes de sus familias.

"Mis padres siempre me han apoyao para que pueda conseguir a nivel estudiantil algo provechoso, siempre me han apoyao a que estudie, a que oriente mis estudios hacia... un estudio superior o una carrera. En mi familia están muy orgullosos y todos me apoyan. Toda mi familia ha estado siempre encima de mí para que estudie... La relación de mis padres con los profesores era buena porque había profesores que habían sido profesores de mi padre, y con mi madre también era buena aunque menos que la de mi padre... A mi madre le gusta bastante leer... Siempre me han controlao ... siempre he tenido un horario así muy ordenado." (Miguel, Aragón, 18 años).

Por otro lado, es interesante constatar a través de sus relatos que los chicos y chicas gitanas que prosiguen sus estudios se convierten en algunas ocasiones en referentes 0 modelos a seguir respecto al resto de miembros de la familia, incluidas las personas adultas: una vez se conoce y se reconoce el valor del éxito académico, otros miembros del grupo familiar deciden iniciar o retomar sus estudios, mediante la participación en programas de formación de personas adultas, habitualmente en programas de alfabetización básica o Graduado Escolar por parte de las madres.

Veamos a continuación algunos testimonios en los que existe una formación por parte de la madre o el padre, condición decisiva en los alumnos y alumnas gitanas, sea porque la escolarización forma parte de las ideas y de las expectativas de normalidad dentro de la familia, sea porque los progenitores se convierten en referentes por sus propios estudios...

"Mi madre además es profesora de Ciencias de la Educación, o sea, que es que... mi padre es profesor de Literatura, no sé, es que, pues los dos, realmente pues, eran... se ocupaban, se preocupaban; y no sólo se ocupaban y se preocupaban, sino que es que, bueno, claro, se preocupaban porque no se trataba sólo de que se preocuparan, de que pasaras los cursos y tal, sino que realmente yo ahora entiendo pues que ellos, diariamente y cotidianamente, practicaban su... lo que ellos sabían, con nosotros, es decir, estaban continuamente, en los viajes, estaban diciendo pues, poemillas, cantando, tal, contando historias, ¿no?, historias e historia, y sobre la vida, y así; eran padres que se preocupaban de estar, ¿no?, despertando la curiosidad y llenando la curiosidad de una mente que pueda estar despierta, que pueda despertarse, ¿no?" (Carlos, Madrid, 30 años).

"Mi padre tenía casi una carrera universitaria... Entonces, claro, nosotros desde pequeños es lo que hemos visto en casa. Y lo que nos han inculcado mis padres desde siempre. No mis padres, incluso mis abuelos... nosotros hemos recibido eso desde pequeños... lo anormal sería el no estudiar... Bueno, es que nosotros no nos lo planteamos el no estudiar... A mí me sacan de pequeño de esta familia y me ponen en otra, y actualmente no soy universitario ni soy nada... Mis padres han sido muy exigentes con nosotros en los estudios... Los tres hermanos hemos estudiado. El primero hizo Formación Profesional. Yo, Económicas. Y el pequeño está haciendo también la Diplomatura en Empresariales... El impulso familiar ha sido el primero, el impulso decisivo ha sido el familiar. Después el personal también." (Luis, Castilla-León, 22 años). 


\begin{abstract}
"Siempre que he tenido problemas... mis padres siempre han querido que tendría una educación o no sé, no sé. Sí, igual es porque ellos han tenido educación, ellos, sus padres a ver, mis abuelos les han dao educación a ellos y ellos han querido que nosotros también tendríamos o no sé, pero desde pequeños estudiando." (Antonio, Navarra, 18 años).

"Mi tía estuvo estudiando, tengo una tía profesora. Pues también eso me animó a seguir estudiando, además de vivir en un barrio integrado y de tener mi familia una situación económica buena... Mi padre sí que quería [que fuera al IES]." (Clara, Castilla León, 29 años).
\end{abstract}

... o bien porque reciben un apoyo incondicional del padre y la madre aunque no hayan estudiado y aprovechen otras oportunidades como personas adultas, exactamente igual que entre los miembros del grupo mayoritario:

"... después mis tías, en su tiempo, cuando ellas eran jóvenes, por como estaban las costumbres gitanas y todo en ese tiempo no estudiaron, se dedicaron a trabajar; pero ahora, después han retomado los estudios, han ido subiendo: tengo una tía que es trabajadora social por la universidad, y tengo otra tía que está trabajando en el Secretariado General Gitano y que ahora está estudiando también, preparándose para la universidad y seguir ampliando los conocimientos... Mi padre siempre ha querido que vaya, que curse estudios superiores, que vaya a la universidad, en la rama que yo quiera. Siempre me ha dejado presentarme, que contra más estudios tengas, aunque no lo necesites, en un momento dao siempre los tienes ahí y siempre te van a servir para cualquier cosa. Me animan a estudiar." (Manuel, Aragón, 21 años).

"Y mi madre que quería entrar, siempre le ha gustado y todavía, dentro de su capacidad, le gusta aprender todos los días... todos han seguido cultivándose con los años." (César, CastillaLeón, 22 años).

"Mi padre siempre me ha dejado escoger, pero me ha dicho que él creía que era necesario y mi madre igual, porque a lo mejor, al trabajar desde muy jóvenes ellos y no haber seguido estudiando, que a lo mejor sí querían, pues se dan cuenta, ¿no?, que si puedes estudiar, puedes estar en un sitio mejor, pues mejor.... Pero eso... mi madre siempre decía eso. Que si fuese por ella ahora, volvería a estudiar y seguiría estudiando, porque para hacer de dependienta dice que siempre hay tiempo.... Es que en mi casa yo creo que se valora bastante esto de los estudios." (Lola, Cataluña, 32 años).

Tratándose de situaciones análogas a las mayoritarias no marginales, es obvio que en estos casos se cumplen todos los requisitos que impone el sistema escolar, con la máxima preocupación por parte del padre y la madre: ser exigentes con los hijos e hijas en relación con las obligaciones que conlleva el ser estudiantes (asistencia, puntualidad, estudiar y realizar las tareas) y atender a las obligaciones que recaen sobre las familias (compra y cuidado del material escolar desde el principio de curso, asistencia a reuniones). Y, por último, se comparte una ideología educativa muy recurrente entre las clases trabajadoras con aspiraciones de movilidad social en la generación de los hijos e hijas: ser un buen padre o una buena madre pasa, por encima de todo, por priorizar el aprovechamiento escolar de los hijos e hijas hasta donde sea posible, y ser un 
buen hijo o una buena hija se define, por encima de todo, por materializar ese aprovechamiento al máximo con buenos resultados y compromiso con la continuidad. El siguiente fragmento lo ilustra a la perfección:

\footnotetext{
"Y todos hemos estudiado, su mayor preocupación era que sus hijos estudiaran y mi padre siempre tenía una frase muy sabia, que decía: -Yo cuando me muera no sé si tendré dinero, si habré podido recopilar dinero para nosotros, pero la mejor herencia, creo que es que vosotros tengáis una mayor preparación para poder trabajar, que sea mi herencia (...) Él pensaba que la única posibilidad que se podía tener para sobrevivir en esta sociedad era que sus hijos fueran al colegio, tuvieran una posición cultural." (Anabel, Cataluña, 42 años).
}

En este punto, es imprescindible destacar la emergencia de una situación no prevista en nuestras hipótesis de investigación: hemos constatado en diversos casos de los casi 400 de nuestra base de datos y en distintas CC. AA. y ubicaciones (rurales y urbanas) que, incluso en condiciones socioeconómicas extremas, la existencia de una disminución física o sensorial91 en los hijos e hijas puede llevar a los padres a realizar toda clase de esfuerzos para garantizar su continuidad educativa. En todos los casos se ha tratado de dotarles de herramientas intelectuales para su inserción laboral, ante la imposibilidad o la mayor dificultad de acceder a ocupaciones tradicionales del grupo doméstico 0 a empleos no cualificados ordinarios.

"Yo empecé a estudiar, pues, porque tengo secuelas de poliomielitis. Mi padre creyó que no me podría ganar la vida de una manera física y fue el artífice de que yo estudiase." (Pedro, Cataluña, 42 años).

Ahora bien, en buen número de casos el padre y/o la madre se han limitado a no poner obstáculos a sus deseos de proseguir estudiando, y en otros casos la familia era partidaria de que dejaran de estudiar. En tales circunstancias, ha sido el propio estudiante y, sobre todo, la propia estudiante quien con su determinación se ha abierto camino a través del sistema escolar con la oposición de su familia. Algunos casos mencionan el apoyo oculto que recibieron de alguno de sus familiares contra la oposición explícita y oficial de la familia.

"Esto en mi familia no era habitual porque somos cuatro hermanos y uno de ellos tiene el Graduado Escolar, entonces para mi familia lo normal hubiese sido que hubiese estudiado hasta octavo de EGB como mucho y luego hubiese ayudado en las tareas del mercadillo, entonces les costó un poco hacerse a la idea, que por qué yo tenía que continuar estudiando... Hombre, a ver, eso era más que como llevas las notas o lo que sea a casa, cuando van a hablar con los profesores y le dicen: ah, pues su hija va bastante bien y en esto tiene pues tal nota y ese tipo de cosas que los profesores ya lo halagaban mucho, pues ese halago se lo trasmitían, ¿no?, pero no ha sido

91 En tres Comunidades Autónomas, Castilla-León, Cataluña y Madrid, contamos con casos de chicas y chicos invidentes, que proceden de situaciones familiares con pocos apoyos (por ejemplo, madres solas, alejadas de su familia extensa por distintos motivos) y en situaciones económicas precarias y dependientes, y que, con la posibilidad de acceder a recursos específicos han llegado a cursar estudios medios y superiores con buenos resultados. 
una cosa que en casa por ejemplo, se haya valorado muchísimo, no, no es algo que... les ha parecido bien, han dicho: pues fíjate que bien que sacas buenas notas, o sea, sí, pero no es algo primordial... Pues ahora lo ven como un precedente, porque tengo más independencia económica, que es mucho mejor pues para que no todos los hermanos dependamos de mis padres, como una oportunidad en la vida. Luego también para cualquier cosa que ellos no entienden mucho, pues mis abuelos o quien sea, siempre me están llamando a mí para que se lo explique." (María, Aragón, 26 años).

"A mí nunca me han quitado. Por ejemplo, mi madre me veía hacer la tarea y tampoco... No me decía que lo hiciera, pero no me decía nada. Yo llegaba a las cinco y mis hermanas se iban a la calle y yo me ponía a hacer la tarea. Yo hacía los deberes y a las seis quedaba con mi amiga paya y eso (...). Pero en casa nunca me dijeron: 'Venga, tienes que hacer los deberes'... Nunca". (Laura, Castilla-León, 25 años).

Algunas trayectorias se truncaron, alguna de ellas porque la tutela pasó del padre a otro hombre de la familia, con ideas opuestas a la continuidad, como en el caso de esta mujer:

"[Mis padres] fallecieron y cuatro años después, una de mis hermanas se casó y después los hermanos nos separamos, claro, y a mi me tocó ir a otro pueblo con la hermana que se había casao y su marido, pues, tenía negocios y no me dejó terminar." (Eva, Aragón, 31 años).

0 bien porque la chica joven asume el rol de su madre cuando ésta muere, a pesar de haber contado con anterioridad con el apoyo del padre. Las nuevas circunstancias lo hacen impensable:

"Luego ya, por causas de la vida, tuve que dejar de estudiar, porque por mi padre hubiera seguido estudiando. A él le gustaba que estudiara y eso. $Y$ no pude. Me tuve que quedar en casa y no pude... Mi padre es el que lleva el dinero, ¿no? El que esto pa comprar..., el que organiza, ¿no?, se dice así, ¿no?, el que organiza la economía de la casa, pagar las luces, pa aquí, pa allá... Y yo soy pues la que lleva la casa, la que hace la compra, la que, no sé cómo decirte... La que hace la compra, la que limpia, la que ordena, trae esto, trae lo otro, compra esto, yo qué sé. Yo soy la mujer de mi casa como quien dice, si viene alguien en mi casa y no estoy yo pues es como si no hubiera nadie. Y mis hermanos sin mí pues no son nadie. Yo creo que se sentirían muy solos, vacíos. Yo qué sé, al faltar una madre, pues ven en mí, yo qué sé, un apoyo..." (Juana, Navarra, 22 años).

Recordemos que la continuidad educativa, la simple permanencia en el centro educativo a partir de la adolescencia, es completamente contradictoria con el ideal de buena moza gitana tradicional, independientemente de los resultados obtenidos. El siguiente fragmento se extiende con toda claridad en este sentido:

"Cuando vio que me empezó a gustar demasiado y que yo le daba más importancia a los estudios de lo normal, porque ya la que se preocupaba de ir a clase todos los días era yo (mi madre antes me llevaba una vez al mes y pasaba completamente), pero cuando yo era ya más grande 
iba al instituto ya todos los días y me involucraba bastante, ¿sabes?, a lo mejor le decía a mi madre: 'No puedo ir a un pedío o a un cumpleaños porque tengo que estudiar', y ya mi madre se empezó a mosquear y dijo: ¿¿Cómo vas dejar de ir a un pedío porque tengas que estudiar?' Ahí empezó la cosa. Y eso era lo que a ella le molestaba y de repente se originó... Claro, el que yo desplazara ahí... cosas, para mi madre la alegría de una mocita estaba en salir, en arreglarse, yo iba aquí siempre sin pintar con mi moño, con mis libros como rata de biblioteca y eso a mi madre, pues no le gustaba (...) Pues [mi madre] venía al instituto a la hora del recreo a sacarme de los pelos, y bueno a veces mejor, a veces peor, a veces a mí me costaba mucho convencerla de que me dejara ir al colegio y por cualquier comentario de la familia o de mis tías todo se venía abajo, y a mí no me importaba lo que ellas pensaran, cuando quien más habla es quien más tiene que callar; hubo un caso concreto que una tía mía decía que no le gustaba que fuéramos al colegio porque nos sentábamos al lao de los payos, y yo me reía pero a mi madre le sentaba mal porque que cuestionen el honor de tu hija, eso es muy fuerte. Hasta que me cansé y dije mira yo soy virgen y el día de mañana aunque haga lo que haga aunque estudie y haga lo que sea yo lo voy a dar, tú a lo mejor te vas a un gimnasio o te vas a la compra y tú estás casá y nadie puede dar la cara por ti; son cosas que por una palabra o una frase echan por tierra. 0 lo de las azafatas, yo para un congreso tenía que llorar y pedir: 'Déjeme ir, por favor', y a lo mejor por un comentario como ése no me dejaba y tenía que llamar y decir que no podía ir porque no me dejaba. (...) Ella me decía que no sólo hay que serlo, sino que hay que parecerlo, o sea, no hay que ser sólo decente, además hay que parecerlo; si tú vas al colegio ni eres ni pareces, la gente que realmente me quiere sabe cómo soy yo, si quiero hacer algo lo hago igual fuera que dentro, la realidad es así, pero también hay que dar una imagen; entonces la imagen de niña buena gitana estereotipo general pues no es el de una niña en un colegio, ni hablar con hombres." (Marta, Madrid, 20 años).

"Me costaba, pero iba aprobando, y estudiaba pero, vamos, en casa pues tampoco podía estudiar mucho... Porque estaba estudiando y mi madre pues me llamaba, pues 'Ven a recoger la mesa' o 'Ven a limpiar...', y si tenía que leer un libro, no me podía ver leyendo y me decía mi padre o mi madre que dejara de leer, que me pusiera a limpiar... Mi madre tampoco... no le importaba que yo estudiara... pero también quería que estudiara, y que ayudara en casa... Y yo estudiaba y los fines de semana trabajaba." (Vanesa, Castilla-León, 22 años).

Es importante que entendamos esta dinámica desde una perspectiva procesual. Hay que tener en cuenta que aunque inicialmente persista una concepción negativa de la escolarización, las ideas y preconcepciones respecto a la continuidad académica en la familia se pueden ir modificando a lo largo del tiempo, ante una mayor comprensión del deseo que manifiesta su hijo o hija por proseguir los estudios y un cambio de expectativas basado en resultados y la visualización de opciones concretas y posibles a partir de la continuidad.

El siguiente testimonio nos revela un aspecto clave: la incomprensión del esfuerzo por algo que no puede valorar ni en sí mismo ni como medio para gozar de mejores oportunidades, aunque sólo se perciba su nivel instrumental, por parte de algunas familias: 
"Yo creo que el problema principal del fracaso escolar está en la familia. Habría que hacer comprender a las familias que adquirir conocimientos no es ningún sufrimiento ni nada por el estiIo". (Andrés, Aragón, 18 años).

En efecto, muchos y muchas de los informantes expresan la existencia inicial en sus progenitores de una sensación de extrañamiento e incertidumbre sobre cómo sobrellevar la escolaridad de sus hijos e hijas, bien por falta de referentes en su entorno familiar o vecinal y/o porque ellos mismos no han pasado por el sistema escolar.

Vemos también cómo no existe un apoyo unánime e igual entre los miembros de la familia sobre la escolarización y la continuidad académica y que las experiencias se alejan de los tópicos. Muchas veces es el padre quien ofrece mayor apoyo mientras que la madre es la que pone mayores impedimentos, es decir, a menudo es la que intenta reproducir los roles sexuales tradicionales, especialmente entre las chicas.

\footnotetext{
"Mi padre siempre me ha dao para que estudiara, mi madre no estaba muy convencida. Mi madre le daba igual, además cuando yo no sabía si seguir estudiando o no, ella me dijo: 'Haz lo que quieras, si quieres seguir sigues, si no, pues no sigas', tampoco me iban a decir... no me iba a obligar. Mi padre, en cambio, me decía: 'Venga, sí, estudia', no sé qué, no sé cuánto...' (Victoria, Navarra, 16 años).
}

Pero también se dan situaciones en las que la figura paterna está totalmente ausente y es la madre quien ofrece un mayor apoyo a su hija o a su hijo. En todo caso, hay una multiplicidad de ejemplos que no nos permiten establecer generalizaciones empíricas en este aspecto. Quien apoya la continuidad puede ser tanto de origen gitano como no gitano, madre o padre. En este sentido, tienen mayor peso las relaciones familiares y comunitarias que se establezcan preferentemente con uno u otro grupo.

\footnotetext{
"Como veía que uno de mis hermanos mayores seguía estudiando, pues yo voy a seguir estudiando... Mi madre me ha dicho que utilizaban un libro para todo, para todas las asignaturas, empezó a leer y escribir, y nada más... Mi madre me decía: "Tú sigue, que vales pa estudiar, sigue, que vales pa estudiar... Mi familia también me apoyaba mucho, y al apoyarme... creía que tenía todas las puertas abiertas y entonces ya decidí seguir estudiando hasta que he llegao aquí, hasta $1^{\circ}$ de Bachiller... El principal objetivo: no estar picando en una obra ni nada por el estilo... Mis padres no han sido de esos de: ¿¿Tienes que hacer algo?'; por ejemplo, me ven estudiando y ellos son los primeros que se callan, pero nunca me han preguntao. Si decía: 'Me bajo, no me apetece hacer deberes', mis padres no me decían nada." (Andrés, Aragón, 18 años).

"Mi padre no había ido a la escuela nunca, sin embargo, sí que le hubiera gustado ir, sí que le hubiera gustado ir, y entonces cuando yo estudiaba sí que me decía : 'Yo quería que mi padre me Ilevara a la escuela, porque no me llevaba, y yo, eh, tenía una cartera de escuela de estas viejicas y cuando salían los niños de la escuela, yo me ponía en la puerta y cuando salían los niños de la escuela corriendo, yo me ponía con ellos con mi cartera corriendo como si saliera de la escuela'. 0 sea, que él era una cosa que le hubiera gustao y no lo hizo nunca." (Julia, Aragón, 36 años).
} 
"En cuanto a la formación, mis padres no han estudiado, pero nos han inculcado a mis hermanos y a mí lo importante de los estudios, nos sentimos muy gitanos pero a la vez capaces de hacer lo que más nos gusta sin miedo a sentir que vamos desapareciendo ... (...) Pues me refiero a atreverse a realizar cosas que como no están vistas entre los gitanos, pues te hacen sentir que no es para ti, sino que es cosas de payos (...) Estudiar, hacer un curso, ir por las tardes a tus clases en vez de todos los días al culto (...) Lo que quiero decir es atreverse a hacer algo distinto y bueno, no tiene por qué ser algo malo, sin perder el norte, dices soy gitana y soy gitana pero capaz de superarme y de salir del montón, ¿no?(...) yo misma, sin que esto suponga un drama o un conflicto personal o familiar." (Mercedes, Madrid, 27 años).

"Además, que en mi casa nunca han visto raro el estudiar, si lo hubieran visto raro con 12 años o menos me hubieran quitado del colegio, pero no me quitaron, ni siquiera me decía mi padre que tenía que seguir estudiando, porque ellos tenían pensado que yo debía terminar y terminé con mi Graduado Escolar, mi certificado y todo, incluso terminé el colegio y se lo dije: 'Papá, me han dicho en el colegio que si voy a seguir', mi padre me dijo: 'Sí, sí, ¿qué vas hacer aquí?, no te vas a quedar en casa, ni te vas a venir a vender ... ¿Tú quieres seguir?', y fue cuando le dije que quería hacer Administrativo. 'Lo que tú quieras', me dijo, y eso hice". (Elena, Madrid, 26 años).

Tengamos en cuenta que en multitud de ocasiones son los propios padres, junto a las personas escolarizadas, quienes luchan contra la presión que ejerce su entorno o bien por parte de su familia extensa; en especial, cuando sus hijos/as se encuentran en "edad casadera" y se convierten automáticamente en mozos y mozas. Algunas veces ceden a estas presiones, pero en otras ocasiones no lo hacen.

"En mi casa jamás, eso de decirme no estudies, no te quedes aquí y eso de a los diez u once años quitarte del colegio porque ya vas siendo una moza, eso en mi casa nunca, nunca. El que me ayudó fue mi padre, yo quería hacer Peluquería o Administrativo, me dijo mi padre que escogiera lo que escogiera que le importaba lo que yo quisiera, incluso me llevaba y me traía el primer año del instituto, luego ya no, porque se iba a vender y me iba sola, pero mi padre siempre me apoyó, incluso hubo un gitano que vino un día a buscarme con mi padre y decía que no me dejara allí, que entre tantos payos una gitana... Claro, mi padre le dijo que yo lo había elegido. Quería ser una persona de estudiar un poco más y ser alguien en la vida, incluso terminé quinto y me dijo mi padre que si iba a seguir estudiando... iQué tonta fui por no seguir!" (Sonsoles, Madrid, 26 años).

"En mi casa mandaba mi padre. Quiero decir que sí yo he continuado y he estudiado ha sido porque ha querido mi padre; no porque mi madre le haya influenciado. Le habrá podido influenciar, pero la decisión la tomó él. (...) Que cuando yo empecé a estudiar, mi padre decidió, cuando mi padre decidió que yo continuara estudiando, lo tuvo que decir a sus hermanos. (...) Bueno, le dijeron que si sabía lo que esto podría comportar, claro. Y, bueno, mi padre dijo que sí, que era consciente y ya está." (Verónica, Cataluña, 35 años).

Por otro lado, hay que señalar que, en parte por las expectativas académicas que proyectan los padres y madres en sus hijos e hijas, existe un repertorio de orientaciones 
que se repite muy a menudo entre nuestros y nuestras informantes con titulaciones medias (cursos especializados, ciclos formativos) y superiores (diplomaturas y licenciaturas): profesiones con claras connotaciones 'de retorno' (desde Derecho, Magisterio, Trabajo Social y Educación Social hasta Mediación, Animación, etc.), de trabajo con las personas, vinculadas con los sistemas de protección y promoción social, que tienen una alta consideración entre las familias y comunidades. A veces son los propios chicos y chicas quienes argumentan en este sentido sus elecciones y preferencias, como un elemento importante a destacar como forma de compromiso e implicación del alumno o alumna gitana con su comunidad. Son nuevas formas de adquirir un cierto estatus de referente y de representación más allá del impacto que puedan tener en otros chicos y chicas que estén estudiando todavía: les reclaman sus familiares y personas cercanas para hacer trámites y gestiones, acompañar procesos, etc.

\footnotetext{
"Bueno, mis padres no comparten todo lo que yo propongo, quiero hacer o sueño, pero me quieren y quieren lo mejor para mí, confían en mí, que es lo más importante, y saben que pueden contar conmigo para lo que necesiten, nos llevamos muy bien, somos amigos, vamos a ver: yo soy la mayor y a veces, aunque tengo hermanos grandes, no mayores que yo, pero con sus años ya, ¿no?, pues cuentan conmigo para todo, soy como el mozo de la casa, pa hacer una gestión con el banco, pa llevar de un lado a otro con el coche a mis padres por ejemplo, no sé, se apoyan mucho en mí también, a veces pienso que debería haber nacido chico." (Mercedes, Madrid, 27 años).

"Mi madre quería que yo fuera médico, pero... y quería que me preparara para eso, pero decidí que no, que yo siempre había querido ir a hacer Derecho y me metí en Derecho." (Javier, Madrid, 23 años).
}

En la misma línea, se insiste en que la participación activa de los padres y madres en el centro educativo de sus hijos e hijas es también un factor favorecedor de su éxito escolar en algunos casos.

"... Mis padres siempre que podían iban a las reuniones de padres. Si podía iba mi padre o los dos, y si no, iba mi madre. Mis padres siempre me obligaban a hacer los deberes, y a que estudiara todos los días." (Richi, Castilla-León, 24 años).

Sin embargo, la inmensa mayoría de las personas entrevistadas señalan que la participación de su padre y su madre en el colegio era nula, alegando también que la no participación no constituía un comportamiento insólito, sino más bien mayoritario en su entorno, aunque este entorno fuera no gitano. Incluso alguno de los casos nos indicó la preferencia de que sus progenitores no aparecieran por el centro para pasar más desapercibido. Así pues, no podemos deducir de los casos estudiados que la implicación y el apoyo directos hayan sido factores imprescindibles en la continuidad educativa. De hecho, las experiencias remiten a situaciones muy dispares:

"A mí nadie me presionaba por estudiar, es decir, yo iba al cole porque había que ir, pero no me exigían resultados, un poco se daba por hecho de que, de que yo no iba a ser un gran estu- 
diante (...) Y recuerdo una frase que decía [mi abuela]: 'Bueno, que no vaya... si tampoco el niño ... no va a ser abogao'. Así, con lo cual, yo jamás podría haber sido abogao." (Mariano, Cataluña, 36 años).

"Mi madre se ha pegao unas palizas conmigo, ahí machacando con las matemáticas, me acuerdo que mi madre siempre me dice que las restas no me entraban!!!" (Jesús, Aragón, 29 años).

"Sí, sí han sido exigentes, porque pues yo a lo primero... De mañana, ¡buah!, te levantas... era lo peor, ¿no?, para ir al colegio. Pero nada, pues mi madre pues de pequeño me levantaba ella, me llamaba, pues me cogía, me vestía ella y todo eso. Ya después te empiezas a acostumbrar y después que te tienes que levantar a las 7 y media." (Ismael, Navarra, 15 años).

"... desde muy chiquita mis padres me han inculcado bastantes valores educativos, por lo cual no me ha sido difícil empezar a estudiar (...) A los cuatro años que entonces empezaba la escuela, mis padres me llevaban siempre, cuidaban de todos los requisitos escolares, mis padres no tienen bastante economía, pero siempre han buscado los métodos para que... tanto mi hermano como yo, podamos seguir con nuestro futuro... mi familia me seguía apoyando, que yo y mis objetivos los tengo claros desde bien pequeña, yo quiero llegar a ser alguien para ayudar a los gitanos... y quiero... y yo sé que de la única manera que puedo subir en puesto de trabajo es subir de nivel académico; de hecho, también me sirve personalmente para la vida cotidiana, y mi familia siempre me lo ha sugerido así, con lo cual con mis trabajos hago los estudios." (Pilar, Aragón, 21 años).

\subsection{La dimensión afectivo-relacional}

\subsubsection{Experiencia intercultural}

En distintas ocasiones en los apartados anteriores hemos visto aspectos que remitían indirectamente a las relaciones interculturales y su papel como favorecedoras o como obstaculizadoras de la continuidad educativa en el alumnado gitano y en la percepción de sus familias: el tipo de barrio, el tipo de escuela, el tipo de grupo de iguales, las prácticas y actitudes del profesorado, etc. Aquí nos referimos a algunos aspectos afectivos de esta experiencia, a través de los casos analizados, y a cómo intervienen en relación con la continuidad educativa.

Este factor se ve propiciado especialmente cuando existe una integración urbanística y social y una experiencia en los padres y madres de buenas relaciones interétnicas como personas adultas. Pero, naturalmente, las vivencias son diversas, algunas de ellas francamente agridulces. Por regla general, parece detectarse que las experiencias negativas han sido las menos frecuentes entre nuestros entrevistados y entrevistadas, y cuando se han dado, ha tenido lugar generalmente en las primeras etapas educativas. Por el contrario, la mayoría de las experiencias relatadas son positivas y se les reconoce un papel en el afianzamiento de la continuidad educativa. Esto último es constatable y se manifiesta de forma explícita en algunos episodios críticos hacia el final de la etapa de Educación Secundaria, especialmente entre chicas. 
Así, entre las personas entrevistadas, es recurrente referirse de forma espontánea a la experiencia positiva en la escuela y a que han sentido aceptación por parte de sus compañeros y compañeras de clase.

\footnotetext{
"Con decirte que todos los años me nombraban delegado... Debo tener unas pintas de responsable y organizador que pa qué [risas]. Siempre han contado conmigo y sin ningún problema. Además fíjate, todos mis amigos, bueno, casi todos, son payos." (Pablo, Madrid, 17 años).

"Muy buena relación, yo he tenido muy buena relación siempre. Porque soy una persona que difícilmente me enfado, ya me tienes que hacer cosas pa que yo salte; entonces, no tengo problemas en relacionarme con nadie." (Carlos, Madrid, 30 años).

"Fuera de la escuela mantenía relación con los compañeros de clase. Hacíamos muchas cosas juntos y, de hecho no he perdido la amistad pese al tiempo y la distancia. Cuando voy al pueblo me junto con mis amigos antiguos y vuelvo a hablar como antes. Todos mis amigos eran payos, e iba al colegio con ellos, y luego fui al instituto con ellos." (Anabel, Cataluña, 42 años).
}

Los casos que relatan experiencias negativas, de rechazo y de racismo, por parte de algún compañero o compañera de clase son excepcionales, aunque también los hay, y a veces se aduce la experiencia negativa como una especie de espoleta hacia la continuidad,

"... porque en mi casa se vivía, en ocasiones, el racismo de la población no gitana, eso me ayudó a estudiar, o sea, que el rechazo sí que me animó y a decir pues, voy a ver, vamos a indagar en esto, a ver por qué no somos iguales, por eso estudié en parte." (María, Aragón, 26 años).

"Cuando faltaba alguna cosa en clase, todas las miradas se volvían hacia nosotros o algún comentario de algún profesor (...) todo el mundo miraba a esta chica gitana y a mí." (Oscar, Aragón, 27 años).

o bien se interpreta la dificultad de relación inicial a causa del desconocimiento y el miedo:

"Más que sentirse respetado por los payos, lo que percibía era que la gente tenía miedo, [nos] tenía miedo... El racismo viene dado por el miedo". (Eva, Aragón, 31 años).

Además, aunque son pocos los casos de alumnos y alumnas gitanas que no se relacionaban con el resto, la sensación de soledad a la que hemos hecho referencia en apartados anteriores, no siempre es simbólica, ni está imbricada dentro de las estrategias de invisibilidad. Personas de distintas edades mantienen recuerdos muy dolorosos en ese sentido:

\footnotetext{
"No tenía amistades en clase... era bastante sensible, entonces yo no... no iba alardeando por ahí de que era gitano, pero tampoco, si alguien me preguntaba pues, no lo negaba, siempre lo confesaba." (Adrián, Madrid, 25 años).
} 
"En el primer cole (...) Ahí sí que estaba sola, y eso que iban al colegio niñas de mi barrio. Y, nada, venían... vamos, que eso nunca se me olvidará, venían a quitarme el bocadillo... se me lo comían y se iban... Siempre me hacían lo mismo, y siempre estaba sola... Yo creo que era porque era gitana... porque como son del barrio, y... y sus madres, supongo que también se lo decían las madres... porque los niños ¡qué van a saber con cinco años...! Me Ilamaban 'gitana', yo qué sé, para insultarme me Ilamaban 'gitana'... Yo no sé por qué me llamaban 'gitana', si decirme eso para mí no era un insulto. Pero para ellos sí. Por eso, me llamaban 'gitana'." (Vanesa, Castilla-León, 22 años).

"Yo notaba, vamos a ver, una cierta soledad; me sentía muy solo en el colegio. Y yo creí que era por eso, porque nunca había salido de casa, me imagino que como todos los demás niños, pero aparte de eso, es que las gentes te acorralaban un poco por ser gitano, y lo sabía... (...) Y yo, que conste, que lo he intentado, de verdad. Yo, realmente, nunca he tenido mal genio ni he sido nervioso (nervioso exteriormente, por dentro sí); siempre he procurado (a pesar de que nunca he sido un niño terrible, travieso, a pesar de eso) siempre he procurado ser mejor. Pero no he conseguido nunca llegar a romper esa muralla, que hay en medio. Esa muralla no se cayó nunca, a pesar de que yo lo he intentado; yo sí que la saltaba, yo me la he saltado millones de veces; pero mis amigos no." (Armando, Castilla-León, 49 años).

Los efectos de las relaciones con las y los compañeros de clase, cuando éstos se van convirtiendo en el grupo de iguales de referencia para la persona, se acentúan especialmente en la etapa de la adolescencia. Esto puede conllevar un cierto distanciamiento de su grupo familiar y comunitario, como sí hemos visto anteriormente, y se generan nuevos interrogantes, nuevas inquietudes, y también nuevas expectativas:

"Empiezas a conocer otro tipo de gente, empiezas a relacionarte con gente que dice otro tipo de cosas, te empiezan a formar en cosas distintas, el lenguaje también, hay otro tipo de lenguaje distinto, y que tú también eres capaz de absorber este tipo de cosas." (Emilio, Cataluña, 36 años).

"Pues porque yo, yo les veía a las otras, a mis amigas, a las compañeras que ellas estudiaban y que iban al cole, que hacían cosas y como yo siempre estaba con ellas pues yo seguía ese bloque, ¿no?... Si hubiera estado más relacionada con gitanas quizá no hubiera estudiado. No, no hubiera estudiao, no hubiera hecho nada. Me hubiera casado y hubiera tenido una familia y ya está. Ésa es toda la meta." (Sara, Navarra, 36 años).

"Nunca tuve claro que quería llegar a la universidad hasta la tarde que acabé los exámenes de selectividad, yo me presenté a la selectividad pensando: 'Me lo saco por sacármelo, por si tengo suerte de pedirme con algún gitano que me deje estudiar o algo y por tenerla, por satisfacción personal'... Hasta que ya esa misma tarde hablé con una amiga mía y con su madre y me dijeron: 'Chica, estás como una cabra... si has llegao hasta aquí estudia, si no te deja tu familia pues búscate las habichuelas como puedas y sácalo pa adelante', y ya eso me hizo pensar, ¿sabes?, yo sabía que no podía estudiar en mi casa, entonces, como sabía que no podía hacer nada, la única alternativa que tenía era irme de mi casa pa estudiar, pero claro, a mí ni me entraba en la cabeza, pero si tienes a alguien que te lo dice, que tiene su propia idea, lo ves posible." (Marta, Madrid, 20 años). 
Algunas y algunos de nuestros informantes señalan como un factor de integración intercultural y de anclaje con el sistema escolar la participación en actividades extraescolares, especialmente en las deportivas. Pero este fenómeno del deporte como factor de estímulo para la integración escolar se da sobre todo en los chicos: el fútbol, y en algún caso otro deporte, ha constituido un factor favorecedor de integración en varios casos de estudiantes gitanos. Estas actividades introducen formas de sociabilidad no académicas pero sí escolares, más allá de las redes de parentesco, desconocidas en generaciones anteriores, que permiten establecer otros tipos de continuidades.

\footnotetext{
"Aparte de que yo... por ejemplo, en quinto me apunté al equipo de baloncesto, y eso me ayudaba mucho. A mis padres también les gustaba eso. Yo todos los años me iba a jugar al baloncesto, tenía el chándal del equipo del colegio. En el instituto volví a apuntarme al equipo femenino." (Laura, Castilla-León, 26 años).

"Para mí, jugar al futbol con los compas del cole era muy importante, para mí y para todos." (Paco, Castilla-León, 19 años).
}

En definitiva, la mayoría de los entrevistados y entrevistadas sostienen en sus reflexiones como personas adultas que las relaciones interculturales, el contacto intergrupal, han sido para ellas y para ellos una fuente de satisfacción personal. Dicen haber podido elegir aquellos aspectos (se refieren a prácticas, valores, concepciones) propios de la "cultura mayoritaria" y de la "cultura gitana" que mejor les satisfacen, o al menos así lo expresan:

"El estar con payos es positivo. Es la posibilidad de conocer a otra cultura... otras costumbres, etcétera. Igual a esas edades tampoco te paras a pensar si es diferente a ti o no, ¿no?, simplemente es tu compañera y ya está, pero los hábitos que se van tomando..." (Laura, Castilla-León, 26 años).

"En el colegio, el único gitano era yo, yo no estaba en un barrio gitano, y a ver, intentaba pasar desapercibido en clase. Nunca nadie se metió conmigo. (...) con mis amigos del colegio pues tenía una relación perfecta, me lo pasaba bomba, en mi casa teníamos una relación totalmente gitana, pero esto no significa que yo tenga que trasladar eso a la calle, ni a la vía pública, ¡ni hacer una manifestación de gitaneidad!" (Mariano, Cataluña, 36 años).

"Pero con el tiempo veo que era la fusión perfecta, sabes que eres gitano, y los gitanos buscamos un futuro más intercultural. Pero no hacía falta luchar, ni el uno, ni el otro, esto era totalmente inadmisible. Pero los gitanos se separan de los que no lo son, también lo suelen hacer los payos, pero bueno, de cara a mí, mi propia lucha interna, quiero decir con los gitanos... no hace falta construir nuestra identidad oponiéndonos a los otros, podemos construirla en esa relación con los demás. Tradicionalmente, ha habido un rechazo de los gitanos hacia el resto de la sociedad, entre otras cosas." (Ramón, Cataluña, 44 años).

Como en otros aspectos analizados, experiencias y opiniones se forjan y se influencian a medida que se suceden en el tiempo. Unas compañeras o compañeros de clase pue- 
den intimidar y separar en un momento del ciclo vital, pero otras y otros llegan a ser decisivos en la continuidad académica, como referentes, apoyos escolares y vínculos emocionales. Es el caso de una de nuestras informantes, que lo relata de manera simple y contundente:

\footnotetext{
"Si no hubiera sido por la gente de clase yo no lo termino, porque me ayudaron un montón al final, porque al final yo iba muy mal y ellos me ayudaron... Se lleva peor de pequeña. Porque te dicen: 'Yo no voy con esa porque es gitana' ... Yo tenía miedo de venir al Instituto." (Adriana, Aragón, 18 años).
}

\subsubsection{Socialización y pautas de género diferenciales}

Pero las complicaciones relacionales surgen también durante el período de la adolescencia, cuando los chicos y las chicas mayoritarios -compañeros y compañeras en el aula- empiezan a acudir a espacios de ocio nocturnos y comienzan a relacionarse de forma afectiva con sus iguales con mayor intensidad. Aunque la presión por el mantenimiento de límites en este sentido por parte de los padres y las madres gitanos se puede detectar en estudiantes de ambos sexos, no hemos tenido ni un solo testimonio femenino en que las familias y personas adultas responsables hayan sido permisivas y hayan autorizado unas prácticas de sociabilidad semejantes. El siguiente fragmento relata una situación recurrente para una chica:

" [En el Instituto] Ya me costó allí más, porque ya salí de mi grupo y sí que entré con chicos. Y a mí me costó mucho la relación con chicos porque como en casa siempre: 'No se juega con chicos, no se...', pues yo siempre me costó mucho más allí... [Al cierto tiempo de estar en el Instituto] Se fomentó más la cuadrilla. Empezamos a tener más amigas, más, se amplió, se amplió. (...) Yo sufría, no me dejaban salir. Pero bueno, luego pues los sábados salían, yo no salía. Salía, podía salir, pues, si salían de diez a doce, pues yo salía de diez a once. No, ellas salían más. No tenía mucho dinero. Podía ser que me costaba más relacionarme por eso... Y luego pues empezaban, pues, ya a ir a la discoteca y yo no tenía dinero tampoco. Aparte, que no me dejaban. Eso sí que era prohibitivo. La discoteca ya era lo prohibido y prohibitivo. Y eso puede ser con 14 años, 14, 15 puede ser que ya empezaron la discoteca y eso. Y yo ya allí, se acabó. En esa época sí que ya no, ya no salí...." (Sara, Navarra, 36 años).

Este punto, el de la experiencia divergente y la ruptura con el grupo de iguales forjado en la institución escolar, nos lleva inevitablemente a considerar los aspectos de la socialización familiar en términos de género. Como muestran las trayectorias de algunas mujeres gitanas con experiencias de éxito y continuidad, éstas se han visto favorecidas cuando ha existido en su familia una posición socio-cultural más integrada en las relaciones y pautas entre los sexos. Es decir, los roles en su hogar han sido menos rígidos y opuestos a la formación académica de la mujer y de su incorporación al mercado laboral extradoméstico y extrafamiliar, más allá de las ocupaciones disponibles dentro de su entorno familiar y comunitario. 
Pero éstas no han sido las condiciones habituales para la mayoría de nuestras entrevistadas, sino que la familia mantenía una postura más tradicional y recelosa al respecto, y ha sido la propia joven la que ha tenido que ir convenciendo y negociando con sus padres y buscando soluciones de compromiso -como analizaremos posteriormente-, e incluso en algunas ocasiones Ilegando al enfrentamiento para seguir estudiando. Pero hablar de posiciones integradas en este campo merece una reflexión más precisa, cuando existe el riesgo de confundir la intensidad y el contenido de las diferencias en los roles de género a nivel intradoméstico (la división de tareas) con la existencia de unas pautas de género que excluyen la continuidad educativa de las chicas o que enfrentan completamente su dedicación escolar con su identidad étnica y su consideración moral. A través de los testimonios de dos chicos jóvenes respecto a sus hermanas se hace más que patente esta distinción, la semejanza de la primera situación con la experiencia de la sociedad mayoritaria todavía hoy y la absoluta diferencia de la segunda:

\footnotetext{
"Si te digo la verdad, pues nosotros, vamos, mi madre pues limpia, limpia toda la casa, por la mañana o cuando tiene tiempo limpia, todos los días. Nosotros, mientras, estamos en el colegio, luego venimos, venimos mi hermana y yo, pues comemos, ¿no?, y pues yo cojo mi plato, lo meto en el lavavajillas, ¿no?, y después me voy al sofá o a cualquier sitio. Mi hermana pues, ¿qué hace?, barre, o limpia la mesa, o hace lo que... ayudar a mi madre, hace lo que sea. No sé, yo meter en el lavavajillas, por decir mi madre... Yo tengo pues una tarea en mi casa: sacar la basura. Yo soy el basurero de mi casa." (Ismael, Navarra, 15 años).

"Cuando fue un golpe realmente para la comunidad fue cuando mi padre quitó a mi hermana del colegio al cumplir los 13 años.... recuerdo la conversación que mi padre decía a mi madre: 'Ya estás quitando a la niña del colegio', y mi madre decía: '¿Por qué? 'Porque la he visto venir con un amigo desde el colegio hasta casa' [contestó mi padre]." (Oscar, Aragón, 27 años).
}

Esto no quiere decir que la asignación de las tareas domésticas a las mujeres en exclusiva tenga un papel menos importante que las ideas sobre la inadecuación de la continuidad educativa por ser chica. Las cargas de las estudiantes y las dificultades por compaginar estas responsabilidades con los requisitos cada vez más exigentes de la continuidad escolar, pueden asemejarse a situaciones mayoritarias en las que no se cuestiona la continuidad, pero pueden tener una consideración prioritaria incluso durante la enseñanza obligatoria. Sin embargo, hay que distinguir varias situaciones: la obligación de realizar aquellas tareas que impiden seguir con normalidad el curso escolar en términos de horarios mutuamente excluyentes (por ejemplo, quedarse en casa cuidando hermanos o personas enfermas), y las que requieren una organización y un esfuerzo extraordinario para hacer compatibles unas y otras responsabilidades en términos de tiempo disponible (limpiar, comprar, cocinar, lavar, planchar). Sorprende la corta edad de la siguiente informante al considerar su relato sobre la interrupción temporal de sus estudios por estas razones:

\footnotetext{
"Yo intenté combinar lo que son los estudios con la carga familiar que tenía que llevar. Que era cuidar de un padre bastante inestable físicamente y también estaba el pobre hombre triste. El
} 
tener que unir una familia y los estudios... y es que no tenía horas tangibles para hacerlo. Eran siete horas de clase, cuatro o cinco de hacer la casa, la comida... y es que yo tenía que tener 26 horas al día, y luego ocho horas para dormir. Que no tenía horas... entonces, ya en octubre, es que no tenía... 0 sea, es que yo quería hacer todo, pero no podía.. Entonces, pues, eso se lleva bastante mal, así que te hace madurar... Yo dejé de estudiar.. Dejé de estudiar dos años." (Soledad, Castilla-León, 18 años).

Existen casos de experiencias de éxito y continuidad, o de intentos diversos en esa dirección, en todas las situaciones mencionadas y nos ocuparemos de ellas en el capítulo siguiente, donde también observaremos la persistencia de una ideología sexista completamente tradicional en éste y otros ámbitos, también entre los chicos con éxito y continuidad académicas. Pero avancemos algunos testimonios en este sentido:

"Los fines de semana en vez de dedicarles a otras cosas, pues les dedico a hacer limpieza general. Digamos que ahí tendría que cambiar un poco ... Yo creo que no les tengo que demostrar nada a mis padres, pero me siento mejor conmigo misma. Pero ellos se sienten muy bien dicien-

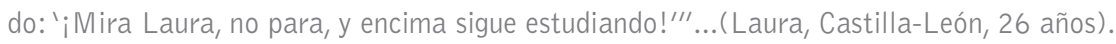

"El monopolio [del trabajo en casa] lo tenían las mujeres: mi madre y mi hermana. Ahora yo le ayudo bastante: hacer las camás, poner y quitar la mesa... Mi padre ve bien que ayude a mi madre. Él no ayuda, pero me dice que yo lo haga. A lo mejor le dice a mi madre: ¿¿A qué te voy a ayudar?: ¿Para que te dé vergüenza?' Es que mi madre tampoco quiere que le ayudemos." (César, Castilla-León, 22 años).

Algunos testimonios, además, muestran indicios de cambio sociocultural en el mismo sentido en que va ocurriendo entre la población mayoritaria cuando hijas e hijos estudian, es decir, no sólo no contribuyen los hijos hombres a la realización de las tareas domésticas básicas, sino que las chicas estudiantes también participan menos en ellas:

"... pero en lo que se refiere a mi hermano, en temas domésticos cero, es algo que para eso, como dice él, estamos mi madre y yo; pero incluso yo he de decir que para ser hija única no hago ni la mitad de cosas que podía hacer mi madre." (Pilar, Aragón, 21 años).

\section{3. 3. Éxito escolar, habilidades sociales y proyecto personal}

En este punto es básico señalar cómo, de forma directa o indirecta, todos nuestros entrevistados y entrevistadas nos remiten a su experiencia de haber recibido claros mensajes de pertenencia al entorno escolar. Así, incluso en condiciones socio-económicas adversas, la persona encuentra un factor de motivación para el éxito y la continuidad proporcionado por alguna experiencia socio-afectiva de valoración positiva. En tales circunstancias, se puede superar también la presión por el aban- 
dono procedente del grupo de iguales ajeno al ámbito escolar y la presión del contexto familiar y comunitario de origen. Así, hemos identificado tres factores de peso para la continuidad que no habíamos contemplado en las hipótesis iniciales de la investigación: la toma de conciencia de los éxitos escolares iniciales, la posesión de habilidades sociales y comunicativas, y el propio empeño de la persona en su proyecto de seguir estudiando, a pesar de circunstancias desfavorables y presiones del entorno en dirección opuesta.

En primer lugar, el éxito constituye siempre una motivación fundamental para la continuidad en cualquier aprendizaje. Esto es obvio: la persona que empieza bien y le va bien, se siente reforzada y más animada a continuar estudiando. En general, el éxito escolar genera más éxito. Así pues, el hecho de obtener buenos resultados académicos y buenas notas constituye un estímulo importante para el logro del éxito y la continuidad escolar. Muchos padres y madres gitanas dejan estudiar a sus hijas e hijos mientras obtengan buenos resultados, no así si empiezan a suspender ( $y$, sobre todo, si se trata de una chica). Este mismo paso dieron hace unos años los padres y madres de las clases sociales medias y bajas de los grupos sociales mayoritarios (hoy, sin embargo, en los grupos sociales mayoritarios insisten a sus hijos e hijas para que sigan estudiando, aun cuando no obtengan en esos momentos buenos resultados académicos).

Pero el impacto del éxito inicial, según las experiencias y trayectorias analizadas, es aún mayor cuando se reconoce y se comparte explícitamente por parte de profesorado y la familia. Esta identificación y comunicación genera una situación de refuerzo y halago (en algunas familias en situación más desfavorecida, también de posible desconcierto momentáneo, por ser algo poco contemplado inicialmente). Por lo tanto, es básico verbalizar y comunicar el éxito y la capacidad de la persona que estudia en todos sus ámbitos de vida cotidiana. En la mayor parte de los casos se relata cómo los resultados académicos eran buenos o muy buenos, siendo un alumno o alumna considerada brillante. Esta explicitación es más frecuente entre las chicas que entre los chicos.

\footnotetext{
"Yo tenía beca, claro, o sea, yo era una chica con notas en aquellos tiempos, y me daban beca.." (Yolanda, Castilla-León, 29 años).

"Luego, pues siempre me ha gustado sacar buenas notas. (...) No es que estudiara más, pero tenía un ritmo más continuo. Sólo me importaba eso. Yo siempre decía: 'Yo de mayor quiero ser profesora... yo de mayor quiero ser... Sí, yo ahí lo tenía muy claro." (Laura, Castilla-León, 26 años).
}

Es obvio que en algunos casos de gitanos y gitanas que han alcanzado estudios medios y superiores se encuentran simultáneamente los factores de inclusión familiar previa (a nivel académico, urbanístico y económico), la implicación familiar en los estudios, la existencia de un grupo de iguales que continúa estudiando y con el que tiene una buena vinculación, las habilidades sociales, los buenos resultados académicos iniciales y la determinación del propio estudiante de proseguir estudiando, así como el apoyo del profesorado.

En segundo lugar, dentro de esta perspectiva, otro factor que ha favorecido tal vez no el éxito en sí, pero sin duda la continuidad en situaciones de toma de decisiones -se 
desprende de la experiencias y trayectorias de nuestros entrevistados y entrevistadas, aunque en muchos casos no sean conscientes de ello- lo constituyen las habilidades sociales (competencia social, asertividad, habilidades comunicativas). Son con frecuencia personas que ante posibles señalamientos y presiones de una u otra parte saben responder de un modo airoso (ni encolerizándose ni acomplejándose), sino de una manera cordial, conciliadora, positiva, e incluso en ocasiones con humor.

Resulta evidente que, además de los elementos propios de la personalidad individual, las experiencias de sociabilidad plurales, compartiendo o participando de relaciones con miembros de la minoría y de la mayoría, promueven el desarrollo y la adquisición de tales habilidades. Estas habilidades generan otras, básicas en el tema que nos ocupa, como la capacidad de negociación para hacer efectiva la propia voluntad.

En tercer lugar, a través del análisis de los casos de los chicos y chicas jóvenes gitanos que han logrado una mayor continuidad académica hemos constatado que la mayor parte se caracteriza por su tenacidad y empeño personales (frente a dificultades intrínsecas de tipo intelectual y académico y frente a situaciones de presión por el abandono) ante los estudios, unido a su habilidad social para negociar con su familia y su entorno familiar. Estos dos factores están presentes en la práctica totalidad de las mujeres entrevistadas. Se añade el hecho inequívoco, también señalado por toda Ia literatura disponible, de que nuestras entrevistadas han debido desarrollar un rol doble, demostrando por encima de toda duda su compromiso con la mayoría de expectativas familiares depositadas en su condición de mujeres y con todas las obligaciones derivadas de una situación de división sexual del trabajo intradoméstico tradicional.

Las familias gitanas con frecuencia están expectantes con respecto al colegio, y es el propio alumno o alumna el que con su decisión y determinación consigue que sus familias vean bien el que siga estudiando. Éste es uno de los aspectos en los que se pone en evidencia la divergencia de motivaciones, estrategias y posibilidades de hombres y mujeres gitanos frente al éxito y la continuidad educativa. Muchas de nuestras entrevistadas disfrutan estudiando y mencionan que esto constituye una liberación para ellas. Sin embargo, a partir de ciertos momentos clave en el ciclo vital, los chicos parece que no ganan mucho con la continuidad, porque en su medio ya tienen una posición claramente favorable frente a la de las chicas.

Por otra parte, muchas de nuestras informantes gitanas que han estudiado o están estudiando se mantienen solteras o se casan con no gitanos, situación anteriormente desconocida en la experiencia cultural gitana. Este extremo puede constituir en sí mismo una presión diferencial para las chicas, mientras que las opciones derivadas de la continuidad académica de los chicos no se modifican, al menos en teoría92. Por eso podemos hablar en muchos casos de proyecto, en el caso de ellas de forma más clara:

92 En este punto debemos constatar que, además de la soltería de las mujeres, aparece la de los hombres, aunque pensamos que tiene otras características, ya que entre éstos sí hemos documentado casos de matrimonio con mujeres sin instrucción y/o con mujeres varios años más jóvenes que ellos. En este sentido, su estrategia matrimonial sigue abierta y ellos pueden decidir qué opciones desarrollar, no así en el caso de las chicas con instrucción dentro del contexto gitano. De hecho, tenemos más hombres solteros en nuestra muestra de casos, incluso entre los mayores de 30 años. Las situaciones de pareja menos convencionales, como la cohabitación, sólo las hemos podido documentar entre mujeres, tanto en las muestra de los 50 casos analizados como en el registro general en curso. 
"Mi meta por lo menos era llegar hasta aquí, ahora ya veremos que meta me pongo, pero yo por lo menos, ya te digo...(...) Porque me niego a llevar la vida de una gitana, no la vida de una gitana, sino la vida de las gitanas que llevan ahora. (...). Yo no tengo por qué estar aguantando a un marido cuando lo puedo aguantar dentro de muchos años, ¿no?" (Victoria, Navarra, 17 años).

Así, la convicción y la tenacidad de la propia alumna se conjuga en muchos casos con una disposición extraordinaria para colaborar en el trabajo doméstico y en la contribución a los ingresos familiares: a la joven estudiante gitana se la presiona a menudo para que cumpla simultáneamente con sus obligaciones como estudiante (buenos resultados académicos como prueba de que su empeño va 'en serio'), desde su definición de miembro femenino de un entorno familiar tradicional (responsabilidades domésticas y cuidado de personas, trabajo extradoméstico) y desde las presiones comunitarias a las que está expuesta y probablemente comparte su familia:

\footnotetext{
"A mí me gustaba mucho estudiar. Yo siempre he sido un poco, un poco seria, ¿sabes? No he sido nunca.... hay gente muy extrovertida, yo nunca lo he sido demasiado. Puede ser que lo he sido cuando era más mayor, porque cuando uno se hace mayor, uno aprende a ser más extrovertido con la gente, ¿eh? Pero no lo he sido demasiado. A mí me gusta mucho estar en casa, leer mis libros, a mí me encantaba estudiar, me gustaba mucho. (...) Yo iba encantada, para mí lo que me gustaba era ir al cole. Claro, yo estaba, yo qué sé, unos días sin ir al cole, porque estaba enferma, o todas las vacaciones de verano, y yo estaba, lo que quería era volver, y además yo me metía a jugar, y yo no jugaba con muñecas ni nada, jugaba a bibliotecarias, je, je, je,.... Sí, sí, sí. Me gustaba mucho, me gustaban mucho los libros". (Verónica, Cataluña, 35 años).
}

La mayoría de las mujeres estudiantes entrevistadas se autodefinen como "muy tenaces y luchadoras" ("Yo desde pequeña lo tenía muy claro..."). En el hombre que estudia puede haber existido un componente de apoyo familiar ("Mis padres me animaban a que siguiera estudiando", "Mis padres me obligaban a hacer los deberes" ...); sin embargo, en la mayor parte de las mujeres se detecta que más que el apoyo familiar, ha sido decisivo su propio empeño personal. Este esfuerzo e implicación se ve acompañado en bastantes ocasiones por la implicación de su padre o de su madre. También ocurre en algunos casos que dicho apoyo ha sido fuerte para que estudiara hasta un determinado nivel, y luego es la propia chica la que se plantea seguir estudiando más allá de esas expectativas familiares iniciales.

Asimismo, en muchos casos, la capacidad de negociación les ha posibilitado estudiar sin tener que llegar a una ruptura con su familia y/o su entorno. Esta actitud conciliadora les ha permitido mantener la relación con su familia y/o su entorno, pero esto ha sido, en ocasiones, a costa de perder ciertas oportunidades académicas y laborales, al menos temporalmente. Donde existe un entorno familiar y/o vecinal desfavorable, el empeño en llevar a cabo un proyecto propio se torna un eje fundamental para que la alumna o el alumno pueda seguir adelante y cumplir con sus expectativas académicas, llegándose a una solución de compromiso que se refleja en los relatos de vida de las gitanas entrevistadas: ser buenas estudiantes, "formales" desde el punto de vista 
tradicional/patriarcal, y que colaboran activamente en el trabajo doméstico y/o con trabajos fuera del hogar.

A la mujer se le exige muchísimo más que al hombre: la chica tiene que demostrar a unos/as y otros/as que por estudiar no deja de ser gitana, y que siendo gitana puede estudiar. Mientras que el chico que quiera estudiar está exento de tareas y se le cuestiona menos su etnicidad en términos morales. La gitana estudiante tiene que aplazar la boda93 (que aparece actualmente como el centro de la gitaneidad, y no admite una declaración que no contemple tal posibilidad a priori), pero a cambio debe cumplir en los estudios y en la casa.

Sin embargo, algunos de los casos recogidos relativos a mujeres en proceso de estudios post-obligatorios han llegado al enfrentamiento abierto y a la ruptura con parte de su familia, que le impedía la continuidad. De estas cuestiones nos ocupamos en los siguientes capítulos.

93 Se da el caso de que una chica y un chico gitanos, ambos con estudios superiores, se conocieron y se enamoraron en uno de los encuentros organizados a nivel estatal que reúne con cierta periodicidad a gitanos titulados y que desde el momento en que la relación se formaliza ante ambas familias a la chica le impiden que vuelva a acudir a otros encuentros para preservar su buena imagen ante la familia del novio. 
Experiencias y trayectorias

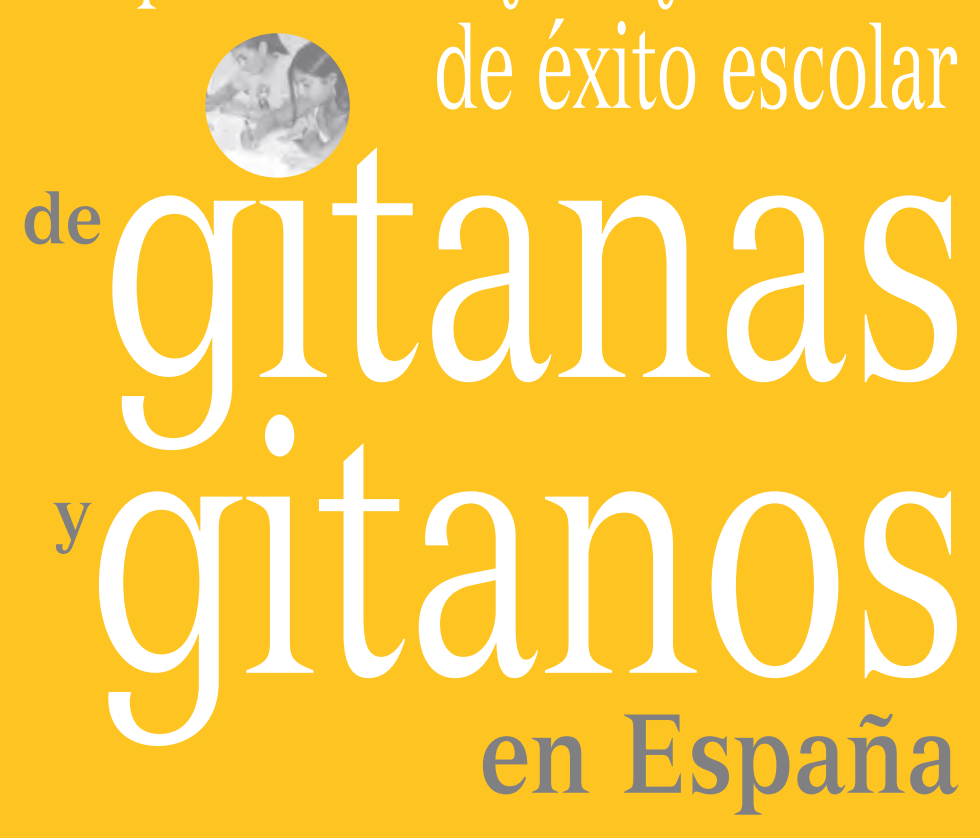

\section{| TERCERA PARTE |}

Gitanas y gitanos en la encrucijada

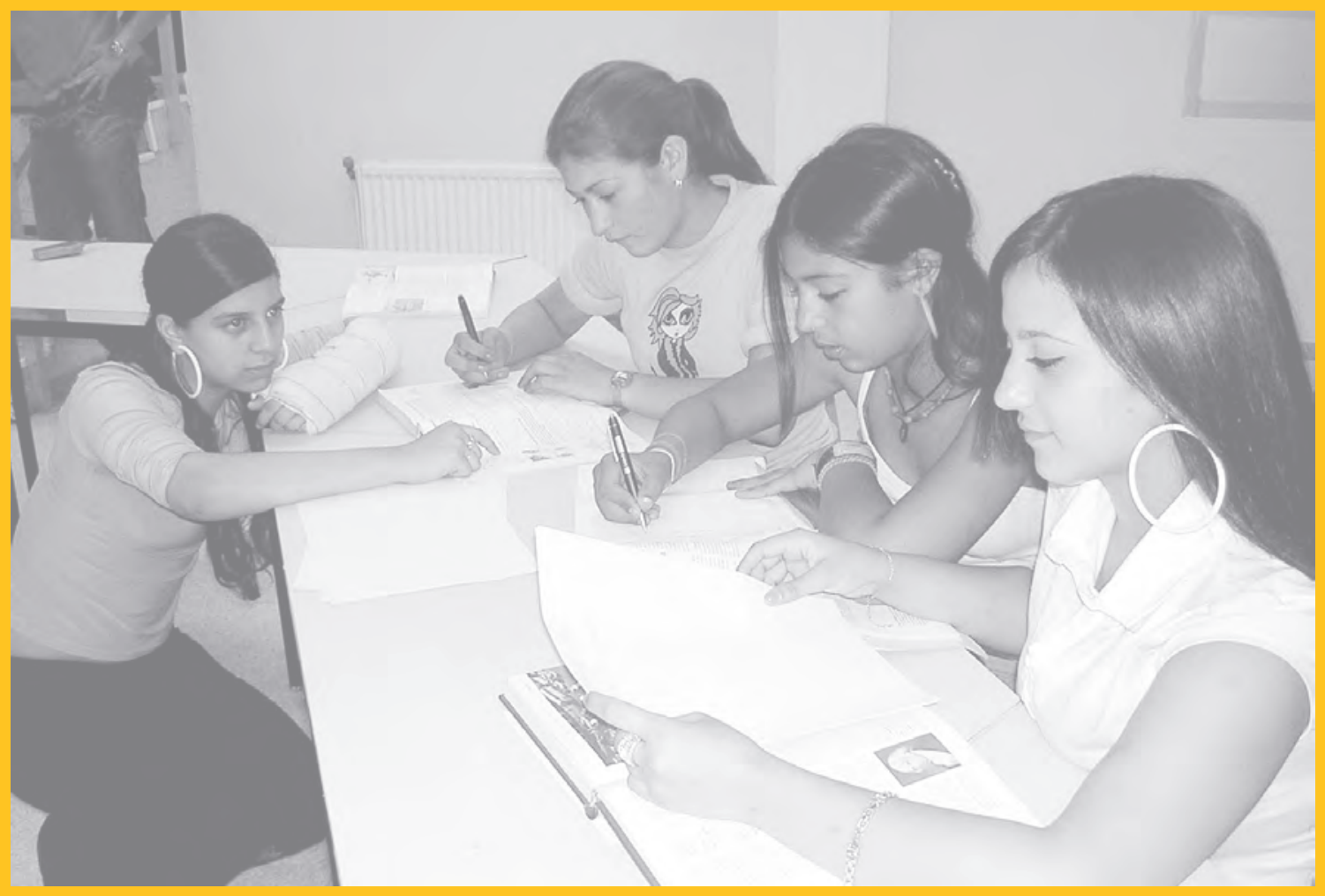




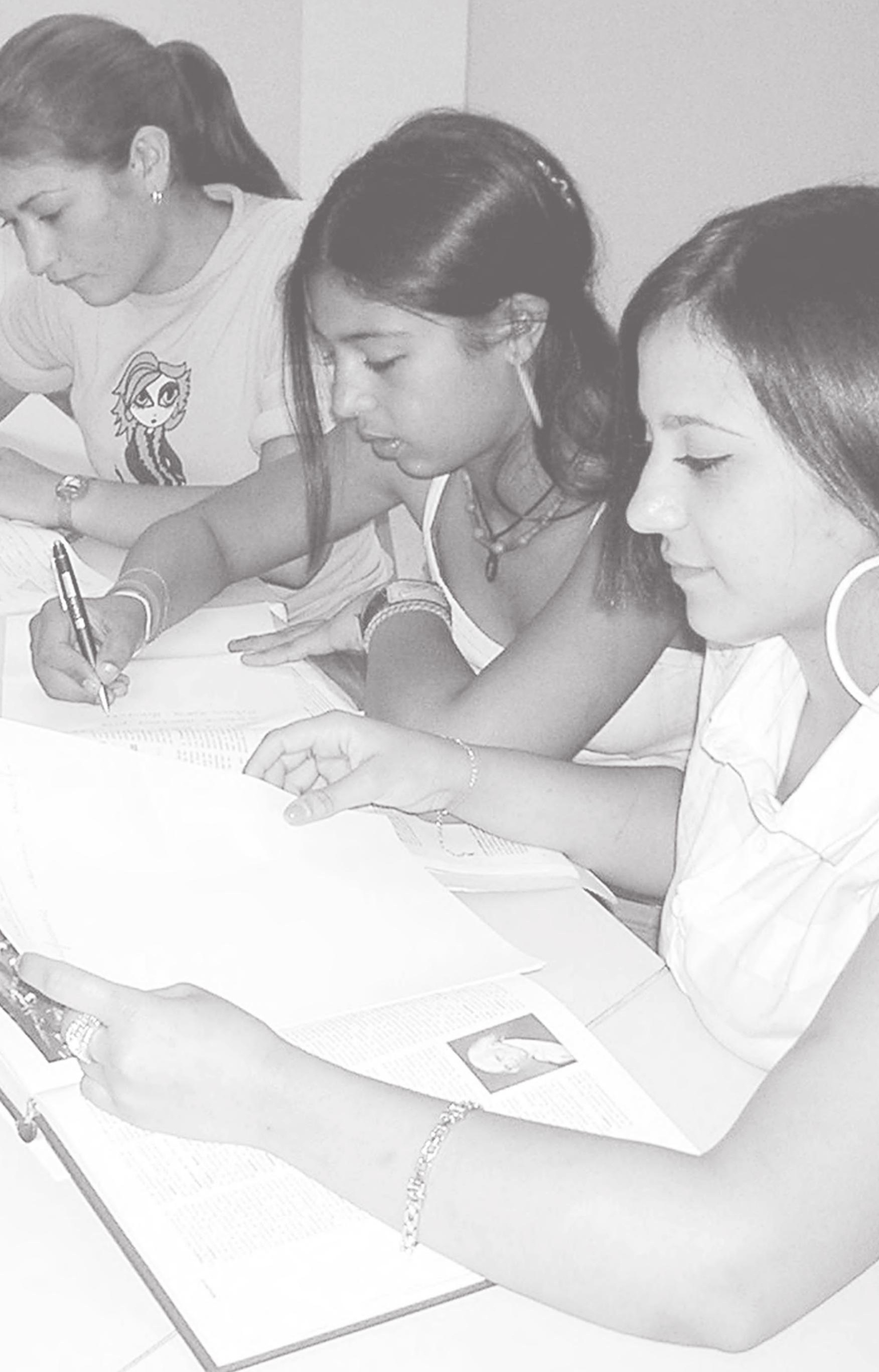




\section{CAPÍTULO 5: CUESTIONES DE GÉNERO, EDUCACIÓN Y RELACIONES INTERCULTURALES}

\subsection{Desigualdades por razón de sexo en la valoración y en el apoyo educativos}

Entre la población gitana, así como entre la población mayoritaria en épocas recientes, con frecuencia los padres esperan más y se interesan más por las realizaciones de sus hijos que por las de sus hijas y tienen ambiciones más elevadas relacionadas con los estudios y la vida profesional de ellos. Por lo tanto, están más dispuestos a realizar mayores sacrificios para que continúen los chicos, siempre en el caso de que tales padres y familias consideren la continuidad educativa como una opción para ellos, actitud que no está ni mucho menos extendida, como hemos visto.

Por otra parte, el sexismo mayoritario y el relativismo mal entendido se suman a esta diferenciación: hemos llegado a documentar casos en los que los profesionales -incluso, algunos mediadores- intervienen de un modo más incisivo si hacen una gestión con una familia relacionada con el absentismo de un chico que si la que falta es una chica, situación mejor aceptada implícitamente.

Entre la población gitana de mayor edad que ha pasado por la Universidad encontramos un número superior de hombres, pero esta tendencia no parece ser paralela entre la gente más joven. Es indudable que en épocas pasadas pero recientes el ser chicos jugó a su favor para continuar estudiando, entre la población gitana igual que entre la población mayoritaria. Para algunos casos de gitanas universitarias de mayor edad el hecho de proseguir estudiando les supuso enfrentamientos serios con alguno de sus familiares. Y hoy, a pesar de la evolución habida, todavía persiste esta idea. Tanto ellas como sus familias se arriesgan a la pérdida de prestigio. Una de nuestras entrevistadas, al referirse a sus intenciones de continuidad académica, confiesa: "Mi padre, por él me dejaría seguir estudiando, pero por los demás no me deja".

Al finalizar los estudios, la situación también puede ser distinta para mujeres y hombres. Algunos chicos no son bien mirados mientras estudian, pero cuando obtienen una acreditación se les considera con prestigio y se les hace llegar explícitamente esa consideración. A las chicas no siempre les mejora esta consideración con las acreditaciones, puesto que se sigue considerando su éxito social desde la perspectiva del matrimonio, que generalmente se aplaza o se aleja definitivamente. La continuidad escolar de las chicas gitanas sigue constituyendo en muchos ámbitos un tema que se contempla con mucha cautela y prevención, si bien existen cambios y se plantean dudas, y muchas familias están expectantes, esperando a ver qué pasos dan las demás familias.

Además, se da poco crédito a los intereses de las mujeres por seguir estudiando o bien se considera de forma diferencial el mismo interés que muestra un chico o la existen- 
cia de un interés sólo medio en ellos y ellas. Por ejemplo, uno de nuestros entrevistados recuerda que él en el IES no estudiaba gran cosa y era bastante "juerguista" y que se siente orgulloso de "haber compaginado las dos cosas". Sin embargo, con relación a su hermana (que tiene una actitud en el IES similar a la que él tuvo, de estudiar sólo lo justo y querer pasárselo bien), por las misma razones por las que él se siente orgulloso de su estrategia de paso por el IES, considera que ella debe abandonarlo. Lo que en su caso es destacable por ser 'listo', en el caso de su hermana o de su hija es inaceptable por ser 'inmoral'.

\footnotetext{
"Las chicas corren "el doble de peligro", si una chica no estudia mucho y la gusta mucho salir y divertirse con los compañeros y compañeras no debe seguir estudiando: lo que ella quiere es divertirse y no estudiar; y, tal como está la vida, yo no quiero que se dedique a ir por ahí con los chicos y las chicas de farra." (Armando, Castilla-León, 49 años).
}

La realidad es que todavía parece existir un número superior de estudiantes gitanos hombres que de mujeres en los centros de Secundaria. Pero, como ya hemos destacado anteriormente, también parece que actualmente el número de estudiantes gitanas en la Universidad es similar al de los hombres e incluso ligeramente superior. Lo que las estudiantes gitanas buscan con su continuidad educativa y lo que esta continuidad les proporciona es seguramente mejor valorado por ellas que por ellos, por una situación de partida distinta. Ahora mismo, muchos padres y madres que han logrado una inserción laboral y de vivienda tienen más expectativas de que estudien sus hijos hombres: han empezado a constatar que los estudios pueden constituir un factor de promoción socio-laboral o de consolidación de las nuevas posiciones adquiridas, y les gustaría que sus hijos hombres lograran un mejor estatus que ellos, por la vía de los estudios; sin embargo, la vía de la continuidad académica la perciben cargada de riesgos para sus hijas. Muchos de estos padres y madres alientan a sus hijos hombres para que prosigan estudiando, y a ellos les Ilenaría de orgullo tener un hijo universitario; y, sin embargo, sólo ven conveniente que sus hijas sigan estudiando si son buenas estudiantes y "formales", en el sentido conservador, tradicional y patriarcal, del término. A sus hijos, a menudo a pesar de no obtener unos resultados muy brillantes y de preferir la diversión y la sociabilidad, les animan a proseguir estudios, mientras que si sus hijas obtienen similares resultados académicos y tienen buena relación en el tiempo libre con el resto del alumnado, se las conmina a que abandonen la vía académica, argumentando el 'peligro' que esto conlleva por ser mujer, contraponiendo la diversión personal a las mínimas posibilidades de continuidad académica. Obviamente, a esto se añade el horror que sigue causando la posibilidad de que la hija entable relaciones con un no gitano para una proporción importante de la población gitana. Algunas de nuestras informantes participan de esta posición extrema de limitación de las relaciones interétnicas y admiten la condición implícita acordada con sus familias de rechazar tal posibilidad como parte de la autorización a seguir estudiando. Se da por sentado que la mayor integración de las chicas en el entorno mayoritario, aunque sea por la vía del estudio, es intrínsecamente negativa para todo el grupo.

De forma indirecta, a través de los testimonios analizados, entre algunos gitanos padres de familia que han logrado ellos mismos una integración socioeconómica reco- 
nocida hemos constatado una estrategia recurrente: el aumento de su inserción en la sociedad mayoritaria por la vía del apoyo a la continuidad académica del hijo, y el mantenimiento del prestigio ante su red de relaciones gitanas por la vía de 'reservar' a la hija para el rol tradicional, lo cual incluye alejarla de tal continuidad. Esta concreción divergente está encaminada a mantener y aumentar el prestigio también dentro de la comunidad. Veamos qué peso ha tenido el hecho de ser hombre y de ser mujer en los casos de continuidad educativa analizados:

A) El haber sido hombre o mujer no le ha proporcionado muchos privilegios dentro de su familia.- Éstos son los casos donde no se reproducen los roles sexuales tradicionales de forma muy marcada; existe, pues, una relación de mayor equidad entre las hijas y los hijos de la familia al margen de su adscripción de género.

Así, por ejemplo, la hermana de uno de los entrevistados quiere hacer Doctorado; no parece que haya distinción de género en el momento de poder elegir con libertad la continuidad académica:

"No, igual. Hemos ido todos iguales. Hemos estudiado lo que hemos querido. 0 sea, hasta la ESO

hemos estudiado todos, ¿no?, y luego cada uno ha podido elegir lo que ha querido." (Antonio,

Navarra, 18 años).

Son múltiples los casos donde se han recibido críticas y presiones por parte de miembros externos a la familia debido al trato igualitario dado en el núcleo familiar y a la decisión de las hijas y los hijos de proseguir sus estudios más allá de la etapa obligatoria.

B) El haber sido mujer le ha condicionado en el momento de proseguir sus estudios dentro de su familia y en su entorno.- Hay casos que no vienen tan determinados por la presión que puede ejercer la familia, y sí su entorno de referencia (otras chicas gitanas que dejaban la escuela en la adolescencia). Han tenido más barreras sociales para seguir estudiando dentro de su entorno que un chico, puesto que algunas personas de su barrio cuestionaban que siguiera estudiando o no veían bien que la chica, al entrar en la adolescencia, siguiera en la escuela. Como tendencia general, las mujeres gitanas entrevistadas que se hallan en esta situación han tenido más coraje y han aprovechado mejor los estudios que sus hermanos o primos hombres.

En un caso muy ilustrativo la entrevistada se ha encontrado con muchas más barreras familiares por ser mujer que sus hermanos, debido a los mandatos de género que priman dentro de ciertas tradiciones gitanas. Por ser mujer, se le impone (sobre todo, por parte de su padre) que sirva a los hombres como prioridad frente a los estudios y se le castiga si no lo hace (en uno de los casos, incluso físicamente); en la adolescencia, es retirada de la escuela pese a sus deseos y a los de su madre; así mismo, tiene cierta presión desde el entorno gitano para que no estudie puesto que, según argumentan apelando a las tradiciones, los estudios de la mujer a partir de la adolescencia son incompatibles con el matrimonio, y el matrimonio es el destino para el que se educa y se orienta a las mujeres gitanas. En otro caso, la chica no sólo se ha topado con la discriminación sexual en su familia, sino también en la academia, cuando con- 
sigue cierta continuidad: por ser chica, también estudió taquigrafía en vez de contabilidad debido a la segregación profesional que existe en la sociedad en función del sexo. Al grupo de chicas las pusieron a hacer taquigrafía y a sus hermanos, que no lo aprovecharon, les pusieron a hacer contabilidad, desde la distribución de plazas de la propia academia donde se matricularon.

En algunos casos manifiestan que les hubiera gustado ser hombres porque su continuidad académica no se vería tan cuestionada, y no serían tantas las presiones que reciben de otros miembros de la familia o de la comunidad; junto a ello, la decisión de interrumpir su continuidad académica por parte de su padre y/o su madre por el hecho de ser chica no serían tan palpables en el caso de un chico:

"Lo hubiera tenido más fácil, seguro, segurísimo además. Yo creo que siempre he deseado ser hombre, sí, de verdad, porque claro, incluso sinceramente, yo me alegro de haber tenido un hijo en vez de una hija porque pienso que hubiera tenido mucho más difícil el educarla, con ese contrasentido, de vivir, porque claro mi marido no es gitano, ni mi suegro ni toda su familia, y mi familia sí. Entonces si hubiera sido una chica, está claro que yo le daría una educación de que ella decidiese, de que fuese libre, pero, claro, como a ti te han educado de esa manera y aunque tú no lo hayas visto has seguido la rutina de la cultura, de mantenerte virgen antes del matrimonio, de no, en fin pues, en el inconsciente eso te queda y si hubiera tenido una hija pues yo creo que, aunque no lo hubiera exigido me hubiera gustao, no lo sé, o sea son quebraderos de cabeza que te vienen, pero menos mal que ha sido chico." (Julia, Aragón, 36 años).

Pero también ocurre en algunas ocasiones que los deseos de continuidad aparecen más tarde, puesto que inicialmente la chica acaba deseando hacer lo que se espera del rol que le designa en su contexto comunitario y sigue de forma prácticamente total el grupo de edad y género al que pertenece (y no por condicionantes económicos o necesidad de su colaboración en el hogar) sin experiencia inicial de ruptura ni de contradicción. La construcción cultural tradicional de algunas gitanas como mujer joven se ha desarrollado sin demasiadas presiones explícitas y sin contemplar opciones distintas:

\footnotetext{
"Lo típico cuando empiezas a ser moza, te quieres quedar en casa y asumir responsabilidades que no te competen, por lo menos en ese momento, pero todas las niñas gitanas somos muy parecidas en ese sentido, menos mal que yo he tenido unos padres que me han encaminao por otro lao, al fin y al cabo todo lo que he hecho ha sido porque ellos me han apoyao." (Mercedes, Madrid, 27 años).

"Me saqué el Graduado y luego ya pues me puse, como todas las gitanas, a fregar y a barrer. Lo que pasa que luego yo un día me dije por qué no voy a estudiar, es tontería, ¿qué hago aquí? Estoy harta de fregar y barrer por las mañanas, pues me voy a estudiar y por lo menos veo gente... yo soy muy rancia. Yo soy de las que ponen a comer y al primero que echo es al más viejo." (Sonsoles, Madrid, 26 años).
}

C) El haber sido hombre le ha supuesto una serie de privilegios respecto a sus hermanas o primas.- Esta situación se da a partir de diversas experiencias pero se basa 
sobre todo en dos factores: uno, el reconocimiento de la capacidad de elegir, si se trata de un hombre, como parte de su masculinidad; dos, el hecho de que el establecimiento de relaciones sociales más amplias y diversas y, sobre todo, las relaciones con chicas y chicos no gitanos, no es considerado en sí mismo algo negativo o contaminante para el chico, mientras que es uno de los principales factores que impiden la continuidad de las chicas. Ello no significa que no existan presiones por abandonar o por priorizar otros aspectos de su vida, fundamentalmente los relacionados con el matrimonio, cuando llegan a ser mozos.

\footnotetext{
"Yo ahora tengo mi hermana en casa, que son 14 años, que está en $2^{\circ}$ de la ESO. Y el paso que tuvo al Instituto, ese paso se lo pensó mi madre, porque ya son 13 años, ya se le van poniendo a mirar los mozos o lo que sea y te la pueden quitar, ¿no?, que se lía con un chaval y se vaya de casa. Y eso también ha sido lo que me favorecería a mí, que sea chaval. En caso de mi hermana, ahora mi madre la ha escolarizado, como ya he dicho, está en $2^{\circ}$ de la ESO y no ha tenido ningún problema, pero se lo estuvo pensando, que 'A ver si pasa ya, que venga cualquier chaval y nos la quite"'". (Eugenio, Navarra, 18 años).
}

Un aspecto importante observado es que a las chicas las familias les han sobreprotegido ante la presencia de lo que los progenitores consideran un entorno hostil, donde la niña/chica puede verse afectada por la exposición a una influencia negativa, por ejemplo, dentro del mismo barrio segregado, algo de suma importancia frecuentemente ignorado por los y las responsables educativos:

\footnotetext{
"El ser chico me ha facilitado, por tanto, poder desenvolverse por la calle con mayor seguridad y que mi familia tenga menos miedo de que me pueda pasar algo, lo que ha facilitado en un principio que asistiera a la escuela [a diferencia de mis hermanas]. (Pablo, Madrid, 17 años).

"Si hubiera sido chico gitano pues quizás sí hubiera estudiado más. Y por ejemplo, si hubiera habido alguien delante de mí que hubiera aportao más económicamente, yo no hubiera estao tan, tan arropada por mi padre y por mi madre, pues quizás sí. Sí habría estudiao." (Sara, Navarra, 36 años).
}

No es siempre un apoyo unívoco o uniforme, sino que a veces viene determinado por un miembro en concreto, el padre o la madre. No podemos determinar si es el padre o la madre con mayor frecuencia quien ejerce la distinción de roles por género, esta situación es diversa según cada caso. A veces es el padre quien presiona para que su hijo o hija siga los estudios y la madre es quien adopta una actitud de mayor disconformidad; otras veces es al contrario. Lo que sí es una tendencia generalizada, y esto es un factor muy importante que debemos tener en cuenta, es que las decisiones que toma el padre son las que acaban por determinar las decisiones en la familia. Ninguno de nuestros informantes recuerda una confrontación directa, ni un cuestionamiento abierto de la mujer hacia el marido, aunque no esté de acuerdo con la decisión de éste de interrumpir la escolaridad de la hija. Sólo hemos recogido un testimonio de confontación directa de la madre con los parientes de su difunto marido en un caso. Al 
contrario, sí se relatan fuertes presiones de la madre hacia el padre o hacia la hija cuando es la propia madre la que no está convencida de lo positivo de la continuidad de su hija. En los casos del primer tipo, se mencionan estrategias de las madres para apoyar a sus hijas de forma decidida pero subrepticia,

"Yo siempre he pensado que se debe tener una formación para el día de mañana, para no tener que depender de nadie, eso es lo más principal; y luego he tenido mucho apoyo de mi madre, que ha sido la que más me ha apoyado cien por cien, aun cuando mi padre no nos dejaba, y sobre todo que a mí me ha gustao mucho y me sigue gustando." (Cristina, Madrid, 37 años).

pero predominan los casos del segundo tipo:

\footnotetext{
"No soy infeliz por culpa de mi madre. Yo por eso digo: 'Prefiero equivocarme', aunque mi madre tenga razón, porque es algo que te hace más mayor, te hace más responsable, te hace pensar mejor las cosas. Hay que tener las cosas claras.... Más por mi padre que por mi madre. Sí, porque mi padre por ejemplo pues siempre, ¿no?, 'Pues si sigues estudiando vas a tener más oportunidades pa' trabajar', no se qué... Mi madre en cambio me dice: 'Yo no sé pa' qué estudias tanto si total luego te vas a casar y no vas a hacer nada'. ¿Me entiendes? Me lo dice así, que sí, que me apoya yo qué sé. Al final voy a hacer lo que yo quiera, si voy a seguir seguiré porque yo quiero. Tengo esa libertad o esa responsabilidad que si sigo estudiando es porque yo quiero, no me obligan mis padres. Yo elijo lo que quiero y elijo si sigo o no." (Victoria, Navarra, 17 años).
}

Como decíamos en la introducción a este capítulo, en algunos casos de chicos u hombres entrevistados, éstos manifiestan abiertamente la disconformidad de que sus hermanas prosigan sus estudios, a través del discurso conservador más tradicional, aludiendo a lo inaceptable de que ellas tengan el mismo comportamiento y actitud que los propios informantes hombres, incluso si se muestran partidarios de la continuidad educativa de los hombres, de lo positivo de la vía académica como promoción social personal y del grupo étnico, o incluso del valor de cierto grado de escolarización entre las propias chicas, por ejemplo, hasta cumplir con la escolaridad obligatoria actual. Por lo tanto, su propia experiencia educativa no sirve para fundamentar nuevas actitudes y prácticas ni su transmisión, posición que nunca encontraríamos en una chica: si ella valora la continuidad y disfruta de ella, no va a negarla jamás a sus hijas $y_{\text {, }}$ huelga decirlo, tampoco a sus hijos. Hemos querido mantener el siguiente testimonio en toda su reflexión, porque se trata de un chico joven con continuidad educativa que expresa perfectamente la reproducción del pensamiento más conservador y sus contradicciones:

"El tema ése, es peor ser chica que chico para los gitanos, porque una chavala no puede salir como sale un gitano, porque enseguida tiene la fama y se queden por ahí, a partir de una hora, yo qué sé, una hora las 10, las 11, no es lógico que veas una gitana por ahí, siendo las costumbres gitanas, aunque se van cambiando ahora mucho las costumbres. Por un lado, está bien que salgan y por otro, no, pero allá su familia. En mi familia, a mí no me gustan que salgan las chicas. Tienen que estar en casa, que vayan con su madre a un lado, que se vayan con sus primas, 
que estén un rato por ahí, pero a cierta hora, que estén en casa, que sepan cumplir sus costumbres, no, que no sean unas 'ahí por ahí'... No es lo mismo mis pensamientos que tengo yo con los pensamientos que tiene mi padre. Para mi padre, que salga mi hermana, pues no la deja. Y para mí, estar unas cuantas horas por ahí no está mal que esté, que eso lo he vivido yo. Encerrarte en casa, no lo puedes hacer, que tendrás que disfrutar un rato por ahí. Pero es que ya son distintos pensamientos. Yo les dejaría salir hasta cierto tiempo, aunque las encierras más y son peores. Dejad con libertad, que hagan lo que quieran, que ya tendrán su propia cabeza, ¿no? Está ahí, el tema de las chicas que salgan, en mi casa, lo digo.... Lo veo normal que estudie y que tiene que sacarse el Graduado Escolar. El Graduado Escolar lo tiene que sacar, por lo menos, hasta los 16 años. Pero que a los 16 años la saque mi madre lo veo normal porque ya no es edad... Es una edad para seguir estudiando para la sociedad mayoritaria pues sí, pero entre nosotros, pues no, porque ya empieza una edad en que tiene que estar con sus padres y todo eso con el tema de que la gente no la desprecie y no le ponga la fama y todo eso. Y en el tema de mi hermano, pues a mi hermano lo apoyaría, simplemente por ser varón. Pero a mi hermana lo mínimo el Graduado Escolar, hasta eso. Pero luego que ya haga lo que quiera, es decisión de mis padres. Lo que haga que estudie o que deje de estudiar es decisión de mis padres." (Eugenio, Navarra, 18 años).

Otro informante recuerda que también hace 25 ó 30 años algunas chicas payas de clase obrera que estudiaban en la Universidad sentían que algunos chicos de su grupo social que no estudiaban las miraban con recelo: esos chicos no veían lógico emparejarse con una chica que tuviera mayor nivel académico que ellos. Es decir, considera que para los chicos no existe contradicción en ser gitanos y realizar estudios universitarios: se defienden en la sociedad mayoritaria y entre los gitanos (adaptándose a cada situación). Sin embargo, para las chicas es una contradicción irresoluble, pues por ser mujeres en la comunidad gitana se las va a pedir un plus de prudencia y de no mezclarse ( $y$ en ese plus ponen el honor de ellas y de toda la familia de origen y de la futura familia del que pueda ser su marido)... Nos explica que para él mismo y para sus hijos hombres aspira al máximo de integración social, y curiosamente añade que "sería ideal que ellas estudiaran y ojalá cambien las costumbres de los gitanos y puedan estudiar", algo que parece que no depende de él mismo y de lo que él y otros como él estén dispuestos a cambiar. Se expresa claramente la nuclearidad de identificación entre la "preservación" de la chica y la "preservación" del grupo étnico:

\footnotetext{
"Y, claro, una niña para llevarla pura, casta e inmaculada, sin mancha, pues tiene que estar en casa con su madre. Es que no hay otra... es que no hay otra. Es, es salir con sus amigas gitanas, y ya cuando llega unas ciertas edades tampoco, porque... Entonces, para salvar esa barrera... para salvar esa barrera hay que quitar esto. Lo de que los, los gitanos, los hombres la cogen limpia. Y, sin embargo, es eso lo principal. Es una de las cosas gitanas que, por aquí, eso no se pierde ni en 3.000 años... Es el punto que, digamos, más difícil de cambiar... Porque, lo primero, es por lo que más orgullosos nos sentimos. Es por lo que más orgullosos nos sentimos, y lo decimos así de claro. Ese muchacho que va con la cabeza bien alta porque su mujer... tal, tal. El otro, sin embargo, es que tiene que agachar un poco las orejas, porque su mujer cuando era joven... que tal y que cual, porque una vez no sé qué. Y hace una vez cualquier historia y, claro, eso ya queda... Entonces, es que para nosotros eso es la honra del hombre, la honra de la mujer, la honra de los
} 
padres, la honra de los abuelos, la honra de los tíos. Entonces, es una cosa súper, súper, súper seria para nosotros, y eso para cambiarlo... ¡Fff!... Es imposible. Yo creo que esto no lo vean ni mis nietos cambiado." (Luis, Castilla-León, 22 años).

En estos casos, tales actitudes están relacionadas con su identificación con una idea tradicional de lo gitano: más identificación con lo gitano, menos compensación entre los roles hombre-mujer. El ser gitano lo demuestran públicamente en su comunidad a través de lo privado, concretamente a través de sus propias mujeres gitanas. Por contraste, las mujeres con estudios quieren formarse porque ven con espíritu crítico su realidad y observan que a ellas sí les interesa cambiar ese entorno: ellas son las que luchan por el cambio, muchas veces por pura supervivencia, porque no ven otra salida posible.

Ahora bien, en este punto debemos preguntarnos cuáles son las estrategias que utilizan las chicas que han estudiado más que la mayoría de las demás gitanas para sortear las dificultades existentes en su trayectoria escolar. $Y$ si esas dificultades y esas estrategias que se ven impelidas a aplicar tienen que ver con su condición de mujeres. A este respecto, hemos podido constatar cinco tipos de dinámicas diferentes:

1. Apuesta clara de los padres y madres por la continuidad escolar de su hija.Algunas de nuestras entrevistadas, jóvenes estudiantes gitanas, han sido animadas claramente a estudiar por su padre y madre: alguna chica cuyo padre es militante de izquierdas, alguna hija de matrimonio mixto, alguna en la que la situación socioeconómica, académica, laboral y urbanística de su familia era de clara inclusión social y de una posición económica acomodada (algunas familias gitanas de clase media, que viven en barrios integrados, en algunas en las que trabaja la madre fuera del hogar en trabajos no familiares, y/o en las que cuentan con tradición escolar por haber estudiado el padre y/o la madre más allá de Primaria). En todos esos casos ha existido una posición socio-cultural también integrada en las relaciones de género y en los roles en el hogar, facilitadores de la formación académica de la mujer y de su incorporación al mercado laboral extradoméstico y extrafamiliar.

"Ellos [los padres] se dan cuenta de que vamos avanzando y ellos no tienen ningún problema. Ellas saben lo que tienen que hacer, y mis padres pues les dan permiso para que ellas estudien. Muchas veces hasta les obligan a estudiar, si ven que no se pone, pero sale de ellas mismas. Son muy buenas, y mis padres confían". (Pablo, Madrid, 17 años).

"Me dicen que es para mi futuro, igual seas chica que chico. Mis padres han tratado igual a mi hermano, que es el único chico, que a nosotras. Nos han dado las misma oportunidades para estudiar y para todo y para ayudar y para todo. No hemos tenido diferencia." (Arantxa, Navarra, 23 años).

En algún caso, la apuesta por la continuidad de la hija es aún más clara debido a la actitud de desinterés del hijo varón ante las mismas oportunidades: 
"Mi padre estaba encantado de que mi hermano hiciera algo, pero no le gustaba estudiar, era una rebelde sin causa y a mi padre le hubiera encantado que mi hermano estudiara. Pero él lo dejó porque es un vago y no le gusta nada estudiar. Pero mi padre se llevó un gran disgusto porque le hubiera encantado, fíjate tú, fíjate lo que es la cultura... Le hubiera encantado a mi padre, si yo hubiera sido chico, vamos, hubiera sido médico... Porque, siendo chica, y me está apoyando en todo momento... Porque él dice: 'Es que me encanta...' Porque dice: 'Es que me da igual lo que piense la gente; tú estudia, confío en ti como...' Porque quiere que siga estudiando, pero que tenga mis valores... y eso es difícil, porque, claro, ya lo estoy viendo. Y siendo mujer, y me está ayudando... pues si llego a ser hombre, vamos... Porque a los chicos, siempre les tiran más los chicos." (Soledad, Castilla-León, 18 años).

2. Negociación de soluciones de compromiso.- En algunos casos el padre y la madre no han animado explícitamente a que prosiguieran estudios, pero tampoco se han opuesto a que estudiaran, y ellas han ido buscando soluciones de compromiso, tales como: estudiar al tiempo que realizar las tareas domésticas y/o contribuir a la economía doméstica trabajando fuera del hogar (compatibilizar una doble o triple jornada de estudiante, ama de casa y/o trabajadora asalariada); seguir estudiando y pertenecer a alguna asociación de mujeres gitanas o trabajando en alguna asociación gitana, en la que han encontrado apoyo en su continuidad académica, y en ocasiones acceder a una ocupación que se convierte en una fuente de ingresos aceptable por parte del resto de la red de relaciones gitanas de su entorno, por la misma vía; estudiar en un colegio de monjas sólo para chicas (solución de mujeres gitanas mayores con continuidad académica); o bien, como en el testimonio siguiente, simplemente esconderse de otras familias gitanas si quiere seguir estudiando:

\footnotetext{
"Hombre, ya te digo, que dejó pasar unos años y como ya vio que nos quedamos pa vestir santos pues dijo que lo hagan si quieren y además sabe mi padre..., tiene confianza en nosotras que no vamos hacer ná malo por estudiar o por trabajar y eso es muy importante, al tener libertad no haces ná malo porque puedes hacer lo que quieras, es todo lo contrario, porque nosotras en esa época en que volvimos a estudiar había varias niñas que las decían que eran cenicientas y se escaparon con un chico, ya me entiendes lo que te quiero decir, o sea, que cuando tienes libertad no tienes por qué hacer lo que no debes." (Cristina, Madrid, 37 años).
}

3. Enfrentamiento a la oposición familiar.- En algunos casos el padre y/o la madre se han opuesto a que sus hijas prosiguieran estudiando y éstas se han visto en la tesitura de o bien seguir estudiando y ser cuestionadas e incluso abiertamente rechazadas por su familia y su comunidad de origen, o bien dejar de estudiar. Algunas de estas jóvenes han sufrido serias crisis personales, otras han abandonado finalmente los estudios, y alguna ha llegado incluso a fugarse de casa.

\footnotetext{
"... es que yo mi sueño era ése, el pedirme con un niño que me dejara estudiar, tiene que ser súper guay ir a la facultad y tener a tu lado a tu novio gitano, eso es lo mejor, saber que he cumplido conmigo misma, he cumplido con mi familia he cumplido y todo el mundo contento (...) pero no me arrepiento de nada, acabo de aprobar la selectividad, empiezo mis clases de Turismo en unos
} 
días y ahora que no vivo con mis padres, les echo de menos pero me llevo mejor con ellos. No me he casao con un niño gitano, pero éste me quiere y me deja estudiar." (Marta, Madrid, 20 años).

"Pues ya te educan... teniendo un pensamiento de que no puedes hacer esto, y te lo meten en la cabeza... Y me fui [de casa] con mucho miedo (...) Estoy cuidando unos niños desde hace año y medio, pero no quiero estar ... no quiero estar con este trabajo siempre, y como... nos hemos comprado piso y todo, pues no puedo... no puedo estudiar por la mañana, ni nada y... el año pasado ya iba a apuntarme a la Escuela de Adultos para hacer ... porque hay ciclos formativos y... puedes ir por la tarde... Y se me pasó el plazo, y no pude ir, y estoy mirando para apuntarme en septiembre para hacer algo." (Vanesa, Castilla-León, 22 años).

4. Trayectorias académicas interrumpidas y postergadas.- En otros casos, se ha ido reemprendiendo o postergando la trayectoria académica personal según las circunstancias (exigencias de dedicación y contribución a la familia) y la virulencia de la oposición, o el cálculo de costes y beneficios de mantener la firmeza en algunos momentos y avanzar, supuestamente abandonando en otros momentos. Una de nuestras informantes, por ejemplo, ha pactado con su futuro marido (en este caso, además, no gitano) su acceso a la universidad, ante la tajante negativa de su familia de origen ante su proyecto, que Ileva tiempo esperando poder realizar.

"Conocí a J. que fue mi amigo y ahora es mi pareja y bueno, pues el también me animó, también me animaba mi hermana mayor (...) y ya pues me puse a estudiar ... están todos muy orgullosos, muy contentos." (Eva, 31 años, Aragón).

Naturalmente, el repertorio de razones aducidas, son las que hemos observado en el capítulo anterior: necesidad de contar con su fuerza de trabajo fuera y dentro de la familia, miedo a las relaciones dentro del entorno mayoritario, desconcierto e inquietud frente al cambio de perspectivas vitales que se abren cuando se inicia una continuidad educativa, deseo explícito de asegurarse cuanto antes un matrimonio joven para la chica como proyecto deseable, o bien, interpretación de los titubeos y dificultades en las condiciones de escolarización de la chica como falta de seriedad. Una de las experiencias más tristes es la de una chica, a quien su padre no permitía seguir estudiando con el argumento de que su único interés por el instituto era estar con otros chicos y chicas y divertirse, que estuvo varios días al principio del curso acudiendo a su colegio (el colegio que había tenido que dejar) en los recreos y a la salida de clase, para ver a sus compañeras y compañeros, aumentando aún más la sensación de impotencia del profesorado y del equipo directivo. Este argumento, el de la sospecha y reprobación de que las chicas no estén aprovechando los estudios y el de un interés prioritario por la sociabilidad intercultural, está completamente ausente en las experiencias de los chicos, que no reciben presiones de la familia en este sentido.

Pero ahora observamos estas interrupciones y aplazamientos desde la perspectiva de la evolución de los proyectos de las propias chicas o de sus estrategias para reem- 
prenderlos en momentos más propicios, evitando inseguridades propias y enfrentamientos previsibles:

\begin{abstract}
"Yo, en Segundo, me parece que era, lo dejé, porque, no por estar, o sea, porque me daba pereza estudiar, me daba pereza levantarme, pero me obligaban. Y no sé. Hombre pa los libros, la verdad es que... pues... o sea, que... nunca empezaba con todos los libros. En Cuarto me parece que empecé ya con todos los libros compraos, o sea, pero... siempre tardaba... pa cuando tenía todos: meses. Siempre o me dejaba alguien o me ponía con alguien, para que... o sea, al final tenía siempre libros pero... pues costaba." (Josefa, Navarra, 17 años).

"Hombre, a mí me gustaría trabajar ya, y ayudar a mis padres, porque aunque mi padre trabaje pues siempre el dinero siempre viene bien, y me gustaría trabajar en lo que he estudiado. Y hacer el Superior [el Ciclo Formativo de Grado Superior], de momento no, porque... no creo que me dejaran. No es que no me dejaran, sino... no creo, que no, yo no me veo haciendo el superior." (Adriana, Aragón, 18 años).

"Mi padre cuando dejé de estudiar, en cuarto, no me dio muchas facilidades... Yo dejé de estudiar y no se preocupó... Porque hoy llega a ser uno paisano, seguro que me hubiera buscado una chica para que hiciera la casa y yo hubiera ido al instituto a seguir mi vida, pero al ser gitano, pues dijo... y como me vio, yo creo, con responsabilidad, porque me vio una chica madura, pues, dijo, no. 0 sea, yo creo que me cargué yo la responsabilidad. Dije no, yo llevo mi casa." (Vanesa, Castilla-León, 21 años).
\end{abstract}

Algunas de las trayectorias se interrumpen temporalmente para contraer matrimonio o por su inminente maternidad y para hacerse cargo del cuidado de su hijo/a. Esto afecta única y exclusivamente a las mujeres:

"¿En éstos momentos? Pues en estos momentos quería haber hecho muchas cosas, pero como tengo el niño, pues,...Quería haber seguido estudiando, quería haber hecho Estética o Peluquería, pero como tengo al niño..." (Ana, Navarra, 19 años).

5. Madres jóvenes que iniciaron estudios y que pueden proyectar trayectorias distintas.- Algunas madres llegaron en su día a estudiar algún curso más que la mayoría de las chicas gitanas de su generación, pero finalmente abandonaron los estudios, se casaron pronto y tuvieron hijos muy jóvenes. Estas madres pueden proyectar diversas expectativas sobre sus hijas:

A) Algunas quieren que sus hijas tengan estudios y lleguen a estudiar lo que ellas no consiguieron por las circunstancias que les tocó vivir; consideran que ahora los tiempos han cambiado y que es indudablemente positivo que sus hijas disfruten de una continuidad educativa sin límites. Otros casos reflejan una situación más decidida: son las madres quienes ven en sus hijas un proyecto de vida al que ellas por varios condicionantes no pudieron acceder: 
"Para mí es un ejemplo muy sorprendente y muy admirable, es una mujer moderna, es una gitana moderna, de hoy en día, que puede entender ciertas cosas, dice: 'Bueno, yo no las entiendo porque ya soy mayor, pero que cada uno haga lo que quiera. No por eso voy a dejar de ser gitana, ni voy a ser más, ni voy a ser menos. Hay cosas que yo soy más antigua y no las veo bien, pero si ella lo ve bien y lo quiere hacer..."' (Anabel, Cataluña, 42 años).

B)Otras, por el contrario, mantienen una postura ambigua, son escépticas y temerosas sobre la posibilidad de que sus hijas prosigan estudios más allá de la adolescencia. Son ahora jóvenes madres que parecen encontrarse en la encrucijada y moverse entre la resignación y la valoración de cosas que considera ideales, pero ven improbables. Señalan que a ellas las fue bien en el instituto y que los estudios son muy importantes, pero proyectan unas expectativas escolares un tanto pobres sobre sus hijas (construyen un discurso de falta de capacidad de sus hijas como defensa de su temor) y no se sienten ni siquiera seguras de que sus hijas acudan al IES.

\subsection{Sobre el impacto del éxito y la continuidad educativa}

\subsubsection{Continuidad educativa y construcción identitaria personal}

La continuidad educativa conlleva a la larga la adquisición de prácticas culturales generalizadas en los grupos sociales mayoritarios y reflejadas por los medios de comunicación, que es otra fuente de aculturación de primera magnitud. Así, se observa que estamos asistiendo en este sentido a un proceso de cambio profundo. Los procesos de cambio suelen venir acompañados de acusaciones más o menos frontales de 'apayamiento', pero ya hemos ido anotando que no es comparable ni en intensidad ni, realmente, en contenido, cuando se dirige a mujeres y cuando se dirige a hombres, en las experiencias y los casos analizados. El hombre que se plantea una continuidad académica -igual que el que no se la plantea- está completamente exento de sobrecargas en tareas asociadas a su condición según los roles de género tradicionales vigentes y no tiene que ir 'demostrando su gitaneidad' continuamente, aunque se espera de él que no deje de cumplir de la forma que el resto de su familia considera adecuada con, por ejemplo, las visitas a los enfermos, la asistencia al culto si ésta es la práctica familiar o ayudando el fin de semana a su familia en el mercado, como también hemos señalado con anterioridad.

El complejo de atribuciones y proyecciones sobre un hombre que continúa estudiando pasa generalmente por una valoración moral negativa de su trayectoria, pero no pasa por las relaciones interculturales que establece ni por su sexualidad. Se valora negativamente por la distancia real que implica la fragmentación de actividades entre ocu- 
paciones de los padres y ocupaciones de los hijos y por la desconfianza respecto al compromiso real a hacerse cargo de los suyos, que también se expresa respecto a la población no gitana. El siguiente testimonio se refiere así mismo a la reacción que suscita en él la experiencia de acusación, rechazo y desconfianza:

\footnotetext{
"... para llevarlo encima es un dolor, porque te digan tus primos que te estás apayando, no porque los payos sean malas personas, ni los gitanos sean mejores que ellos, sino porque son costumbres que tenemos encima y como las vayas perdiendo te vas alejando de la familia y lo que sea. Pero luego, yo qué sé, si quieres ser un gitano que te respeten de mayor, tienes que tener todas las costumbres. No las tienes que tener, sino que las vas adquiriendo con el tiempo: 'Mira, ése es buena persona, ése ha respetado esto y eso'. Y desde el momento que de pequeño ya te van diciendo que eres un payo, pues es que ya no te tratan como te tendrían que tratar ellos, sino que te vas alejando de ellos. Yo en este caso, lo he estado asumiendo y el tema eso, pues no es de decirte que seas un payo, pues que me lo han dicho. Tienes que intentar de pasar de ellos, no pasar de ellos, que es tu familia, que tienes que vivir con ellos, pero en ese tema, te dicen 'que eres un payo'... Bien, vale, no lo soy, porque sabes que llevo tu misma sangre y eso. Pero con las mismas costumbres que están haciendo ellos que van a trabajar con sus padres y todo eso, y tú el mismo día, estás dejando a tu padre apartado para ir al colegio, que siempre ven a tu padre solo, y todo eso, eso es muy difícil. Pero, ¿qué tienes que hacer? Asumirlo y llevarlo para adelante, que estás optando para tu futuro. Es que ellos viven al día. Es muy difícil asumirlo eso, muy difícil." (Eugenio, Navarra, 18 años).
}

En las mujeres, además de estos componentes, la valoración moral incluye la limitación de relaciones interculturales y el control de su sexualidad como partes fundamentales de sus posibilidades de mantenimiento de su identidad étnica. Persona, género, familia y comunidad se convierten en niveles de reconstrucción identitaria por el impacto del éxito y la continuidad educativa en mayor medida para las chicas y las mujeres que para los hombres. El siguiente testimonio femenino reúne los componentes de acusación, rechazo y desconfianza surgidos de la presión familiar y comunitaria de forma muy clara, aludiendo a la negación de prácticas no reconocidas de sus hijas (sin continuidad educativa) en buena parte del discurso público que presiona a los padres y a las madres de las hijas que siguen estudiando:

\footnotetext{
"Es que la gente también es muy puñetera, a nada que te ve ponen mucho, mucho más, eh... Si te ven con payas, igua!, es que va con payas, vete a ver lo que va a hacer, es que no sé qué... y si te ven con gitanos, es que ésa lo único que quiere es buscar marido, y no saben ni lo que quieren ellos. Como te vean un día un poco más tarde, ibua!, es que es un pijotera, ¿entiendes? Es que es eso lo malo. Pero el que más habla es el que más tendría que callar, porque no ve lo que tiene en su casa. Mi madre, por eso, siempre dice, cuando le preguntan, ¿tu hija fuma? Mi madre lo que dice: 'Delante mía no, pero por ahí no apostaría por ella', y mi madre sí sabe que no fumo, pero no sabe lo que hago fuera. 0 como mi madre: 'No tiene novio, que yo sepa...'. En cambio, hay otras madres que dicen: 'Mi hija no fuma, mi hija no sé qué...' Y cállate la boca porque te das la vuelta y si estarán haciendo esas cosas... ¿Sabes?, pero eso lo hacen todos los gitanos, cri-
} 
tican y eso duele también. Duele que porque vayas de una forma o porque simplemente juegues ya te están diciendo, jes que es una pijotera! Bueno, dices lo que quieras pero al fin y al cabo lo demostraré [que estoy estudiando en serio]". (Victoria, Navarra, 17 años).

Pero vayamos por partes. Independientemente del impacto diferencial que hayan tenido las experiencias de continuidad educativa en las dinámicas identitarias de mujeres y hombres, nos interesa revisar en primer lugar los efectos generales, positivos y negativos, de tal impacto. En los casos analizados se distinguen tres tipos de efectos y a distintos niveles: los efectos positivos experimentados a nivel personal y defendidos como tales, los efectos negativos sufridos también a nivel personal expresados de forma explícita, y los efectos positivos relativos al grupo familiar de pertenencia de cada persona, reconocidos por el grupo y por la persona, que veremos más adelante.

Dentro de los aspectos personales positivos, a su vez, se distinguen los siguientes:

- Una mayor aculturación, entendida y expresada como cierto distanciamiento crítico de las costumbres gitanas tradicionales y un mejor conocimiento de la realidad social más amplia. Además de la continuidad educativa, la incursión en el mundo laboral convencional, según una opinión generalizada en los casos analizados, es positiva porque favorece las relaciones con el contexto no-gitano, posibilitando su conocimiento real, en su pluralidad y la emergencia de visiones críticas con el entorno de origen.

"Al estudiar ya no tienes una venda en los ojos, ves mucho más allá, entiendes mucho más, das mucho más y entonces exiges más y no te conformas con cualquier cosa. (...) Yo soy lo que soy gracias a los estudios, entonces hoy en día tanto puedo hablar con una persona que es de raza gitana, como con una persona que es de raza paya, de cualquier clase, todo el mundo me escucha porque sé hablar y sé adaptar mi conversación a la persona con la que estoy hablando, y si hubiese sido una gitana normal y corriente no..." (Sonsoles, Madrid, 26 años).

- Una mayor autonomía personal y, consecuentemente, un mayor poder de decisión.

"He hecho la carrera que me gustaba, no de rebote sino elegida, me he sentido muy identificada con mi profesión, creo que he aprendido mucho, no sólo profesional sino personalmente, como desarrollo de la persona, creo que me ha ayudado mucho a madurar como persona mi trabajo y mis estudios, me han abierto mucho la mente, me han dotado de herramientas que ahora me sirven para tener acceso a otro tipo de formación y sí que me siento orgullosa; no obstante, yo creo que nunca hay que quedarse en lo que has conseguido hasta hoy, sino que hay que ir más allá, ¿no?, y siempre encuentras cosas o metas, pues cuando no quieres estudiar unas oposiciones pues ahora pues me da por los temas esotéricos, cuando no me ha dao por iniciar a lo mejor psicología que es una cosa que me gusta, pero yo creo que siempre hay que tener en la mente un reto personal, ¿no?, que no se acaba aquí. Estoy muy contenta con lo que tengo, pero necesito ir más allá, es como la zanahoria, ¿no?" (Julia, Aragón, 36 años). 
- Una mayor flexibilidad y pluralidad en el desarrollo de los roles esperados, como casarse, aplazar la edad de entrada al matrimonio o no planteárselo como algo prescrito.

"(... ) yo soy quien quiero ser, pero es verdad que a la hora de pedirme y formar una familia me lo he pensado mucho, porque no es mi meta única, sino una más, muy importante y que no descarto en absoluto pero..., que he tenido que priorizar mi carrera profesional es cierto." (Mercedes, Madrid, 27 años).

Este desarrollo a menudo forma parte de un proceso de cambio también en las y los familiares cercanos respecto a la persona y a las formas tradicionales de ejercer la educación familiar de los hijos, y sobre todo de las hijas, cuando crecen:

\footnotetext{
"Su costumbre [del padre] es que no salen los hijos de casa, yo qué sé, tan pequeños, una hija menos. Una hija menos. Y ahora yo creo... me siento con bastante libertad, no como antes. Antes era más cerrao [el padre]. Ahora me siento con más libertad para decidir lo que quiero hacer y lo que no quiero hacer. Si quiero estudiar o no. Si quiero trabajar o no." (Juana, Navarra, 23 años).
}

De hecho, la escolarización obligatoria se basa en una periodización y unos contenidos del ciclo vital que no se corresponden con los de la cultura gitana tradicional, puesto que presupone la existencia de una fase intermedia entre la infancia y la vida adulta, la juventud sin responsabilidades laborales ni familiares para ambos sexos, en pleno proceso de ampliación en todas las sociedades avanzadas. Éste es otro de los componentes del proceso de aculturación vinculado a la continuidad educativa, que en términos mayoritarios y en términos legales se entiende inequívocamente como las fases ulteriores a la finalización de la educación obligatoria, por lo tanto, siempre más allá de los 16 años ${ }^{94}$. Recordemos que, para el caso de la población gitana y a efectos de esta investigación, estamos entendiendo la continuidad educativa como la superación de las etapas que corresponden a haber realizado un curso más que la antigua $E G B$, es decir, haber cursado el antiguo $1^{\circ}$ de BUP o de $F P$, y que suponen momentos críticos por la transición problemática generalizada de Primaria a Secundaria y ya descrita en los capítulos anteriores:

\footnotetext{
"Mientras progresas de curso también te haces más mayor y la edad es lo que sorprende, que a estas edades sigas estudiando, porque ya no haces lo normal en la comunidad gitana. El casarse o el comprometerse en una edad temprana, de eso es lo que se sorprenden, no de que sigas estudiando." (Pilar, Aragón, 21 años).
}

Por otra parte, dentro de los aspectos personales negativos, que algunas personas reconocen aunque no mayoritariamente, como parte del impacto producido por la continuidad académica, se distinguen los siguientes:

94 Esto es, desde la implantación de la LOGSE en España, periodización y límite de la enseñanza obligatoria, vigente con anterioridad en todas las democracias avanzadas. 
- Un cierto sufrimiento por distanciarse de la familia, del grupo de iguales gitano y del entorno comunitario gitano.

"He tenido miedo al decir: me estoy distanciando, porque mira lo que piensan de mí mis primas, que soy una paya, y yo no quiero que piensen eso, y muchas veces se lo decía a mis padres y me decían: 'Pero eso, no ves que es la envidia, no ves que porque ellas no pueden, que sus padres no quieren."' (Adriana, Aragón, 18 años).

"En la escuela, yo creo que en la escuela dejé de ser gitano en la escuela, sí se puede decir así, no sé si está bien dicho o no. Pero en la escuela hubo una época que me dediqué tanto a mí, a mi formación, no pensaba en nada; ni la verdad es que no sabía si... pero sí que me alejé un poco. (...) Me acuerdo que me pasaba muchas veces que yo intentaba hablar con otros muchachos gitanos, cuando yo era adolescente, y claro ya no me interesaba, a mí por ejemplo me interesaba hablar de Nietzche, porque a mí me gustaba esto mucho, me hacía sentirme bien. $Y$ esto ellos no me lo daban, como lo que más me importaba era llenar esa parte no pensaba en nada más, pero claro pasaba el tiempo y yo me preguntaba cosas y yo decía que necesitaba cosas, cada vez me gustaba más el flamenco, cada vez me atraía más... yo era un chico normal." (Ramón, Cataluña, 44 años).

- Un cierto desarraigo respecto al origen social a la hora de reconstruir la sociabilidad y de buscar pareja dentro del propio grupo, debido al desarrollo personal:

"Confiaba un poco en que de la misma manera que yo estaba estudiando sé que hay gitanos que también estudian, entonces confiaba en que me pidiera con un niño como yo, porque cuando una persona se prepara, y no es que yo sea una superdotada, pero con un gitano a lo mejor canastero, que no tenga estudios, que no pueda hablar ni entenderme, pues yo no me veía, entonces yo quería una persona que fuera como yo, y una persona así la podría encontrar en muchos sitios, podría estar en un pedío o no, podría ser un amigo de mis primos o no..." (Marta, Madrid, 20 años).

"Si tú haces algo tienes que asumir las consecuencias, no puedes pedir que los gitanos piensen como tú. Por ejemplo, yo al ser estudiante habrá muchos gitanos que piensen que me he vuelto payo. Existe el miedo, estamos en una sociedad machista. Existe el miedo y se protege a la mujer gitana, porque si los gitanos estamos mal mirados, por parte de los hombres existe ese sentimiento de protección. [... P Para estar hoy aquí yo no he pedido permiso, si fuera una chica supongo que sí... [rompiendo] esquemas se gana credibilidad, pero también se pierde prestigio dentro de algunos gitanos. Entonces eso, si quieres perderlo o no quieres perderlo. Y tengo 21 años, la gente de mi edad ya está casada. Las chicas que quedan o son muy pequeñas o son muy mayores para mí. Yo he perdido el ritmo al salirme de esa corriente... No en la forma de perder costumbres gitanas, sino en la forma de asimilar hábitos y de la sociedad... que para triunfar es necesario en la época de ahora. Tienes que asimilar, pues, nociones básicas de conducta o de vivir en sociedad... Para estudiar es necesario cambiar algunos hábitos gitanos tradicionales, hay que 'apayarse' algo para triunfar en esta época.... Seguir estudiando para un chico gitano supone a veces ser cuestionado un poco." (César, Castilla-León, 22 años). 
"Y al estudiar no podíamos estar... pues, igual por buscar novio, o igual ya no gustabas tanto a los gitanos jóvenes o a los mozos, porque claro, tú estabas estudiando, salías, entrabas... igual esto ya hacía que no se fijaran tanto en ti, por esta libertad que te daban tus padres, ¿no? Y, entonces, supongo que en parte lo veían mal para sus hijas, aunque lo viesen bien en nosotras." (Teresa, Cataluña, 26 años).

- En algunos casos, aparece una gran confusión identitaria y un conflicto interior al atribuir la continuidad escolar y la obtención de una titulación académica a prácticas intrínsecamente mayoritarias, por parte de su grupo de iguales y de su entorno gitano. El siguiente testimonio, aunque no lo expresa manifiestamente, a lo largo de su historia personal se aprecian sufrimiento y rupturas en el lenguaje que usa; por ejemplo: "me doy asco, hablar así con mis primos (...) estudiar para ser como un payo". Está en pleno conflicto personal y se observan contradicciones en el relato, ya que el entrevistado nos cuenta, por otra parte, lo siguiente:

\footnotetext{
"Me di cuenta que aprovechando más el tiempo, te da tiempo de hacer más cosas, está más satisfecho uno consigo mismo y... estás mejor, más a gusto, te sientes mejor... Para mí no influye nada, yo sé lo que soy, soy una persona con unos conocimientos mínimos o máximos y sigo siendo gitano y me relaciono con otro tipo de gente... se ganan muchas cosas, ya no mato el tiempo, me he dado cuenta que el tiempo se puede aprovechar mucho más y al aprovechar el tiempo se siente uno mucho mejor consigo mismo." (Andrés, Aragón, 18 años).
}

Todas estas dimensiones del impacto del éxito escolar y de la continuidad educativa en las reconstrucciones identitarias de las personas y también, indirectamente, de sus grupos familiares y comunitarios de pertenencia, presentan notables diferencias si se trata de experiencias de mujeres o de hombres, como hemos querido poner de manifiesto al inicio de este apartado. Por lo general, las mujeres entrevistadas se muestran mucho más abiertas a los cambios que los hombres entrevistados, sobre todo en lo relativo a un cambio de roles más igualitario y al matrimonio mixto. Tomando como punto de partida el statu quo actual, parece evidente que las mujeres tienen más que ganar con los cambios que los hombres, y de ahí que las posturas inmovilistas respecto a las mujeres se den más entre los hombres (aunque ellos mismos protagonicen trayectorias de continuidad, incluyendo la universidad). Además, el mantenimiento de algunas posiciones mucho más conservadoras en los hombres no presenta diferencias internas relativas a la edad ni al nivel de estudios obtenido, sino que se localizan entre hombres mayores y jóvenes indistintamente. También, lógicamente, las excepciones se dan en todas las edades y niveles.

Sin embargo, es cierto que la mayoría de nuestras entrevistadas no formulan un discurso de emancipación social y de cambio cultural (al menos no en términos de las diversas opciones del discurso feminista y sus reivindicaciones) y, como ejemplo, algunas mencionan con orgullo cómo siguen realizando actividades de servicio y cuidado total para los hombres de sus familias, "además de" continuar estudiando: 
"¿Cómo se reparten [las tareas]? Pues que el más tonto se lleva la peor parte, que dicen... y como yo soy la más tonta, pues ya está.... Mi madre, por ejemplo, hoy es la primera que me dice: 'Vete [a estudiar]'... pero mi cosa me tira a hacerlo. (...) por mi cabezonería me quedo hasta las cinco y media y voy a comprar yo. Y me siento luego mejor. Porque si ya he hecho la compra, puedo llegar a casa a las ocho y ya está. Y sí que tengo tarea, por ejemplo, yo siempre me dedico a tender la ropa y a plancharla." (Laura, 25 años, Castilla-León).

Pero hay que entender todos los cambios personales y grupales como procesos. Las hijas mayores abren camino, en la continuidad educativa y en la libertad de movimientos que contribuye a generar un proyecto propio, pero esto tiene sobre todo efectos en las propias madres, generalmente calificadas de sobreprotectoras tanto por parte de las mujeres como de los hombres:

"Mi madre me protegía mucho. Si hubiera sido por mi madre, ante el más mínimo fracaso me hubiera sacado, por no enfrentarme yo al fracaso." (Ramón, Cataluña, 44 años).

Ahora bien, donde mayor distancia se produce en las experiencias de hombres y mujeres es en la equiparación de las prácticas rituales relacionadas con el control de la sexualidad y de la reproducción, también en las percepciones e ideas de las propias mujeres sobre estos temas. Incluimos a continuación un largo fragmento de una de las mujeres más jóvenes que han formado parte de nuestros casos y que produce un discurso teórico tradicionalista sobre el ritual del pañuelo en la boda gitana al tiempo que expresa un alejamiento explícito de aquello que considera desventajas de género en el contexto gitano. Desde otras perspectivas y apartados a lo largo de nuestro análisis ésta es una contradicción recurrente, como estamos observando, incluso en una persona que ha estudiado Bachillerato y un Ciclo Formativo de Grado Medio y que trabaja como auxiliar sanitaria, en correspondencia con sus estudios:

"También pienso que una forma de demostrar que eres gitana es sacando el pañuelo. Mucha gente dice, los payos, que eso es un salvajada; bueno, depende cómo lo mires... A mí me parece muy bonito, por ejemplo, la cara que pone tu abuelo, tu padre... cuando dicen, pues sí, mira sabes, es muy bonito. (...) Y mi hija, pues no sé. Si tendría hija, no sé qué decirte si se lo sacará o no. Pienso que es una costumbre que se va quitando, porque la mayoría de las gitanas no se lo sacan, cada día se casan más jóvenes, cada día no se casan, se escapan porque no son vírgenes. Entonces llegará un tiempo en el que se lo sacará una de diez, y no, y no porque ya está pasando, cada día se casan más jóvenes y no puede ser eso, porque lo único que hace es amargarte la vida.... Me dicen que soy muy rara, porque yo no me quiero casar, que no lo sé, ¿eh?...que a lo mejor mañana encuentro al hombre de mi vida y me caso, porque eso nunca se sabe, ¿entiendes?... Yo creo que en cuanto ves un chico pues sabes que es, ¿no?... Y sabes si estás preparada para casarte 0 no; yo no estoy preparada para casarme, en estos momentos, no. Yo creo que no aguantaría, porque sí, a lo mejor te mantengo una semana, haciendo la comida, limpiando y eso, pero sólo una semana, nada más, no aguantaría más. Eso es una desventaja de las gitanas, por ejemplo, una paya puede conocer más a fondo a su novio antes de casarse, porque yo qué sé, puedes ir a vivir con él, puedes tener más intimidad. En cambio una gitana no puede tener eso, y al fin y al cabo 
es distinto, la convivencia sin casarte, sin haberla tenido, porque una gitana con su novio, por muy novio que sea, no... 0 sea, y a ver, eh... tampoco te puedes pegar todo el día con él, ¡hala!... Entonces te chillarían, te dirían algo, pero bueno. Yo estoy orgullosa de ser lo que soy, y el día que no lo sea, por ejemplo, nunca en mi vida he dicho: 'Ojalá Dios que no fuera gitana'. Nunca, porque son tus raíces y es tu vida... A mi madre le haría mucha ilusión con un gitano, porque su primera hija, es distinto, y aparte... Si le diría que me caso con un payo y no le importaría. Eso sí, me tendría que sacar el pañuelo, si no, me raja la cabeza, así que me matan. Además, yo creo que es una deshonra." (Victoria, Navarra, 17 años).

En este sentido y como se ha señalado ya en el capítulo anterior, a las mujeres gitanas que desean seguir por la vía académica, por corta que ésta sea, se les plantea con mayor virulencia que a los hombres una fuerte disyuntiva, tan falaz como desgraciadamente extendida -algunas chicas participan de la falacia, sin alterar los términos en los que se les plantea, como se hace notar en el ejemplo del párrafo anterior-: tener que 'demostrar' la preservación de su 'identidad gitana', 'a pesar de' la continuidad académica. Esto no es nuevo ni emerge específicamente de las reacciones entre distintos sectores de la población gitana ante los cambios, como señala Gairazábal (2000): "La pervivencia de los mitos que sostienen los mandatos clásicos de la feminidad tradicional puede ser vivida por algunos sectores sociales como forma de preservar una cultura que se ve amenazada, reforzándose así el papel tradicional de las mujeres." (Gairazábal, 2000: 44).

Este tipo de presiones se añade a las anteriores y suele conllevar enormes renuncias, como las que se identifican incluso en nuestras entrevistadas, todas ellas con algún grado de éxito y continuidad académica. Así, el contenido de la identidad que se les presenta y con el que se las presiona las hace prácticamente responsables últimas de la 'supervivencia' de toda la comunidad, equiparando directa e indirectamente la igualdad de las mujeres gitanas y los hombres gitanos a la desaparición cultural del pueblo gitano, lo cual constituye una perversa coartada para el mantenimiento de la desigualdad.

Pero es obvio que el contenido del cambio se aleja de definiciones tradicionales basadas en la desigualdad de las posiciones y de las relaciones de género. Es decir, los contenidos del sistema de género se transforman inevitablemente con la continuidad educativa. Y, naturalmente, en la medida en que tiene que ver con la pérdida de privilegios, este proceso de aculturación lo protagonizan de forma más decidida las mujeres, como viene sucediendo en todas las sociedades y grupos culturales del mundo.

Además, y apuntando a un fenómeno nada explorado hasta la fecha, algunas informantes reconocen la diferencia radical entre el mantenimiento de discursos oficiales o públicos en la comunidad y consejos que se dan a las chicas jóvenes por parte de un sector nada desdeñable de las mujeres mayores:

"Ya tienes dos formas de pensar, ellas no, ellas tienen sólo ésa, la que... la que han vivido toda... Pero tú tienes la otra... Aunque te críen como gitana, la costumbre es casarse joven, pero tú, tú misma no estás tonta y vas oyendo, y ellas, las que se han casao jóvenes nos dicen: 'No os caséis, 
que pa qué, porque os vais a amargar porque... pa nada, porque se está mejor como estáis, como vais a estar ahora no vais a estar nunca...' Pues tú misma vas oyendo eso... y luego en tu casa, según qué padres tengas, los míos me decían que no... que no hiciera eso [casarse joven]." (Adriana, Aragón, 18 años).

\subsubsection{Continuidad educativa, relaciones familiares y relaciones comunitarias}

Dentro de los efectos positivos sobre el grupo de pertenencia que las mujeres y los hombres en las trayectorias analizadas atribuyen a su continuidad educativa, se distinguen de forma clara tres aspectos interrelacionados. En primer lugar, aquellos aspectos de distancia crítica y aculturación relativa que ha afectado a su familia, y también señalados respecto a sí mismos. Se transforma la actitud general del grupo familiar y se normaliza la continuidad de otros miembros, adquiriendo la adscripción étnica un valor simbólico de referencia pero no de pertenencia, combinado con una práctica de relaciones sociales abierta:

"... Mi casa puede ser que sea un poco más rara de lo normal, nosotros somos gitanos pero hemos cogido, por decirlo así, las costumbres buenas de los payos; buenas, pues, como el estudiar, el trabajar [se refiere al trabajo asalariado], el saber ahorrar, el no sé... el distribuirte bien el dinero, el saber vestir, el saber con quién juntarte, si estás con unas personas, hacerte a esas personas y si estás con otras hacerte a esas cosas (...) Todas mis amigas siempre han sido payas, y a mí no me importa porque me da igual payos que gitanos, pero todas han sido así y te vas haciendo, no a ellas, porque tienes tus raíces, tus costumbres, muy, muy tuyas, pero te vas haciendo también a ellas (...) entonces es cuestión de adaptarse, pues no sé... me he criao entre los payos y entre los gitanos y creo que tengo los pensamientos más normales." (Elena, Madrid, 26 años).

"El ir a clase y convivir día a día con los payos pues te hacen coger las cosas buenas que tienen ellos y adentrarte más en el mundo de los payos." (Miguel, Aragón, 18 años).

Y las razones derivadas del contexto social no escapan al análisis de las personas que han disfrutado de otras condiciones y que han construido otros procesos y trayectorias:

\footnotetext{
"Entonces, cuando yo veo ciertas gitanas por aquí, con esa mentalidad, con tan pocas ganas de cambiar, ¡jolín! ¡Cómo es posible, pero cómo es posible! Bueno es posible porque mi madre ha tenido unas circunstancias que evidentemente no se le acercan ni mucho menos a las que hay, a la que hay en San Cosme, por ejemplo. 0 la que pueda haber en la Mina, y es eso lo que hace que tu vida cambie, las circunstancias que te rodean y cómo se viven." (Anabel, Cataluña, 42 años).
}

En segundo lugar, aquellos aspectos que, a menudo derivados de los anteriores, permiten a la persona con continuidad educativa adquirir y manejar competencias y habilidades interculturales en los distintos ámbitos de la sociedad mayoritaria y permiten 
al grupo beneficiarse de ellas. El desprestigio y la falta de apoyo se invierten. El siguiente testimonio opina que el éxito y la continuidad educativa no sólo no le ha alejado de la comunidad gitana, sino que le ha acercado más a ella: "te acerca más al pueblo gitano y a lo que eres". Y añade:

\footnotetext{
"Y la inmensa mayoría de los gitanos se sienten orgullosos de tener algún gitano estudiante o con estudios superiores... La gente de tu entorno a la vez se siente orgullosa de ti, por haber llegado a unas pequeñas metas, mi familia está muy orgullosa de mi trayectoria escolar y mis amigos también están ahí, apoyándome... Yo me siento bien, yo es que ante todo y sobre todo yo me considero una persona estudiante, luego ya por lo que soy, por lo que estoy haciendo y la ocupación que tengo. Luego ya, enfocándolo desde la perspectiva gitana, pues, me siento bien e intentando ser un ejemplo para las generaciones venideras." (Miguel, Aragón, 18 años).
}

En este sentido, en algunos casos las personas afirman que el hecho de tener una titulación académica ha mejorado su posición y su estatus dentro de la comunidad, interviniendo algunas veces como asesores y consejeros, apreciando pues, que la gente de su entorno les tiene depositada una gran confianza:

\footnotetext{
"De hecho, cuando alguien de mi familia cercana o incluso no tan cercana, pues tiene algún problema o me comenta algún caso, pues '¿Y tú qué harías, y tú que piensas, y qué puedo hacer', ¿no?, siempre hay alguien al que le puedes echar una mano... Creo que sí que sirve, que sirve." (Julia, Aragón, 36 años).

"... voy a acabar mi carrera, pero en cuanto miro atrás digo: ¡ostras! Yo pensaba, tenía la ilusión de... quería ser maestra, pero... el camino ha sido muy tortuoso, ¿sabes? Y cuando me veo aquí digo: ¡¡Madre mía!! ¡¡Yo tengo que hacer algo por ayudar a los demás también!!" (Eva, Aragón, 31 años).
}

Se repite aquí, ahora desde la perspectiva del impacto de la experiencia de continuidad, algo que ya señalábamos en el capítulo anterior: en muchas ocasiones, nuestras y nuestros entrevistados manifiestan que el reconocimiento familiar y de su entorno inmediato llegó tras su formación y la obtención de una titulación académica, y no mientras estaba en su proceso formativo.

En tercer lugar, la valoración positiva de las nuevas posibilidades de inserción laboral, por el tipo de trabajo y por el tipo de ingresos que puede obtener la persona que ha seguido sus estudios y que, en diversos casos de mujeres y de hombres entre nuestras y nuestros informantes, se ha convertido en el único sostén seguro de toda su familia. No es nada secundario el hecho de que también se transformen las aspiraciones y expectativas socioeconómicas y vitales generadas a partir de la observación de las trayectorias de continuidad educativa de las y los familiares y personas conocidas.

"Muchos han visto que, a través del estudio, se puede conseguir una salida más o menos buena, entonces me dicen que he acertao y muchos de ellos ahora se arrepienten de no haber seguido 
por ese camino, porque ahora ven que el camino que han elegido ellos es muy difícil, como está hoy en día la vida, sin una cualificación más o menos buena, media, es muy difícil acceder a tener ahora un piso, a tener una vida digna es muy difícil, sin tener una cualificación." (Manuel, Aragón, 21 años).

Aunque también se dan situaciones contrarias, y algunas personas con continuidad educativa experimentan (en mayor o menor grado) dificultades de inserción sociolaboral por el handicap que supone tener que competir en un medio abiertamente hostil al grupo minoritario y por carecer de capital social (de redes de información e influencia familiar) para acceder a un puesto de trabajo acorde a la preparación obtenida.

También algunos/as de los/las informantes (especialmente, de los y las más mayores) nos han manifestado que en algún momento de su vida profesional han percibido recelos y desconfianza por parte de alguno o alguna de sus compañeros y compañeras de trabajo, cargos directivos y/o usuarios/as de sus servicios, motivados por su pertenencia étnica. A su vez, consideramos que este "estado de latencia" de dichas prevenciones y obstáculos laborales por motivo étnico guarda relación (como causa, en principio) con la aplicación de posibles estrategias de invisibilidad étnica (ocultar que se es gitano o gitana), y también con la opción de desempeño laboral como contratado/a dentro del movimiento asociativo gitano y de los programas de desarrollo gitano95 u otros puestos de trabajo en la Administración en general (donde, en un país democrático, las discriminaciones laborales son más improbables).

Por otra parte, esta posibilidad de discriminación tanto en el acceso al trabajo como en su desempeño a pesar de contar con titulaciones se esgrime a veces a priori por parte de su entorno de procedencia y puede funcionar como profecía auto-cumplida de lo que -en términos de Ogbu- denominaríamos techo de empleo:

\footnotetext{
“¡Bah!... pero a ti que te... ¡aahh! Pero sí somos gitanos, ¡a ti que te van a dar el trabajo ese!, pero pa qué vas a perder el tiempo si luego no te vas a.... si no vas a acabar." (Jesús, Aragón, 29 años).

"Pues, no sé, a mí me dicen que: 'Pa' qué me sirve lo que estoy haciendo, que pa' qué, que luego qué voy a hacer ...'Yo les digo que es para prepararme mejor, para colocarme luego en un buen puesto de trabajo." (Juana, Navarra, 22 años).
}

De tal manera que el gitano o gitana que opta por la continuidad en la vía académica puede encontrase con mensajes (más o menos intermitentes y puntuales) de rece10, tanto en su grupo de pertenencia como entre personas de la sociedad mayoritaria, y tanto mientras estudia como en la búsqueda de trabajo y, posteriormente, en el desempeño del mismo. De modo que las titulaciones pueden (y a menudo, aunque no siempre, ocurre así) aumentar las posibilidades de inserción laboral (como hemos señalado en el apartado anterior), pero es verdad también que (con diversa frecuen-

95 Unido, así mismo, a la voluntad de contribuir a la inserción social y a las reivindicaciones de su propio grupo étnico, y también al hecho de que dicho trabajo en pro de la comunidad o comunidades gitanas de su zona puede conllevar una re-valorización de su prestigio en su entorno de procedencia. 
cia e intensidad) dicho acceso al mercado laboral de la sociedad mayoritaria va acompañado para los gitanos y gitanas titulados de un extra de presiones $y$, por consiguiente, va a requerir un plus de asertividad y habilidades sociales.

Finalmente, algunos entrevistados hombres, más que mujeres, han manifestado el temor a no cumplir con las expectativas que su entorno familiar y comunitario gitano ha proyectado en ellos. Cuando se ha conseguido una titulación académica, se espera que ésta sirva para conseguir un trabajo mejor remunerado y acorde a su formación, lo cual supone otra experiencia sin referentes y una especie de prueba del valor de la continuidad educativa que se ha estado defendiendo:

\footnotetext{
"Hubiera preferido hacer Psicología o Sociología, pero... (...) Espero aprobar, espero encontrar un trabajo que... bueno, eso es lo que espero." (César, Castilla-León, 22 años).

"Me refiero a que tengas el puesto de trabajo adecuado, que no estés todo el día ahí, ocho horas metido a pico y pala (...) A ver si obtengo algo, si no... Porque trabajo ya lo tengo: trabajar con los caballos... Será complicado, pero no estás ahí todo el día reventado que ya no puedes al día siguiente ni levantarte, aunque trabajas." (Eugenio, Navarra, 18 años).
}

El asociacionismo parece haber tenido un papel mayor en la inserción laboral de las y los jóvenes y también entre los hombres mayores, más que entre las mujeres mayores de 30 años. Por otra parte, los ámbitos frecuentes de formación son integrables en las necesidades y funciones de las asociaciones, al tiempo que éstas pueden empezar a desempeñar en cierta medida aquel espacio del capital social en estos mismos tipos de ocupaciones, junto a los vínculos familiares ya señalados. De todas maneras, en este momento y a partir de las trayectorias y experiencias analizadas, se hace difícil pensar en las condiciones reales de absorción de los y las tituladas gitanas sin el contexto de la formación y de las nuevas ocupaciones que el escaso e irregular estado del bienestar proporciona en el marco de las acciones destinadas a la propia minoría.

\subsection{Relaciones interculturales, parejas mixtas y continuidad educativa}

Una proporción de los casos de éxito y continuidad que se van incorporando al registro abierto de la investigación están resultando ser descendientes de matrimonios mixtos, situación que también se refleja en los casos seleccionados para este primer análisis (11 sobre 50), tal como se observa en el cuadro de las características de la muestra del capítulo 2. Por otro lado, observamos que un sector de las gitanas y gitanos que han alcanzado estudios superiores se han casado con personas no gitanas, especialmente las mujeres mayores de 30 años. Así mismo, una parte de las y los líderes de las asociaciones gitanas y de asociaciones de mujeres gitanas descienden de matrimonios mixtos, aunque esta proporción es menos importante entre los menores de 30 años. Otro tanto ocurre entre las personas implicadas en programas y estudios para la 
mejora de la escolarización de la infancia y juventud gitana. Es obvio que este extremo sólo puede ser tratado como efecto y causa al mismo tiempo, porque su condición de efecto o de causa es altamente dependiente del contexto social en que se produzca esta experiencia de matrimonio mixto. Sin embargo, cuando se trata de sectores sociales con aspiraciones de movilidad por la vía académica y no de sectores marginales, esta circunstancia puede resultar en un mejor pronóstico de continuidad. Sin duda, éste es uno de los hallazgos no previstos al iniciar la investigación.

Somos conscientes de que este hecho podría ser mal interpretado, contribuyendo involuntariamente a reforzar la inaceptable idea de que la población gitana posee algún rasgo intrínsecamente negativo o de que la herencia cultural gitana es un lastre para los estudios. Nada más lejos de nuestra intención. Esta interpretación supondría una distorsión, incluso una perversión, de lo que estamos argumentando. Lo que en realidad, ocurre -y así lo estamos señalando- es todo lo contrario: cualquier persona, en la medida en que goza de mejores oportunidades sociales (inserción urbanística, laboral, social y escolar), aumenta sus herramientas y sus expectativas, y las experiencias de relaciones interculturales positivas contribuyen a desarrollar aquellas herramientas, en todas las personas. Por lo demás, los matrimonios mixtos en los padres y madres o en las parejas actuales de nuestros y nuestras informantes no son los más frecuentes ni en la muestra más amplia ni en los casos aquí analizados.

Así pues, una dimensión importante en el éxito escolar del alumnado gitano es la de la inserción social que, a su vez, puede retroalimentar procesos similares al descrito por Gibson (1988)96 y conocido como acomodación sin asimilación. A través del mismo, y entre otros aspectos, las generaciones más jóvenes de un grupo minoritario adoptan una actitud pro-académica como parte de los elementos que seleccionan para acomodarse sin conflictos a requisitos básicos de la sociedad mayoritaria (valoración de la escolarización prolongada) al tiempo que evitan las discontinuidades en relación con su espacio familiar y comunitario de referencia. Esta constatación desvela y desmitifica otros planteamientos y obliga a otras perspectivas, y exige a unas y a otras personas. No se trata de una mera suma de factores favorables de índole económica, urbanística, familiar y escolar, ni siquiera de la importancia de algún factor central para otros factores favorables, como puede ser el barrio y colegio no segregados porque eso hace posible formar parte de un grupo de iguales que, aunque sea mínimamente, sigue estudiando, como hemos apuntado después. Ahora estamos refiriéndonos a condiciones y estilo de vida o dimensiones que agrupan a varios factores que apuntan en una misma dirección.

Incluso en la construcción identitaria de una informante procedente de una pareja mixta, se combinan estos elementos de acomodación sin asimilación: parte de una adscripción aparentemente voluntaria a la parte gitana de su familia, pero en su selección de "lo gitano" no incluye aspectos de posible confrontación sobre su continuidad educativa, porque "no ha tenido esos ejemplos" desde la parte no gitana de su familia. Es decir, se identifica como gitana y considera indirectamente como no gitanas

96 Margaret Gibson (1988), Accommodation without assimilation. Punjabi sihks in a Californian High School. Falmer Press. 
aquellas prácticas seguidas por la mayoría de sus conocidas gitanas pero que entrarían en contradicción con su experiencia práctica no gitana y con sus aspiraciones académicas y vitales. Por una parte manifiesta:

\footnotetext{
"Por ser mestiza, para los gitanos soy paya y para los payos soy gitana y bueno, lo que tú te consideres tendrán otro punto de vista, la verdad que a veces te sientes cohibida; siempre estás con el qué dirán pero, pero ya llega un momento en el cual siempre que cumplas las cinco costumbres de la etnia gitana que para mí son las esenciales y yo las cumplo porque me salen del alma: el respeto hacia los mayores, hacia mis difuntos, el cariño y el amor hacia mi familia, el estar siempre con ellos y como soy mujer el hecho de respetar mi virginidad, eso lo haré hasta el día de mi boda y lo demás hasta el día de mi muerte. (...) (Pilar, Aragón, 21 años).
}

Pero más adelante, sin embargo, añade:

"... tengo 21 años y no me he comprometido ni pienso comprometerme por ahora, eso lo tengo bien claro. Yo, hasta el día de mañana que tenga mi carrera universitaria no me quiero casar y bueno, Dios dirá si luego pasa o no, pero lo que sí tengo claro es que no me voy a cerrar las puertas y hacer como la mayoría hace... con 16 años y ya hasta su primer hijo, no quiero, no he tenido esos ejemplos y gracias a Dios no, no voy a optar por ello, ya soy bastante madura y espero seguir en mis metas, que por ahora no son ésas." (Pilar, Aragón, 21 años).

En otro orden de cosas, si bien una mayor inserción y la aculturación relativa que conlleva puede contribuir a unas mayores probabilidades de éxito y continuidad académicas, y viceversa, esto no asegura una promoción laboral y socio-económica automática, ni tampoco el que redunde en un mayor respeto y prestigio dentro de su propia comunidad, ni en que sirva necesariamente de referente para los miembros más jóvenes de la misma. Estamos ante un proceso histórico de cambio y readaptación sociocultural muy importante y existen fases dentro de este proceso que nos Ilevan a escenarios cambiantes, no lineales, como ya han mostrado exhaustivamente décadas de investigación en otras realidades sociopolíticas y culturales comparables. Algunas de estas fases pueden resultar así de variadas en términos de diversas parejas mixtas dentro de una sola familia de origen, que en cinco casos entre los estudiados tienden a aumentar en generaciones sucesivas, como en el ejemplo que sigue:

\footnotetext{
"Mis padres y mis hermanas... Mi hermana la mayor está casada con un payo, y la segunda, pues no sabemos, porque no lo sabe ni él, o sea que suponemos que es payo... y mi hermano, no te puedo decir, porque no conocí a su mujer y no sé si es paya o gitana... a los 14 años se marchó y estuvo trabajando, salió a un hotel y de allí fue pasando a otro, para ascender de categoría, y acabó en Madrid, y tuvo unos años que se le perdió la pista hasta que se casó, ahora ha vuelto a casa, y está separado. Me creo que una paya, pero vamos... ahora está en su propia casa, en el pueblo de al lado." (Yolanda, Castilla-León, 29 años).
}

Aunque las experiencias son muy diversas en este sentido, parece importante diferenciar cuál de los dos cónyuges es gitano y cuál no lo es. Aparentemente, cuando el padre no es gitano, las hijas y los hijos suelen tener experiencias más alejadas de los 
contextos comunitarios propiamente gitanos. En cambio, si la madre no es gitana, se incorpora con mayor frecuencia al grupo familiar gitano del marido, dentro de contextos comunitarios gitanos. Obviamente, se ignora cuál es el alcance proporcional de estas situaciones en el conjunto de la población gitana, pero en los casos analizados y en el conjunto de casos disponibles hasta la fecha en la investigación que se sigue desarrollando, predomina esta segunda situación:

"Y después el hecho de que mi madre no fuera gitana, también condiciona mucho la forma de vida, que se adapten el uno al otro condiciona mucho. No es lo mismo una familia sólo de gitanos que una familia mixta, se nota. No porque sea ni peor ni mejor, simplemente porque cada uno tiene ciertas costumbres, que se van acoplando el uno al otro." (Alba, Cataluña, 24 años).

"Mi madre no es gitana, es mi padre. El hecho de que mi madre no sea gitana no quiere decir que nosotros no nos hayamos criado en un ambiente gitano, al contrario, porque mi madre se adaptó muchísimo. Quiero decir, que mi familia es una familia muy abierta, mucho de coger la gente, como acostumbran a ser todas las familias gitanas, y mi madre se integró por completo." (Verónica, Cataluña, 35 años).

"Mi familia paterna al completo es gitana. Mi familia materna no es gitana. En mi familia hay varios casos de familias mixtas, como la mía." (Juanjo, Navarra, 18 años).

Esta posible tendencia nos permite adelantarnos a desmentir una también posible asociación demasiado simple y probablemente sociocéntrica entre algún supuesto papel diferencial de las madres y de los padres gitanos y no gitanos y una menor o mayor continuidad educativa de sus hijos y, sobre todo, de sus hijas. Aunque sí se han dado algunas situaciones en las que esta diferencia de origen étnico ha creado presiones contradictorias frente a la continuidad académica de la chica y, cuando esto se ha dado, la presión porque la chica interrumpa sus estudios sí procede únicamente de su contexto familiar y comunitario gitano. En este sentido, es interesante observar la experiencia de una de nuestras entrevistadas en la atribución de su identidad 'apaya$\mathrm{da}^{\prime} \mathrm{y}$ de su continuidad educativa al hecho de proceder de pareja mixta, padre no gitano por parte de sus iguales, aunque ella no haya convivido realmente con su grupo familiar no gitano:

"(...) siempre he estado en las colonias de Caritas en grupos así de juveniles, es lo que de vedad me ha enseñado a mí algo del mundo payo, porque, ya digo, que con mi familia paya he convivido, pero apenas, y mi padre, debido a su edad o lo que sea, siempre es más cerrado... Sí que te sigues sorprendiendo porque quieras o no te llegan [comentarios] a los oídos y bueno, como en todo, como en casi toda mi vida, pues es lo que surge, que soy más apayada, que es normal que siga este curso porque mi padre es payo..." (Pilar, Aragón, 21 años).

Algunas de las experiencias de ruptura con la familia, aunque se hayan inciado con el deseo firme de la chica por continuar estudiando, se han materializado definitivamente con el enamoramiento de un chico no gitano, llegando en dos casos entre los analizados a la fuga del domicilio familiar. Una entrevistada procede enteramente de 
familia gitana pero señala que ella nunca quiso casarse con un gitano, pues piensa que los gitanos "son muy machistas y yo ya lo había visto en mi casa", y a pesar de la oposición férrea de padres y abuelos, se fugó con un novio no gitano y continuó estudiando cuando pudo.

La opinión favorable a los matrimonios mixtos es mucho menos extendida entre los hombres y chicos jóvenes, pese a la aparente mayor frecuencia de parejas de hombre gitano con mujer no gitana. Aun así, en el extremo opuesto, uno de nuestros entrevistados expresaba directamente su opinión de que estas parejas pueden constituir en sí factores favorables a la inserción social y a la promoción escolar:

"(...) y yo creo que es bueno, que la gente se mezcle, se abra." (Richi, Castilla-León, 24 años).

Resulta innegable reconocer que, en nuestros días, en la sociedad mayoritaria hay más libertad individual, estudia una proporción mucho mayor de población, se ha retrasado mucho la edad de casarse, ha cambiado la conceptualización misma del hecho de tener hijos y los modos de compartir la vida en pareja y, como trasfondo y como efecto, existe una ideología que se extiende progresivamente y que es favorable a una igualación en cuanto a derechos y prácticas entre las personas de ambos sexos, a pesar de las dramáticas resistencias que revela a diario la violencia contra las mujeres. Progresivamente, aunque de forma no tan visible ni homogénea, también las familias gitanas están asistiendo y produciendo un cambio en términos de las relaciones de género y en la conceptualización de la persona y de su libertad individual. Uno de los indicadores que dan cuenta de estos cambios tiene que ver con las actitudes y las prácticas relacionadas con la elección del cónyuge, y esto inevitablemente conlleva a una posibilidad de aceptar los matrimonios mixtos de las hijas:

\footnotetext{
"Y creo que la primera vez cuando le dijo mi hermana a mi madre que tenía un novio, y que era payo, lo primero que le dijo, eso sí, le dijo que entrara ya en la casa, que ya sabía lo que tenía que hacer, pues por eso, ¿no?, que sus cosas, pues... lo que se entiende... pues eso, de ser una buena chica, de ser una buena mujer y eso, y que entrara a la casa ya cuanto antes y que también le dijo, dice: 'Es payo', y dice: 'Bueno, hija, ya sabes que... el padre del mismo pueblo es muy bonico, pero bueno, no pasa nada, si es al que quieres, pues ya está, porque... si, hombre, si fuera gitano, pues mira, a lo mejor me alegraría un poco más, pero ... bueno, teniéndote'. Y ahora, muchas veces mi madre me dice que... vamos... 'Pues, mira, no le daba yo por ningún gitano del mundo'." (Javier, Madrid, 23 años).
}

Si interpretáramos los testimonios analizados en términos del repertorio de identidades planteado por Davidson (1996)97 que supuestamente desarrollan las y los estudiantes minoritarios, deberíamos llegar a la conclusión provisional de que la mayoría de ellas y ellos se construyen identidades transculturales, en tanto que personas con éxito y continuidad académica no esperados que paralelamente mantienen vinculacio-

97 Anne Locke Davidson, (1996) Molding and making identities in school, Falmer Press. 
nes positivas y activas respecto a su cultura familiar y comunitaria de origen. Este proceso es más claro entre las mujeres y los hombres más jóvenes, con mayor frecuencia en las mujeres, ya que para la mayoría de ellas la continuidad en sí misma representa y precipita otras transformaciones y recombinaciones entre prácticas y universos culturales a menudo distantes. Sin embargo, esto significa que la poca frecuencia de las trayectorias y experiencias descritas (de unas y de otros) nos lleva a la inquietante conclusión de un predominio de las, también en términos también de Davidson (1996), identidades conformistas, para el resto del alumnado gitano sin continuidad educativa. Desgraciadamente, una gran mayoría todavía hace lo que se espera directa o indirectamente de ella desde amplios sectores ${ }^{98}$ del sistema educativo y de la sociedad mayoritaria y, por distintas razones que ya se han puesto de manifiesto, desde su entorno comunitario: abandonar y conformarse al estereotipo y al margen.

\footnotetext{
98 En el momento de revisar la redacción de este libro se acaban de producir unas declaraciones escalofriantes, por simples y rotundas, de la viceconsejera de Educación de la Comunidad de Madrid sobre su opinión de que los alumnos inmigrantes "no han venido aquí a estudiar" añadiendo que "Algo parecido ocurre con los gitanos. El niño lo que quiere es ir con su padre con la fregoneta al mercado a vender fruta". El País, viernes 28 de mayo de 2004. Estas declaraciones pretenden justificar su autorización a los institutos madrileños para organizar itinerarios segregados para distintos tipos de alumnado, que contiene la LOCE, paralizada por el Consejo de Ministros. Sobre los nefastos efectos de los itinerarios educativos precoces o streaming sobre los alumnos de grupos minoritarios, aplicados y contestados en otros sistemas educativos, como el norteamericano, ver especialmente: Mehan, H. (1996) Constructing Schoo Success: untracking minority students, SUNY Press, y Hallam, S. \& Ireson, J. (2003) Ability Grouping in Education, London: PCP, SAGE.
} 


\section{CAPÍTULO 6: REPENSAR EL CAMBIO SOCIAL Y CULTURAL DESDE LAS EXPERIENCIAS DE ÉXITO Y CONTINUIDAD EDUCATIVA}

\subsection{Recapitulando: sobre el éxito y la continuidad educativa del alumnado gitano}

El análisis realizado ha tenido en cuenta las trayectorias y las experiencias de los 50 casos seleccionados para determinar el alcance de nuestras hipótesis y supuestos a partir de los interrogantes principales planteados en la investigación. Así, algunos de los factores que establecimos al principio han sido ampliamente modificados, otros han afianzado su valor explicativo y otros, la mayoría, se han hecho más complejos. Todos nos indican nuevas vías de investigación y profundización. Pero, por otra parte, nuestros entrevistados y entrevistadas nos han ofrecido también sus visiones personales sobre los temas abordados. Es decir, no sólo nos han proporcionado reconstrucciones de sus propias trayectorias y experiencias, sino que también han vertido en ellas reflexiones y opiniones sobre las mismas. Naturalmente, todos estos aspectos muestran, así mismo, la diversidad de las personas que han constituido los casos. Sus circunstancias y trayectorias han sido y sus opiniones y posiciones actuales también son diferentes, sus reflexiones les llevan a conclusiones diversas. Como en cualquier grupo de personas, las ideas y opiniones expresadas son muchas veces discrepantes, contradictorias e incluso opuestas, y sus percepciones no tienen por qué coincidir con nuestra interpretación de las condiciones que propiciaron sus trayectorias de continuidad. Ya hemos ido señalando algunas tendencias en este sentido a lo largo del texto, pero a continuación vamos a sintetizar brevemente algunas de ellas, especialmente en relación con su percepción del factor clave en su continuidad académica.

Los factores que nuestros y nuestras informantes señalan como claves de sus trayectorias, tanto en aquellos casos en que las condiciones socioeconómicas familiares y la situación del entorno no hacía prever la continuidad educativa como en las más favorables, se sitúan principalmente en la dimensión afectivo-relacional (en el grupo familiar y comunitario y en los centros educativos), aunque también se recuerda la importancia de algunos factores específicamente educativos, o directamente dependientes de la política educativa, en algunos momentos. Pueden resumirse en los diez puntos siguientes, por orden de importancia entre los señalados por las y los entrevistados con mayor frecuencia:

- Sentirse valorado/a y apoyado/a. La continuidad académica condicionada por la autoestima, unida a la aceptación por parte de otras personas. 
"La familia sí que te apoya, ¿vale? Por ejemplo, en mi casa lo que es mis padres siempre me han apoyado y siempre me han dejado hacer lo que he querido. Es decir, mi padre no me ha puesto normas, ni nada. Siempre me ha dejado escoger. Que a lo mejor es lo que a alguna gente le falta, que tampoco pueden escoger." (Lola, Cataluña, 32 años).

- El apoyo de su madre y/o padre son decisivos, en el sentido del proyecto y en sentido de la ayuda.

"Mi madre, es que no me cansaría de hablar de ella. Mi padre, es verdad que ha sido el que ha luchado para que por lo menos yo pudiera tener mis libros, porque él es un luchador de sacar la economía a flote y usar todos los medios posibles, ¿no?, y mi madre es la que siempre me ha inculcado valores de vida, la que ha hablado con los profesores y mis compañeros, porque sin ellos no hubiera podido seguir estudiando." (Pilar, Aragón, 21 años).

"Cuando llegué a parvulitos o a primero, bueno, a una edad que se supone que sólo haces dibujos... y mi madre me enseñó a leer, a escribir, a sumar, a restar... Me enseñó todo eso. Y, claro, yo llegué a clase y la gente, pues claro, hacía, yo qué sé, plastilinas, o algo así. Y la profesora, pues claro, se quedó pues flipando..." (Soledad, Castilla-León, 18 años).

- El fuerte convencimiento individual para proseguir sus estudios.

"El primer factor y el más importante, pues, mis ganas de estudiar y de sacar algo provechoso del estudio. Y luego vienen unas circunstancias más externas: el apoyo de familiares, de los profesores." (Miguel, Aragón, 18 años).

- El propio coraje, esfuerzo y capacidad para afrontar y buscar soluciones para superar las barreras que le imponían a la persona.

"Fundamentalmente, empeño, empeño, empeño, aunque no le quito mérito para nada a las profesoras que he tenido, ¿eh?, y a la directora del colegio." (Julia, Aragón, 36 años).

- El fenotipo y su modo de autopresentación (vestimenta, peinado, manera de hablar y relacionarse, etc.) no corresponde al aspecto que tradicionalmente se asocia a la apariencia gitana.

"Y además pues eso, no... mi aspecto físico no es especialmente gitano, y... y mis padres me han vestido siempre como cualquier chico igual que visten los gitanos, pero no... he tenido siempre el pelo corto... si es que son... la verdad es que parece mentira, pero todas esas tonterías estúpidas de... pues muchas veces son casi más importantes, ¿sabes?, es decir, el hecho de que a primera vista sea reconocible o no como gitano, tiene una importancia, yo creo que tremenda. 0 sea, la reacción que va a tomar la gente así a primera vista, ¿no?, esa, esa primera impresión, ¿no? Que... que rara vez se profundiza, es tan importante que, que a mucha gente la marca definitivamente." (Marcos, Madrid, 24 años). 
- Un apoyo desde el profesorado y el centro educativo si no constante, sí en los momentos de toma de decisiones que pueden afectar la continuidad educativa.

"Si no hubiese sido por el apoyo que he recibido del colegio y luego con posterioridad del Colegio Mayor por parte, por ejemplo, de la directora que tranquilizaba mucho a mi madre de darle la sensación de decirle: '¡No se preocupe, que su hija va a estar bien aquí!'... En el instituto y en el Colegio, si no hubiese sido por los profesores y la directora, pues no... pues no hubiese estudiado... porque me han apoyado mucho." (María, Aragón, 26 años).

"Ha habido momentos que, de verdad, de desesperación: -¡No puedo seguir! No puedo!. Pero siempre ha habido alguien que me ha dicho: -Tranquilo, no te preocupes, que te vamos a echar una mano y te vamos a ayudar. Me han dado aliento y he seguido. Me ha costado, es pasar una montaña, tú piensa que, bueno, ir un año a la escuela con las monjas, y luego el Graduado Escolar y luego la Universidad, te encuentras con unos socavones que te caes. Porque yo no he tenido una enseñanza reglada, normal, como tiene otro niño. Pero como la lucha que yo tenía interior era tan grande y es, y sigue siendo, me ha hecho superar todas estas cosas." (Ramón, Cataluña, 44 años).

- El/la entrevistado/a ha percibido un sentimiento de igualdad con la sociedad mayoritaria.

"Yo estaba integrada totalmente: me venían a buscar a casa, me iba con ellas al colegio, me iba a tomar algo; en fin ... ya te he dicho, como gente normal. Si no tenía mucho que hacer, mucho que estudiar, nos íbamos por ahí a dar un paseo o a tomar algo... Me gustaba salir, me relacionaba, tenía amigos, tenía amigas. Tenía amigos chicos, amigas chicas. ¡A mí me gustaba! ¡Me lo pasaba bien en el colegio!" (Clara, Castilla-León, 29 años).

- El acceso a becas es mencionado por una mayoría de informantes, especialmente aquellos que han tenido trayectorias académicas más largas. El disponer de una beca de estudios puede constituir un factor que, en momentos de duda, puede inclinar la balanza hacia la continuidad escolar. ${ }^{99}$

"Y, ¡claro!, las cosas que te mandan en primero [de BUP], ¡libros! Y ahí fue cuando por primera vez me dieron una beca, la Asociación Gitana, de once mil pesetas. Me acuerdo que me compré un diccionario, nunca había tenido un diccionario, iah, y los rotring! Daba dibujo y me compré los rotrings. Todavía les tengo." (Laura, Castilla-León, 26 años).

- La necesidad de la persona por salir de un entorno de precariedad económica, que se espera superar con la obtención de una titulación académica y una mejor inserción laboral.

99 La experiencia de otros países resulta clave para comparar los efectos de la reducción de los gastos sociales en educación sobre los estudiantes minoritarios: por ejemplo, en EE.UU. se señala cómo han disminuido notablemente las cifras de estudiantes negros y latinos en la universidad en tales circunstancias. Vid.: McCarthy, C. (1994): Racismo y curriculum. La desigualdad social y las teorías políticas de las diferencias en la investigación contemporánea sobre la enseñanza, Madrid: Ediciones Morata. 


\begin{abstract}
"Yo creo un poco, un poco es la familia, te han aconsejao los profesores y aparte de tener información, sabiendo de primera mano, por casos y por amigos, las salidas, que había en el mundo laboral, la salida de vida, de qué pasaría si no tienes estudios, qué pasa si tienes estudios... Yo he visto un poco las dos realidades, y sin estudios, pues no me ha gustao las salidas que hay. Yo pienso que como está hoy en día el mercao, si no tienes una preparación mediana, es muy difícil seguir adelante... entonces, los estudios es la única manera de salir un poco adelante. Aunque tengas estudios y no... igual no lo necesitas en este momento, pero el estudio nunca viene mal, siempre viene bien, en un momento te puede servir, te sirve para muchas cosas." (Manuel, Aragón, 21 años).
\end{abstract}

\title{
- Su actitud abierta e independiente.
}

"Tengo buen carácter. Buena filosofía de vida.... Joe, el jefe. Soy de la familia que mejor nota está sacando; pues cómo me voy a sentir. Y de los que conozco, así, gitanos que estudien soy el que más, me parece. Pues me siento muy feliz." (Antonio, Navarra, 18 años).

Ahora bien, tal como se indica en el título de este apartado, es necesario sistematizar nuestras interpretaciones sobre las trayectorias y las experiencias de éxito y de continuidad educativa del alumnado gitano, que en parte coincide y en parte no coincide con las percepciones anteriores. Para ello, empezaremos por formular algunos hallazgos clave a partir de los casos trabajados en forma de generalizaciones empíricas, que constituyen, a su vez, nuevas hipótesis a contrastar en ulteriores estudios. Estos hallazgos van a contribuir decididamente a la discusión y a la valoración de las mismas más adelante. Algunas generalizaciones relacionadas con la pertenencia a uno u otro sexo y a la asignación de papeles sociales y a estereotipos o mandatos de género responden y matizan aspectos contenidos en la propia perspectiva de análisis, como interrogante transversal a todas las hipótesis, mientras que otras cuestiones apuntan a factores y a estrategias de continuidad educativa no previstos en aquellas.

Una revisión exhaustiva de lo expuesto en los capítulos precedentes nos permite formular, pues, las siguientes generalizaciones:

- Invisibilidad étnica de algunas chicas y chicos estudiantes gitanos como causa y como efecto de su éxito inicial y de su continuidad, especialmente entre los casos de mujeres y hombres mayores: como causa, porque puede resultar de una estrategia familiar de alejamiento de los barrios con alta segregación, adoptando perspectivas y prácticas mayoritarias no marginales con relación a la escolarización; como efecto, porque no se identifica y no se proyecta una baja expectativa hacia la/el estudiante a lo largo de su trayectoria, bien por su completa acomodación, bien porque realmente no se le distingue y la persona no explicita su adscripción étnica si no se establecen relaciones de mayor intimidad en el entorno escolar. 
- Existencia de relaciones interculturales y convivencia intercultural positivas en las experiencias de los padres y/o en los barrios y zonas de residencia del grupo familiar, así como en los centros educativos frecuentados por las distintas personas del grupo familiar, como factor positivo en las condiciones favorables a la continuidad educativa.

- Impacto del éxito inicial no esperado, identificado, valorado y presentado a la familia por parte del profesorado, como factor de apoyo a la continuidad, en ambos sexos.

- Emergencia de un proyecto personal de continuidad educativa en la chica o en el chico, hasta cierto punto independiente de las condiciones socioeconómicas, familiares y comunitarias y no necesariamente materializado sin interrupciones, llevado adelante por el propio empeño de la persona y a través de estrategias, negociaciones y acomodaciones múltiples.

- Impacto de las habilidades sociales de la persona para ocupar roles normalizados de alumna o alumno y de compañero/a en las relaciones establecidas dentro del centro educativo, y para negociar las condiciones de la continuidad académica con el grupo familiar, en los casos en los que no existe apoyo inicial.

- Desarrollo de una doble sociabilidad en la mayoría de los casos analizados tanto en paralelo y/o alternativamente en el tiempo y en distintos momentos del ciclo vital, combinando relaciones y posiciones distintas en el grupo de iguales gitano, generalmente asociado al entorno familiar y comunitario, y el grupo de iguales no gitano, generalmente asociado al entorno académico.

- Reconocimiento diferencial de esta doble sociabilidad y de sus ámbitos por género, según una interpretación tradicional de las relaciones interétnicas de los chicos y de las chicas.

- Aplazamiento de la entrada en el ciclo reproductivo por medio del matrimonio hasta finalizar los estudios en ambos sexos.

- Entre algunas mujeres más jóvenes con trayectorias interrumpidas, aplazamiento de la continuidad para después del matrimonio y se confía en el acuerdo del futuro marido para proseguir estudiando, posible indicador de una incipiente estrategia generacional.

- Emergencia del fenómeno de la soltería entre mujeres y hombres gitanos, en algunos casos como resultado de priorizar la continuidad educativa y la inserción sociolaboral.

- Aumento de la constitución de parejas mixtas formadas por mujeres y hombres gitanos con hombres y mujeres no gitanos, posible indicador de una incipiente estrategia matrimonial de clase por encima de una estrategia matrimonial de etnia (al menos en términos de afinidades en el nivel de instrucción y en las expectativas y relaciones de género). 
- Entre las mujeres gitanas, preferencia por estudios vinculados con lo que denominamos profesiones de "retorno a la comunidad", en formación profesional (Mediación, Animación Sociocultural, etc.) y en estudios universitarios de ciclo corto (Educación Social, Trabajo Social, Enfermería, Magisterio).

- Entre las mujeres gitanas, preferencia por empleos fuertemente feminizados, frente a una proporción aparentemente muy baja o nula de profesiones no vinculadas al ámbito educativo-asistencialista y de ciclo largo.

- Entre los hombres gitanos, preferencia mayor que entre las mujeres por estudios que, aunque inicialmente no están vinculados con empleos de "retorno a la comunidad", posteriormente se orientan hacia esa aplicación (Periodismo, Derecho, Políticas, Empresariales) a través del mundo asociativo.

- Entre los hombres gitanos, aunque ésta parece una orientación relativamente minoritaria, se encuentra con mayor frecuencia que entre las mujeres un tipo de estudios vinculados con el desempeño de un oficio de forma profesionalizada sin un aparente retorno a la comunidad (por ejemplo, chicos que han estudiado formación profesional y que ejercen su profesión, incluso como autónomos, frente a chicas que han estudiado Peluquería y que han ejercido nada o poco su profesión, o que han estudiado para profesiones intrínsecamente dependientes, asalariadas o temporales, por ejemplo, Azafatas de Congresos).

- Entre las mujeres gitanas con estudios post-obligatorios parece más frecuente la vinculación laboral con el mundo asociativo, a distintos niveles, y en sectores de empleo público relacionados directa e indirectamente con la propia comunidad.

- Tanto las mujeres como los hombres gitanos con estudios medios o superiores pueden encontrarse ( $y$, de hecho, se encuentran con alguna frecuencia) con personas que proyectan hacia ellas/os prejuicios racistas, tanto durante la época de búsqueda de empleo como, posteriormente, en el desempeño del mismo (a lo que hay que sumar la falta de redes sociales de influencia para el acceso al mundo laboral). A su vez, esta lamentable circunstancia puede esgrimirse a priori por personas de su grupo de procedencia para desalentarles en su opción de continuidad académica.

- Se produce de un modo progresivo un cambio de actitud (en parte, en las opiniones y en parte, corroborado por las prácticas) en las familias ante la escolarización, tanto entre aquellas que pueden apoyar la continuidad debido a sus posiciones socioeconómicas más integradas como en aquellas que la apoyarían si se dieran mejores condiciones socioeconómicas.

- La traducción del cambio de actitud frente a la continuidad educativa de chicos y chicas, especialmente de chicas, en prácticas de apoyo real por parte de sus padres, está altamente condicionada por la presión comunitaria más próxima y la familia extensa.

- Este condicionamiento se hace sumamente dependiente, a su vez, de la existencia de recursos de apoyo, no necesaria ni sistemáticamente material, a la continuidad de las chicas (apoyo del profesorado, ayuda en la tramitación de becas, intervención 
del movimiento asociativo, existencia de un centro cívico donde se realiza estudio extraescolar, al margen de o además de acceso a becas y otros recursos).

- En relación con el punto anterior, el papel de los apoyos materiales y humanos en la continuidad educativa de mujeres y hombres es radicalmente diferencial: en los hombres, aportan condiciones y modelos, así como presiones para la continuidad cuando se producen dudas por parte del chico; mientras que en las mujeres, resultan decisivos los apoyos materiales y humanos para posibilitar la materialización de proyectos deseados por las propias chicas, tanto si experimentan dudas al respecto como si no (esto es coherente con alguna de las generalizaciones anteriores).

- Mientras que entre las personas mayores, tanto entre las mujeres como entre los hombres, o que ya han finalizado sus estudios, las trayectorias excepcionales y poco comparables entre sí son más frecuentes, entre los chicos y chicas más jóvenes con continuidad educativa las trayectorias y las condiciones de tal continuidad son mucho más similares.

- Aparentemente, y a través de los distintos relatos biográficos, no se perciben diferencias entre niñas y niños en la etapa Infantil con relación a los estudios, en posiciones socioeconómicas más integradas.

- Persiste de forma clara, en el momento de entrada en la etapa de mozos y mozas, una discontinuidad en las prácticas y valores de socialización y control vinculadas al género y una diferencia de estatus considerable entre ambos sexos.

- Estas discontinuidades se manifiestan a través de una divergencia en las posibilidades de continuidad entre ambos sexos, también en posiciones integradas de las familias a nivel socioeconómico.

- La continuidad educativa exige de forma completamente diferencial esfuerzo, dedicación y cumplimiento de comportamientos y limitaciones de los mismos entre chicas y chicos gitanos en la mayoría de los casos.

- En relación con el punto anterior, parece cada vez más extendido (especialmente entre las chicas gitanas) el uso de estrategias de negociación con la familia, especialmente no sobre la escolarización en sí misma, sino sobre la conciliación de modelos relacionales basados en una idea de mujer gitana tradicional (que implica prohibiciones de acceso a espacios de ocio comunes extraescolares y a las relaciones con compañeros dentro del espacio escolar) y el deseo de inclusión social de la alumna gitana en los contextos escolares y las relaciones con sus compañeros y compañeras.

- Un sector muy importante de las mujeres gitanas con continuidad académica valoran los estudios porque ven con espíritu crítico su realidad y desean cambiar su entorno; luchan por el cambio: no están de acuerdo con un reparto de papeles predesignados y limitados. De alguna manera, constatan que hay dos dinámicas en virtud de las cuales se va a ver constreñida su vida: una, la falta de oportunidades en el conjunto de la sociedad por pertenecer a una minoría étnica estigmatizada y, con frecuencia, también a una clase social desfavorecida; y dos, el papel subordinado al 
que la confinan las presiones de su comunidad, por ser mujer. Y perciben que el sistema escolar (a pesar de todas sus limitaciones) es la mejor palanca para intentar mejorar sus oportunidades vitales y soslayar o mitigar la subordinación de clase, de etnia y de género. Por eso, lo que las estudiantes gitanas buscan con su continuidad educativa y lo que esta continuidad les proporciona es seguramente mejor valorado por ellas que por ellos, por una situación de partida distinta.

- En un sector de las chicas y mujeres gitanas emerge un discurso que alude a la reinvención de la identidad gitana femenina, en parte como resultado de la presión por acallar posibles críticas generadas en torno al incumplimiento de prácticas tradicionales y del rol tradicional que se les atribuye a los padres.

- Otro sector, especialmente formado por mujeres mayores con continuidad educativa, se muestra completamente contrario a cualquier intento de definición de la identidad de género tradicional o de conciliación con una eventual definición tradicional o adaptada de la misma, apostando por la necesidad de la igualdad sin reservas.

- Emerge, así mismo, un discurso alternativo sobre la masculinidad que pasa por cuestionar las prácticas culturales que entran directamente en contradicción con las prácticas reales (como "no gitanas") en algunos chicos u hombres que han pasado por un proceso de escolarización prolongado y defienden la aceptación de relaciones igualitarias entre las personas de ambos sexos.

- Sin embargo, entre un sector de los chicos y los hombres con continuidad educativa y con experiencias de inserción sociolaboral integrada persisten actitudes y prácticas completamente sexistas en relación con las posibilidades de continuidad educativa y de inserción sociolaboral de las chicas y las mujeres.

- Estas posiciones son completamente inexistentes entre las chicas y las mujeres, que verbalizan radicalmente su apoyo real (en la actualidad) o planificado (si llegan a ser madres) a la continuidad educativa máxima para las y los jóvenes gitanos de sus comunidades y grupos familiares, en general, y a sus hijas y a sus hijos, en particular, aunque también verbalizan su comprensión hacia las generaciones mayores que no la consideran positivamente.

- No se observan diferencias entre las distintas Comunidades Autónomas en lo que se refiere a los factores de éxito en sí mismos ni en las tendencias seguidas por la población gitana de cada zona, pero sí en la existencia mayor o menor de situaciones sociales y económicas diversas que lo hacen posible, derivadas de la estructura social (general, de la sociedad mayoritaria y particular, de la población gitana) y territorial diversa, por una parte y, sobre todo, de las políticas y prácticas impulsadas desde las administraciones autonómicas y locales, por la otra. Se destacan las siguientes ${ }^{100}$, por la incidencia observada, directa e indirectamente, en la continuidad educativa:

100 Evitamos hacer referencia a su incidencia relativa en las distintas CC.AA. por una razón fundamental: la estructura social y territorial puede favorecer más o menos la continuidad educativa normalizada a nivel local, pero también esta misma diversidad puede requerir de forma diferencial el desarrollo de políticas y prácticas distintas para actuar en cada uno de los niveles locales con el fin de favorecer esa continuidad. Hemos optado, por lo tanto, por enumerar situaciones y factores que favorecen la continuidad educativa de forma global, a la espera de que ulteriores publicaciones surgidas de la investigación especifiquen las condiciones sociales y los efectos de las políticas implementadas en cada territorio autonómico y local. 
- La localización de población gitana en pueblos pequeños con una sociabilidad interétnica positiva y constante que se refleja en las instituciones educativas y que da lugar a la continuidad educativa normalizada de chicas y chicos gitanos en Educación Secundaria.

- La proporción más alta de barrios no segregados (barrios con alta segregación existen en todas las comunidades) y escuelas no segregadas en entornos socioeconómicos no marginales.

- La existencia de instituciones educativas de Educación Secundaria y de Educación Superior públicas o accesibles cercanas a los lugares de residencia.

- La existencia de una política decidida de becas y ayudas al estudio conocidas y accesibles desde los centros educativos.

- La disponibilidad de recursos materiales complementarios (por ejemplo, libros de texto) para hacer efectiva la gratuidad de la enseñanza obligatoria.

- La existencia de una política decidida de ayudas familiares en forma de recursos socioeconómicos generales.

- La existencia de recursos de apoyo socioeducativo accesibles, cercanos y coordinados con las instituciones educativas.

- La existencia de directrices y prácticas de implicación y seguimiento de la continuidad educativa de todo el alumnado desde las autoridades educativas responsables de la zona hasta la finalización de la enseñanza obligatoria (por ejemplo, desde la inspección educativa y desde instancias municipales).

- La existencia de directrices y prácticas de promoción de la escolarización universal en el segundo ciclo de Educación Infantil (3-6) desde las autoridades educativas responsables de la zona.

- La existencia de plazas suficientes en escuelas infantiles públicas para la etapa 0-3 en los barrios de residencia de la población minoritaria.

- La existencia de programas de inserción sociolaboral accesibles, cercanos y conocidos por la población minoritaria, públicos o apoyados por su interés público (generales o específicos para la población minoritaria).

- La existencia de programas de educación de personas adultas de calidad (segundas oportunidades) para quienes han interrumpido sus trayectorias educativas, accesibles, cercanos y conocidos por la población minoritaria.

- La emergencia de redes de mujeres derivadas del asociacionismo intra e interétnico.

A la luz de los resultados obtenidos, las distintas hipótesis de partida de nuestra investigación se han visto enriquecidas, algunas de ellas provisionalmente corroboradas y otras refutadas, o parcialmente refutadas. Esto nos permite reconsiderar la inciden- 
cia de los factores de éxito y continuidad educativa tomados inicialmente en cuenta como parte de las hipótesis iniciales. Veamos ahora detalladamente cómo.

Para conocer las condiciones que favorecen las experiencias personales de éxito y continuidad educativa entre la población gitana, era necesario explorar las trayectorias de tales personas y los momentos clave en las mismas. Para ello prestamos especial atención a la superación de los niveles alcanzados generalmente por parte de la mayoría de la población gitana en el sistema educativo anterior y su equivalente actual, a la transición de etapa y espacio educativo (requisito común en el sistema público) entre Primaria y Secundaria, y al paso de la antigua y de la nueva educación obligatoria a la educación postobligatoria. Estos y otros momentos clave de la experiencia educativa formal tienen lugar en etapas muy tempranas del ciclo vital de las personas y son altamente reveladores de los factores de cambio y continuidad sociocultural, en la medida en que implican valoraciones, posicionamientos y tomas de decisiones del grupo familiar al que pertenece la persona con respecto a expectativas sociales y a identificaciones culturales. De la misma forma que resulta esclarecedor comparar situaciones sociales y épocas distintas en las que tienen lugar esos momentos clave, nuestros objetivos de investigación no tendrían sentido si no nos hubiéramos propuesto analizar también el impacto relativo de las experiencias de éxito y continuidad de las personas a distintos niveles. Esto exige la inclusión de personas mayores y de personas jóvenes en la muestra, según los criterios de selección ya explicados en el apartado metodológico, a partir del registro disponible en la investigación.

Tras el análisis de las experiencias y trayectorias, podemos adelantar que éstas se pueden agrupar en cuatro grandes tipos, que han estado representados de forma variada en nuestra selección, aunque todo ellos pertenecen a lo que podrían considerarse dos generaciones con estudios con personas de ambos sexos: entre las mujeres y los hombres mayores, se encuentran personas universitarias vinculadas o no al movimiento asociativo y profesionales vinculados generalmente al movimiento asociativo, ambos grupos con experiencias de continuidad total y con experiencias discontinuas hasta alcanzar la situación presente; entre las mujeres y hombres más jóvenes, se encuentran las chicas y los chicos cursando actualmente Secundaria de forma normalizada en algún pueblo o barrio sin alta concentración de población gitana, pero también chicos y chicas que están experimentado situaciones de discontinuidad o aparente ruptura total de la escolarización en otros barrios y localidades.

El desarrollo de la investigación nos ha permitido acceder a un repertorio de indicadores que constituyen un verdadero apoyo a la centralidad de la perspectiva de género para conocer y comprender los factores de éxito y continuidad educativa en la población gitana y su íntima interrelación con los procesos de cambio social y cultural. La contextualización y la comparación sistemática de las variaciones y los matices descubiertos en las experiencias y trayectorias de los casos analizados, revelan la situación de encrucijada a la que nos referimos en el subtítulo de este libro y a la que hacíamos mención en el primer capítulo, como parte de nuestras intuiciones iniciales. Para empezar, podemos afirmar que el éxito y la continuidad educativa de las chicas y mujeres gitanas no tiene carácter de excepcionalidad a pesar de los datos aislados 
pero recurrentes que informan de sus mayores dificultades para consolidar la transición de Primaria a Secundaria. En efecto, cuando ésta se realiza y emerge un proyecto propio en las alumnas, las probabilidades de retención parecen incluso mayores que entre los alumnos chicos. A pesar de las peores condiciones iniciales para un buen número de chicas antes de la transición, durante la misma y a lo largo de las trayectorias de continuidad, el sentido del cambio lo están protagonizando ellas, en la línea de los estudios de Gillborn y Mirza (2000) en Gran Bretaña sobre el éxito creciente de las chicas en todos los grupos minoritarios y en todas las situaciones sociales, en los últimos años. Es en las condiciones sociales donde los resultados han sido más complejos de lo esperado. El carácter exploratorio y probabilístico de nuestras hipótesis, que se planteaban como la búsqueda de los factores que constituyen condiciones favorables para el éxito y la continuidad educativa, nos permite ahora valorar el alcance relativo de los factores considerados y el peso relativo de otros factores descubiertos. Pero vayamos por partes.

A la luz de nuestros resultados, parece que no todas las condiciones favorables sostenidas en el tiempo que tuvimos en cuenta en nuestras hipótesis iniciales constituyen por sí mismas factores de éxito y continuidad educativa. En primer lugar, las condiciones socioeconómicas, en términos de integración urbanística y de buenas relaciones minoría-mayoría, aunque reducen las presiones contra el abandono porque requieren mucho menos de la colaboración económica y doméstica de los hijos y de las hijas, tienen en sí mismas un valor predictivo menor del esperado y, hasta cierto punto, en un sentido insólito: por una parte, es cierto que en los pequeños núcleos de población no segregados y con una oferta educativa que permite pocas estrategias de diferenciación social por medio de la elección de escuela, la continuidad es, efectivamente, mayor; pero, por la otra, en las experiencias y trayectorias de la población más joven procedente de núcleos urbanos más segregados tienen mayor peso las acciones políticas y sociales de apoyo y seguimiento, siempre que no se trate de grupos familiares en situaciones de fuerte marginalidad ${ }^{101}$. Además, entre las personas mayores de 30 años se relatan situaciones de traslado residencial, de núcleos muy segregados y precarios a otros entornos, paralelas a cambios de centro educativo que, si bien mejoran las posibilidades de continuidad educativa por razones aducidas en otras hipótesis, no actúan como 'causas' de la misma.

Algo parecido ocurre con el hecho de poseer una posición económica integrada, porque identificamos desde esta perspectiva al sector social que mejor representa la situación de encrucijada con la que queremos definir el momento actual, en todos sus extremos. El análisis de las experiencias revela tres tipos de situaciones: una primera situación de indiferencia hacia el éxito y la continuidad educativa de hijos e hijas, que pasa cada vez menos por el desconocimiento o la falta de consideración de las oportunidades de inserción laboral fuera de los nichos ocupacionales tradicionales sino por la desconfianza en que tales oportunidades se le puedan presentar a alguien de etnia gitana. Esta posición puede ser mantenida por grupos familiares en mejores y en peo-

101 Tal como ya se hizo notar en el capítulo 4, insistimos en la necesidad de distinguir siempre las situaciones de pobreza o precariedad socioeconómica -incluso extrema- de las situaciones de marginalidad social (delincuencia, toxicomanías, etc.), que ninguno de nuestros casos experimentó. 
res situaciones económicas y puede dar lugar a una actitud de laissez faire ante una trayectoria de éxito y la voluntad de continuidad educativa de los hijos e incluso de las hijas, pero corresponde con mayor frecuencia a experiencias de chicas y chicos más jóvenes, que aún se encuentran en proceso de formación. En este sentido, el umbral socioeconómico mínimo tendría influencia negativa en aquellos casos carentes de toda protección social general o específica. Una segunda situación se identifica en aquellas experiencias y trayectorias de personas cuyos núcleos familiares han generado aspiraciones de movilidad ascendente que incluye en cierta medida la vía académica, pero que, tanto en situaciones más desahogadas como en situaciones más apremiantes, no valoran positivamente el éxito escolar de sus hijas y resultan implacables en su oposición a la continuidad educativa de las mismas, apoyando la de sus hijos, si ellos la plantean. En tercer lugar, y en estos mismos grupos económicamente dispares dentro de las posiciones medias y desahogadas, se identifican a su vez dos posiciones claramente distintas: unos grupos familiares que, valorando la vía académica de chicos y chicas, apoyan la continuidad de ambos, pero condicionan la de sus hijas a demostraciones simbólicas o materiales de preservación de roles y relaciones de género desiguales tradicionales, y otros grupos familiares cuya ideología educativa no difiere de la de las clases medias y superiores mayoritarias, es decir, que no se plantean bajo ningún concepto la no continuidad de hijas e hijos hasta cierto punto más allá de la enseñanza obligatoria.

Por lo tanto, no existe en realidad una clara correspondencia entre las situaciones estrictamente económicas, en términos de ingresos estables y de origen normalizado de los grupos familiares, y la mayor continuidad educativa de las hijas y de los hijos, sino que estas condiciones son altamente dependientes de otros factores. En este sentido, nos referíamos a posiciones económicas integradas, pero tiene mayor peso el conjunto de factores que permiten hablar de posiciones socioculturales integradas, en el sentido no sólo de permitir sino de favorecer la continuidad educativa como obligación ciudadana y como parte de las aspiraciones sociales para los hijos e hijas (como parte de la integración social), sin distinciones de género (como parte de la integración cultural). No serían automáticamente aplicables las categorías de las configuraciones familiares construidas por Lahire (1993), pero estos aspectos reforzarían su planteamiento con elementos más complejos para incluir las realidades minoritarias.

Por otra parte, todavía adquiere mayor peso el hecho de disponer de recursos sociales y redes de apoyo que garanticen la continuidad educativa de chicos y chicas, pero muy especialmente en el caso de las chicas. Inicialmente exponíamos la necesidad de que estos recursos y redes no debían ser segregados, a partir de la experiencia profesional de los componentes del equipo de investigación. Sin embargo, dada la escasez resultante de los recortes sociales en becas y ayudas generales sufridas en las dos últimas legislaturas, por una parte, y a partir del análisis realizado, por la otra, posiblemente sea necesario reivindicar el papel crucial que pueden jugar unos recursos generales suficientes (no segregados), pero también del apoyo a nuevos recursos específicos, materiales y humanos, vehiculados por medio del movimiento asociativo gitano (específicos). En todas las trayectorias analizadas, excepto en aquellas que hemos señalado en el punto anterior (es decir, las que parten de posiciones socioeconómicas 
más integradas), el hecho de disponer de estos recursos y apoyos (becas de comedor, becas de libros y material escolar, becas y ayudas de transporte, así como clases de apoyo extraescolar, etc.) ha resultado decisivo (o, cuando menos, importante) para la continuidad educativa, bien porque ha compensado la patente precariedad económica en algunas situaciones, bien porque ha inclinado la balanza favorablemente en otras situaciones en las que a las dudas y temores iniciales, se añadía la inseguridad de una inversión educativa sostenida, sin experiencia para anticipar claros resultados o contrapartidas comprensibles. La función de estos recursos en esta última situación es más compleja que la estrictamente contenida en los análisis de clase social, coincidiendo con el análisis de Casa-Nova (2002).

En segundo lugar, las experiencia de condiciones educativas y afectivo-relacionales favorables adquiere un peso, no mayor del esperado, pero sí mucho más concreto, en las trayectorias analizadas porque se añade otro elemento nuevo dentro de esta categoría: los efectos del éxito inicial reconocido y valorado. En efecto, el papel del profesorado es clave en este sentido y la experiencia de valoración, afecto y altas expectativas académicas mantenidas en el tiempo, desde las primeras experiencias y en acciones educativas no segregadas. En la mayoría de relatos se destacan espontáneamente episodios referidos, como pronosticábamos, al seguimiento y a la comunicación individual con el alumnado sobre sus posibilidades y trayectorias, a la co-responsabilización, al consejo y a la orientación, a la detección y acción ante posibles problemas y dificultades, y a la movilización de recursos extraordinarios, coincidiendo plenamente con los resultados de la investigación de Bempechat (2003) sobre las creencias del alumnado sobre su propio éxito y la fundamentación de las mismas por parte del profesorado. Sin embargo, también pensábamos que este tipo de actitudes de implicación y de valoración del profesorado se vinculaban a otra condición, la existencia de un clima de afectividad y cooperación con el resto del grupo clase, en alusión a los planteamientos metodológicos de enseñanza-aprendizaje no competitivos sino colaborativos. Lo que sí nos revelan las experiencias y las trayectorias analizadas es la importancia de las relaciones sociales en el aula y en el centro, la creación del sentido de pertenencia y de legitimidad personal del alumnado, pero no necesariamente vinculadas a metodologías más innovadoras ${ }^{102}$. Por lo tanto, pese a no disponer de servicios específicos como el descrito en el estudio de Bhopal y Gundara (2000) para el alumnado gitano británico (TES, Traveller Education Service), muchos de nuestros entrevistados y entrevistadas han experimentado en momentos clave de sus trayectorias un refuerzo de las relaciones de confianza de la escuela con su entorno familiar, que coinciden con uno de los principales elementos destacados en nuestras hipótesis y también por los estos autores en su investigación. En resumen, en las condiciones favorecedoras de la continuidad escolar del alumnado gitano emerge lo que podríamos denominar el sentimiento de competencia y de pertenencia, o, dicho en otros términos, el desarrollo de identidades académicas positivas (la vinculación académica, según Davidson, 1996) y de experiencias relacionales positivas (interculturales e interpersonales) en el ámbito escolar.

102 Esta investigación no tenía entre sus objetivos el análisis de los efectos inclusivos/exclusores de la aplicación de diversas metodologías docentes. El hecho de que los casos analizados no evocan en ningún momento nada en este sentido mientras sí se otorga un peso muy especial a las relaciones sociales y afectivas con el profesorado y entre el profesorado y el centro con la familia no supone, por lo tanto, ninguna valoración negativa de aquellas. 
En tercer lugar, debemos poner de manifiesto que la existencia de condiciones familiares y comunitarias favorables al éxito y a la continuidad educativa no ha formado parte, en general, de la mayoría de las experiencias y trayectorias analizadas. Esta constatación complementa, desde la perspectiva de las actitudes de valoración y apoyo, la falta de correlación en la práctica entre condiciones económicas y continuidad educativa. Es decir, la diferenciación social en los aspectos materiales de la integración social no está dando paso todavía a otros aspectos relacionados con transformaciones culturales. Están en juego aspectos de clase y etnia que, una vez más, no se muestran coincidentes.

De esta manera, si exceptuamos aquel pequeño sector de población ya mencionado, que comparte la ideología y la práctica educativa mayoritaria, en el resto de entornos familiares ha tenido más peso una actitud poco favorable. 0 bien se han mantenido indiferentes ante el éxito y el deseo de continuidad, o han obstaculizado los deseos de Ilevarla a cabo, en dos sentidos: en el caso de las chicas, por medio de estrategias de deslegitimación moral de la misma en términos de género y etnicidad (discurso) y/o de sobrecarga de responsabilidades y tareas domésticas incompatibles con la continuidad educativa en condiciones adecuadas (prácticas); en el caso de ambos, chicas y chicos, también ha sido frecuente enfrentarse a acusaciones de deslealtad étnica, pero sobre todo ha tenido una presencia común la presión derivada de los mensajes de desconfianza y anticipación del fracaso, combinada con las presiones anteriores. En este punto, es necesario matizar que se observa indirectamente una cierta nuclearización familiar, al nivel de toma de decisiones, en algunas actitudes de apoyo a la continuidad educativa, sobre todo en casos de chicas y mujeres. Es decir, el grupo familiar primario se puede enfrentar hasta cierto punto a la familia extensa y a los vecinos/as y a otros miembros de la comunidad del mismo grupo étnico, o bien adoptar estrategias de conciliación o de evitación alrededor de este tema. Estas estrategias se construyen de forma progresiva, a lo largo del proceso de toma de conciencia y negociación de prácticas culturales y roles sociales de los hijos y de las hijas imprevistos y en gran medida desconocidos. Ahora bien, ha sido recurrente en las trayectorias analizadas el cambio experimentado por la mayoría de mujeres y hombres en el apoyo y la valoración recibidos por parte del grupo familiar primario y extenso, y por parte de otros miembros del entorno comunitario, después de haber alcanzado niveles educativos postobligatorios. Por lo tanto, no sólo las personas que protagonizan trayectorias de continuidad educativa con apoyos irregulares o con la falta de los mismos están reconstruyendo activamente su etnicidad, sino que también lo hacen, en gran medida y como consecuencia, la mayoría de sus grupos familiares, a pesar de las presiones comunitarias. Algunas de estas presiones dan lugar, como hemos visto en los párrafos anteriores, a estrategias completamente diferenciales por parte de algunas familias en posiciones económicas medias y desahogadas, deseando y apoyando la continuidad educativa de los hijos y deslegitimizando y oponiéndose a la de las hijas.

En esta línea y también a diferencia de lo esperado en las hipótesis iniciales, el éxito y la continuidad educativa de chicas y las mujeres gitanas en estos momentos no se puede explicar en absoluto por la existencia de posiciones sociales más integradas en las relaciones de género, ni en sus grupos familiares de origen, ni de forma generali- 
zada en las personas de ambos sexos de su misma generación. En algunos casos analizados, una minoría entre ellas, ni siquiera en las propias chicas protagonistas de tales continuidades se plantea la igualdad entre hombres y mujeres en todos los ámbitos, aunque en este punto sí difieren de las mujeres mayores que han tenido trayectorias de continuidad y del resto de las entrevistadas. Las condiciones familiares y las condiciones comunitarias, por lo tanto, deben ser consideradas de otra manera más compleja de la explicitada por nuestra hipótesis.

En cuarto lugar, la existencia de redes de apoyo desde el asociacionismo gitano y sus prácticas comunitarias y la participación activa de la familia en este sentido no ha resultado ser importante en las trayectorias analizadas. De hecho, todavía es incipiente el nuevo tipo de acciones diseñadas y llevadas a cabo por las asociaciones gitanas que pueden convertirse en impacto positivo para la continuidad educativa: aparece como un elemento de importancia creciente para las generaciones más jóvenes y de forma transversal a las situaciones económicas y familiares de las chicas y los chicos gitanos que están estudiando en estos momentos.

Por último, una segunda hipótesis de investigación matizaba todos los aspectos contenidos en la primera y principal. Sosteníamos que, aunque se dieran las condiciones adecuadas en la situación socioeconómica, escolar, familiar y comunitaria, debía existir una valoración compartida por el grupo de iguales de lo positivo de la vía académica para posibilitar realmente el éxito y la continuidad educativa. Hemos podido acceder a experiencias marcadas por una enorme soledad, o bien por el esfuerzo por desarrollar una sociabilidad doble, entre un grupo de iguales, generalmente no gitano, más próximo a la continuidad educativa, y otro grupo de iguales, gitano, vinculado al grupo familiar y al entorno comunitario. 0 bien por ambas cosas. En este sentido, son reveladoras las experiencias de aquellos casos representados por chicas y chicos más jóvenes que, a pesar de partir de condiciones socioeconómicas y familiares adversas, han accedido a espacios de sociabilidad intraétnica por medio de algunas acciones de apoyo y refuerzo extraescolar ${ }^{103}$. Las relaciones intrageneracionales encarnan de forma inequívoca las presiones ejercidas por las fuerzas comunitarias -en términos de Ogbu- en las chicas y los chicos que construyen proyectos y desarrollan trayectorias de continuidad educativa, planteando en el plano afectivo disyuntivas identitarias que pasan por el cuestionamiento de tales proyectos y trayectorias, en la línea de los procesos descritos por Fordham (1988) y por Ogbu y Fordham (1986) para la población afroamericana, expuestos en la primera parte. Por lo tanto, el carácter condicional que habíamos atribuido a nuestra segunda hipótesis -la influencia del grupo de iguales, por encima del conjunto de condiciones expresadas en la primera hipótesisparece más que corroborado por nuestros resultados de investigación.

Para terminar esta recapitulación podemos preguntarnos cuáles parecen ser, finalmente, los factores más importantes para crear las condiciones favorecedoras del éxito y la continuidad educativa en la población estudiada. Hemos podido detenernos

\footnotetext{
103 En varias de las CC.AA. existen algunas experiencias de apoyo extraescolar, en algunos casos organizadas desde el tejido asociativo (Fundación Pere Closa, en Cataluña; Secretariado Diocesano Gitano en Pamplona; Cáritas, en Aranda de Duero; Asociación de Promoción Gitana en Burgos; etc.)
} 
en relatos y testimonios que apuntan en varias direcciones y que plantean el carácter complejo, dinámico y procesual de las posibles respuestas a este interrogante central. Sin embargo, pensamos que es posible establecer dos grandes grupos de factores:

1) Los que dependen de las características personales, que podrían resumirse así:

- La emergencia de un proyecto personal de continuidad educativa, fomentado por el éxito precoz.

- El empeño de la persona por buscar condiciones para llevar a cabo tal proyecto.

- Su capacidad de negociación con el grupo familiar, con las presiones comunitarias, con el grupo de iguales gitano.

- Sus habilidades sociales y su acceso a un grupo de iguales de apoyo (inter o intraétnico).

2) Los que tienen que ver con el papel que juegan las instituciones sociales (y las relaciones socio-afectivas que en ellas tienen lugar) en su capacidad para acoger y alentar la formación y el desarrollo de proyectos personales de continuidad académica:

- La valoración, el apoyo y el compromiso sostenido del profesorado.

- La experiencia escolar integrada y el buen clima de centro en las relaciones sociales.

- La valoración y apoyo del grupo familiar, normalización de las expectativas de continuidad educativa.

- El acceso a recursos humanos y educativos (referentes y apoyos) y económicos generales y específicos.

Ahora bien, estos aspectos pueden resultar insuficientes y pueden dar lugar a experiencias frustrantes si los conocimientos alcanzados en la etapa de Educación Primaria son inadecuados y el paso a la Educación Secundaria va acompañado de vacíos importantes, o presupone la existencia de determinadas experiencias escolares en el entorno familiar. Este desajuste se repite y se amplía mucho más en el paso a la enseñanza postobligatoria; se trata de una situación generalizada para la mayoría de familias de clases populares y compartida, así mismo, por amplios sectores sociales gitanos. Debemos recordar aquí que hemos estado considerando en cierta medida el éxito a través de la continuidad educativa, debido a la situación educativa general que persiste entre las chicas y los chicos gitanos en la actualidad, que ya presenta las dificultades expuestas para completar la educación obligatoria. Por lo tanto, para que aquel conjunto de factores señalado contribuya realmente a crear condiciones favorables al éxito y a la continuidad educativa, no sólo para hacerlo posible para una parte del alumnado gitano, sino para hacerlo probable para la mayoría del mismo, es necesario añadir otros dos factores decisivos: 
- La intervención de las autoridades educativas en el cumplimiento real de la escolarización obligatoria y no segregada104 de la población gitana adolescente.

- La implicación del movimiento asociativo gitano en acciones de apoyo y refuerzo a las trayectorias escolares de las chicas y los chicos gitanos a nivel local.

Podemos representar la incidencia de los factores más decisivos para la continuidad escolar de la población gitana estudiada con el siguiente esquema (aunque es necesario recordar que estos factores no aparecen necesariamente asociados):

FACTORES MÁS IMPORTANTES QUE HAN CREADO CONDICIONES

FAVORECEDORAS DEL ÉXITO Y LA CONTINUIDAD EDUCATIVA EN LA POBLACIÓN GITANA ESTUDIADA

MENSAJE INEQUÍVOCO (DIRECTO
O INDIRECTO) DE VALORACIÓN POSITIVA
DE SUS POSIBILIDADES ACADÉMICAS

\footnotetext{
104 Nunca insistiremos suficientemente en este punto: de nada sirve acudir a los centros educativos donde se escolariza la mayoría de la población no gitana si las alumnas y los alumnos gitanos están después sobre representados en aulas segregadas por su frecuente calificación, real o ficticia, de alumnado con necesidades educativas especiales, situación frecuente cuando se accede a la Educación Secundaria. Ni los mecanismos segregadores del refuerzo escolar (siempre fuera del aula ordinaria) tolerados por la LOGSE y apoyados por un sector del profesorado, ni los itinerarios que legitima la LOCE se basan en los resultados de investigación sobre inclusividad educativa y efectos de los grupos de nivel en el alumnado de grupos minoritarios e inmigrantes.
} 


\subsection{Algunas implicaciones teóricas: continuidad educativa, género y cambio}

Las circunstancias sociales y culturales en las que tenía lugar la escolarización y la experiencia educativa de la infancia gitana han cambiado en todas partes y se han hecho más complejas. Por lo tanto, es necesario que exista un interés continuado desde la investigación educativa, que explore, documente y proporcione interpretaciones de estas transformaciones y del impacto de las acciones educativas; es necesario, así mismo, que ese interés continuado desde la investigación reciba el apoyo decidido desde las instituciones y organismos responsables de financiarla.

Para las dos últimas generaciones de chicas y chicos gitanos que han pasado por el sistema educativo, las cosas también han cambiado, aunque no en una única dirección ni de la misma manera para todos y todas. Las edades y los momentos del ciclo vital en los que se encuentran las personas han resultado producir más experiencias recurrentes y diferenciadas en las trayectorias estudiadas, según la presencia más o menos importante de los distintos factores tenidos en cuenta en las hipótesis. Y, naturalmente, en todas las situaciones sociales se identifica inequívocamente que el factor más determinante para pronosticar la continuidad educativa de las personas es su posición en el sistema de género.

La diferenciación social y, por lo tanto, la existencia de unas condiciones favorables sostenidas en el tiempo para un sector mínimo pero decididamente más amplio de la población gitana, ha permitido que para las chicas y los chicos gitanos de esos mismos sectores, la continuidad académica sea lo esperado, con el consiguiente apoyo y valoración. Pero este sector social con mejores condiciones socioeconómicas es, sin embargo, extraordinariamente heterogéneo y no genera sistemáticamente y bajo todos los supuestos las mismas condiciones para las chicas que para los hijos. Esto nos hace pensar que estamos a las puertas de un cambio, el que estas chicas y chicos probablemente protagonizarán como madres y padres, pero que todavía no se ha elegido un camino que lleve al mismo conciliando la integración social con la preservación identitaria sin el sacrificio de las chicas.

Ninguna de las aportaciones de la literatura sobre el tema revisadas en este texto nos habla de supuestas especificidades culturales originales de las minorías -de ningún grupo en posición de minoría cultural en ninguna parte del mundo- como causas de un mayor fracaso o abandono, o de una mayor vinculación o desvinculación escolar ${ }^{105}$, de lo que sí dan cuenta es de las readaptaciones que la minoría realiza ante las precarias y contradictorias condiciones de su escolarización que la sociedad mayoritaria impone para una incierta integración social, respuestas minoritarias que frecuentemente revierten negativamente en su propia condición, porque aleja a las generaciones más jóvenes de la vía académica y del establecimiento de relaciones interculturales positivas.

105 Ésta es la traducción de la expresión anglosajona 'school engagement'/school disengagement', clave en la literatura socioantropológica actual sobre minorías y educación. Se propone y se utiliza de este modo en el texto del Grupo ELIMA "Educación, aculturación y género. Reflexiones a partir de la investigación en Cataluña", Nómadas. Revista Latinoamericana de Ciencias Sociales, n 14, Bogotá. 
Al mismo tiempo, todas las aportaciones revisadas nos indican que las prácticas y planteamientos con resultados positivos para la minoría son igualmente recomendables para todo el alumnado, en situación de "mayoría cultural", que sobrevive irregularmente hasta terminar el sistema educativo obligatorio, con resultados tan mediocres como aceptados y normalizados desde el propio sistema educativo. Recordemos qué ocurre entre las élites, entre las cuales ciertas formas de exclusión (y mucho menos, de expulsión) son impensables, incluso para el alumnado menos motivado y más disruptivo, de manera que existe una variedad de centros educativos ciertamente innovadores que jamás pierden su apuesta educativa por todo el alumnado, y que jamás llegan a atribuir a sus alumnos y alumnas causas colectivas e inmutables de fracaso.

Pero observamos, a través de nuestra experiencia profesional y de nuestro trabajo de campo, que en los barrios donde se localiza una mayor proporción de población con muy bajos niveles de instrucción en las familias, con situaciones económicas precarias y/o altamente irregulares, se localizan con frecuencia, así mismo, tipos de entorno escolar más tradicional ${ }^{106}$ en términos de metodologías docentes y organización escolar. Las adaptaciones y esfuerzos que la escuela está convencida que hace no suelen ser transformadores, sino versiones tan arbitrarias y descontextualizadas del proceso de enseñanza y aprendizaje y de los objetivos educativos como el modelo más tradicional, pensado para un alumnado tipo que cuenta con capital cultural medio, altas aspiraciones de movilidad social que pasan por una escolarización prolongada, de orientación enciclopédica, que suele coincidir con los valores de la propia extracción social del profesorado o de sus propias aspiraciones. Este tipo de entorno escolar, profundamente socio-céntrico además de etnocéntrico, lleva a aceptar un desarrollo educativo mínimo de su alumnado, aduciendo como pretexto el perfil de la población que debe atender. Forma parte de la actitud de indefensión y de la profecía autocumplida desgraciadamente frecuente en el propio profesorado. Parece que, ante mayores dificultades, se desarrollan los dos extremos posibles de proyecto educativo: uno, el más tradicional, que genera menos problemas a los más cercanos sociocultural y familiarmente (incluida buena parte del profesorado) pero más problemas a los más distantes y menos previstos por él; otro, el que tiene mayor potencial transformador, que suele encontrar, con frecuencia, toda clase de incompresiones y trabas legales y administrativas para ser llevado a cabo107. Este es un aspecto clave que afecta a las condiciones generales de escolarización de los grupos, más que a las experiencias y trayectorias individuales, sobre el que debemos profundizar.

Por otra parte, como ya hemos señalado, los elementos y tendencias de cambio cultural se constatan en el momento en que una generación asume tareas y responsabilidades reproductivas hacia la siguiente. En este sentido, si una proporción importante

\footnotetext{
106 Conviene siempre recordar que un centro educativo no deja de tener un planteamiento organizativo y docente tradicionalista y reproductor por el hecho de declarar que apuesta por una educación intercultural o de añadir de vez en cuando alguna actividad supuestamente intercultural a su práctica habitual, sin cuestionársela.

107 Véase el ejemplo del IES Badalona-7 y la inflexibilidad de la administración, que impidió el pleno desarrollo de su proyecto educativo, todavía insuficientemente analizado desde esta perspectiva. No obstante, en otros casos que han podido desarrollar proyectos como el de las Comunidades de Aprendizaje o ciertos planes de Mejora de Zona (por ejemplo, en Valladolid), han sido apoyados por la Administración. (Vid. $n^{\circ} 25$ del Boletín de Enseñantes con Gitanos, en prensa).
} 
de nuestras informantes mejor formadas y/o con una convicción clara de valoración y apoyo a la continuidad educativa no tienen hijos o hijas, es obvio que no nos permiten hablar de aumento de "referentes dentro de la cultura gitana", sino de indicadores de profundos cambios y profundas resistencias en la misma, porque su mayor proporción de soltería -y dando por sentado que, en la situación actual, no reproducción y soltería son completamente coincidentes- es ya de por sí una excepcionalidad dentro de la experiencia social y de la cultura gitana tradicional. Una consideración parecida puede tener el matrimonio mixto de chicas gitanas mejor formadas. Inversamente, las ambivalentes ideas sobre educación escolar que sostienen algunos de nuestros informantes gitanos (los chicos) mejor formados en relación con sus hijos y, sobre todo, con sus hijas, refleja también cambios y resistencias decisivos para acelerar o frenar el desarrollo de una nueva cultura gitana. Y este es otro de los aspectos fundamentales sobre los que debemos profundizar, en un contexto en el que "el cambio educativo acelera los cambios en los proyectos de género y en los procesos de inserción, tanto en el conjunto de la sociedad mayoritaria como entre las mujeres inmigrantes y minoritarias." (Grupo Elima, 2001: 5).

Este es un camino de investigación abierto, que puede dar sus mejores frutos para orientar la intervención social y educativa junto al compromiso de la militancia étnica gitana en luchar contra la perversión de los vínculos identitarios que presionan a los chicos y a las chicas, pero que sólo las excluyen a ellas de las oportunidades educativas.

Todos los individuos pertenecientes a una sociedad compleja y moderna, en pleno proceso de cambio acelerado, experimentamos procesos de aculturación constantes. Nuestros referentes culturales de origen (nuestras habilidades, conceptos, prácticas, pautas de relación y valores, en definitiva, aquellos elementos que constituyen nuestras formas de vivir, pensar y sentir) son afectados, reordenados y recreados porque accedemos a nuevos referentes (informaciones, habilidades, relaciones) por medio de la experiencia, al tiempo que desarrollamos nuestra capacidad de identificación múltiple y creativa. Este proceso es aún más notorio entre quienes hemos pasado una parte muy importante de nuestra existencia en las instituciones educativas y, por nuestras ocupaciones, estamos expuestos y expuestas de forma constante a la actualización profesional. Es obvio que la escolarización prolongada de una generación acelera los cambios culturales que su grupo de referencia experimenta con la historia: las culturas son procesos y productos dinámicos y cambiantes, y los individuos, creadores y recreadores de culturas, en uno $u$ otro sentido. Veremos si ambos sectores, el grupo minoritario y la sociedad mayoritaria, están preparados para ello. Pero sobre todo, veremos si estamos preparados y preparadas para que los nuevos procesos los lideren las mujeres gitanas. 


\section{RECOMENDACIONES}

En esta última parte se exponen las principales implicaciones para la acción que se derivan de los resultados de esta investigación, y ello en un doble plano: 1) en lo relativo a implicaciones para las políticas y las prácticas educativas que se desprenden del análisis realizado; 2) en lo que atañe a implicaciones para el desarrollo de la investigación educativa.

\section{Recomendaciones para las políticas y las prácticas educativas}

En las páginas precedentes hemos estado analizando las condiciones favorecedoras del éxito y la continuidad académica del alumnado gitano. Una de las implicaciones más claras que se desprende de las mismas es que se ven propiciadas en la medida en que las distintas instancias sociales y educativas realicen una apuesta clara y coherente en su favor.

Señalamos a continuación algunas medidas concretas en este sentido a distintos niveles y que se refuerzan cuanto más interrelacionadas se presentan.

\subsection{Política social comprometida y coherente hacia la inclusión y la cohesión social}

En un país democrático la Administración no puede permanecer impasible y haciendo la vista gorda ante las situaciones de discriminación y desigualdad de oportunidades. Antes al contrario, constituye una garantía de cohesión social al tiempo que un mandato constitucional el que las políticas de los poderes públicos estén guiadas por el criterio de la igualación social. Este imperativo legal y ético implica que las diversas Administraciones Públicas realicen evaluaciones rigurosas de las distintas áreas donde se desarrolla la vida social de las personas y grupos más desfavorecidos y lleven a cabo programas que erradiquen las dinámicas de marginalidad instaladas en ellas. Trabajo y vivienda vertebran la vida de las personas y posibilitan o reducen su inserción social y, por tanto, repercuten en las condiciones que favorecen la continuidad académica de sus hijos e hijas, y a estos dos ejes hay que dedicar toda la atención posible y decidida.

- Política urbanística que apueste decididamente por los barrios integrados y posibilite el acceso a viviendas no segregadas.

El barrio integrado resulta básico para establecer relaciones sociales integradas, y para que puedan generarse amistades interétnicas dentro y fuera de la escuela. De ahí que sea fundamental el que las administraciones públicas Ileven a cabo políticas 
urbanísticas que posibiliten el acceso a la vivienda integrada de las familias gitanas con escasos recursos económicos.

- Apoyo a la inserción socio-laboral de las y los jóvenes gitanas y gitanos con titulación.

Es importante que la juventud gitana con distintos tipos de acreditación por la vía académica (no nos referimos a los estudios no reglados, sino a todos los niveles oficiales, independientemente de su cualificación) logre acceder a puestos de trabajo acordes a su titulación. De lo contrario, se extiende el mensaje de que los estudios son irrelevantes para un mejor acceso al mercado laboral y que suponen una inversión estéril.

No podemos ignorar el riesgo existente en la actualidad de que las y los jóvenes gitanos con acreditaciones académicas vean cerrado su acceso al mundo laboral, tanto por carecer de las redes y el capital social adecuado como por prejuicios racistas de algunos de sus posibles contratantes. Por eso, es conveniente que la Administración potencie programas de búsqueda de empleo para las personas con titulación del grupo minoritario.

\subsection{Política educativa comprometida y coherente hacia la inclusión y la cohesión social}

El sistema escolar está condicionado por las circunstancias sociales, y a su vez tiene un peso fundamental en el futuro de las personas. Por ello, es de suma importancia que desde él se promueva la igualdad de acceso y continuidad y se propicien las condiciones que hagan más factible el éxito y la continuidad académica del alumnado gitano:

- Elaboración, puesta en marcha y evaluación de planes integrales para favorecer el éxito y la continuidad escolar del alumnado gitano.- Consideramos muy conveniente que la administración educativa planifique programas específicos con profesorado de apoyo, no como meros parches o paliativos ante problemas puntuales, sino como compensación real de las desigualdades y con un objetivo más ambicioso: que cada vez sea mayor el número de alumnos/as gitanos/as que consiguen titulaciones académicas de grado medio y superior. Programas dotados de medios, con permanencia en el tiempo, con la debida coordinación con el resto de los elementos del sistema educativo (así como con los recursos de tiempo libre, con las demás administraciones y con los servicios sociales), y que contemplen la realización de evaluaciones periódicas de los mismos (para analizar si se va logrando el objetivo marcado de mejorar las acreditaciones entre el alumnado gitano, y qué cambios es preciso introducir).

- Mensaje claro de la obligatoriedad de la escolarización hasta los 16 años.Instaurar, por parte de la Administración Educativa, una dinámica clara sobre la 
obligatoriedad de la escolarización hasta los 16 años, como algo incuestionable. Establecer mecanismos de apoyo a nivel local al servicio de los centros educativos de tipo transversal, como responsabilidad intersectorial.

- Apuesta por la comprensividad, la inclusión y la coeducación de todo el alumnado.No basta con que se cumpla la Ley en el sentido de que todos y todas acudan a los centros escolares al menos hasta los 16 años, es importante que no existan segregaciones ni guetos, pues las expectativas de continuidad escolar del alumnado gitano aumentan en la medida en que tienen una escolarización no marginal.

- Necesidad de plazas suficientes de Escuelas Infantiles gratuitas o asequibles.- La Educación Preescolar y Educación Infantil constituyen una enseñanza no obligatoria, pero que contribuye al desarrollo de las capacidades y destrezas de los niños y niñas más pequeños, a la vez que juegan un papel como ámbitos de socialización y relación social. Dichas Escuelas Infantiles han de ser, preferentemente, integradas. Por otra parte, si las familias tienen a su alcance plazas asequibles de Escuelas Infantiles ("Guarderías", "Escoles Bressol") se hará más improbable el que las hermanas adolescentes se vean abocadas por las familias tradicionales al cuidado de hermanos y hermanas menores, abandonando el sistema escolar.

- Política amplia de becas al estudio para la población desfavorecida.- La ausencia de recursos económicos puede hacer que aquellos alumnos y alumnas de familias con escasos ingresos familiares abandonen tarde o temprano el sistema escolar, para incorporarse al mundo laboral. De hecho, ésta es una de las causas principales para poner fin a la escolaridad de los alumnos y alumnas gitanos que han realizado Enseñanza Secundaria y no llegan a acceder a la Universidad o a otro tipo de formación post-obligatoria. Por el contrario, el contar con una beca constituye un estímulo que apoya la prosecución de los estudios.

- Fomento del apoyo al estudio extra-escolar en centros sociales y/o centros escolares.- El contar con un lugar de estudio extraescolar se ha demostrado en nuestra investigación que supone un apoyo a la continuidad escolar, al contribuir a hacer efectivas las exigencias escolares de realizar tareas académicas fuera del horario lectivo. Al mismo tiempo que, en torno a estos centros de estudio asistido extraescolar, va generándose un referente de jóvenes que prosiguen estudios y un grupo de iguales que valora la continuidad académica dentro de la propia minoría. También se fomenta la sociabilidad intercultural si el tipo de actividad se organiza desde centros cívicos o desde el propio centro escolar y no desde asociaciones étnicas.

- Organización del acompañamiento en la transición de Primaria a Secundaria desde las autoridades locales y/o educativas.- El instituto es un ámbito desconocido y sin tradición en sus vidas todavía para muchas familias gitanas, y sobre él gravitan con frecuencia por parte de algunas familias ciertos temores y recelos (por haber alumnado mayor, por si sus hijos e hijas no van bien preparados para las exigencias académicas del mismo, por si van a ser señalados por otras familias si llevan a estudiar a sus hijas adolescentes, por lo que les pueda pasar, etc.) En estos momentos sigue siendo muy alta la proporción de alumnado gitano que abandona el IES antes de 
terminar la ESO, incluso teniendo posibilidades de seguir y apoyo del profesorado. $Y$ en algunos lugares, son mayoría (especialmente las chicas) los/as que ni siquiera llegan a pisarlo. Se requiere, por tanto, acompañar el paso de Primaria a Secundaria y cuidarlo en todos los sentidos desde las autoridades locales y educativas, proporcionando los medios para que desde los centros y los barrios se pueda llevar a cabo adecuadamente.

- Formación del profesorado desde la proximidad y la realidad de las condiciones educativas locales.- En éste como en otros casos, es necesario tomarse en serio la formación del profesorado, puesto que se trata del agente educativo clave para un verdadero cambio generalizado en la situación educativa del alumnado gitano. El profesorado debe comprender en profundidad la diversidad de situaciones que se esconden en las dinámicas escolares del alumnado gitano y debe comprender también el proceso de cambio profundo que tiene lugar y al que puede contribuir en positivo, apostando por sus alumnas y alumnos concretos. Las autoridades educativas y locales deben comprometerse a diseñar y llevar a cabo planes continuos de formación en los barrios y sectores donde se detecte la necesidad de promover el cambio educativo generalizado. Además, es necesario crear foros de debate e intercambio entre profesorado, profesionales y mediadores/as.

\subsection{Acción educativa de los centros escolares}

\section{comprometida y coherente con la inclusión y la}

\section{continuidad académica del alumnado gitano}

- Potenciar el éxito inicial de los alumnos y alumnas gitanas.- En esta investigación se ha evidenciado que el mejor pronóstico de éxito escolar futuro es el éxito inicial y su explícito reconocimiento. De ahí que sea fundamental el lograr que los primeros contactos de la persona que estudia con la escuela sean gratificantes, de modo que desarrolle una autoimagen positiva en los aprendizajes, del sistema escolar, y de sus propias posibilidades ante los mismos.

- Altas expectativas sobre los alumnos y alumnas gitanas: afecto unido a exigencia.El alumnado gitano se sentirá competente y afrontará los aprendizajes con autoexigencia y confianza en la medida en que puede percibir valoración por parte del profesorado. El profesorado es el principal mediador para el aprendizaje. Es preciso, por ello, fomentar un estilo de enseñanza-aprendizaje motivador y estimulante, unido a una evaluación continua y formativa, de tal modo que se propicie el éxito escolar en cada una de las materias.

- Colaboración con las familias.- Aunque este aspecto no ha resultado determinante en muchas de las trayectorias analizadas, sigue siendo cierto que el establecimiento de un clima de confianza y colaboración mutua con las familias y de participación de éstas en la vida del colegio hace más probable que las familias del alumnado confíen más, a su vez, en las posibilidades escolares de sus hijos e hijas. Para ello 
es fundamental también que el profesorado se comunique además de con las madres también con los padres no sólo para transmitirles normas o quejas, sino que, por el contrario, les haga llegar mensajes de valoración de sus hijos e hijas y de elogio de sus capacidades, resultados y comportamientos.

- Organizar apoyo extra-escolar.- También los centros escolares pueden favorecer el estudio asistido extraescolar en sus propias instalaciones, como un elemento de desarrollo social comunitario para todo el alumnado y sectores sociales que atiende, como medida original. Esto debe ser apoyado por las autoridades educativas y locales, desde la gestión de las necesidades de los barrios.

- Potenciar la cohesión, tanto en las actividades académicas, como en las complementarias y extra-escolares.- En esta investigación hemos podido comprobar cómo la inserción en un grupo de iguales que, o bien tiene aspiraciones de continuar estudiando o simplemente no se ha planteado dejar de hacerlo, y el buen clima social entre los compañeros y compañeras de clase contribuyen poderosamente a la continuidad escolar del alumnado gitano. Por eso, es muy importante que el profesorado propicie un clima de respeto y cooperación dentro del aula (a través de la acción tutorial, el trabajo en equipos y, sobre todo, a través de la práctica cotidiana). Y que se motive al alumnado gitano para que participe en las actividades extraescolares, complementarias y deportivas, por lo que tienen no sólo de complemento educativo, sino también de ámbito de creación/refuerzo de vínculos sociales y de mensaje de valoración de todo lo que se realiza en el centro escolar.

- Potenciar las tutorías, así como la educación antirracista y la lucha contra el etnocentrismo en el curriculum.- La acción tutorial y la práctica académica cotidiana constituyen ocasiones muy propicias para que tanto el alumnado gitano como el no gitano se sienta más cohesionado y más guiado y estimulado en su labor de estudiantes. Es imprescindible que todo el alumnado sea formado en una educación antirracista. En todo caso, como ya hemos señalado en apartados anteriores, estimamos que lo primordial no consiste en trabajar contenidos académicos sobre la diversidad cultural, sino el desarrollo de perspectivas y actitudes críticas para analizar los mensajes, las actitudes y las prácticas etnocéntricas y racistas, entendiendo la experiencia de las personas afectadas. Por lo mismo, es obvio que en aquellos centros que cuentan con alumnado gitano sólo es posible una auténtica educación intercultural en la medida en que exista un clima cooperativo y unas expectativas altas también sobre este alumnado (es decir, no puede haber educación intercultural si no se da una vinculación social y académica del alumnado, sin excepciones).

- Acompañar el cambio de etapa con coordinación y orientación académica desde el centro.- Tal como ya hemos indicado, la inmensa mayoría de las familias gitanas carecen de tradición escolar en Educación Secundaria. Es importante, por ello, que tanto desde los centros de Primaria, como sobre todo desde los de Secundaria, se cuide el cambio de etapa y de centro, la acogida inicial, la labor de seguimiento y tutorización del alumnado, la orientación académica individual y la evaluación continua. 
En resumen, es necesario: asegurar que el alumnado gitano acuda al IES con un buen nivel de conocimientos y buena autoestima; posibilitar que el alumnado gitano tenga un grupo de iguales con actitudes positivas hacia la continuidad; informar y acompañar también a las familias; potenciar la tutoría personalizada en la ESO, tanto para las alumnas como para los alumnos; establecer una buena coordinación entre las etapas a nivel de tutorización del alumnado y a nivel de contenidos, procedimientos y prácticas, y trabajar la flexibilidad en otros aspectos en el profesorado de Secundaria.

- Mensaje claro de la obligatoriedad de la escolarización hasta los 16 años.Conjuntamente con los centros de Primaria y con las autoridades educativas y locales, instaurar por parte de los IES una dinámica clara sobre la obligatoriedad de la escolarización hasta los 16 años, como algo incuestionable.

\subsection{Movimiento asociativo con una actitud}

\section{comprometida y coherente con la inclusión, la cohesión social y la continuidad académica del alumnado gitano}

- Es deseable que desde las distintas asociaciones que componen el tejido asociativo ciudadano (partidos, sindicatos, ONGs, asociaciones de padres y madres, asociaciones vecinales, fundaciones, asociaciones culturales, etc.) se realice una apuesta clara y reivindicativa por políticas sociales y educativas comprometidas y coherentes con la justicia y la cohesión social.

- Es deseable que dentro del tejido y las prácticas comunitarias extendidas entre la población gitana (como la Iglesia Evangélica de Filadelfia, otras prácticas religiosas o civiles o las distintas Asociaciones y Fundaciones Gitanas) realicen una apuesta clara por el desarrollo de los talentos de la juventud gitana y por su continuidad académica. Es básica su corresponsabilización en la promoción del éxito y la continuidad, con vistas a la promoción socio-laboral y como una obligación inexcusable al menos hasta los 16 años, tal como señala la legislación vigente.

- Es deseable que las y los gitanos participen en el movimiento asociativo de la sociedad mayoritaria y reclamen unas políticas sociales y educativas comprometidas y coherentes con la justicia y cohesión social, así como con el respeto a la diversidad.

\section{Recomendaciones para la investigación educativa}

Esta investigación ha revelado algunos campos en los que es urgente y preciso seguir investigando para tener elementos de análisis mejores y contribuir de un modo más eficaz a propiciar la escolaridad del alumnado gitano, y su éxito y continuidad educativa. 
- Es imprescindible disponer de informes periódicos basados en conjuntos de indicadores clave (actual, científico, pormenorizado, cualitativo y cuantitativo) de las condiciones de vida de los gitanos/as de cada comunidad autónoma: demografía, condiciones de los barrios y viviendas, laborales, económicas, sanitarias, escolares, asociacionismo, participación ciudadana, etc. Este estudio de contexto es necesario para conocer con precisión el punto de partida en el que nos hallamos y para fundamentar debidamente los diversos programas y la financiación necesarios en los distintos ámbitos (formativo, urbanístico, sanitario, asociativo y de ayudas sociales).

- Debe realizarse una evaluación rigurosa de los programas de desarrollo gitano que se están llevando a cabo en cada región, para conocer con mayor profundidad los nuevos retos que esta realidad nos demanda.

- Debe llevarse a cabo un estudio amplio sobre la situación escolar de la infancia, adolescencia y juventud gitana de cada C.A. ${ }^{108}$, sus dinámicas y características internas y las prácticas de socialización y experiencias de sociabilidad.

- Es necesario contar con una evaluación seria de los programas de Atención a la Diversidad, Educación Compensatoria y Educación Intercultural vigentes en cada ámbito territorial (autonómico y local), y su orientación y su impacto real.

- Es necesario disponer de estudios sobre el asociacionismo gitano y las iniciativas organizadas que intervienen en cada Comunidad Autónoma desde la sociedad civil (asociaciones y federaciones de asociaciones gitanas, asociaciones de mujeres gitanas, asociaciones juveniles, fundaciones gitanas, asociaciones que trabajan con población gitana), sobre su orientación y su impacto real.

- Deberían llevarse a cabo estudios más intensivos en contextos donde se dan alguna de las condiciones que se han demostrado claves para la continuidad académica:

- Población gitana que vive en barrios o pueblos integrados y con buena experiencia de relaciones interétnicas.

- Lugares donde hay alguna asociación gitana (general y específica de mujeres gitanas) con implantación real y con capacidad de convocatoria.

- Barrios donde ha existido un centro de estudio asistido de carácter extraescolar bien organizado y con tradición de varios años.

- Familias gitanas cuyos padres han estudiado al menos Enseñanza Secundaria.

- Centros escolares con experiencias de éxito y continuidad educativa del alumnado gitano y de población desfavorecida.

- Pueblos y barrios donde residen mujeres y hombres gitanos con estudios medios o superiores y sus funciones como referentes.

\footnotetext{
108 De hecho, diversos equipos de las CC.AA. ya están trabajando en estos estudios a partir del resto de datos obtenido en el trabajo de campo desde hace tres cursos académicos.
} 
- Debería realizarse en breve una investigación sobre las condiciones del éxito y la continuidad educativa de la población gitana andaluza, por ser Andalucía la Comunidad Autónoma con el mayor número de gitanas y gitanos titulados del estado.

- Es imprescindible que los planes integrales para favorecer el éxito y la continuidad escolar del alumnado gitano que se pongan en marcha (tal como hemos sugerido en el apartado anterior) cuenten con una cuidadosa evaluación, tanto diacrónica como sincrónica. 


\section{REFERENCIAS BIBLIOGRÁFICAS}

AA.VV. (1991) Migration, minority status and education: European dilemmás and Responses in the 1990s, monográfico de Anthropology \& Education Quarterly, 22 (2).

Abajo, J. E. (1997) La escolarización de los niños gitanos. El desconcierto de los mensajes doble-vinculares y la apuesta por los vínculos sociales y afectivos. Ministerio de Trabajo y Asuntos Sociales, Madrid.

Abajo, J. E. (1998) La afectividad, clave pedagógica y apuesta social. Cuadernos de Pedagogía, n² 273, pp. 80-87.

Abajo, J. E. (2000) Educación Intercultural como ecología mental y social. I tchatchipen, $n^{\circ} 30$, pp. 29-31.

Abajo, J. E. (2002) Cultura gitana y escuela. Arakerando, 86, pp. 8-16.

Afshar, H. ; Maynard M. (1994) The dynamics of race and gender: some feminist interventions en Afshar, H. (ed) (1994) Women, Development and Survival in the Third World, Longman London.

Aguilera, P. (2000) La participación política en la comunidad gitana. Gitanos: Pensamiento y Cultura, $n^{\circ}$ 4, abril 2000, pp.16-19.

Ainscow, M., et al. (2001) Index for inclusion, CSIE. Manchester

Amadiume, I. (1987) Male Daughters, Female Husband's: Gender and Sex in an African Society, London, Zed.

Amadiume, I. (1997) Reinventing Africa. Matriarchy, Religion and Culture. London. Zed Books.

Aparicio, J. M. (2002): Prensa y educación: Acciones para la desaparición de un gueto. Editorial Libre de Enseñanza, Madrid.

Ardèvol, E. (1986) Vivencias y cambio en la cultura de los gitanos. En San Román, T. (comp.) Entre la marginación y el racismo. Reflexiones sobre la vida de los gitanos. Alianza Editorial, Madrid.

Arnfred, S. (1995) (ed) Issues of Methodology and Epistemology in Post-colonial Studies, Occasional Paper nº. 15, IDS Roskilde.

Asociación Secretariado General Gitano/Grupo Amat de Sociología (1992) La situación de las personas minusválidas de etnia gitana que residen en la Comunidad Autónoma de Castilla y León. Asoc. Secretariado Gral. Gitano, Madrid.

Aymí, 0. (2002) Ocho familias gitanas, expulsadas de un camping de l’Ametlla de Mar. El País, 14 de agosto de 2002, edición Tarragona. 
Ayuntamiento de Pamplona, ed. (1998) La comunidad gitana en la Acción Social en Pamplona. Aproximación a la Comunidad Gitanas desde el Trabajo Social, Área de Servicios Sociales Pamplona.

Barañí, ed. (2000) Mujeres gitanas y sistema penal. (En línea). Proyecto Barañí, Madrid. http://www.personales.jet.es./gea21 (Consulta 12 de diciembre de 2003).

Bempechat, J. (2003) Learning from Poor and Minority Students Who Succeed in School, Harvard Educational Review (en línea), july/august 2003.

Bempechat, J. (1999) Against the Odds, Harvard University Press.

Bhopal, W., Gundara, J., Jones, C., Owen, C. (2001) Working towards inclusive education. Aspects for good practice for Gypsy Traveller Pupils, DfEE Research Brief 238.

Boletín Oficial de las Cortes Generales n 520 del 17 de diciembre de 1999.

Borman y Rachuba (2001), Academic Success among poor and minority students. An Analysis of Competing Models of School Effects, Johns Hopkins University, CRESPAR Report, $n^{\circ} 52$.

Borrull, R. (2004) Una generación de solitarios. Boletín de la Asociación de Enseñantes con Gitanos, n² 25 (en prensa).

Cabanes, P. (1998) La escolarización de los niños gitanos en el País Valenciano, Alternativas. Cuadernos de Trabajo Social, n 6, Escuela Universitaria de Trabajo Social de Alicante.

CAC (1999) Dictamen del sobre el tractament de la imatge de les minories ètniques. Consell Audiovisual de Catalunya, Barcelona, 1-2.

Camilleri, C. (1992) Évolution des structures familiares chez les Maghrébins et les Portugais de France, Revue Européenne des Migrations Internationales.Vol 8 (2).

Carrasco, S. (2003) La escolarización de los hijos e hijas de inmigrantes extranjeros y de minorías étnico-culturales en España, Revista de Educación, 330, MECD.

Carrasco, S.; Soto, P. (2003) Immigracoió i diversitat sociocultural a les escoles de Barcelona. Característiques i concentració escolar a les escoles públiques municipals $i$ de Ciutat Vella. Observatori de la Immigració, Ajuntament de Barcelona.

Carrasco, S. (2002), Inmigración, minorías y educación en España. Ensayar algunas respuestas y mejorar algunas preguntas a partir del modelo de John Ogbu. Ponencia del IX Congreso de la FAAEE, Barcelona: Institut Català d'Antropologia (CD-Rom, 2003) y Suplementos OFRIM, (Junio 2004).

Carrasco, S. (2000-2001) Glossari en Tema del curs: Multiculturalitat i Escola, Guix. Elements d'acció educativa nos. 268-276.

Carrasco, S. (1997), Uso y abuso del concepto de cultura, Cuadernos de Pedagogía, $n^{0} 262$. 
Casa-Nova, M. J. (2002) Etnicidade, género e escolaridade: estudo em torno das socializaçoes familiares de género numa comunidade cigana da ciudade do Porto. Instituto de Inovaçao Educacional, Lisboa.

Colectivo de Salamanca de Enseñantes con Gitanos (1999) La cultura gitana en el curriculo de Infantil y Primaria. Editorial Amarú, Salamanca.

Comisión Consultiva del Ministerio de Trabajo y Asuntos Sociales para el Programa de Desarrollo Gitano (1999) El Pueblo Gitano y la Educación. Documento para debate. Ministerio de Trabajo y Asuntos Sociales, Madrid.

Comité de las Naciones Unidas para la eliminación de la discriminación racial (informes presentados por los estados partes conforme al artículo 9 de la convención). MTAS, España, 6 de junio de 2003.

Davidson, A. (1996) Making and Moldling Identity in Schools: Student Narratives on Race,Gender and Academic Engagement. State University of New York Press. New York.

Fernández, A. (2003), Projecte de millora del procés d'atenció a l'absentisme escolar a la zona IV de Serveis Personals y Annex II. Benchmarking amb altres municipis. Ajuntament de Badalona.

Fordham, S. (1988) Racelessness as a Factor in Black Students' School Success: Pragmatic Strategy or Pyrrhic Victory?, en Harvard Educational Review, vol. 58 (1)

Fresno, J. M. (1994) Diagnóstico de la Situación de la Población Gitana de Castilla y León. Junta de Castilla y León. Consejería de Sanidad y Bienestar Social, Valladolid.

FSGG, ed. (2001) La lucha contra la discriminación en el empleo. Claves de intervención de la FSGG. Gitanos: Pensamiento y Cultura, n 12/13, diciembre 2001enero 2002, 23-62.

FSGG ed. (2002) Evaluación de la normalización educativa del alumnado gitano en Educación Primaria. FSGG, Madrid.

FSGG, ed. (s.f.) Los gitanos en la prensa. Madrid, FSGG. http://www.fsgg.org. (Actualización mensual).

Gairazábal, C. (2000) "La feminidad tradicional: cambios y crisis en la identidad de las mujeres". Gitanos: Pensamiento y Cultura, n5, 40-45.

Garriga, C.; Giménez, A. (1998) Ostelinda: Jo vinc de tot arreu. La Galera, Barcelona.

Garriga, C. et al. (2000) Gitanos de Barcelona. Una aproximación sociológica. Diputación de Barcelona, Área de Servicios Sociales, Barcelona.

Garriga, C. et al. (2002) Gitanos de Badalona. Una aproximación sociológica. Diputación de Barcelona, Área de Servicios Sociales, Barcelona. 
Gibson, M. (1988) Accommodation without Assimilation. Punjabi Sihks in a California High School, Ithaca:Cornell University Press.

Gibson, M. (1999), Promoting Academic Success among Immigrant and Minority Students, Educational Policy, vol 6 (12).

Gibson, M. \& Ogbu, J. (1990) Minority status and Schooling. A Comparative Study of Immigrant and Involuntary Minorities, New York: Garland Press.

Gillborn, D. \& Mirza, H. S, (2000) Educational Inequality. Mapping Race, Class and Gender. Office for Standards in Education.

Giménez, A.; Piasere, L.; Liegéois, J. P. (2003) The education of gipsy childhood in Europe. Universitat Jaume I, Departament d'Antropología Social, Castelló. http://www.opre.roma.uji.es

Gobierno de Navarra (1999) Plan de lucha contra la Exclusión Social en Navarra. 1998-2005, Departamento de Bienestar Social, Deporte y Juventud del Gobierno de Navarra.

Gómez-Bueno, C., et al. (2002), Identidades de género y feminización del éxito académico, Instituto de la Mujer-CIDE, Madrid.

Grupo Eleuterio Quintanilla (1996) Materiales para una educación antirracista, Plataforma Asturiana de Educación Crítica. Talasa, Oviedo.

Grupo ELIMA (Carrasco, S.; Ballestín, B.; Bertran, M.; Bretones, E.), (2001), "Educación, aculturación y género en Cataluña", en Nómadas. Revista Latinoamericana de Ciencias Sociales nº 14, Bogotá.

Grupo PASS (1987) Mapa de la vivienda gitana en España. Asociación Secretariado General Gitano, Madrid.

Grupo PASS, ed. (1991) Estudio sociológico sobre la comunidad gitana en España. PASS, Asesoría de programas de servicios sociales, Madrid.

Hallam, S.; Ireson, J. (2003) Ability Grouping in Education, PCP, SAGE, London.

Idom, consultoría (2003) Informe sobre el barrio de La Mina. El País, edición Cataluña, 20 de noviembre de 2003, pág.5

INE, ed. (1999) Encuesta sobre Discapacidades, Deficiencias y Estado de Salud. INE, Madrid.

Instituto de la Mujer (comp.) (2002) 50 mujeres gitanas en la sociedad española. Publicaciones del CIDE, Madrid.

Instituto de Sociología Aplicada de Madrid y Asociación Secretariado General Gitano (1979 y 1990) Estudio sociológico: Los gitanos españoles. Asociación Secretariado General Gitano, Madrid. (La primera edición, policopiada). 
Juliano, D. (1998) Las que saben: subculturas de mujeres. Horas y Horas, Madrid.

Knipmeyer, M.; González, M.; San Román, T. (1980) Escuelas, Pueblos y barrios. Akal, Madrid.

Lahire, B. (1993) Culture écrite et inégalités scolaires. Sociologie de I"I échec scolaire "à l'école primaire, Presses Universitaires de Lyon, Lyon.

Lahire, B. (1999) L'Invention de I'" illettrisme ". Rhétorique publique, éthique et stigmates, Éditions la Découverte, Paris.

Laparra, M. (2000) Una perspectiva de conjunto sobre el espacio social de la exclusión: el caso de Navarra en el contexto español de precariedad integrada, Pamplona. Documento de trabajo.

Laparra, M. et al. (2003) La Garantía de ingresos mínimos en Navarra. Un estudio evaluativo de la Renta Básica, 1990-2001. Departamento de Bienestar Social, Deporte y Juventud, Gobierno de Navarra, Pamplona.

Lasa, B. (2002) La escolarización, una realidad creciente entre las familias gitanas. Aula de Infantil, nº.

Liégeois, J. P. (1998) Minoría y Escolaridad: El Paradigma Gitano, Editorial Presencia Gitana/Interface, Madrid.

López-Varas, M. L.; Fresnillo, G. (1995): Margen y periferia. Representaciones ideológicas de los conflictos urbanos entre payos y gitanos. Fundación Secretariado General Gitano, Madrid.

López, C.; Balaguer, S. (2000) La imatge de les minories ètniques a les televisions de Catalunya. Aproximació quantitativa. Quaderns del CAC , 48-53.

Martínez Frías, Ma L. (1993) Malformaciones congénitas en la población gitana: un estudio epidemiológico en un grupo de la población española. Real Patronato de Prevención y de Atención a Personas con Minusvalías, Madrid.

McCarthy, C. (1994): Racismo y curriculum. La desigualdad social y las teorías políticas de las diferencias en la investigación contemporánea sobre la enseñanza, Madrid: Ediciones Morata.

MEC (1994) Curso escolar 1994/1995. Datos y cifras. Servicio de Publicaciones del MECD, Madrid.

MECD, ed. (1999) Las desigualdades de la educación en España II. CIDE-MECD, Madrid.

MECD ed. (2000) La compensación de las desigualdades en educación. (En línea) http://www.mec.es/cesces

Mehan, H. (1996) Constructing School Success: untracking minority students, SUNY Press, London. 
Mulinari, D. (1995) Motherwork and politics in revolutionary Nicaragua: "Huellas de Dolor y Esperanza". Bokbox, Lunds university.

Ogbu, J. (1994), "Racial stratification and education in the US: why inequality persists", Teachers College Record, 96 (2).

Ogbu, J. (1987) "Minority coping responses and school experience", The Journal of Psychohistory, vol. 18 (4): 433-456 (Traducción castellana en Boletín de la AEG, nº 25 , en prensa)

Ogbu, J., Simons, H.D. (1998), "Voluntary and Involuntary Minorities: A CulturalEcological Theory of School Performance with Some Implications for Education". Anthropology \& Education Quarterly 29(2): 155-188.

Ogbu, J. \& Fordham, S. (1986) "Black Students' School Success: Coping with the burden of 'Acting White'"', en The Urban Review, vol 18 (3).

Potash, B. (ed.) (1986) "Widows in African Societies: Choices and Constraints", California, Stanford University Press.

Puigvert, L., Martín, S., Vaqueral, E. (2003) Brudila Callí: Las mujeres gitanas contra la exclusión, VII Congreso de Sociología, grupo de trabajo de sociología de la educación, sesión $3^{a}$ : Educación y desigualdades sociales. http://www.ase.es/comunicaciones

Reyna, C. (2000) "Lazy, Dumb or Industrious. When Stereotypes convey attribution information in the classroom", Educational Psychology Review, vol 12 (1)

Rodríguez, I. (2002) La relevancia de la vivienda en los procesos de inclusión social con la Comunidad Gitana. Gitanos: Pensamiento y Cultura, n 16, octubre 2002, 2024.

Salinas, J. et al. (2003) Maj khetane (Más juntos). Materiales interactivos para trabajar la cultura gitana. (CD y folleto). Comisión de Educación del Programa de Desarrollo del Pueblo Gitano, Madrid.

San Román, T. (1984) Gitanos de Madrid y Barcelona. Ensayos sobre aculturación y etnicidad. Publicaciones de Antropología Cultural, n³, UAB.

San Román, T. (1994) La diferència inquietant, Altafulla, Barcelona

San Román, T. (1999) El desarrollo de la conciencia política de los Gitanos. Gitanos: Pensamiento y cultura, nº, Abril 1999, FSGG, Madrid.

San Roman, T.; Carrasco, S; Soto, P.; Tovías, S., (2001), Identitat, pertinença i primacia a l'escola. La formació d'ensenyants en el camp de les relacions interculturals. Colección de Antropologia Cultural, n² 17. UAB.

Sorolla, J. A. (2000a) La imatge de les minories ètniques a les televisions de Catalunya. Consell de l'Audiovisual de Catalunya (CAC). Barcelona. 
Sorolla, J. A. (2000b) El tractament informatiu de la immigració a Catalunya, Quaderns del CAC $n^{\circ} 12$ http://www.audiovisualcat.net/publicacions/q12sorolla.pdf.

S.O.S. Racismo (ediciones anuales de 1996 a 2203) Informe anual sobre el racismo en el estado español. Icaria editorial. Barcelona.

Stanley, L. (1991) Feminist praxis: Research, theory, and epistemology in feminist sociology. Routledge, New York.

UGT, ed. (2000) Integración y escuela. (En línea), UGT-FETE. http://www.fete.ugt.org

Unión Romaní ed. ¿Periodistas contra el Racismo? La prensa española ante el pueblo gitano (versiones 1995-1996, 1997, 1998-1999, 2000-2001)

Unión Romaní ed. (2004) Directorio de Asociaciones Gitanas 2004. Unión Romaní, Barcelona.

Unión Romaní (2004) Alianza Romaní, un partido en marcha. Nevipens Romani, nº 379,3 .

Velasco, M.; Pisa, A.; Pérez, J. (2004) Plan de Zona Pajarillos-Pilarica. Boletín de Enseñantes con Gitanos, n 25 (en prensa).

VV.AA. (1998) Las condiciones de vida de la población pobre en España. Informe General. Fundación Foessa, Madrid.

Wagnan, D. (Dir.) (2000): Proyecto Barañí. Criminalización y reclusión de mujeres gitanas. Asociación La Kalle, Madrid. (policopiado)

Weiner, B. (1979). "A theory of motivation for some classroom experiencies". Journal of Educational Psychology, 71, 3- 25.

Weiner, B. (1986). An attribution theory of motivation and emotion. Springer-Verlag, New York.

Zabalza, M. (2001) Procesos de Exclusión Educativa: la escolarización gitana. Departamento de Trabajo Social de la Universidad Pública de Navarra, Pamplona. Trabajo de investigación. 
Experiencias y trayectorias de éxito escolar

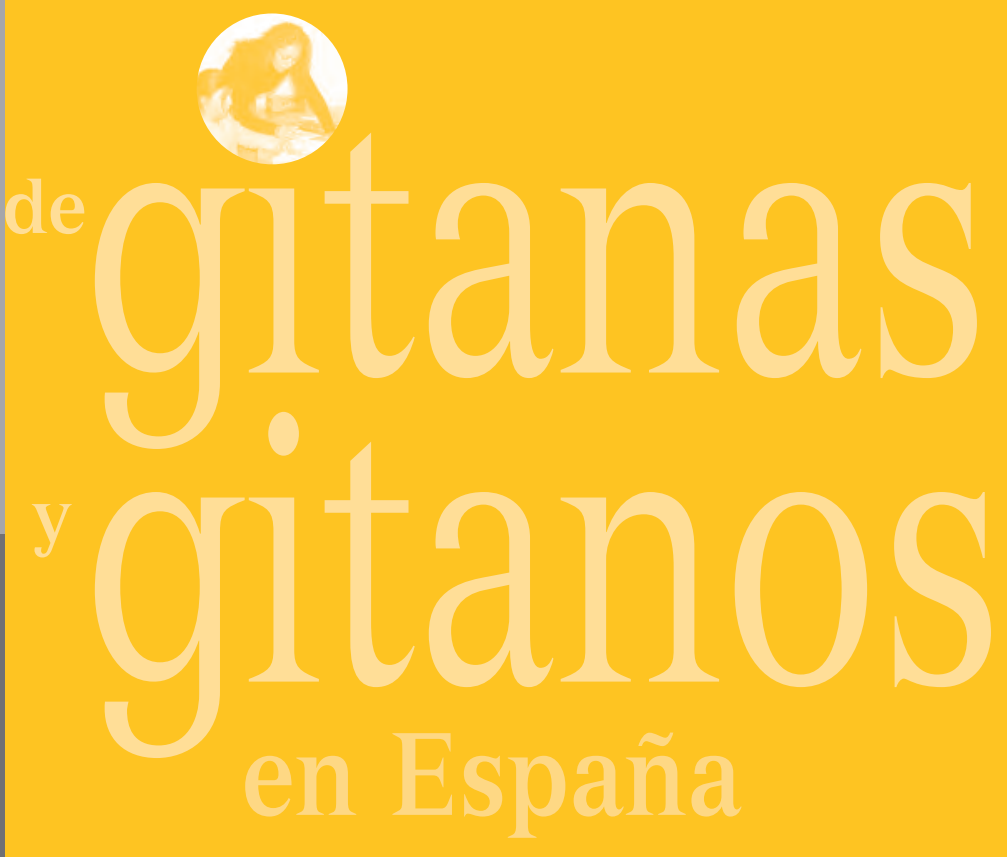

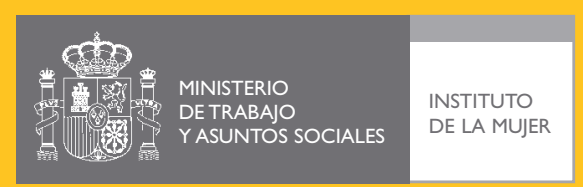

www.mtas.es/mujer

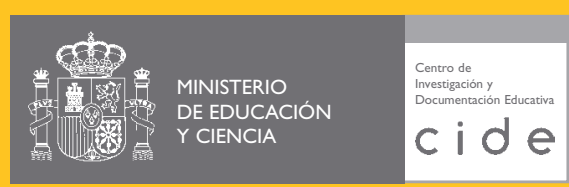

www.mec.es/cide 